University of South Florida

DIGITAL COMMONS Digital Commons @ University of @ UNIVERSITY OF SOUTH FLORIDA South Florida

6-1-2014

\title{
Multimodal Transportation Best Practices and Model Element
}

CUTR

Follow this and additional works at: https://digitalcommons.usf.edu/cutr_nctr

\section{Recommended Citation}

"Multimodal Transportation Best Practices and Model Element," National Center for Transit Research (NCTR) Report No. CUTR-NCTR-RR-2013-12, Center for Urban Transportation Research, University of South Florida, 2014.

DOI: https://doi.org/10.5038/CUTR-NCTR-RR-2013-12

Available at: https://scholarcommons.usf.edu/cutr_nctr/86

This Technical Report is brought to you for free and open access by the National Center for Transit Research (NCTR) Archive (2000-2020) at Digital Commons @ University of South Florida. It has been accepted for inclusion in Research Reports by an authorized administrator of Digital Commons @ University of South Florida. For more information, please contact digitalcommons@usf.edu. 


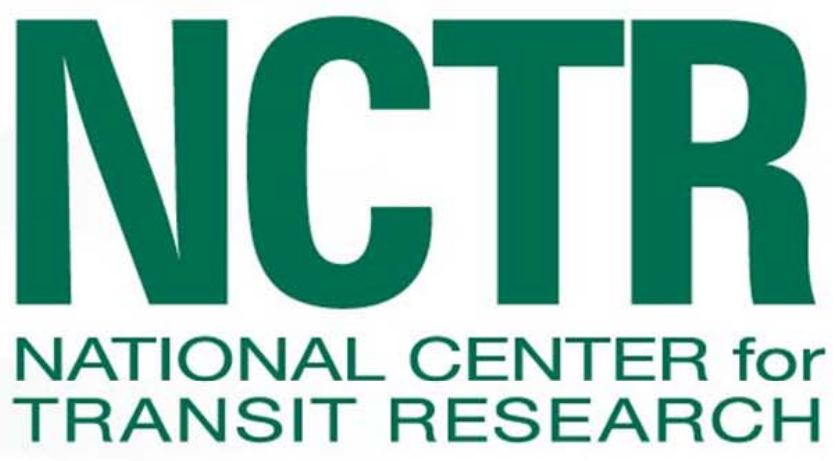

\title{
Multimodal Transportation Best Practices and Model Element
}

\author{
J une 2014
}

PROJ ECT NO.

BDK85-977-49

Final Report

PREPARED FOR

Florida Department of Transportation

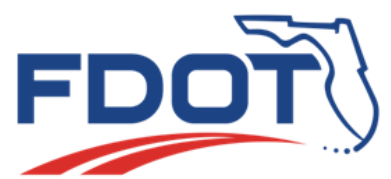




\section{Multimodal Transportation Best Practices and Model Element}

BDK85-977-49

\section{Final Report}

Prepared for:

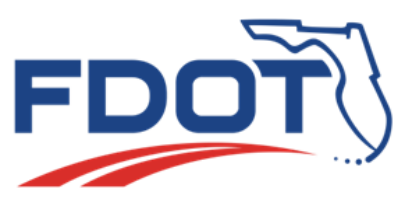

Florida Department of Transportation

Maria Cahill, AICP, Project Manager

Prepared by:

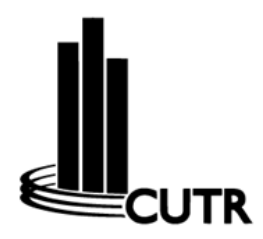

\section{USF Center for Urban Transportation Research}

Principal Authors

Kristine M. Williams, AICP, Principal Investigator

Karen E. Seggerman, AICP, CNU-A, Co-Principal Investigator

Research Assistants

Daniel Shopf

Singeh Saliki

Chris Zuppa

Contributors and Reviewers

Rob Gregg

Sara Hendricks, AICP

Martin Catala

J une 2014 


\section{Disclaimer}

The contents of this report reflect the views of the authors, who are responsible for the facts and the accuracy of the information presented herein. This document is disseminated under the sponsorship of the U.S. Department of Transportation University Transportation Centers Program and the Florida Department of Transportation in the interest of information exchange. The U.S. Government and the Florida Department of Transportation assume no liability for the contents or use thereof. 


\section{Metric Conversion}

\begin{tabular}{|c|c|c|c|c|}
\hline SYMBOL & WHEN YOU KNOW & MULTI PLY BY & TO FI ND & SYMBOL \\
\hline \multicolumn{5}{|c|}{ LENGTH } \\
\hline in & inches & 25.4 & millimeters & $\mathrm{mm}$ \\
\hline ft & feet & 0.305 & meters & $\mathrm{m}$ \\
\hline yd & yards & 0.914 & meters & $\mathrm{m}$ \\
\hline mi & miles & 1.61 & kilometers & $\mathrm{km}$ \\
\hline \multicolumn{5}{|c|}{ VOLUME } \\
\hline fl oz & fluid ounces & 29.57 & milliliters & $\mathrm{mL}$ \\
\hline gal & gallons & 3.785 & liters & $\mathrm{L}$ \\
\hline $\mathrm{ft}^{3}$ & cubic feet & 0.028 & cubic meters & $\mathrm{m}^{3}$ \\
\hline$y^{3}{ }^{3}$ & cubic yards & 0.765 & cubic meters & $\mathrm{m}^{3}$ \\
\hline \multicolumn{5}{|c|}{ MASS } \\
\hline $\mathbf{O z}$ & ounces & 28.35 & grams & $\mathrm{g}$ \\
\hline lb & pounds & 0.454 & kilograms & $\mathrm{kg}$ \\
\hline $\mathbf{T}$ & short tons (2000 lb) & 0.907 & $\begin{array}{c}\text { megagrams } \\
\text { (or "metric ton") }\end{array}$ & Mg (or "t") \\
\hline \multicolumn{5}{|c|}{ TEMPERATURE (exact degrees) } \\
\hline${ }^{\circ} \mathbf{F}$ & Fahrenheit & $\begin{array}{c}5(F-32) / 9 \\
\text { or }(F-32) / 1.8\end{array}$ & Celsius & ${ }^{\circ} \mathrm{C}$ \\
\hline
\end{tabular}




\section{Technical Report Documentation}

\begin{tabular}{|c|c|c|c|}
\hline 1. Report No. & \multicolumn{2}{|c|}{ 2. Government Accession No. } & 3. Recipient's Catalog No. \\
\hline \multicolumn{2}{|c|}{$\begin{array}{l}\text { 4. Title and Subtitle } \\
\text { Multimodal Transportation Best Practices and Model Element }\end{array}$} & \multicolumn{2}{|l|}{$\begin{array}{l}\text { 5. Report Date } \\
\text { J une } 2014\end{array}$} \\
\hline \multicolumn{4}{|c|}{ 6. Performing Organization Code } \\
\hline \multicolumn{2}{|c|}{$\begin{array}{l}\text { 7. Author(s) } \\
\text { Kristine M. Williams, Karen E. Seggerman }\end{array}$} & \multicolumn{2}{|c|}{$\begin{array}{l}\text { 8. Performing Organization Report No. } \\
\text { NCTR 77954-00/BDK85-977-49 }\end{array}$} \\
\hline \multicolumn{2}{|c|}{$\begin{array}{l}\text { 9. Performing Organization Name and Address } \\
\text { National Center for Transit Research } \\
\text { Center for Urban Transportation Research (CUTR) } \\
\text { University of South Florida } \\
4202 \text { East Fowler Avenue, CUT100 } \\
\text { Tampa, FL 33620-5375 }\end{array}$} & \multicolumn{2}{|c|}{ 10. Work Unit No. (TRAIS) } \\
\hline \multicolumn{2}{|c|}{$\begin{array}{l}\text { 12. Sponsoring Agency Name and Address } \\
\text { Florida Department of Transportation } \\
605 \text { Suwannee Street, MS } 30 \\
\text { Tallahassee, FL 32399-0450 } \\
\text { Research and Innovative Technology Administration } \\
\text { U.S. Department of Transportation } \\
\text { Mail Code RDT-30 } \\
1200 \text { New Jersey Ave. SE, Room E33 } \\
\text { Washington, D.C. } 20590-0001\end{array}$} & \multicolumn{2}{|c|}{$\begin{array}{l}\text { 13. Type of Report and Period Covered } \\
\text { Final Report } \\
10 / 31 / 2012-06 / 01 / 2014\end{array}$} \\
\hline \multicolumn{4}{|c|}{ 14. Sponsoring Agency Code } \\
\hline \multicolumn{4}{|c|}{$\begin{array}{l}\text { 15. Supplementary Notes } \\
\text { FDOT Project Manager: Maria Cahill, AICP }\end{array}$} \\
\hline \multicolumn{4}{|c|}{$\begin{array}{l}\text { This report provides guidance in developing a multimodal transportation element of a local government comprehensive } \\
\text { plan. Two model elements were developed to address differences in statutory requirements for communities of different } \\
\text { sizes and planning context. The first model element includes guidance for large local governments and those within the } \\
\text { boundary of a metropolitan planning organization (MPO). The second includes guidance for smaller or more rural } \\
\text { communities outside of MPO boundaries. Each model element encourages a range of best practices in multimodal } \\
\text { transportation planning as identified through a review of the literature, agency plans, and related documents. The } \\
\text { guidance is designed for consistency with } \$ 163.3177(6)(\text { b), Florida Statutes (F.S.), of the } 2011 \text { Florida Community } \\
\text { Planning Act. As such, emphasis is placed on ensuring a multimodal transportation system appropriate to the size and } \\
\text { character of the community, providing for public transportation as feasible, improving accessibility and connectivity } \\
\text { between modes, and coordination with land use and plans of other transportation agencies and modal providers. } \\
\text { Contents include guidance on establishing a community vision and priorities, relevant and professionally accepted data } \\
\text { sources and analysis procedures/tools, guidance on existing and future conditions analysis and mapping, establishing } \\
\text { quality/ level of service standards and other performance measures or benchmarks, future transportation system } \\
\text { network planning strategies, and example goals, objectives, policies, and strategies. }\end{array}$} \\
\hline \multicolumn{2}{|c|}{$\begin{array}{l}\text { 17. Key Words } \\
\text { Multimodal, land use and transportation, comprehensive } \\
\text { planning, transportation element, transportation planning, } \\
\text { transit }\end{array}$} & \multicolumn{2}{|c|}{$\begin{array}{l}\text { 18. Distribution Statement } \\
\text { No restrictions }\end{array}$} \\
\hline $\begin{array}{l}\text { 19. Security Classification } \\
\text { (of this report) } \\
\text { Unclassified }\end{array}$ & $\begin{array}{l}\text { 20. Security Classification } \\
\text { (of this page) } \\
\text { Unclassified }\end{array}$ & $\begin{array}{l}\text { 21. No. of Pages } \\
248\end{array}$ & 22. Price \\
\hline
\end{tabular}




\section{Acknowledgments}

The authors wish to thank and acknowledge the following people for their contributions to this guide:

FDOT Project Manager:

Maria Cahill, FDOT Project Manager, Policy Planning

Project Advisory Committee:

Thomas Deardorff, Polk County Office of

Planning and Development

Jennifer Fortunas, FDOT Systems Planning

Thomas Hill, FDOT District 2

Transportation Statistics

Larry Hymowitz, FDOT District 4

Bill Killingsworth, Florida Department of

Economic Opportunity (DEO)

Ed Lee, FDOT Rail Office

Elba I. Lopez, FDOT District 7

Robert Magee, FDOT Policy Planning

Susan McCune, Orange County

Transportation Planning

Trenda McPherson, FDOT Traffic Safety

Office

Other contributors:

Gina Bonyani, FDOT Systems Planning

Virgie Bowen, FDOT District 3

Lois Bush, FDOT District 4

Bob Crawley, FDOT District 1

Jeffery Dow, FDOT District 7

Danny Lamb, FDOT District 4

Heather Garcia, FDOT District 5

Ken Jeffries, FDOT District 6

Jessica Josselyn, Kittleson \& Associates
Diane Quigley, FDOT Public Transportation Office

Jonathan Roberson, Broward County Transit Division

Gary Sokolow, FDOT Systems Planning

Pat Steed, Central Florida Regional Planning Council

Suraya Teeple, Jacksonville Transportation

Authority (JTA)

Brian Waterman, StarMetro

Les Weakland, Hillsborough Area Regional Transit (HART)

Chris Wiglesworth, Florida Department of Economic Opportunity (DEO)

Jim Wood, FDOT Policy Planning

Mike McDaniel, Florida Department of

Economic Opportunity (DEO)

Lawrence Massey, FDOT District 1

Lindsay Mineer, FDOT District 7

Judy Pizzo, FDOT District 5

Dan Santos, FDOT District 7

Ameera Sayeed, FDOT 2

Andrew Young, FDOT Systems Planning 


\section{Preface}

The model elements and best practices in this report were developed by the National Center for Transit Research at the University of South Florida under a grant from the Florida Department of Transportation (FDOT). The report is intended for use by local government planners and consultants in preparing a multimodal transportation element of the local government comprehensive plan. Florida Department of Transportation (FDOT) staff will also find it useful in their review of local government comprehensive plans and plan amendments in relation to the state transportation system.

The model elements set forth best practices that relate to Florida's multimodal transportation planning requirements. FDOT staff and local governments should also refer to FDOT Procedure Topic No. 525-010-101-d: Review of Local Government Comprehensive Plans, as well as applicable sections of Chapter 163, Part II, Florida Statutes, and related guidance from the Florida Department of Economic Opportunity, Division of Community Development (State Land Planning Agency), and the Florida Department of Transportation to ensure that all State of Florida requirements regarding comprehensive plan amendments and transportation planning are met. 


\section{Executive Summary}

All local governments in Florida must prepare and adopt a comprehensive plan that guides future development and growth in accordance with Chapter 163, Part II, Florida Statutes (F.S.). Comprehensive plans must contain a number of elements, including a transportation element that addresses mobility issues in relation to the size and character of the local government. The plans are to be based on relevant and professionally accepted data sources and analysis methods, and address a variety of issues including multimodal transportation system needs coordinated with future land uses, levels of service, availability of facilities and services, correction of existing deficiencies, and methods for meeting identified needs.

When the Florida Community Planning Act was enacted in 2011, many local planning requirements formerly contained in Rule 9J-5, Florida Administrative Code (F.A.C.) were codified in statute. The Community Planning Act also made sweeping changes to Florida's planning and growth management requirements, making transportation concurrency optional and adding multimodal transportation planning requirements. For example, Chapter $163.3177(6)(b), F . S$. indicates that the purpose of the transportation element is to plan for a multimodal transportation system "that places emphasis on public transportation systems, where feasible. The element shall provide for a safe, convenient multimodal transportation system, coordinated with the future land use map or map series and designed to support all elements of the comprehensive plan."

The Florida Department of Transportation (FDOT) asked the National Center for Transit Research (NCTR) at the University of South Florida (USF) to develop model multimodal transportation elements that can serve as guides for Florida local governments when updating their local government comprehensive plans to meet the provisions of the 2011 Florida Community Planning Act and specifically $\S 163.3177(6)(b), F$. S. Two model elements were developed to address differences in statutory requirements for communities of different sizes and planning context. The first model element includes guidance for large local governments and those within the boundary of a metropolitan planning organization (MPO). The second includes guidance for smaller or more rural communities outside of MPO boundaries.

Each model element encourages a range of best practices in multimodal transportation planning that were identified through an extensive review of the literature, agency plans, and related documents. Emphasis is placed on ensuring a multimodal transportation system appropriate to the community, providing for and promoting public transportation, bicycle and pedestrian travel, and aviation, rail and seaport facilities where applicable, improving accessibility and connectivity between modes (transit stations, intermodal terminals, bicycle and pedestrian facilities), and coordination with land use. The model elements address key concepts in contemporary multimodal transportation planning best practices, which include the integration of land use and transportation planning, focus on both local and regional mobility and accessibility, use of objective language, and regional coordination and consistency with other agency plans and programs.

The model elements are organized broadly around key components of the plan and/or tasks of the planning process. The contents address:(a) community vision and priorities; (b) data sources and analysis procedures or tools; (c) existing and future conditions mapping guidance; (d) level of service standards and performance measures; and (e) example goals, 
objectives, and policies, as well as evaluation and monitoring methods. Guidance is also provided on coordination of the local transportation element with plans and programs of the Florida Department of Transportation (FDOT) including the Florida Transportation Plan and adopted work program, any applicable metropolitan planning organization (MPO) or transportation agency or authority, and other local jurisdictions.

The multimodal transportation plan is intended to reflect the community's vision and priorities; therefore, determining these visions and priorities is a critical activity. The process begins by collecting information: inventorying and analyzing existing land use and transportation conditions; examining other planning efforts; and developing public involvement, which provides continuous feedback on the process. The inventory and analysis of existing conditions highlights both the needs of the current transportation system as well as improvements needed to accommodate growth.

Analyses of both current and future needs share several commonalities, such as quality/level of service analysis for all modes, sketch planning analysis for network planning, and evaluating transit, bicycle and pedestrian needs. Estimates of future travel demand in relation to planned future land use will inform the planning effort, as will estimates of potential future changes in travel behavior based on land use and the availability of additional transportation modes. Local vision statements and supporting goals and objectives can provide a framework for evaluating alternatives and for selecting appropriate projects and strategies for the community.

Goals, objectives, and policies should reflect the community vision and priorities. Chapter 163, Part II, F.S., provides the following definitions for these terms:

- Goal means the long-term end toward which programs or activities are ultimately directed;

- Objective means a specific, measurable, intermediate end that is achievable and makes progress toward a goal;

- Policy means the way in which programs and activities are conducted to achieve an identified goal.

Best practices and strategies for consideration in the development of effective multimodal transportation goals, objectives and policies are categorized as: state; regional and internal consistency; land use and multimodal environment; multimodal quality/level of service; major roadway network; access management; minor street network; public transportation network; transportation demand management; bicycle and pedestrian network safety; and ports, aviation, rail, and intermodal facilities.

This report identifies the proposed content and best practices for each of the model elements along with clear instructions regarding their application. It will serve as a guide to Florida local governments when updating their local government comprehensive plans to meet the provisions of the Community Planning Act, and will provide helpful guidance to any local jurisdiction preparing a transportation plan. 


\section{Table of Contents}

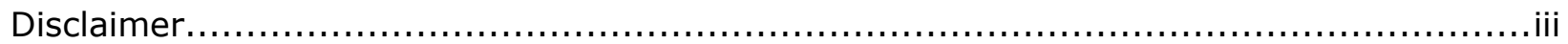

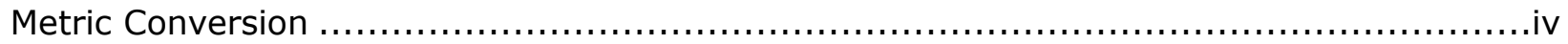

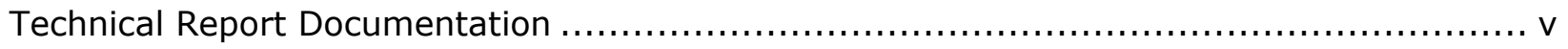

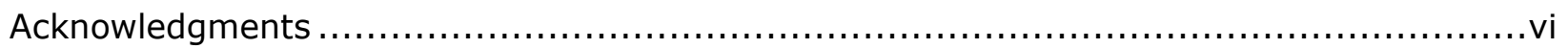

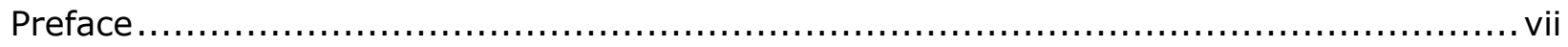

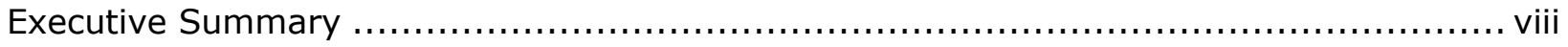

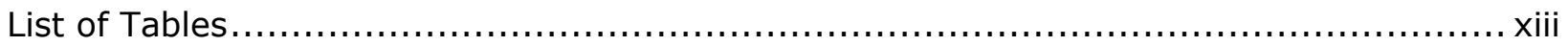

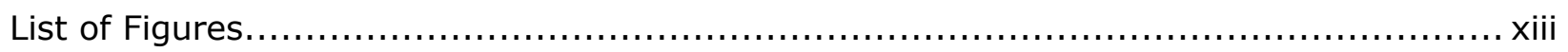

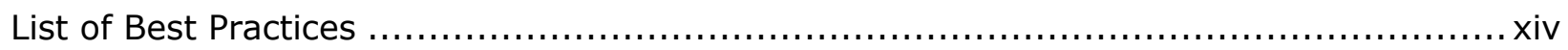

List of Information, Tools, and Resources ..............................................

List of Goals, Objectives, and Policies.........................................................

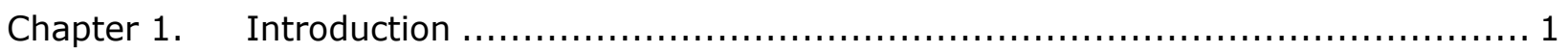

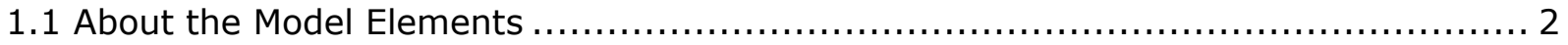

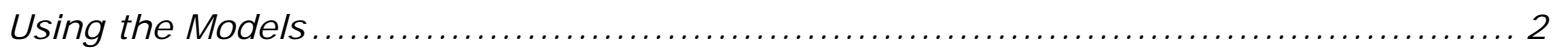

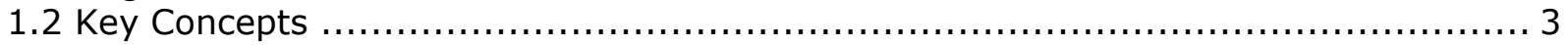

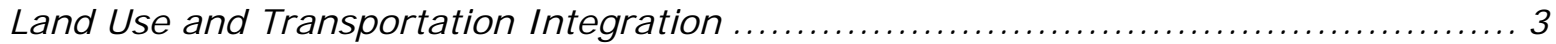

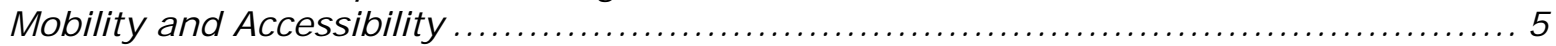

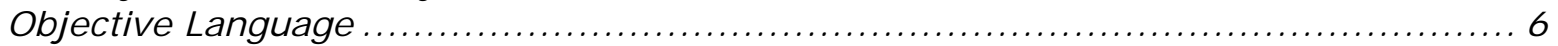

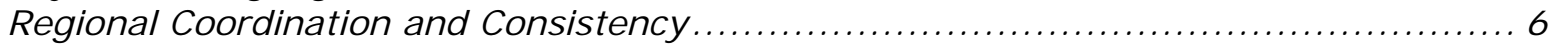

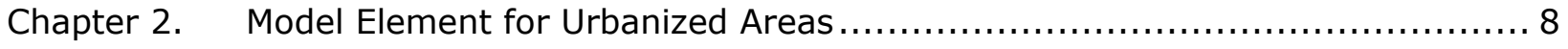

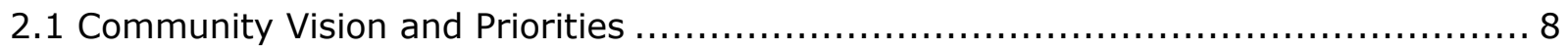

2.2 Inventory and Analysis of Transportation and Land Use Conditions ................... 15

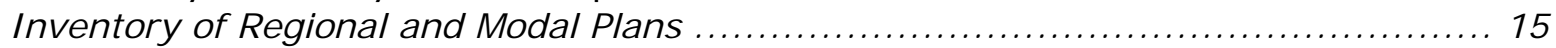

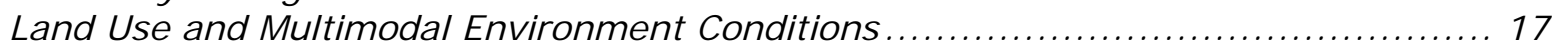

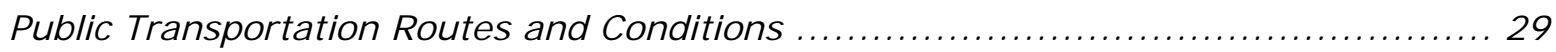

Major Roadways, Evacuation Routes, and Conditions .............................. 38

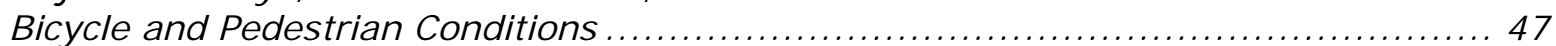

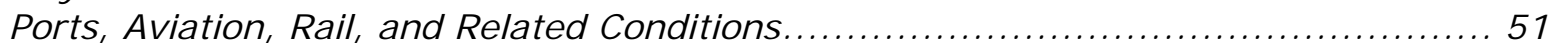

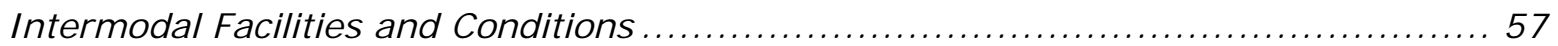

2.3 System Analysis and Future Needs ................................................. 59

Quality/Level of Service Analysis for all Modes ...................................... 60

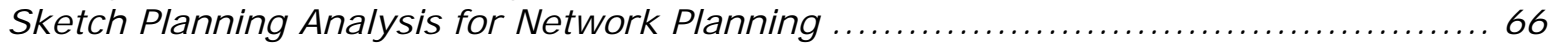

Evaluating Bicycle and Pedestrian Needs ............................................. 68

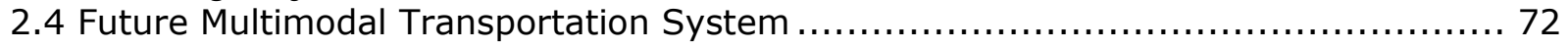

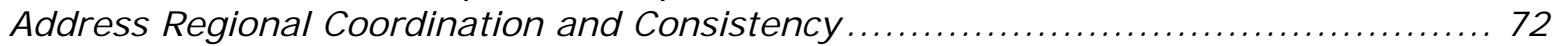

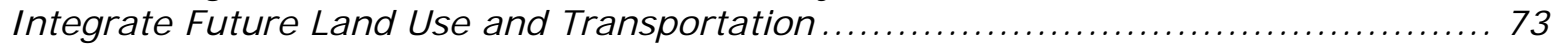

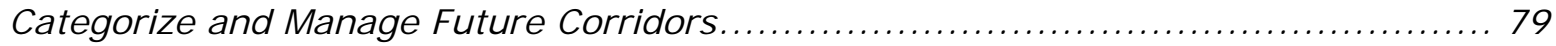

Integrate Connections to Aviation, Rail, Ports, and I ntermodal Facilities .............. 89

Integrate Bicycle and Pedestrian Networks ......................................... 89

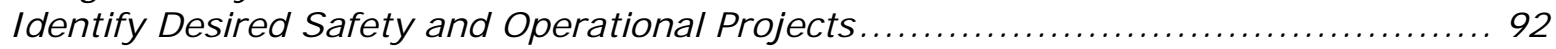

Set Future Q/LOS Standards, Performance Measures, and Benchmarks ................. 95

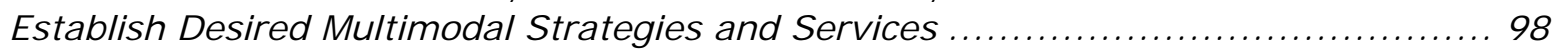

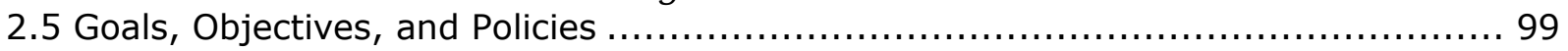

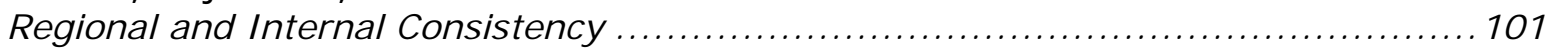




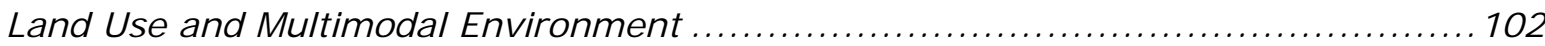

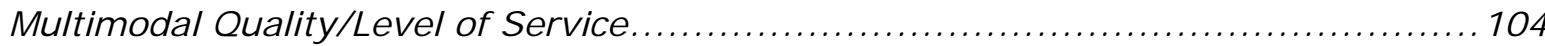

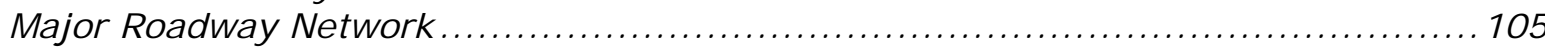

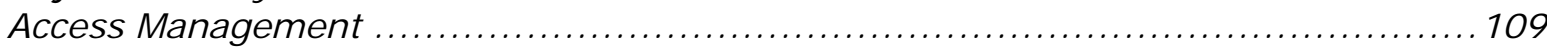

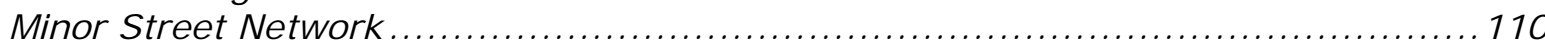

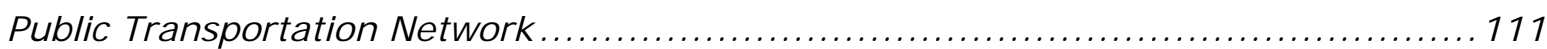

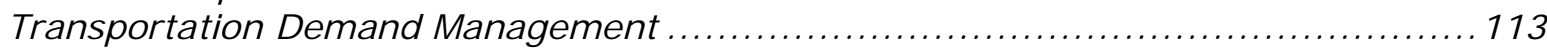

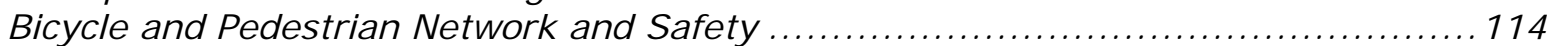

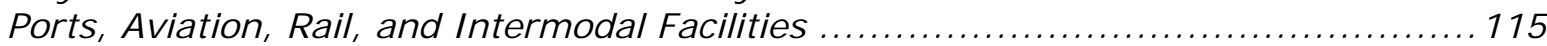

Chapter 3. Model Element for Small Communities and Rural Areas ......................118

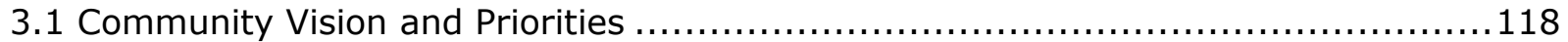

3.2 Inventory and Analysis of Transportation and Land Use Conditions ................... 124

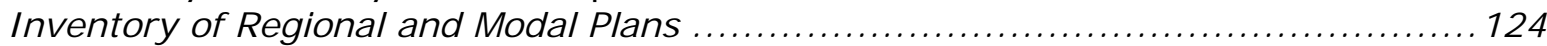

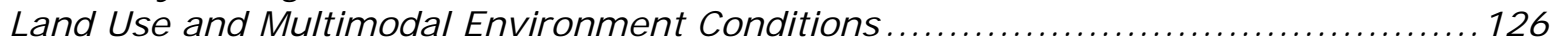

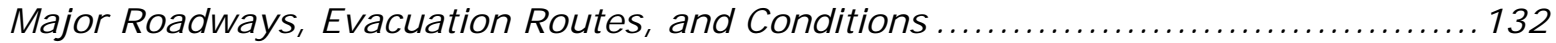

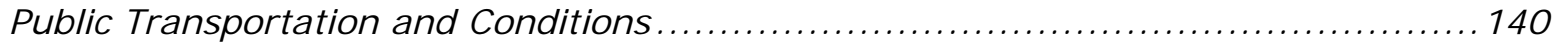

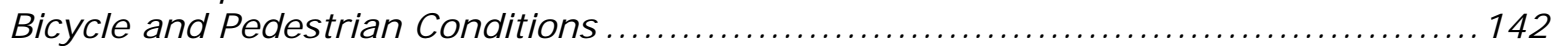

Ports, Aviation, Rail, and Intermodal Facilities ..................................... 144

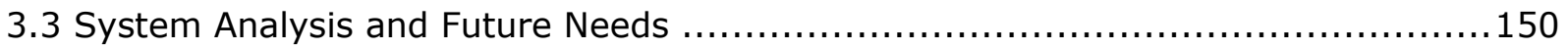

Quality/Level of Service Analysis for all Modes ................................... 150

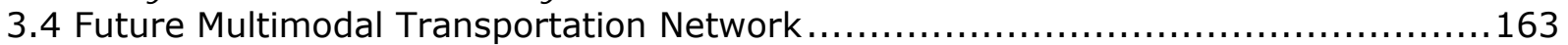

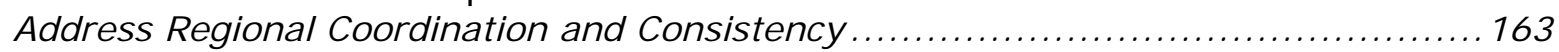

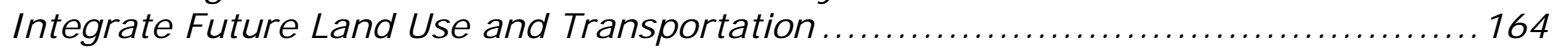

Categorize and Manage Future Corridors............................................ 166

Integrate Connections to Ports, Aviation, Rail, and Intermodal Facilities .............. 174

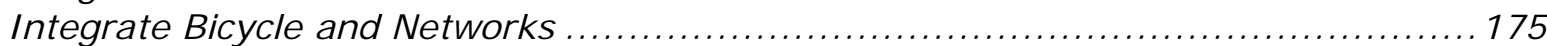

I dentify Desired Safety and Operational Projects ................................. 175

Set Future Q/LOS Standards, Performance Measures, and Benchmarks ............... 175

Establish Desired Multimodal Strategies and Services ................................ 176

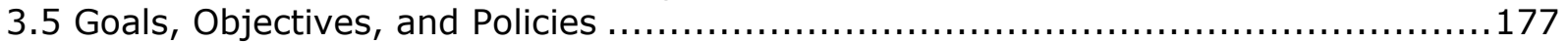

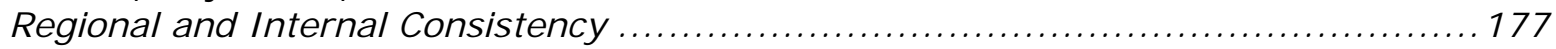

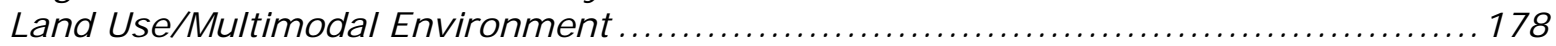

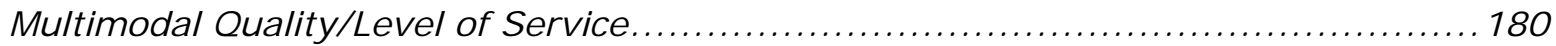

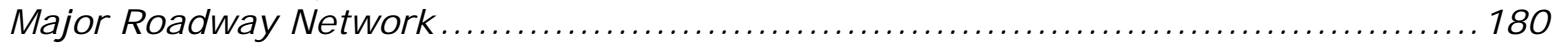

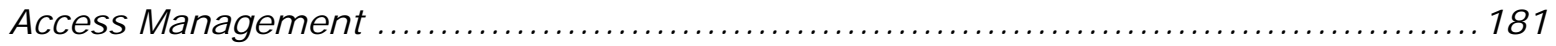

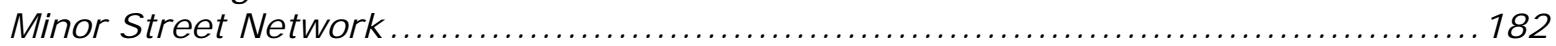

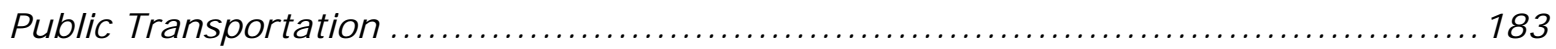

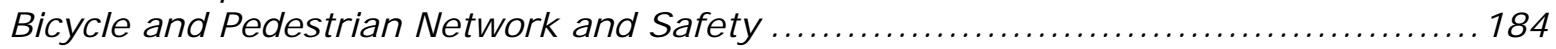

Ports, Aviation, Rail, and Intermodal Facilities .................................... 184

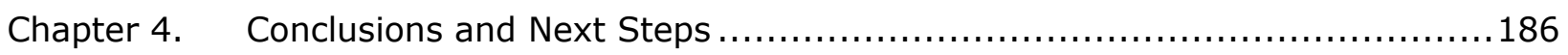

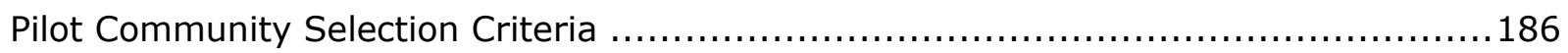

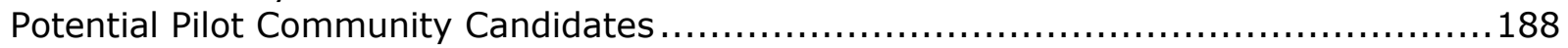

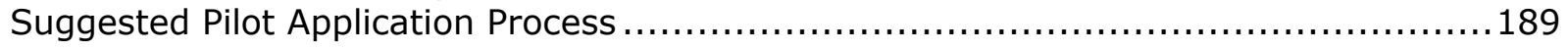

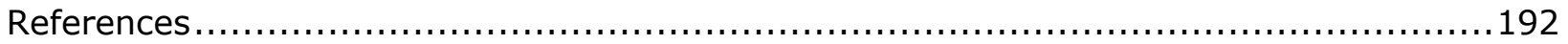

Appendix A - Florida Statutory Requirements for Transportation Elements .................201

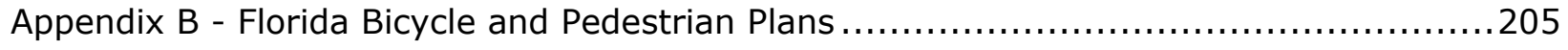

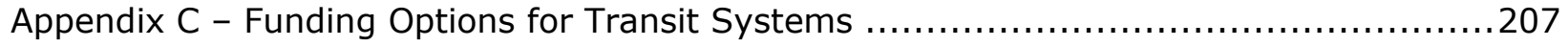

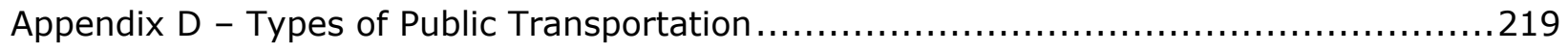




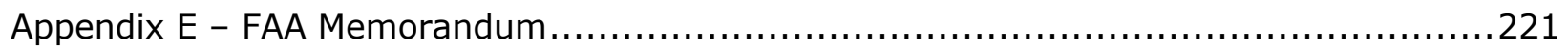

Appendix F - Tallahassee-Leon County Corridor Preservation Policies .......................224

Appendix G - Fort Lauderdale Complete Streets Policy................................227

Appendix H - MPO Long-Range Transportation Plan Adoption Schedule.....................231 


\section{List of Tables}

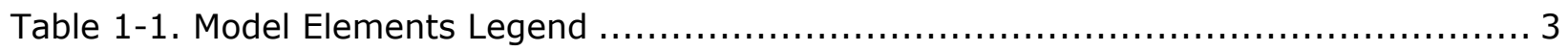

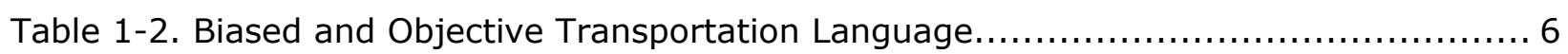

Table 2-1. Land Use Compatibility Matrix ............................................. 21

Table 2-2. Public Transportation Modes of Service and Market Characteristics............... 29

Table 2-3. Example of Mode Choice Information in a Long-Range Transportation Plan ...... 42

Table 2-4. Addressing Airports in the Comprehensive Plan .............................. 57

Table 2-5. Statistically Significant LOS Criteria for Non-Automobile Modes in HCM 2010 ... 63

Table 2-6. Comparison of Principal Arterial and Local Street ................................ 79

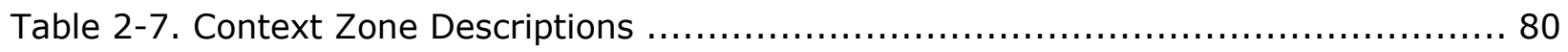

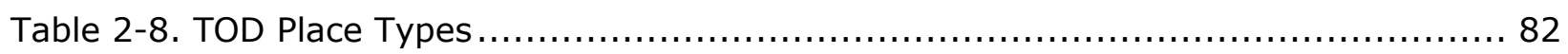

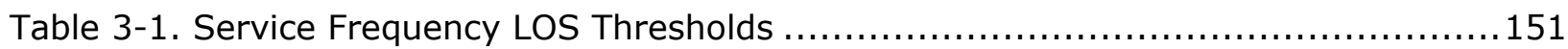

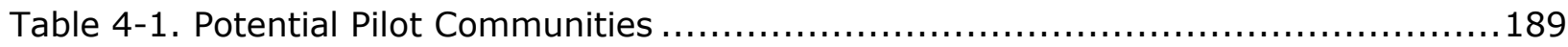

Table A-1. Required and Optional Components of Transportation Elements................203

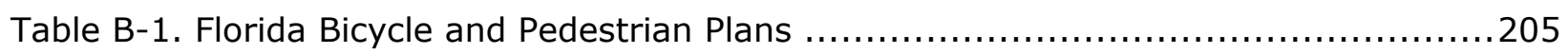

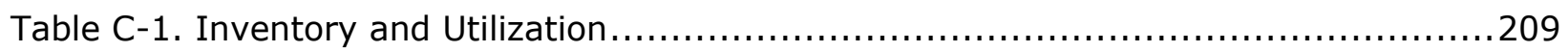

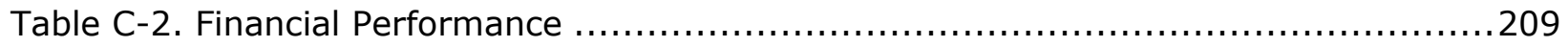

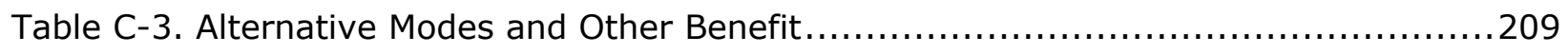

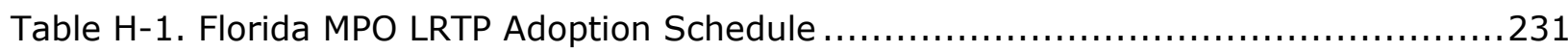

\section{List of Figures}

Figure $1-1$. Conventional versus integrated planning process $\ldots \ldots \ldots \ldots \ldots \ldots \ldots \ldots \ldots \ldots \ldots, \ldots$

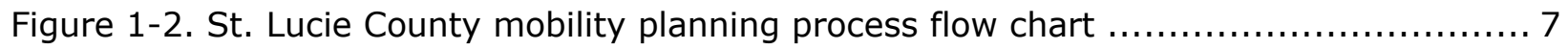

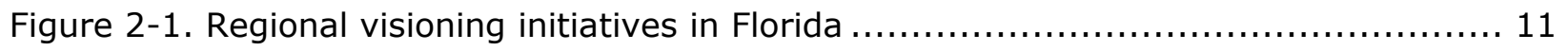

Figure 2-2. Visionary design concept of an urban, intermodal or activity center and travel

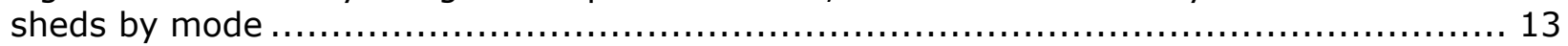

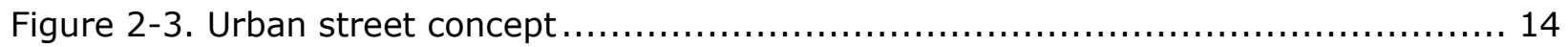

Figure 2-4. Visualization of multimodal access management benefits..................... 23

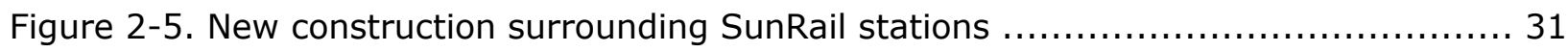

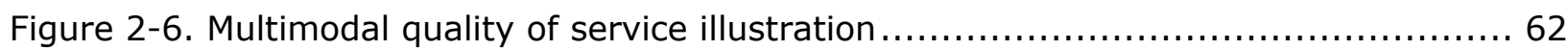

Figure 2-7. Spacing of urban arterial streets based on travel demand $\ldots \ldots \ldots \ldots \ldots \ldots \ldots \ldots \ldots 6$

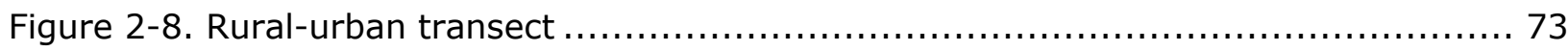

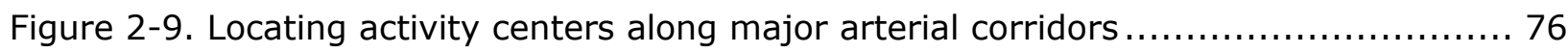

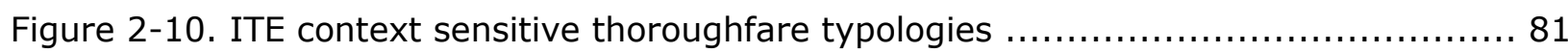

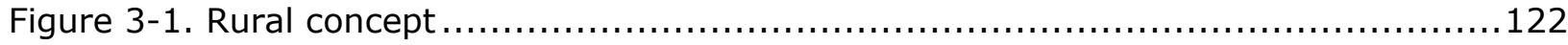

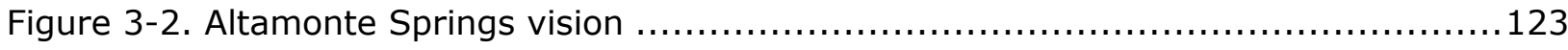

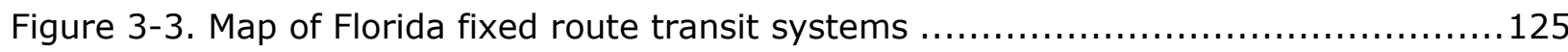

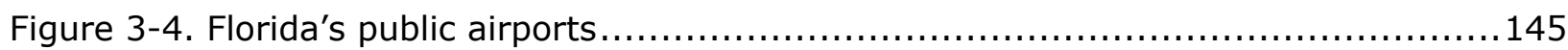




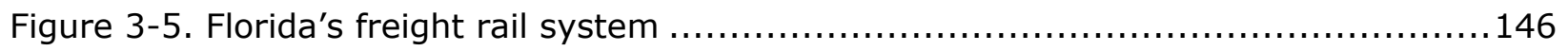

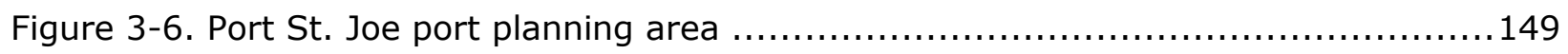

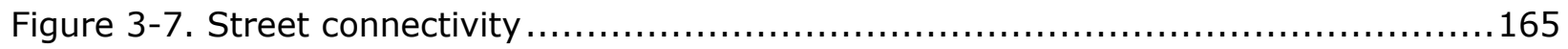

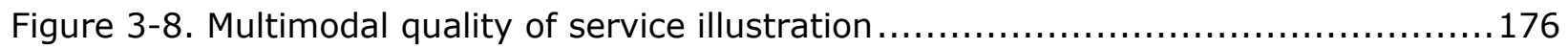

Figure F-1. Future Right-of Way Needs Without an Existing Corridor Alignment ............225

\section{List of Best Practices}

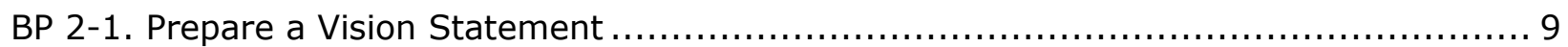

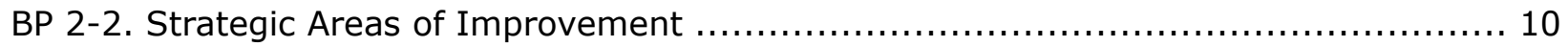

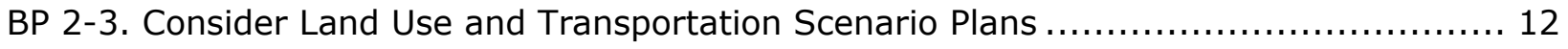

BP 2-4. Analyze Current Transportation and Land Use Conditions....................... 15

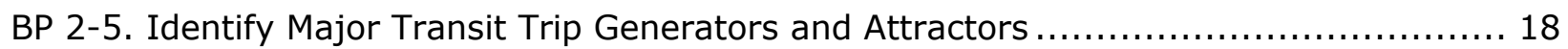

BP 2-6. Identify Major Roadways, Intermodal Facilities, and Activity Centers ............... 19

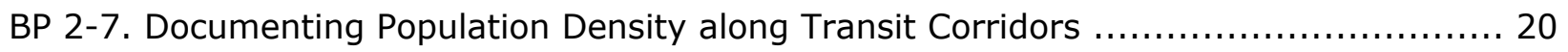

BP 2-8. Strategies for Integration of Transportation and Land Use ....................... 23

BP 2-9. Transit Supportive Densities and Intensities for Station Areas ..................... 25

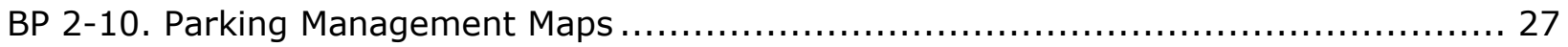

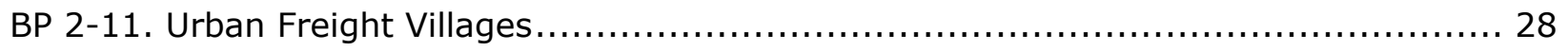

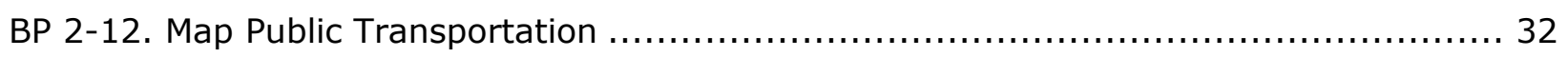

BP 2-13. Identify and Plan for Premium or High Capacity Transit Routes .................... 34

BP 2-14. Address Transit Planning and Land Use Issues................................... 36

BP 2-15. Minimum Density per Type of Transit Service ................................. 37

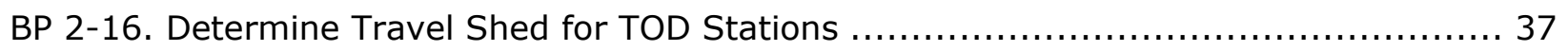

BP 2-17. Map and Discuss Major Thoroughfares and Related Characteristics ............... 40

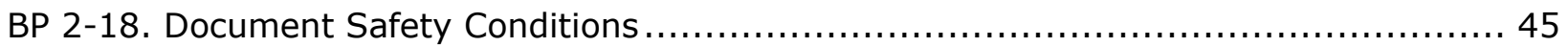

BP 2-19. Consider Vulnerability to Hazards in Infrastructure Investments...................47

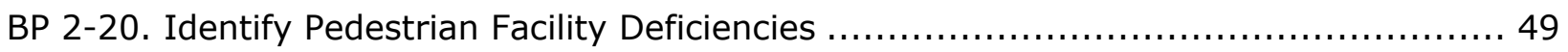

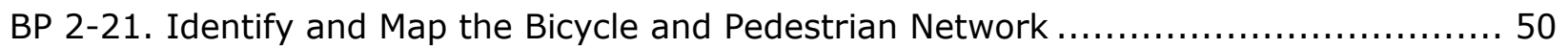

BP 2-22. Document Bicycle and Pedestrian Crash Locations ............................... 51

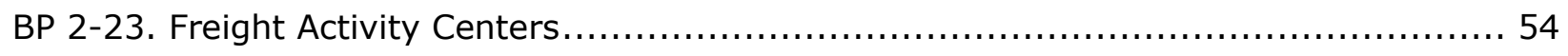

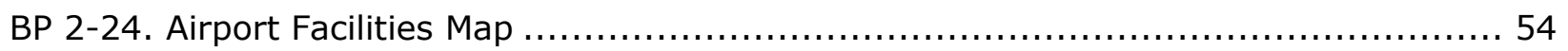

BP 2-25. Identify Existing Rail, Ports, Airports, and Related Facilities ..................... 55

BP 2-26. Identify Access to Airports and Related Data ................................... 56

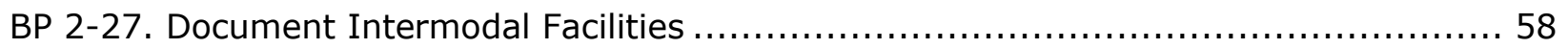

BP 2-28. Identify Deficiencies on the Major Thoroughfares and Transportation Routes ..... 61

BP 2-29. Orange County's Annual Capacity and Availability Report ........................ 62

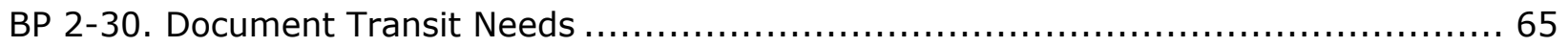


BP 2-31. Apply Spacing and Connectivity Guidelines to the Transportation Network....... 68

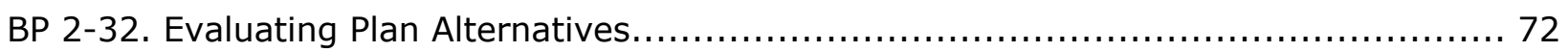

BP 2-33. Designate Areas Intended for Compact Development ........................... 74

BP 2-34. Include a Map Series Relating the Transportation and Land Use Elements ........ 75

BP 2-35. Broward County's Steps to Improve the Multimodal Environment ................ 76

BP 2-36. Apply Multimodal Strategies to Integrate Land Use and Transportation ........... 78

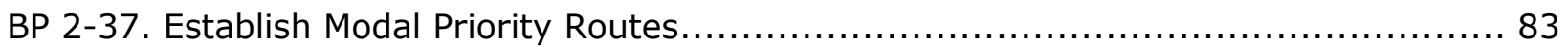

BP 2-38. Functional Typologies for Context Sensitive and Complete Streets................ 84

BP 2-39. Functional Classification and Complete Streets Typologies ...................... 85

BP 2-40. Designate and/or Reinforce Managed Lanes on Major Thoroughfares .............. 86

BP 2-41. Thoroughfare Right-of-way Needs Identification Maps $\ldots \ldots \ldots \ldots \ldots \ldots \ldots \ldots \ldots \ldots . \ldots . \ldots \ldots$

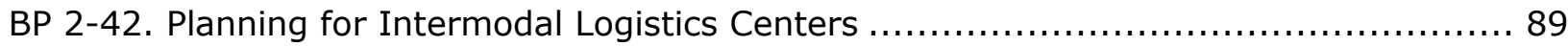

BP 2-43. Steps for Integrating Bicycle and Pedestrian Needs into Transportation Planning 90

BP 2-44. Identify Alternative Strategies for Improving Bicycle and Pedestrian Ways........ 91

BP 2-45. Plan a Bicycle Network That Connects to Transit and Key Destinations ............ 91

BP 2-46. Redesigning Intersections to Improve Bicycle Safety $\ldots \ldots \ldots \ldots \ldots \ldots \ldots \ldots \ldots \ldots \ldots 2$

BP 2-47. Prioritize Multimodal Projects and Strategies ................................... 93

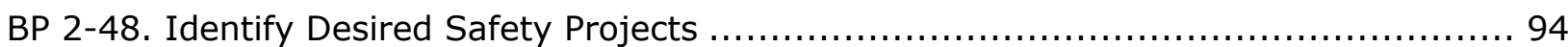

BP 2-49. Example Multimodal Strategies and Corresponding Indicators/Measures.......... 97

BP 2-50. Transit-Oriented Q/LOS Standards................................................ 98

BP 2-51. Ensuring Consistency Between Transportation Plans ............................. 100

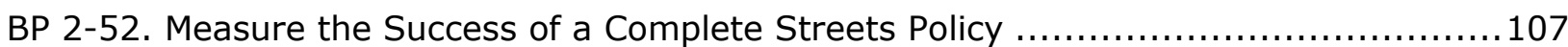

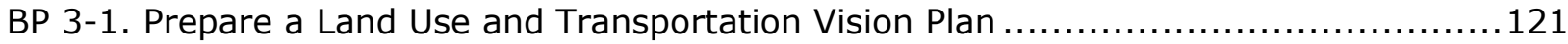

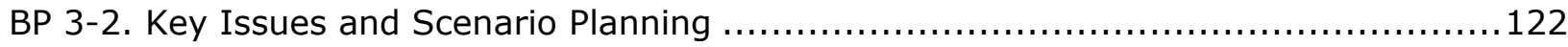

BP 3-3. Rural Areas of Critical Economic Concern and Catalyst Sites .....................127

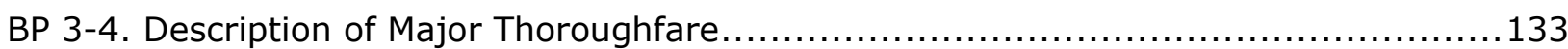

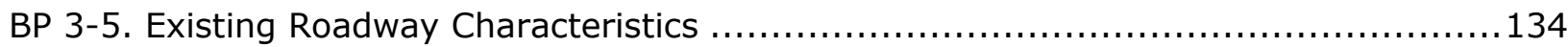

BP 3-6. Pavement Conditions Analysis.................................................... 135

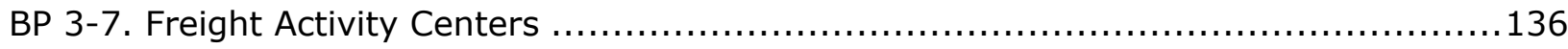

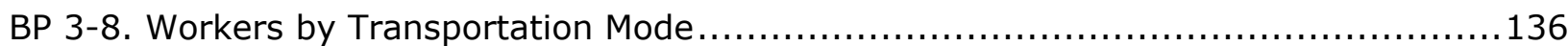

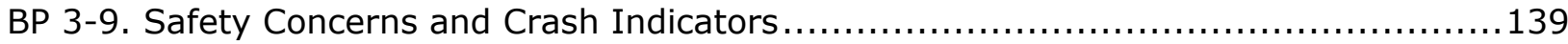

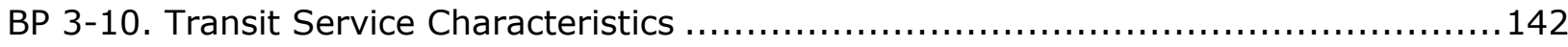

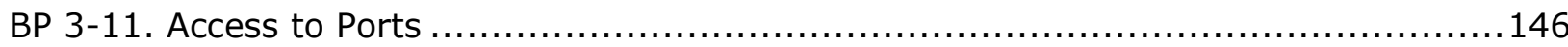

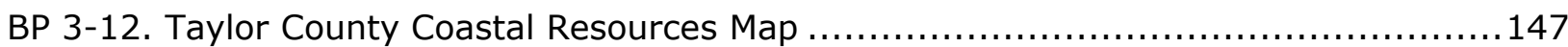

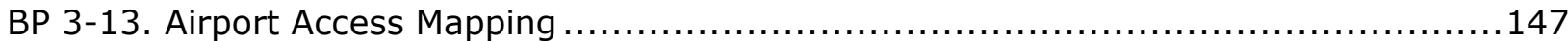

BP 3-14. Existing (2010) Operating LOS - State Roads.................................. 153

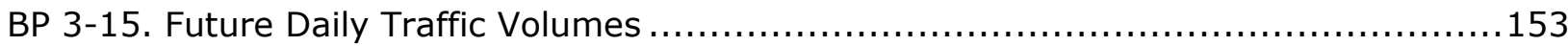

BP 3-16. Future Roadway Volume to Capacity $(\mathrm{V} / \mathrm{C})$ Ratio................................ 156 


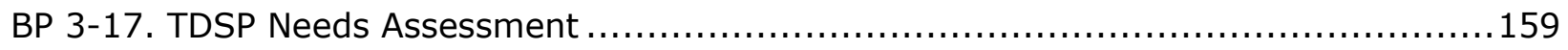

BP 3-18. Non-motorized Rural Town Center Corridor Plan .............................. 161

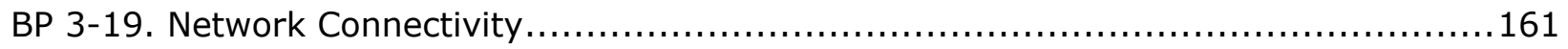

BP 3-20. Generalized Network Concepts for Corridor Management ...................... 167

BP 3-21. Complete Streets Strategies on Rural Roadways .............................. 169

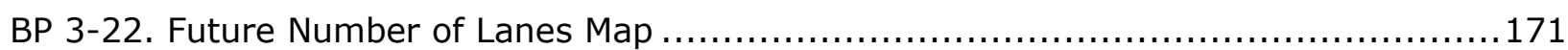

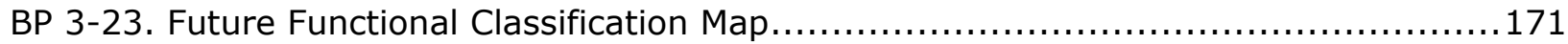

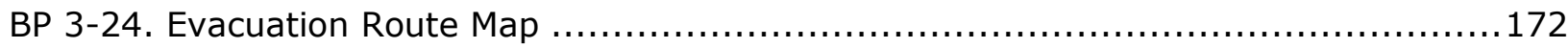

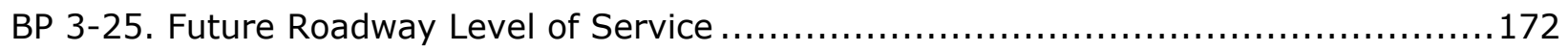

BP 3-26. Mapping Future Transit System and Future Transit Centers .....................173

BP 3-27. Recommendation for Key Policy Themes.................................... 179

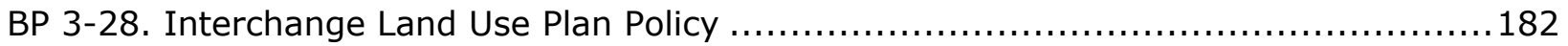

\section{List of I nformation, Tools, and Resources}

ITR 2-1. Plans and Programs of State and Regional Agencies and Modal Providers.......... 16

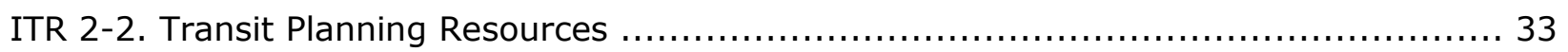

ITR 2-3. Transit System Information Found in the TDP ................................. 35

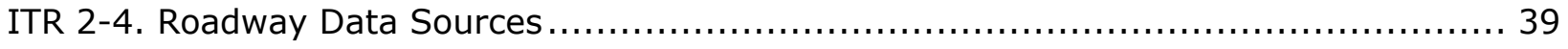

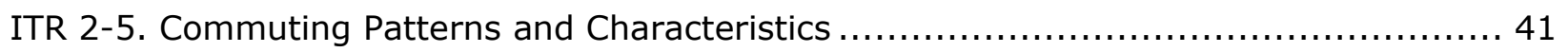

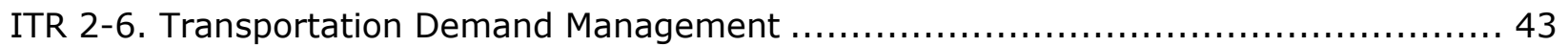

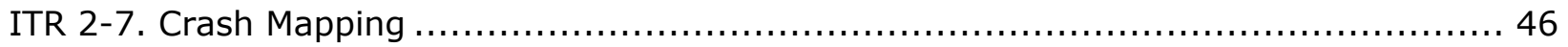

ITR 2-8. Identification of Existing Bicycle and Pedestrian Conditions ....................... 48

ITR 2-9. Rail, Ports, Airports, and Freight Planning Information Sources................... 53

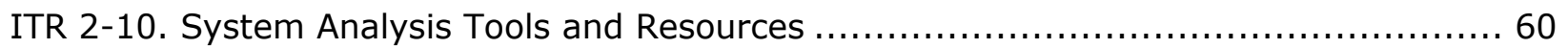

ITR 2-11. Bicycle and Pedestrian Planning Analysis Tools and Resources .................... 69

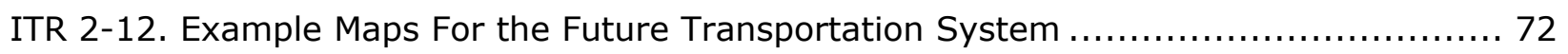

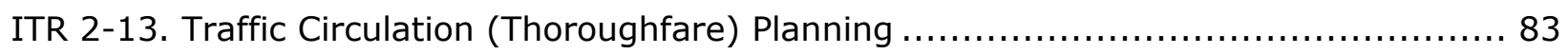

ITR 2-14. Establishing Level of Service Standards and/or Performance Measures ........... 96

ITR 2-15. Selected Performance Review Measures Fixed Route Transit Services ............. 98

ITR 2-16. Planning Process from Citizen Input through Performance Measurement ........100

ITR 2-17. Elements of an Ideal Complete Streets Policy .............................. 106

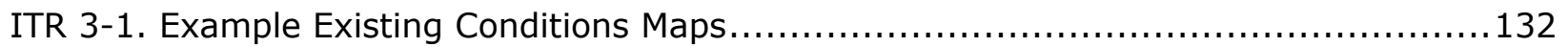

ITR 3-2. Generalized Annual Average Daily Volumes in Florida's Transitioning Areas and

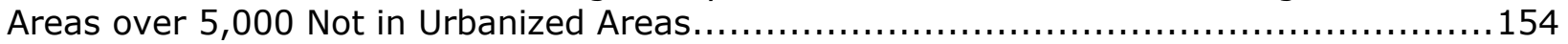

ITR 3-3. Generalized Annual Average Daily Volumes in Rural Undeveloped Areas and Developed Areas Less Than 5,000 Population .............................................. 155

ITR 3-4. Small Communities and Rural Future Transportation System Maps.................. 163 


\section{List of Goals, Objectives, and Policies}

GOP 2-1. Intergovernmental Coordination ................................................... 101

GOP 2-2. Linking Transportation and Land Use through Planned Mobility ...................... 103

GOP 2-3. Developer Contributions to the Multimodal Environment........................... 103

GOP 2-4. Multimodal Level of Service Standards............................................... 104

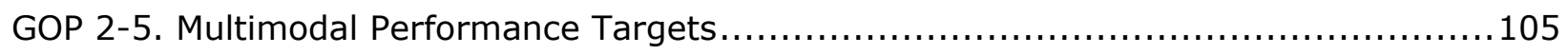

GOP 2-6. Tallahassee-Leon County Corridor Preservation Policies............................. 108

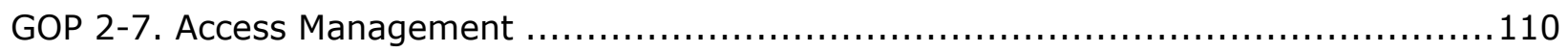

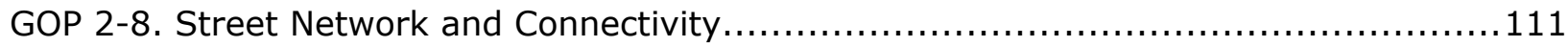

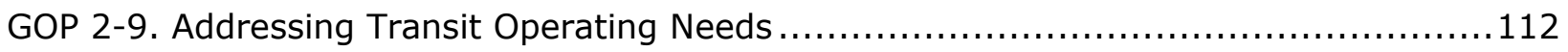

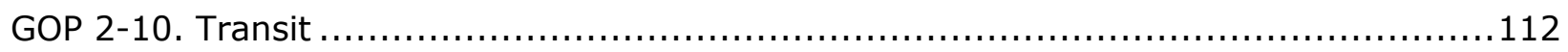

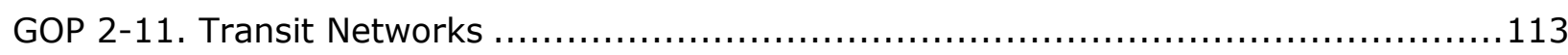

GOP 2-12. Transportation Demand Management ….......................................... 114

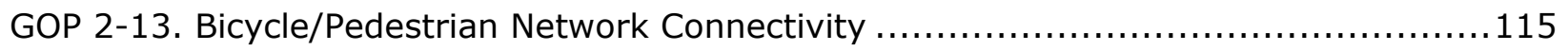

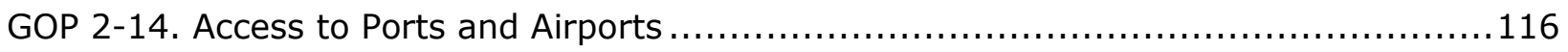

GOP 2-15. Port, Airport, Rail, and Intermodal Integration ................................... 117

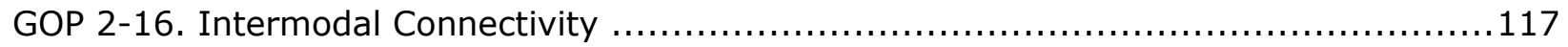

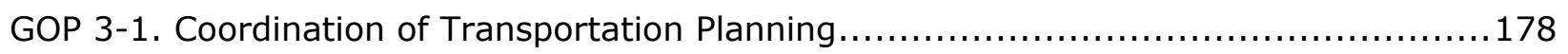

GOP 3-2. Evacuation Routes and Maximum Evacuation Clearance ............................ 181

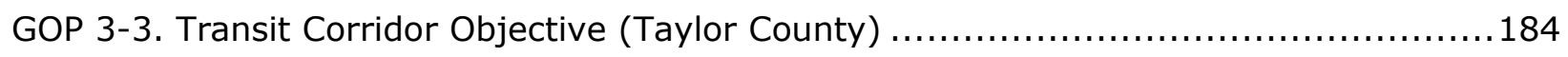

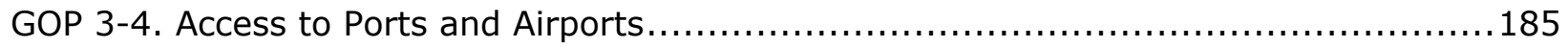




\section{Chapter 1. I ntroduction}

All local governments in Florida must prepare and adopt a comprehensive plan that guides future development and growth in accordance with Chapter 163, Part II, Florida Statutes (F.S.). Comprehensive plans must contain a number of elements, including a multimodal transportation element that addresses mobility issues in relation to the size and character of the local government. The plans are to be based on relevant and professionally accepted data sources and analysis methods, and must address a variety of issues, including multimodal transportation system needs coordinated with future land uses, levels of service, availability of transportation facilities and services, correction of existing deficiencies, and methods for meeting identified needs.

When the Florida Community Planning Act was enacted in 2011, many local planning requirements formerly contained in Rule 9J-5, F.A.C., were codified in statute. The Community Planning Act made sweeping changes to Florida's planning and growth management requirements, making transportation concurrency optional and adding multimodal transportation requirements. For example, Chapter $163.3177(6)$ (b), F.S., states that the purpose of the transportation element is to plan for a multimodal transportation system "that places emphasis on public transportation systems, where feasible. The element shall provide for a safe, convenient multimodal transportation system, coordinated with the future land use map or map series and designed to support all elements of the comprehensive plan."

Each local government is to address mobility issues "... in relationship to the size and character of the local government." Generally, the requirements are as follows:

1. All local governments not located within an MPO "shall address traffic circulation, mass transit, and ports, and aviation and related facilities consistent with this subsection..." except that "...local governments with a population of 50,000 or less shall only be required to address transportation circulation," which is described as "major thoroughfares and transportation routes, as well as bicycle and pedestrian ways."

2. Local governments within a metropolitan planning organization (MPO) boundary must address all modes of travel, including: public transportation, pedestrian and bicycle travel, airports and aviation development, rail, seaports, access to facilities and intermodal terminals, compatibility around airports, land uses to promote public transportation, and evacuation of coastal populations.

3. Regardless of metropolitan planning areas, "municipalities having populations greater than 50,000 and counties having populations greater than 75,000 shall also include mass-transit provisions..." as specified, as well as plans for port, aviation and related facilities, and plans for circulation of recreational traffic.

Appendix A includes Chapter 163.3177(6)(b), F.S., and a table that organizes the requirements by community type into Category $A$ through $D$, for ease of reference. This report guides users as to pertinent details to address in their transportation element, as well as best practice applications, for each of the respective jurisdiction types noted in $\S 163.3177(6)(\mathrm{b})$, Florida Statutes. 


\subsection{About the Model Elements}

The model elements are designed to guide local governments in developing or updating the transportation element of their comprehensive plan in accordance with the 2011 Florida Community Planning Act and specifically $\$ 163.3177(6)(b)$, Florida Statutes. Two model elements are provided to address differences in statutory requirements for communities of different sizes and planning context. The first model element (Chapter 2) includes guidance for large local governments and those within the boundary of an MPO. The second (Chapter 3 ) includes guidance for smaller or more rural communities outside of an MPO.

The model elements are organized broadly around key components of the comprehensive plan and/or tasks of the planning process. The contents address: (a) community vision and priorities; (b) data sources and analysis procedures or tools; (c) existing and future conditions mapping guidance; (d) level of service standards and performance measures; and (e) example goals, objectives, and policies, as well as evaluation and monitoring methods. Guidance is also provided on coordination of the local transportation element with plans and programs of the Florida Department of Transportation (FDOT) including the Florida Transportation Plan and adopted work program, any applicable metropolitan planning organization (MPO) or transportation agency or authority, and other local jurisdictions.

Throughout the model elements the terms transit, mass transit and public transportation will be used interchangeably to have the same meaning. These terms encompass various modes of service including commuter rail, light rail, street cars, trolleys, bus rapid transit (BRT), bus, and paratransit. In addition, Chapter 163, Part II, F.S., refers to major thoroughfares which in the elements encompass major roadways as well as public transportation where applicable.

Each model element encourages a range of best practices in multimodal transportation planning that were identified through an extensive review of the literature, agency plans, and related documents. Emphasis is placed on ensuring a multimodal transportation system appropriate to the community, providing for and promoting public transportation, improving accessibility and connectivity between modes (transit stations, intermodal terminals, bicycle and pedestrian facilities), and coordination with land use.

\section{Using the Models}

Throughout the document are boxes of varying colors containing pertinent information as described in the legend below (Table 1-1). Given the overlap in what may constitute a multimodal transportation planning best practice (BP) for a given context, some "BPs" in the urban element are cross-referenced in the rural element. Cross-referencing is also provided for the information, tools, and resources, as well as example goals, objectives, and policies. Information, tools, and resources include data sources and analysis methods as well as resources for additional guidance. "Practice notes" are provided in green text for information pertinent to the various statutory requirements, applications, and multimodal transportation planning best practices. Various items to address in the planning process are in bold and italics. References are cited by a number in parentheses. 
Table 1-1. Model Elements Legend

Key items to address are denoted in italicized, bold text

Best Practices (BP)

I nformation, Tools, \& Resources (ITR)

Goals, Objectives, and Policies (GOP)

I mportant "Practice Notes" are denoted in italicized, green text

References are cited by a number in parentheses

The methods, policies, and applications appropriate to a given community and the level of complexity in the planning analysis will vary based upon local planning capacity, resources, and context. Local governments, particularly those in smaller communities or urban counties with large rural areas, are encouraged to examine both elements for information of utility to their overall planning vision.

Finally, Florida's multimodal transportation planning requirements include specific coordination requirements with the future land use element. Other comprehensive plan elements related to the transportation element include the intergovernmental coordination element, capital improvements element, housing element, coastal management element, and conservation element.

\subsection{Key Concepts}

Much has been written in recent years regarding contemporary multimodal transportation planning best practices. Key concepts include the integration of land use and transportation planning, focus on both local and regional mobility and accessibility, use of objective language, state and regional coordination and consistency with other agency plans and programs. These concepts are briefly described below.

\section{Land Use and Transportation Integration}

Conventional transportation planning treats future land use plans largely as a "given" and attempts to solve anticipated traffic congestion resulting from these plans primarily by increasing roadway capacity. Contemporary transportation planning practice explicitly recognizes the interrelationship of transportation and land use planning, the importance of multimodal investments in managing travel demand, and the need for coordinating land use strategies with modal investments (see Figure 1-1). In addition, a contemporary transportation planning process has the following characteristics (1):

- Context-Sensitive: looks at the broader context rather than focus on solutions within the right-of-way, a single roadway, or a few intersections; 
- Holistic: identifies transportation solutions that address broader land use issues and integrates land use and transportation for long term viability of a corridor and community;

- Collaborative: forms intergovernmental partnerships to identify and implement strategies that leverage the full value of all infrastructure investments; and

- Multimodal: examines pedestrian, transit, bicycling, and automobile, as well as rail (freight and passenger), air, and water modes of transportation and identifies supporting land use and programmatic strategies.

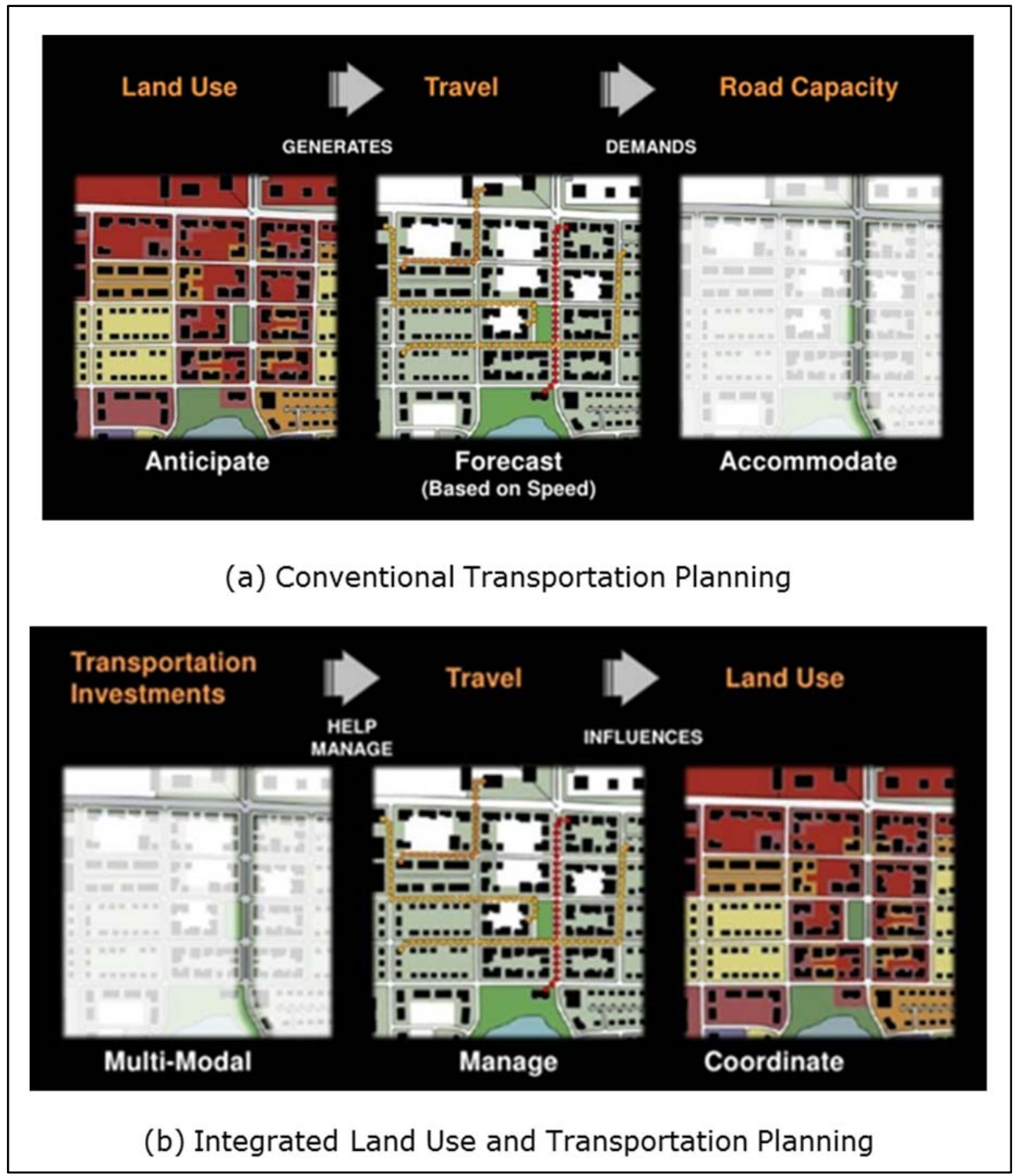

Figure 1-1. Conventional versus integrated planning process Source: State Road 50 Multi-Modal Corridor Study (1)

In the ITE Transportation Planning Handbook, Michael Meyer provides a framework for preparing a contemporary transportation plan. Meyer notes that "issues considered in the transportation planning process often reflect the changing characteristics of society as a whole." (2 p. 5). They include issues such as population growth, changing demographics, 
evolving economic markets, transportation system preservation, technology, financing capacities, changing institutional structures, environmental imperatives, and energy. For example, autonomous vehicles are one of many technology innovations that may change how we plan for transportation.

The proposed process begins with identification of the problems that need to be addressed and creation of a vision that reflects the "interaction between desired states of prosperity, environmental quality, and social equity/quality of life" (2). The visioning step requires extensive community outreach and is generally the most interactive step of the planning process. The next step involves creating specific goals and objectives based on the vision (2). Creating goals and objectives helps to: (a) define the purpose of the planning process for the public, and (b) identify the criteria that will be used to evaluate the plan and its alternatives in the form of system performance measures.

After establishing goals and objectives and collecting the data, the data must be analyzed to determine how the components of the transportation system interact and relationships of the system with other issues, including the environment, the economy, and quality of life. Alternatives for achieving goals and objectives must also be evaluated. Meyer emphasizes the importance of evaluating a range of system alternatives, including projects, as well as programmatic actions or strategies to influence travel behavior, such as rideshare programs or parking pricing (2). A broad range of actions may be considered such as policies, institutional and operational strategies, infrastructure projects, special studies, regulations, education and awareness, financing strategies, and a host of collaborative undertakings. Goals and objectives may need to be modified based on the analysis and data collected.

The final component in the planning framework is system monitoring. The creation of goals and objectives should have led to the identification of system performance measures that emphasize performance issues of importance to decision makers. System performance measures guide data collection and analysis for the purpose of monitoring performance of the planned transportation system following implementation. System monitoring is crucial to the success of a plan because it provides information about how well the planned system is working, whether results are consistent with community objectives, and if changes are needed. Through this process, planners can identify what is working, what is not, and potential opportunities for improvement.

\section{Mobility and Accessibility}

Shifting from an auto-oriented planning process to one that supports all modes of travel involves a change in focus from moving cars to moving people and goods. Mobility is viewed comprehensively, as noted below, rather than only in terms of maximizing through movement of vehicles:

- Accessibility - An area-wide measure of the ease of travel between locations within a defined geographic area (e.g. is the ability to reach a given location from numerous other locations, or the ability to reach a variety of other locations from a given location.)

- Mobility - The ability of people to make trips to satisfy their needs or desires by walking, driving, riding a bicycle, riding public transit, or any combination of modes of transportation. 
This shift in focus involves placing less emphasis on relieving auto congestion in urban core areas or activity centers (often a sign of vitality) and more emphasis on expanding and reinforcing mode choice in those areas, improving walkability, and promoting a diverse and compatible mix of land uses in close proximity. Dense, connected streets with narrower cross-sections and wider, continuous sidewalks are among the determinants of walkability, and also help to make activity centers functional, vibrant, and appealing.

In addition, somewhat less priority is placed in the plan on preventing future congestion through lane expansion and fringe highways that induce exurban growth, and higher priority is placed on managing the existing arterial system. Strategies to improve safe and efficient operations of the major roadway system include access management (e.g., medians, long and uniform signal spacing, median opening and connection spacing, auxiliary lanes), signal coordination systems, incident management, and more effective application of transportation demand management techniques. Providing managed lanes, such as highoccupancy toll lanes, on congested highway corridors is another example strategy.

\section{Objective Language}

Language used in a local government comprehensive plan and related documents may contain certain biases, such as a bias toward automobiles or roadways over buses and transit systems. The model element language attempts to use objective policy language throughout. Model policy language recommended from existing plans has been modified to be objective. Examples of biased and objective policy language are illustrated in Table 1-2.

Table 1-2. Biased and Objective Transportation Language

\begin{tabular}{|l|l|}
\hline \multicolumn{1}{|c|}{ Biased } & \multicolumn{1}{c|}{ Objective } \\
\hline Improvement or improve & Project, modification, change, modify \\
\hline Enhance or deteriorate & Change, decrease, increase \\
\hline Upgrade & Expand, reconstruct, widen, change \\
\hline Traffic demand & Motor vehicle use, travel demand \\
\hline Accident & Crash, collision \\
\hline Alternative modes of transportation & Non-automobile or non-motorized modes \\
\hline
\end{tabular}

Source: Palm Beach City Transportation Language Policy (3)

\section{Regional Coordination and Consistency}

Intergovernmental coordination, particularly at a regional level, plays an important role in multimodal transportation planning. The local transportation element should be consistent with and integrate the future plans and visions of a number of transportation planning entities. An example of such coordination is the 2011 Mobility Plan: Linking Land Use and Transportation - a collaborative planning effort of St. Lucie County, Port St. Lucie, Fort Pierce, and St. Lucie Village. Working groups representing nine governmental agencies (including municipalities), the County School Board, and regional planning agencies were involved. The plan recognizes that transportation is multijurisdictional and "county and municipal boundaries do not dictate travel behavior" (4 p. 2). The planning effort extended into neighboring counties and planning agencies (4). Figure 1-2 illustrates the coordinated mobility planning process.

The update of the local transportation element should also be coordinated with the plans and programs of the FDOT including Florida Transportation Plan and the Adopted Five-Year Work Program, any applicable MPO, or transportation agency or authority. These plans are 
considered best available and professionally accepted data sources. The transportation element update will also need to be internally consistent with other plan elements such as the future land use element. For example, land use densities and intensities adjacent to transportation corridors should be sufficient to encourage and support alternative modes of travel to the automobile.

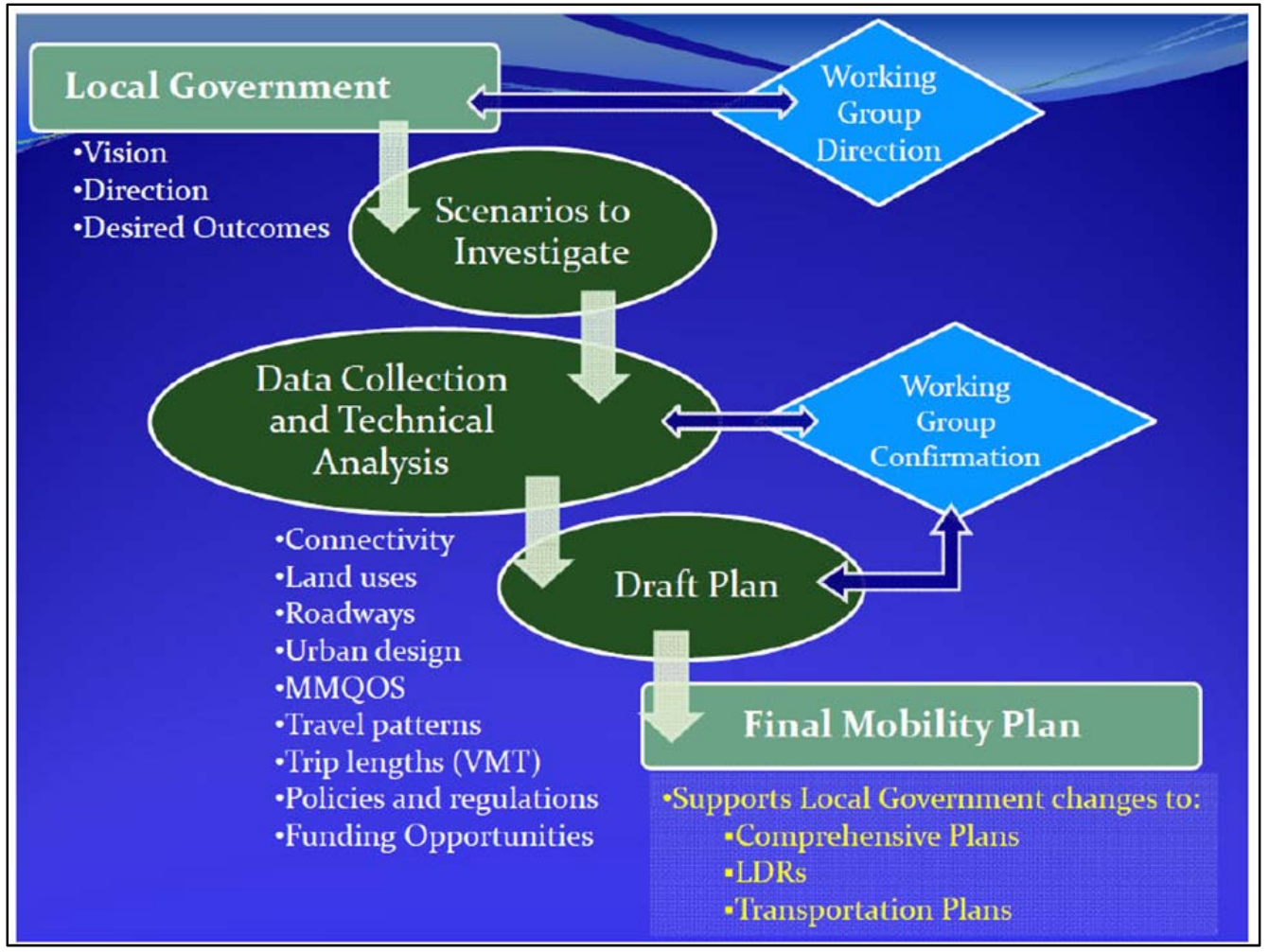

Figure 1-2. St. Lucie County mobility planning process flow chart

Source: 2011 Mobility Plan (4) 


\section{Chapter 2. Model Element for Urbanized Areas}

The model element for urbanized areas includes guidance for large communities and local governments of any size that are within the planning area boundary of a metropolitan planning organization (MPO). Planning requirements specific to these areas are detailed in Appendix $A$ and referenced in various sections of the model. The model element also assumes an integrated approach to land use and transportation planning, as well as integration with regional transportation plans, land use and transportation visions, and modal plans.

Practice Notes: Interpretation of the guidance in the model element involves professional judgment as to the appropriate level of analysis or treatment feasible or appropriate for a given mode or issue, in light of local conditions and priorities.

\subsection{Community Vision and Priorities}

Transportation has a direct impact on the quality of life in a community. It affects the way an area grows, the ability of businesses to retain employees and customers and move or receive freight, the ability of people to move about safely and easily without a car, the quality of the natural environment, and even the health and well-being of local residents. Because the transportation system has so many quality of life implications, it is a central issue in advancing a community's overall vision for its future.

A key step in the transportation planning process is to create community vision or mission statements that reflect the "interaction between desired states of prosperity, environmental quality, and social equity/quality of life" and to identify issues that need to be addressed to achieve that vision (2). Planning is an iterative process, and the vision and priorities will flow from the existing conditions analysis discussed in Section 2.2, other local planning efforts, and the overall public involvement process. The visioning step involves extensive community outreach and is generally the most interactive step of the planning process.

Practice Notes: Chapter 163. 3177(2), F.S., notes that coordination of the several elements of the local comprehensive plan shall be a major objective of the planning process. The elements must be consistent. Each map depicting future conditions must reflect the principles, guidelines, and standards within all elements and must be contained within the comprehensive plan. Although not explicitly required by law, developing a community vision and priorities are important in evaluating and selecting alternatives. Doing so helps to maintain coordination and consistency of the transportation element with other elements of the comprehensive plan. 
This section of the element may occur before or after the existing conditions inventory and should address the roles that the various components of the transportation system play within the community to achieve the community vision, as follows:

\section{Briefly describe the community's vision and priorities as drawn from public meetings and other local and/ or regional plans or visions and prepare a conceptual vision or mission statement (see BP 2-1).}

\section{BP 2-1. Prepare a Vision Statement}

For example, the City of Tampa's transportation mobility element includes this vision of success.

- City and community leaders recognize the critical importance of all aspects of mobility for a livable city. (Standard of Success-Mobility is regularly considered in every important decision affecting the city's future.)

- A rail-based transit system is built that links, at a minimum, the Westshore, Downtown and USF business centers. (Standard of Success-a rail-based transit system is under construction on, or before, 2025, the horizon year of this comprehensive plan.)

- There are more choices for people to be mobile today, and as a result, people are more mobile, readily using more than one mobility choice for their journey. Mobility choices include: railbased transit, automobile, bus (local bus, bus rapid transit), bicycling and walking. (Standard of Success-User surveys show steady increases in the use of multiple mobility systems.)

- Rapid bus transit is built and local adopted bicycle and pedestrian plans are implemented. (Standard of success-self-explanatory)

- Mobility and land use strategies are inseparable. They support each other and create successful city form. (Standard of Success-Mobility choices are designed to fit the scale of the city form in which they are located (e.g. mixed-use corridor village, business center), and land uses are designed to support the mobility choices.)

- Mobility choices integrate and further the seven principles of a livable city. (Standards of Success-Mobility choices in the city: create a sense of place, are attractive, incorporate healthy open spaces in their design, are used to support a choice of lifestyles, are supported by an integrated mix of uses, provide mobility connections to all other mobility options, and promote economic opportunity).

- Mobility choices are available, accessible and affordable. (Standards of Success-Most people living and working in the city can access most mobility choices easily and readily. Most mobility choices are affordable to all people, regardless of income.)
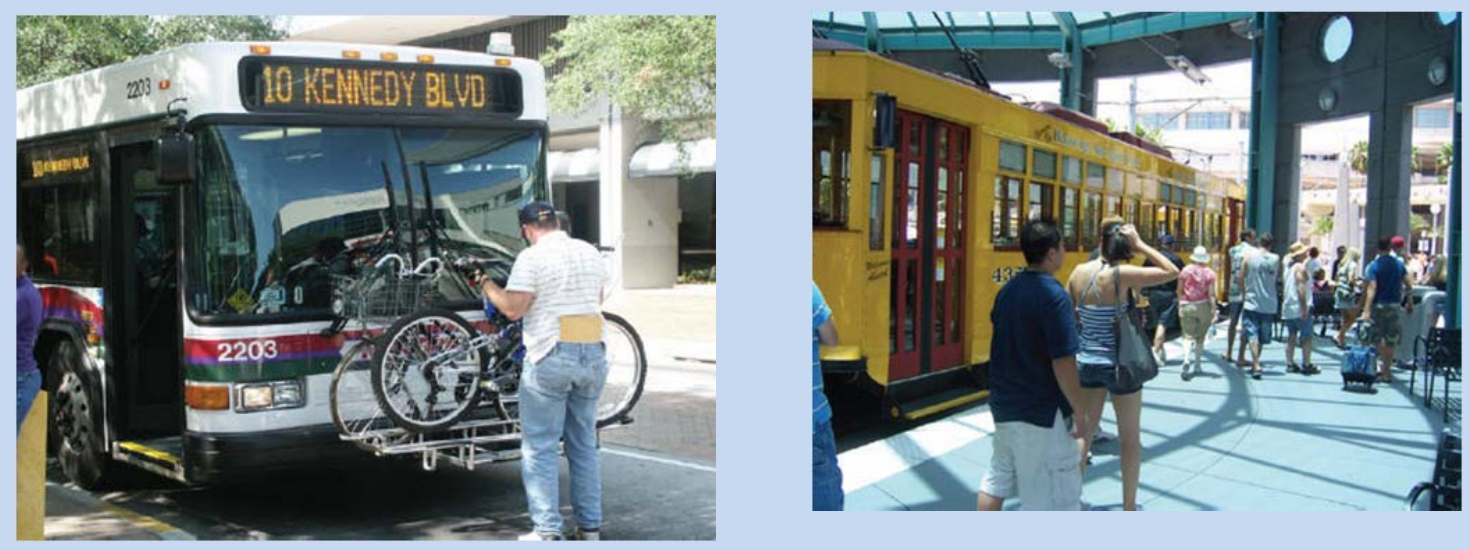

Source: City of Tampa Mobility Element (5) 


\section{Discuss principal findings and identify strategic areas of improvement from the existing conditions analysis as they relate to the vision and priorities (see BP 2-2).}

Synthesize strategic areas of importance to the community into categories for future improvement to be addressed in the plan. These categories help to provide focus in defining the community's future vision and priorities for planning purposes.

\section{BP 2-2. Strategic Areas of I mprovement}

El Paso's Transportation Element includes a discussion of the following strategic areas of improvement that are emphasized in the plan. These topics are typical issues of strategic importance to many communities (6):

- Expand transportation choices and options

- Invest in transit

- Expand safe walking and bicycling environments

- Create safe and complete streets

- Revitalize major corridors

- Address congestion and traffic flow

- Make reinvestment and smart growth the priority

The plan lists a number of strategies to address these issues, including better land use, complete streets, street conversions, adding local streets, improved thoroughfare planning, building bicycle and pedestrian networks and so on. The image below identifies a vision to transform one of the City's roadways into an attractive multimodal boulevard.

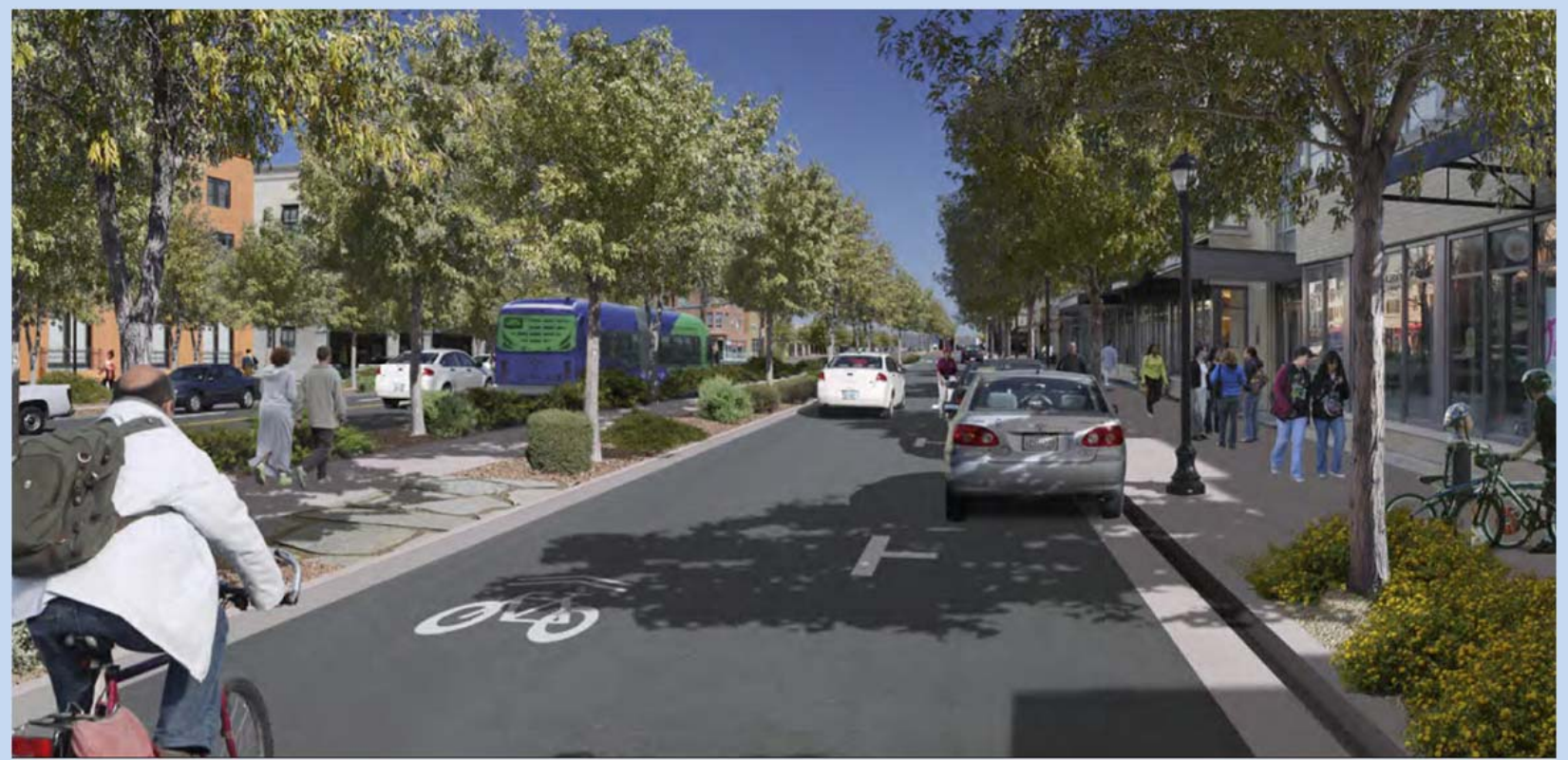

Source: Plan El Paso (6) 


\section{Look at the state transportation vision and the regional vision for the area. Consider preferred scenarios and any incompatibilities resulting from differences in visions and priorities from those of other plans and agencies.}

The Florida Transportation Plan (www.2060ftp.org/) and Florida Strategic Intermodal System (SIS) Strategic Plan (www.dot.state.fl.us/planning/sis/Strategicplan/) contain visions for the future transportation system including future corridors

(www.flfuturecorridors.org/) deemed critical to the state's economic competitiveness and quality of life. Local governments potentially affected should consider connectivity to and land use implications of such future corridors and SIS facilities.

Regional visions can play an important role in increasing regional land use and transportation coordination in multimodal planning. Several agencies and organizations, notably regional planning councils and some chambers of commerce, have undertaken regional visioning efforts in Florida in an effort to make collective decisions about each region's future (see Figure 2-1). Many Florida MPOs have also employed scenario planning to illustrate how transportation needs would be affected by different growth scenarios and to help guide local government land use and transportation planning (see BP 2-3). Local governments often participate in these efforts and may also engage in local visioning efforts that can further inform the analysis.

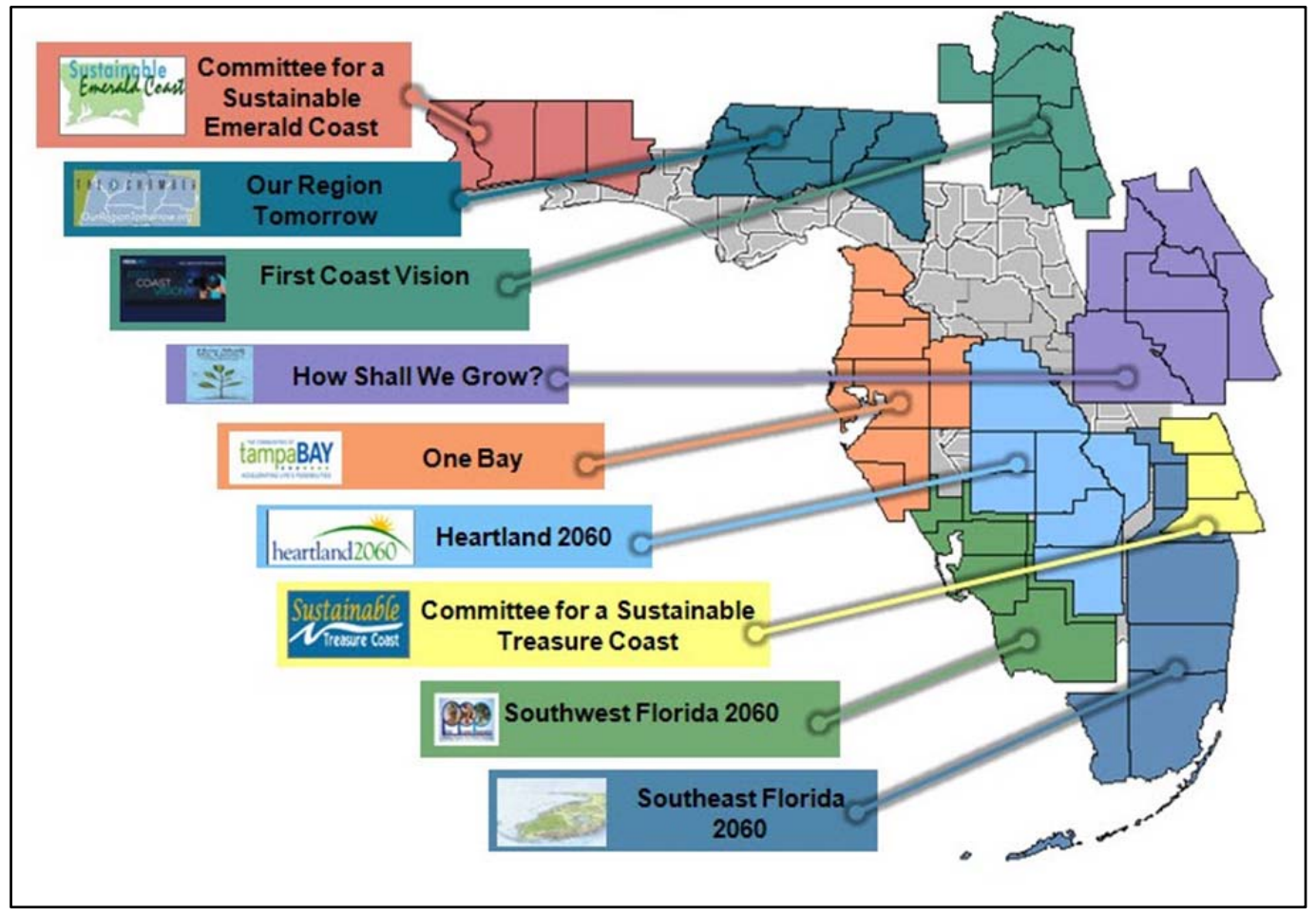

Figure 2-1. Regional visioning initiatives in Florida

Source: Trends and Conditions Report - 2009: Impact of Transportation (7)

Using these visions, the local government should analyze the effects of the various future land use scenarios on the transportation system. Are these scenarios compatible with the 
locally defined vision and strategic priorities? Are they different? Is further intergovernmental coordination required? These are questions that should be addressed in the analysis. In addition, the local government should begin to consider strategies to advance preferred scenarios as detailed in local and regional vision plans. Ideas for achieving local government multimodal transportation and land use visions and planning objectives are provided in Sections 2.4 and 2.5, including methods to evaluate and monitor success.

\section{BP 2-3. Consider Land Use and Transportation Scenario Plans}

The North Florida TPO developed four scenarios their Envision 2035 Long Range Transportation Plan, following community involvement and stakeholder workshops that engaged participants in visioning future regional growth options. Scenario A focused on concentric outer growth with little redevelopment or transit options and significant highway network expansion and investment. Scenario B focused on development of two new urban centers north and south of the existing urbanized areas that would support a north-south commuter rail option and continued highway investment. Scenario $C$ suggested clustering of growth along key transportation corridors forming an outer ring of satellite towns, with some transit throughout the region and continued reliance on highway investment. Scenario D called for compact redevelopment concentrated in major downtowns, envisioned minimal suburban growth, and supported a more robust transit network.

The scenarios were evaluated against current trends using performance measures tied to the community vision. Scenario D was the preferred scenario; analysis identified a $7 \%$ reduction in vehicle miles traveled, $15 \%$ reduction in vehicle hours traveled, $10 \%$ reduction in total carbon emissions, and $22 \%$ reduction in total congestion delay over current trends.

\section{North Florida TPO Envision 2035 Future Growth Scenarios}

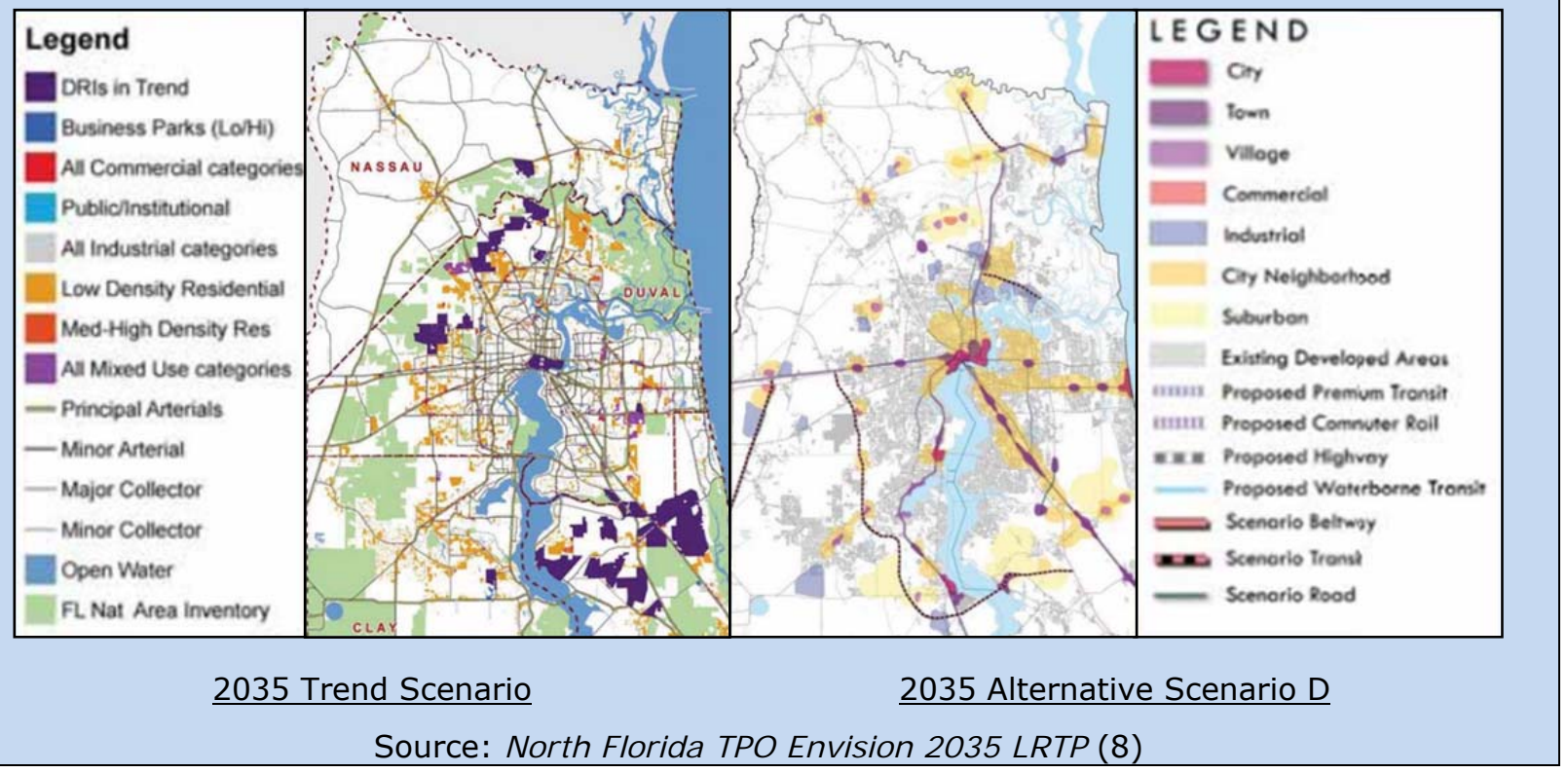

Practice Notes: A visionary land use concept map may be useful to guide official decisions on land use map changes in keeping with the intended community vision and priorities. BP 2-33 and BP 2-34, later in the document, are two examples of integrated land use and transportation concept maps that align land use with public transportation service and other modal or roadway design objectives. Walkable 
areas that may be served by transit, for example, are identified as nodes intended for compact urban development, including transit oriented development.

Preparing visionary design concepts for the desired future transportation system of the community is another effective strategy. Figure 2-2, for example, is a graphical depiction of travel sheds by mode developed by University of South Florida graduate students. The Figure illustrates the service area or travel sheds of various modes of transportation based on specific urban intermodal or activity centers. The students also developed conceptual designs for urban, suburban, and rural corridors that integrate a variety of design and technological innovations (see Figure 2-3). A webcast detailing this and other visionary concepts for Florida's future transportation corridors is available at www.cutr.usf.edu/outreach/webcast/\#tab-4.

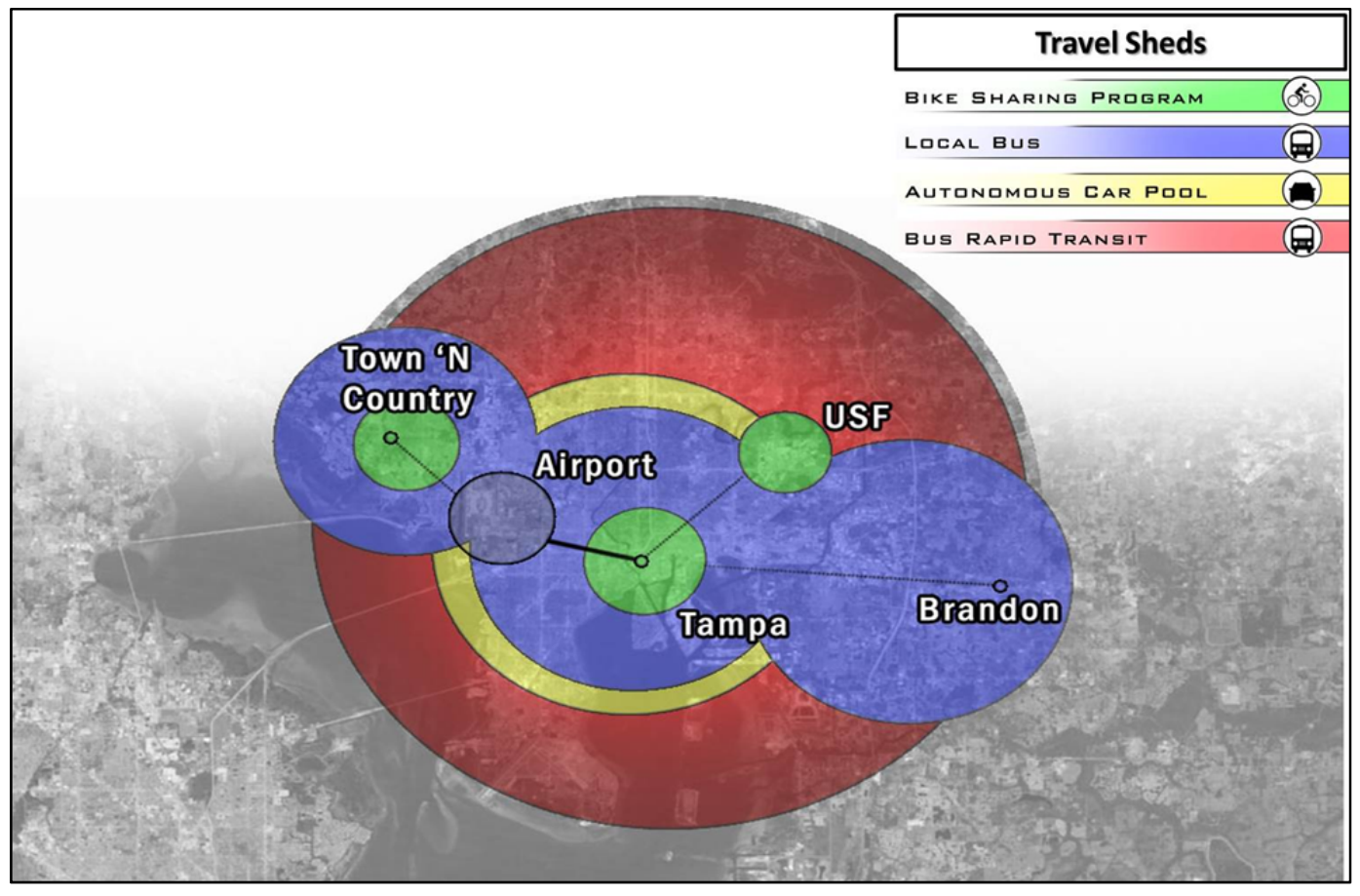

Figure 2-2. Visionary design concept of an urban, intermodal or activity center and travel sheds by mode 


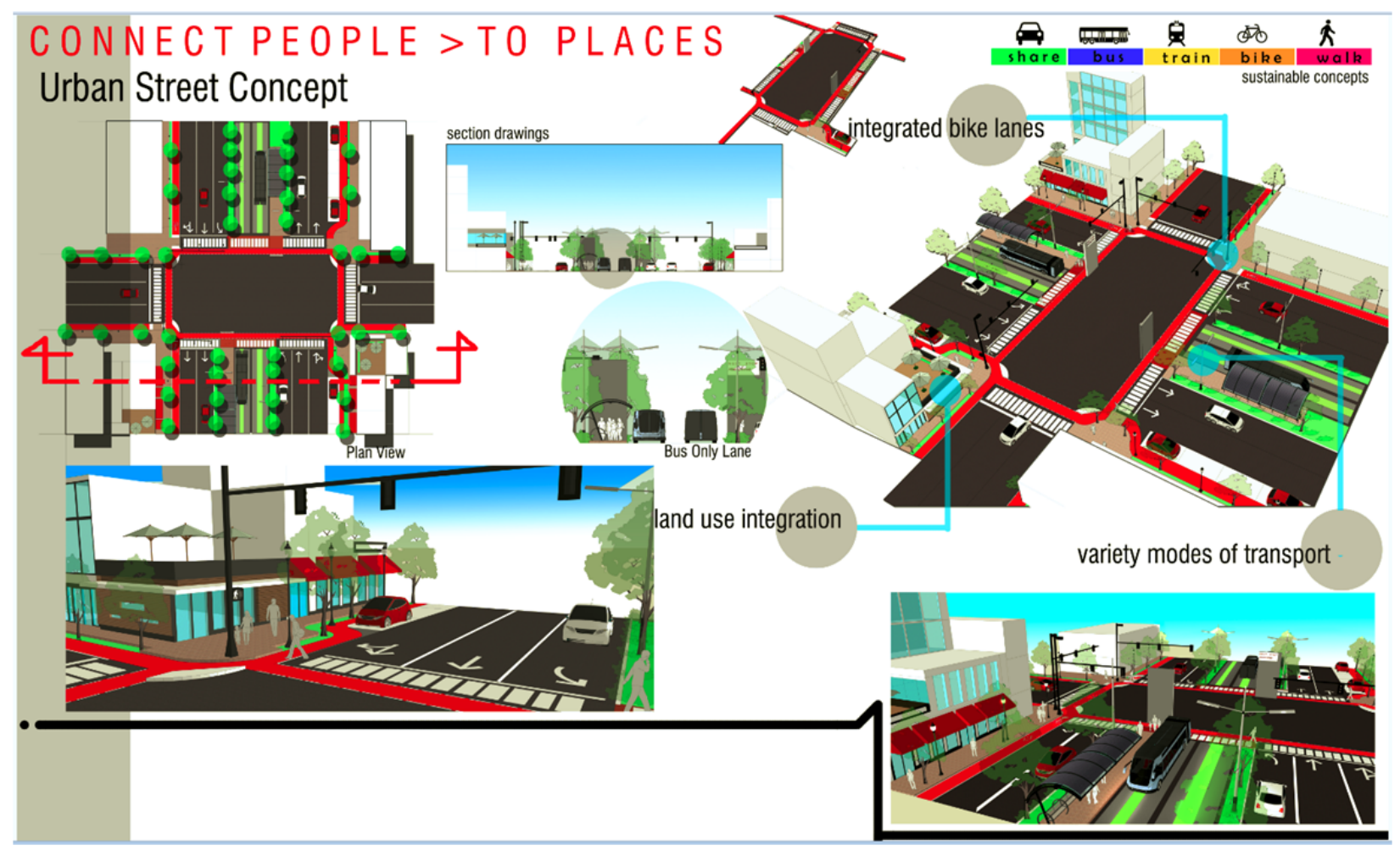

Figure 2-3. Urban street concept

Source: USF Graduate Student Future Corridor Visioning Presentation 


\title{
2.2 Inventory and Analysis of Transportation and Land Use Conditions
}

A detailed inventory and analysis of existing transportation and land use conditions provide the necessary foundation for the future multimodal transportation plan. The inventory will draw heavily from supporting data and analysis obtained in the inventory of modal and regional plans and visions, as well as from a detailed inventory of existing transportation and land use conditions within the local jurisdiction. The information may be summarized in a variety of ways (see BP 2-4 for example). This section reviews data needs and information sources for this inventory and provides guidance on the analysis of existing conditions.

\begin{abstract}
Practice Notes: Chapter 163.3177(1)(f), F.S., notes that the comprehensive plan must be based on relevant and appropriate data collected from professionally accepted data sources. Data and analysis may include, but is not limited to surveys, studies, community goals and vision, and other available data. Copies of key studies and data used in preparing the plan should be included in the plan or they "may not be deemed a part of the comprehensive plan." Other supporting studies, data, or supporting documents may still be used in determining compliance and "must be made available to the public."
\end{abstract}

\section{BP 2-4. Analyze Current Transportation and Land Use Conditions}

The transportation system may be discussed in the context of people and goods/freight mobility, affordable housing, environmental justice, societal issues, economic development, livability, walkability, healthy lifestyles, etc. This information helps to further inform the community vision and priorities. In Plan El Paso: Transportation Element, for example, the City of El Paso discussed current conditions in the following categories (6):

- Regional transportation planning

- Traffic congestion

- Air quality

- Walkability

- Public transit

- Freight

- Regional rail

- Airports

- Parking

\section{Inventory of Regional and Modal Plans}

An initial step in the planning process is to collect the transportation plans of various modal providers and planning entities and to inventory the information in each plan that relates to the local government transportation system. Issues of importance include identified needs, planned and prioritized projects by mode, adopted quality/levels of service, land use and transportation issues and recommendations, and maps of existing and proposed facilities. A goal of the inventory is to document the projects that are being planned in the community by other agencies and to ensure compatibility of local plans with other regional and state transportation planning efforts. Inconsistencies in planning efforts should also be documented and addressed, as noted in Section 2.4. Below is an overview of some items to document. 
1. Inventory agency and modal plans and document data and information on all issues of importance to the local multimodal element, such as, but not limited to:
a. quality/ level of service for various modes and identified deficiencies,
b. crash analyses that have been conducted,
c. land use issues related to the transportation system,
d. access conditions along major thoroughfares,
e. network continuity and gaps,
f. freight movement objectives and needs,
g. projects with committed funding within the next three years,
h. funding commitments, prioritization, and partnering opportunities,
i. inconsistencies with existing state, regional, and local government plans

ITR 2-1 includes some of the state, regional and modal transportation plans to collect and review in this analysis. Subsequent sections of the model element address these issues in more detail by topic or mode, including additional steps for evaluating the local transportation system. Section 2.3 covers system analysis in more detail with regard to quality/level of service, sketch planning, and other analysis methods.

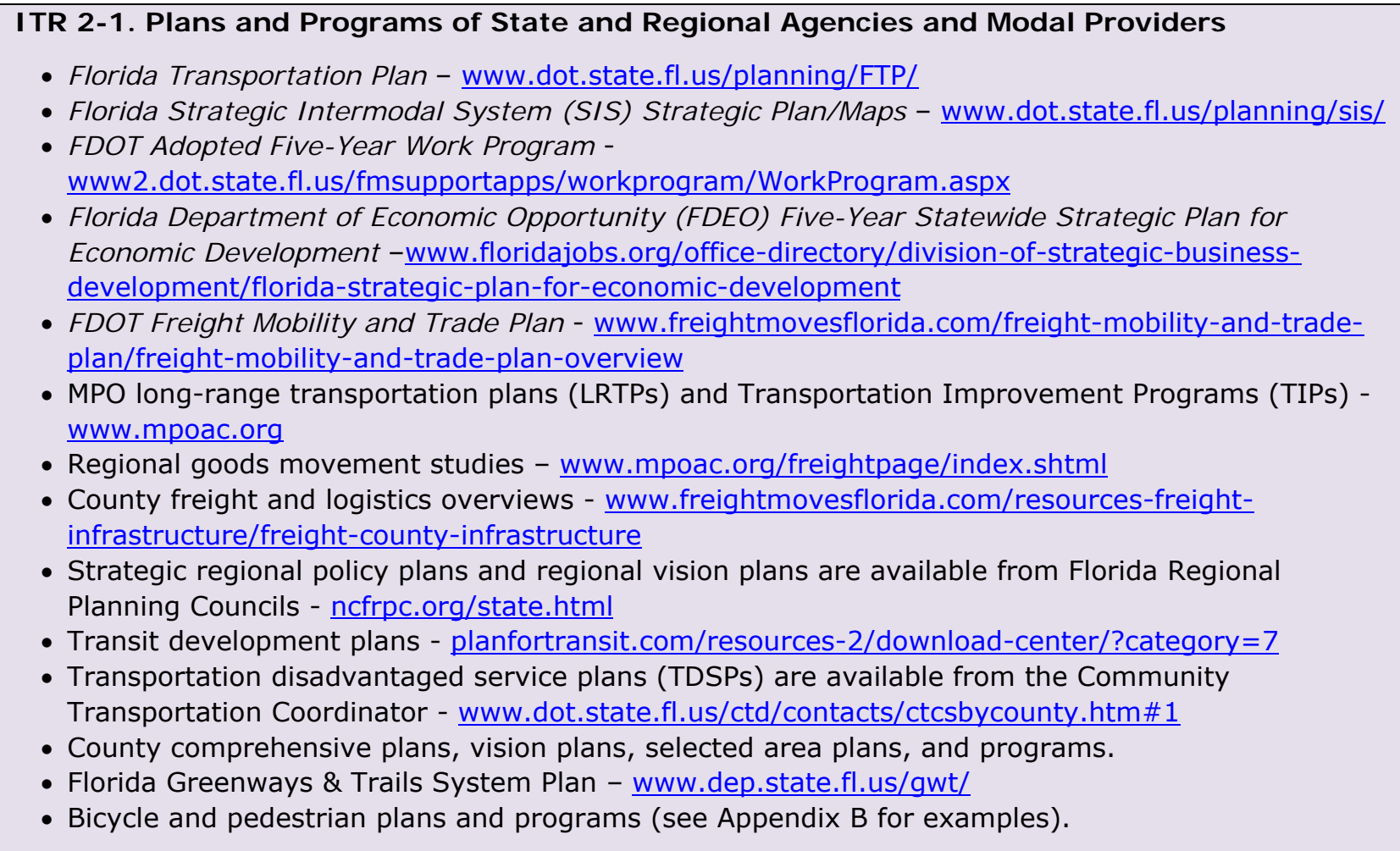




\section{Land Use and Multimodal Environment Conditions}

Understanding how existing land uses relate to the transportation system is key to planning for their integration. Below are items to address in the local land use and transportation inventory and analysis.

1. Map existing land use in relation to existing roadways and public transportation, including major generators/ attractors (e.g., employment centers, shopping centers, hospitals, schools, parking facilities, airports, ports, intermodal logistics centers, etc.); urban core(s); activity centers, and density and intensity of uses (see BP 2-5, BP 2-6).

Building on the findings of the state, regional, and modal planning inventory, the local government should document local land uses and land use conditions that relate to the multimodal transportation system and to system management strategies (e.g., access management, transportation demand management). For example, a transportation element identifies trip generators and attractors to provide a better understanding of travel patterns that may impact roadway needs and/or transit service needs. BP 2-5 is an example from the City of Fort Lauderdale Transportation Element. Another example, shown in BP 2-6, is a map prepared by Pasco County of existing activity centers and significant land uses in relation to a variety of transportation facilities.

Practice Notes: While an existing land use map may indicate general land uses, those uses, centers, or districts that require greater accessibility should be mapped to facilitate this understanding. For the transportation element, future land use concepts should identify areas where walkable and compact urban development is desired. This guides future street design and the application of context sensitive solutions on major corridors, as well as planning and investment decisions relative to public transportation, pedestrian/bicycle services and facilities. 


\section{BP 2-5. I dentify Major Transit Trip Generators and Attractors}

The City of Fort Lauderdale Transportation Element maps major public transit trip generators and attractors; these are concentrated areas of intense land use or activity that produce or attract a significant number of local trip ends. Public transit generators are typified by residential land uses and high population densities. Public transit attractors include commercial, industrial, office, commercial recreation, educational, institutional, and transportation land uses. Ideally, public transit should connect major transit generators to major transit attractors.

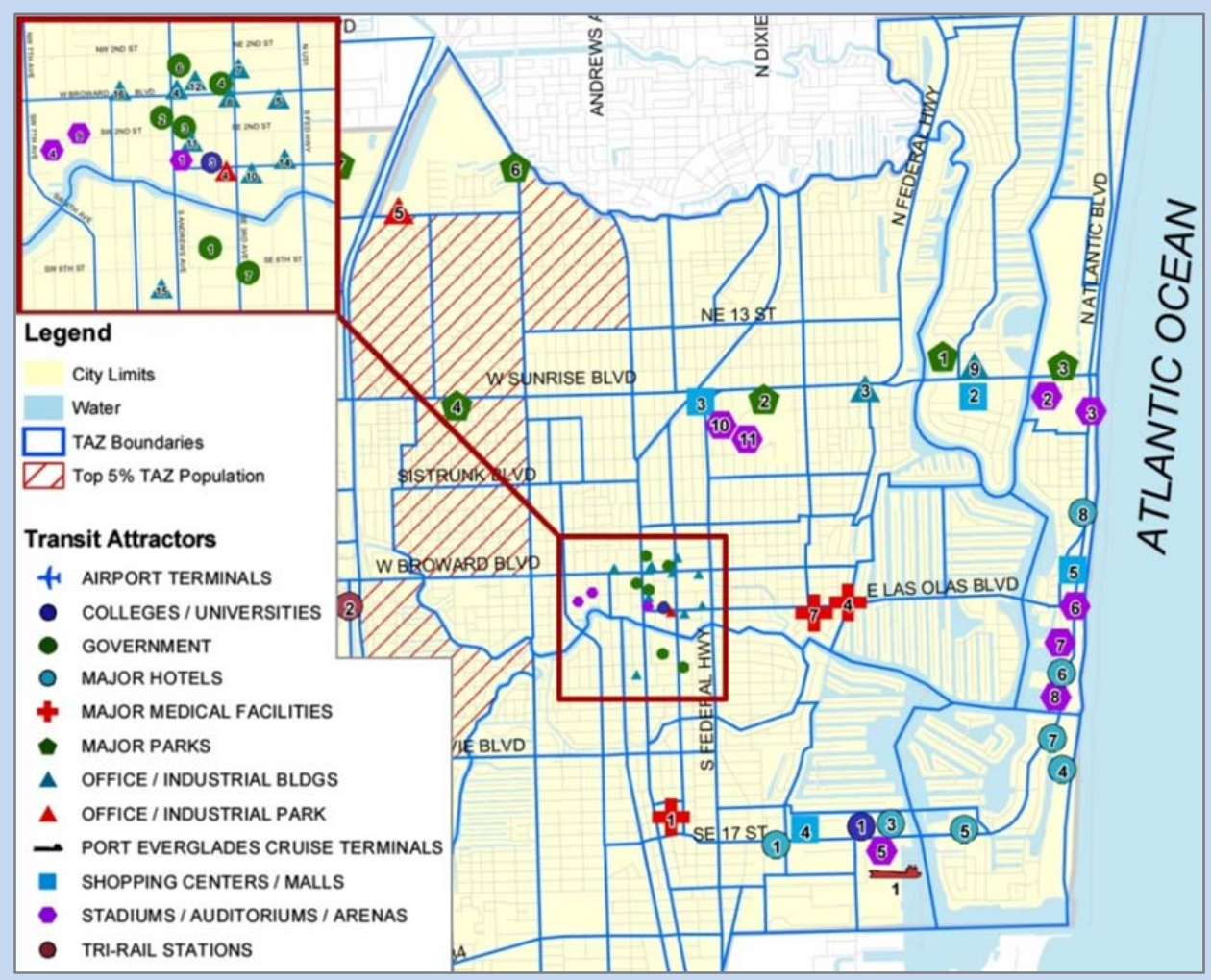

Source: City of Fort Lauderdale Comprehensive Plan (9)

What constitutes a major traffic generator is subject to local interpretation and context - a major traffic generator or attractor in a large metropolitan area will often differ from that of a small community. Hillsborough County, for example, used six socioeconomic variables of population per acre, housing units per acre, median household income, number of females per acre (22-59), auto ownership per household, and number of seniors per acre (62+), to decide how likely an area was to be a significant transit trip generator (10 p. 39). These generators were ranked as high, medium, and low propensity to use transit. To identify trip attractors, Hillsborough County looked for major activity centers such as shopping and services, employment, social and civic activities, and consulted the Land Use Element of the Comprehensive Plan to further identify trip attractors (10 p. 40). 


\section{BP 2-6. I dentify Major Roadways, I ntermodal Facilities, and Activity Centers}

In preparing its transportation element, Pasco County prepared a variety of maps as technical support data. The map shown below, for example, identifies future controlled access routes, rails lines, and intermodal facilities in relation to major activity centers (commercial centers, town centers, employment centers, etc.). The map provides insight into the relationship of land use to the major roadway system and intermodal access routes, noting public and private airports, seaport facilities, bus stations, train stations, and park-and-ride locations.

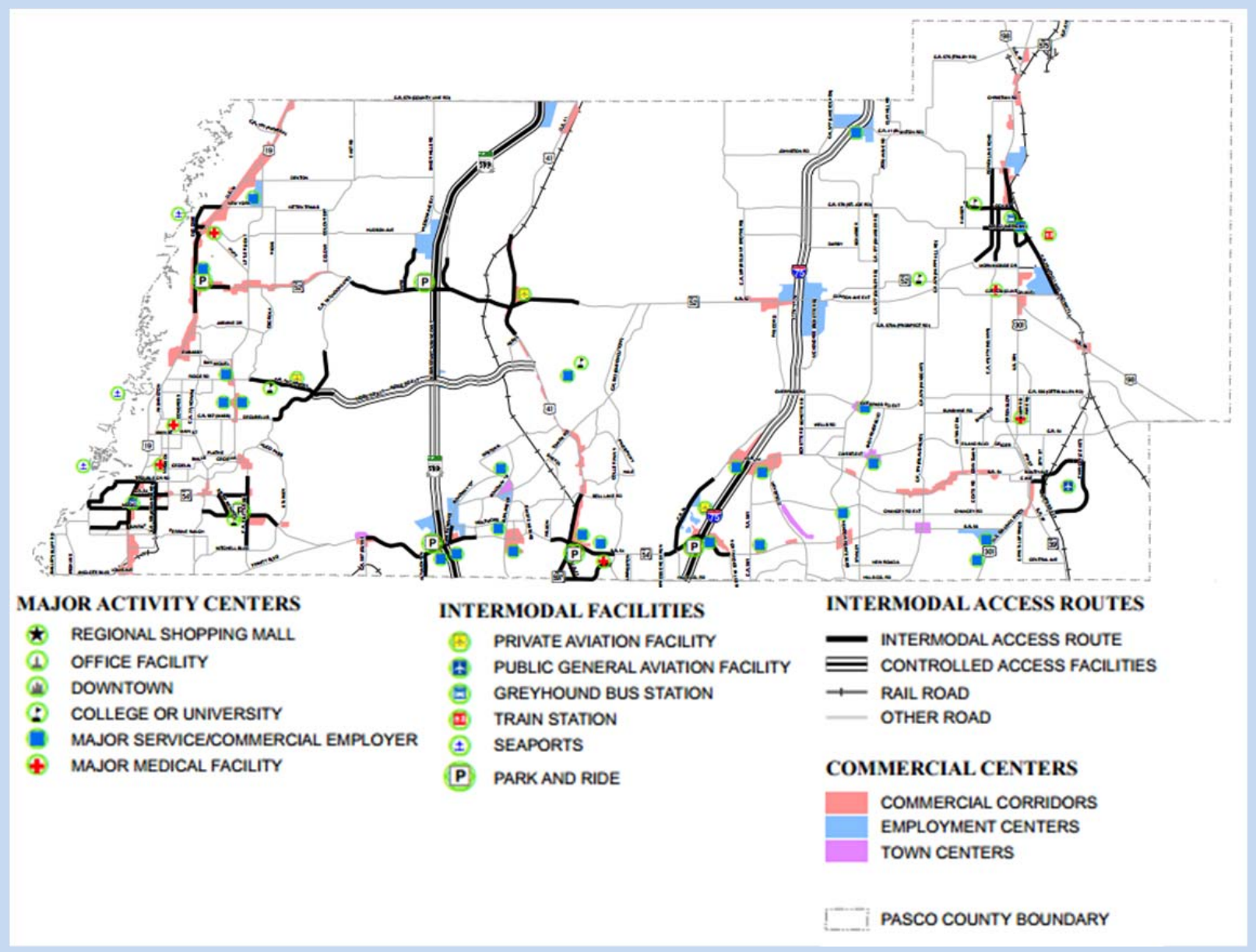

Source: Pasco County Comprehensive Plan, Technical Support Data (11) 
2. I dentify and discuss issues with the current transportation system with regard to existing land use and the multimodal environment, including the following (Note: This I tem emphasizes land use issues related to placemaking and mode choice. I tems $3-6$ address additional issues associated with access, public transportation, parking, and freight, respectively.):

a. land use organization/ location efficiency (e.g., key centers, land use separations)

b. land use mix/ balance (e.g., significant land uses, land use ratios, jobs to population ratios)

c. density/ intensity (e.g., residential, employment density, see BP 27)

BP 2-7. Documenting Population Density along Transit Corridors

Hillsborough Area Regional Transit (HART) provides a map of population densities along transportation corridors.

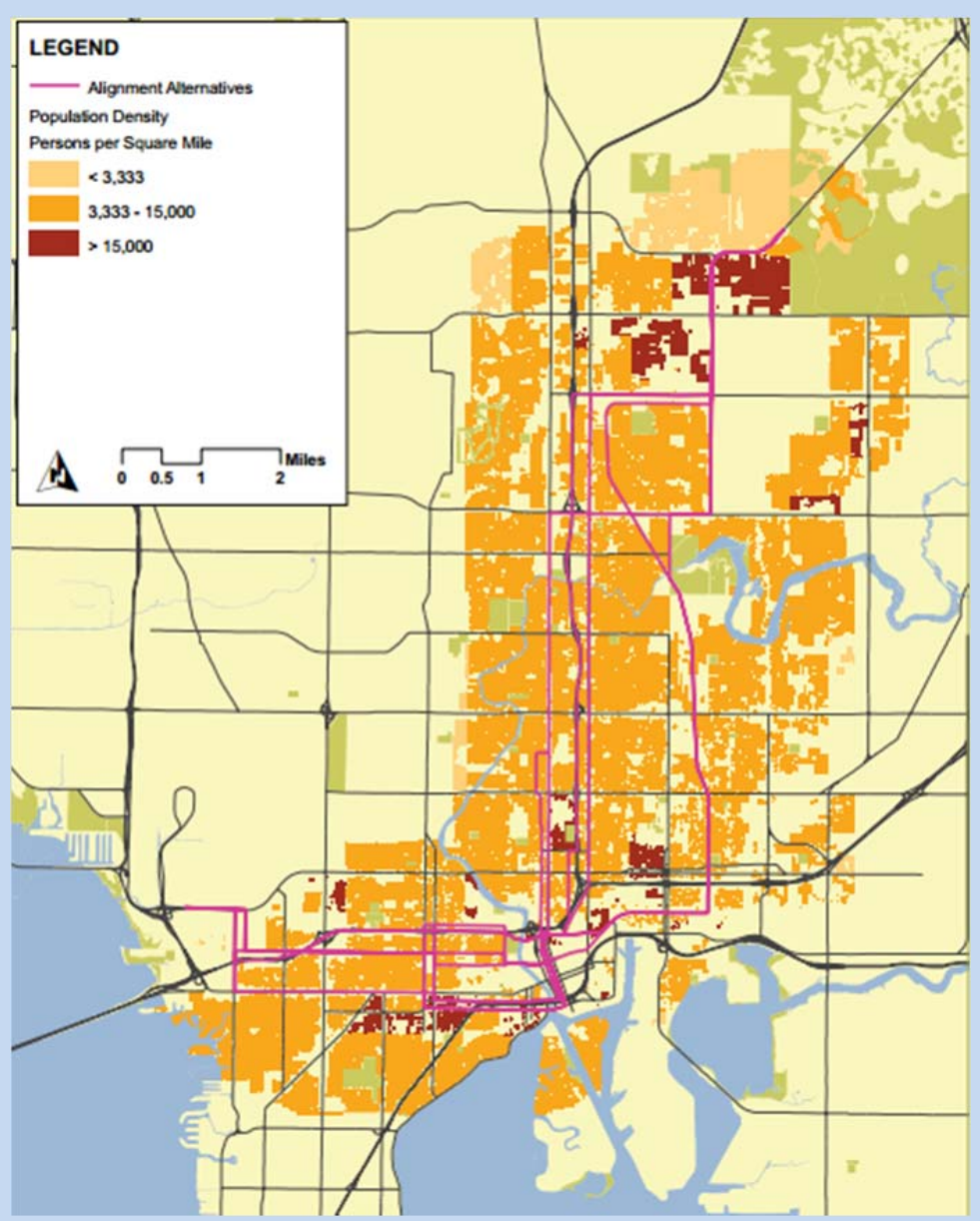

Source: A Framework for TOD in Florida (12) 
The local government should review the existing and proposed future land use map and consider whether it provides for an appropriate organization, mix, and density or intensity of land uses to support multimodal transportation options. Specifically, look to ensure:

- a strong central core or urban center consisting of government centers, transit stations, or a town square surrounded by relatively high density/intensity residential and non-residential development;

- a compatible mix of land uses throughout each core or urban center and within individual sites and buildings that supports non-auto modes of transportation and promotes activity during peak and non-peak hours (see Table 2-1);

- proximity of shopping, services, and employment centers to each other and to the surrounding residential uses to facilitate walking and bicycling, as an alternative to driving, and

- efficient freight and goods movement.

Table 2-1. Land Use Compatibility Matrix

\begin{tabular}{|c|c|c|c|}
\hline & $\begin{array}{l}\text { URBAN } \\
\text { CENTER }\end{array}$ & $\begin{array}{c}\text { REGIONAL } \\
\text { CENTER }\end{array}$ & $\begin{array}{l}\text { TOWN OR } \\
\text { VILLAGE }\end{array}$ \\
\hline \multicolumn{4}{|l|}{ Office } \\
\hline Center Office & $\mathbf{a}$ & a & a \\
\hline Suburban Office & & & $\square$ \\
\hline Local Services & $\square$ & $\square$ & $\square$ \\
\hline Medical Office & $\square$ & $\square$ & $\square$ \\
\hline \multicolumn{4}{|l|}{ Commercial } \\
\hline Hotels & $\square$ & $\square$ & $\square$ \\
\hline Theaters & $\square$ & $\square$ & $\square$ \\
\hline Restaurants & $\square$ & $\square$ & $\square$ \\
\hline Local Shopping Centers & $\square$ & $\square$ & a \\
\hline Regional Shopping Centers & 口 & $\mathbf{a}$ & \\
\hline Convenience Retail & $\square$ & $\square$ & $\square$ \\
\hline Specialty Shopping & $\square$ & $\square$ & $\square$ \\
\hline Hospitals & 口 & a & $\square$ \\
\hline Day Care & $\square$ & $\square$ & $\square$ \\
\hline Recreational & 口 & $\mathbf{a}$ & $\mathbf{\square}$ \\
\hline Cultural & 口 & $\mathbf{a}$ & $\mathbf{\square}$ \\
\hline Schools and Colleges & a & 口 & $\square$ \\
\hline Governmental/Institutional & - & - & - \\
\hline Light Industrial/Manufacturing & $\square$ & $\square$ & $\square$ \\
\hline Residential (mid - high density) & - & $\mathbf{a}$ & $\mathbf{a}$ \\
\hline
\end{tabular}

Legend: . Primary Use, Highly Desirable $\square$ Supporting Use, Contributing Source: Model Regulations and Plan Amendments for Multimodal Districts (13)

Also, consider the effects of various future land use scenarios on the transportation system and identify strategies to advance preferred scenarios as detailed in regional vision plans, MPO plans, and local visioning efforts. Land use strategies should be carefully integrated into the overall transportation plan. An understanding of the land use characteristics needed to support public transportation, walking, and bicycling will be vital to this effort. These are characterized in the literature as the five Ds of development (14 p. 52):

1) Density: population and employment by geographic unit (e.g., per square mile, per developed acre). 
2) Diversity: mix of land uses, typically residential and commercial development, and the degree to which they are balanced in an area (e.g., jobs-housing balance).

3) Design: neighborhood layout and street characteristics, particularly connectivity, presence of sidewalks, and other design features (e.g., shade, scenery, presence of attractive homes and stores) that enhance the pedestrian- and bicycle-friendliness of an area.

4) Destination accessibility: ease or convenience of trip destinations from point of origin, often measured at the zonal level in terms of distance from the central business district or other major centers.

5) Distance to transit: ease of access to transit from home or work (e.g., bus or rail stop within $1 / 4$ to $1 / 2$ mile of trip origin).

Proximity of diverse land uses combined with intersection density are factors that promote walking. Transit use is supported by walkable environments, and by proximity to the service and accessibility provided by public transportation to a range of destinations. Destination accessibility is the most statistically significant variable for reducing vehicle miles of travel (VMT). Alternatively, poor accessibility and single land use areas, and/or strip development are defining characteristics of urban sprawl that contribute to increased VMT (15).

Practice Notes: Research has shown that destinations near the core of metropolitan areas and job centers that are highly accessible with a diversity of uses and well-connected street systems tend to be among the most vibrant and livable places and also have the greatest potential to reduce driving (16). Access management of major routes preserves their viability for through movement of people and freight by reducing travel delay and crashes, thereby protecting regional accessibility to centers and the market area of businesses (17).

\section{I dentify and discuss land development and access conditions on major routes, such as:}

a. shallow commercial strip development and zoning

b. presence/ absence of supporting street network and any gaps that should be connected;

c. possible changes to the supporting street and site circulation system to improve roadway safety and operations;

d. presence/ absence of internal access connections allowing circulation between properties and opportunities for joint access or interparcel circulation;

e. substandard driveway design conditions, such as driveways with excessive grades or slopes, inadequate widths or radii, or inadequate throat lengths; and

f. sites with open frontages or too many driveways and opportunities to reduce superfluous access points.

A typical land use and access management issue, which also reduces destination accessibility, is commercial strip development along major thoroughfares separated from residential areas by walls or barriers. Closely spaced driveways, a lack of unified circulation 
between sites, and sparse or disconnected local street networks increase local trip circulation on major travel routes, traffic conflicts multiply, and crashes increase. The numerous driveways and traffic signals gradually intensify congestion and delay causing regional commute times, fuel consumption, and vehicular emissions to increase. Routes with poorly managed access also increase the potential for vehicular crashes involving bicyclists and pedestrians (see Figure 2-4).

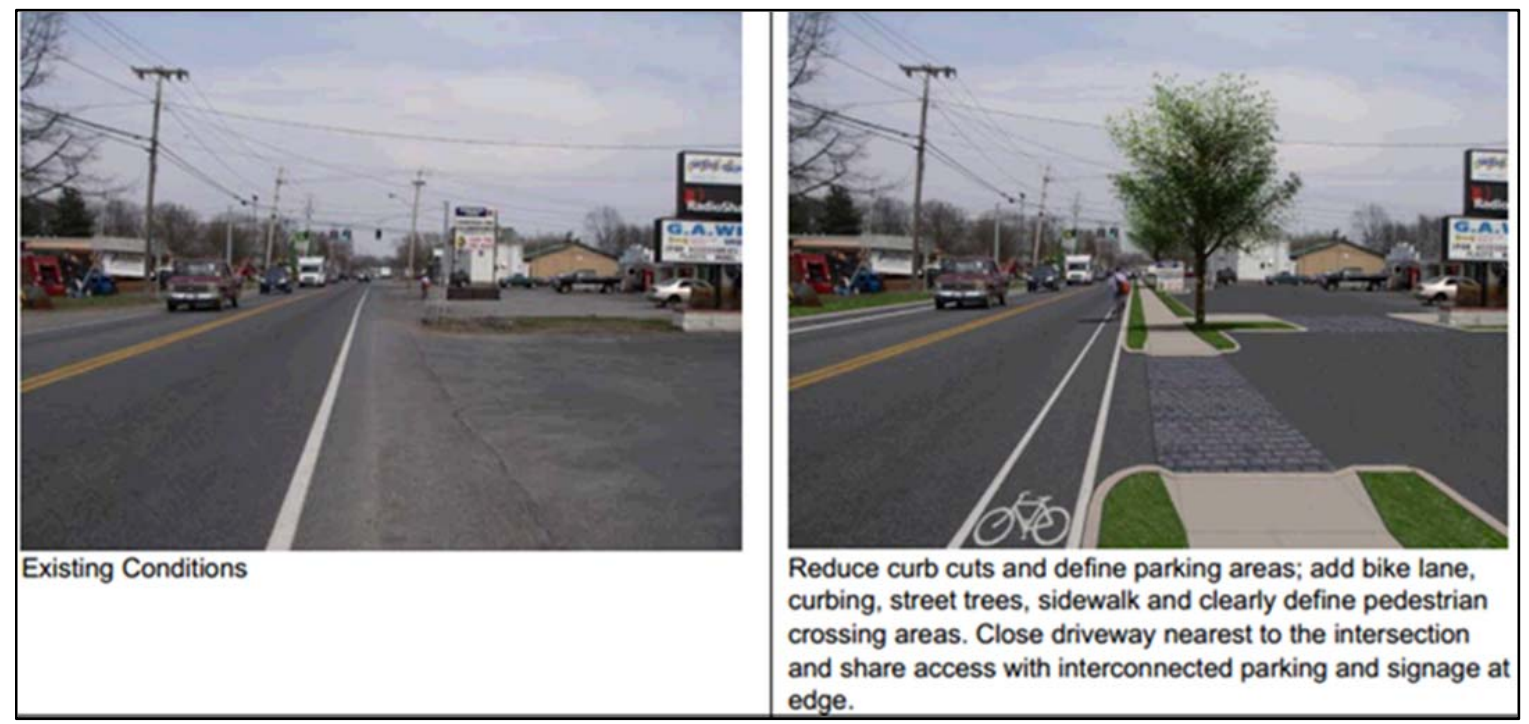

Figure 2-4. Visualization of multimodal access management benefits Source: Access Management Guide (18)

BP 2-8 identifies some strategies to consider for advancing access management objectives in the multimodal transportation planning process. Many others are identified in Section 2.6 and in the TRB Access Management Manual, $2^{\text {nd }}$ ed. (17).

\section{BP 2-8. Strategies for Integration of Transportation and Land Use}

- Encourage multi-use rather than single use developments and neighborhoods;

- Restrict development in the planned right-of-way for transportation facilities;

- Condition zoning approval for certain large transit-compatible developments on the proximity and availability of high-capacity, high-speed transit;

- Orient development along streets in urban areas for improved pedestrian access;

- Plan mixed-use activity centers or transit oriented developments along transit lines;

- Create land use and zoning envelopes along new thoroughfares in rural and undeveloped areas to cluster commercial activity at key nodal points and minimize strip development.

Source: Williams and Levinson(19)

\section{I dentify land use densities, building intensities, and transportation management programs to promote public transportation in designated public transportation corridors. Document whether population densities are sufficient to support public transportation.}

An essential aspect of planning for public transportation is to examine local land use conditions along major public transportation routes and around station areas. Geographic 
information systems (GIS) and land use information can be used to determine whether land use densities or intensities may need to be increased in certain areas along these routes. The Florida TOD Guidebook (20) and Florida TOD Framework (12) are important resources to consult in this analysis; for example, BP 2-9 provides future land use guidelines from the Florida TOD Guidebook for regional, community and neighborhood centers serviced by public transportation.

Another important information source for this effort is the transit development plan (TDP) of the regional transit provider. TDPs are required to include a situation appraisal that analyzes factors affecting the provision of transit service, such as regional transportation issues, land use patterns, socioeconomic trends, travel behavior, policy issues, available technology, service and operational trends, organizational issues, and environmental issues. 


\section{BP 2-9. Transit Supportive Densities and I ntensities for Station Areas}

The efficiency of a transit system increases as the number of jobs and housing units within walking and biking distance of stations increases (20). Therefore, maximize the efficiency of transit station areas by establishing minimum density standards, minimum intensity standards, total residential unit targets, and total employment targets. The Florida TOD Guidebook provides the following density and intensity recommendations:

\begin{tabular}{|c|c|c|c|}
\hline \multicolumn{4}{|c|}{ Station Area - Total Residential Unit Targets (from TOD Framework) } \\
\hline \multirow{2}{*}{$\begin{array}{c}\text { TOD Place } \\
\text { Type }\end{array}$} & \multicolumn{2}{|c|}{ Desired Number of Residential Units per Transit Mode } \\
\cline { 2 - 4 } Regional Center & $10,000-15,000$ units & $5,000-10,000$ units & $3,000-5,000$ units \\
\hline Community Center & $5,000-6,000$ units & $3,000-5,000$ units & $1,000-3,000$ units \\
\hline Neighborhood Center & $3,000-4,500$ units & $2,000-3,000$ units & $1,000-2,000$ units \\
\hline
\end{tabular}

\begin{tabular}{|l|c|c|c|c|}
\hline \multicolumn{5}{|c|}{ Station Area - Employment Targets from TOD Framework } \\
\hline $\begin{array}{c}\text { TOD Place } \\
\text { Type }\end{array}$ & Employment Target & Heavy Rail & $\begin{array}{c}\text { Commuter/ } \\
\text { Light Rail }\end{array}$ & BRT/Bus \\
\hline \multirow{2}{*}{$\begin{array}{l}\text { Regional } \\
\text { Center }\end{array}$} & Station Area Total Employment & $60,000-80,000$ & $40,000-60,000$ & $20,000-40,000$ \\
\cline { 2 - 5 } & $\begin{array}{c}\text { Gross Employment Density } \\
\text { (jobs/acre) }\end{array}$ & $200-250$ & $100-200$ & $50-125$ \\
\hline $\begin{array}{l}\text { Community } \\
\text { Center }\end{array}$ & Station Area Total Employment & $18,000-24,000$ & $12,000-18,000$ & $6,000-12,000$ \\
\cline { 2 - 5 } & $\begin{array}{c}\text { Gross Employment Density } \\
\text { (jobs/acre) }\end{array}$ & $65-90$ & $45-65$ & $20-45$ \\
\hline $\begin{array}{l}\text { Neighborhood } \\
\text { Center }\end{array}$ & Station Area Total Employment & $2,000-3,500$ & $2,000-3,000$ & $1,000-2,000$ \\
\cline { 2 - 5 } & $\begin{array}{c}\text { Gross Employment Density } \\
\text { (jobs/acre) }\end{array}$ & $20-30$ & $15-20$ & $10-15$ \\
\hline
\end{tabular}

\begin{tabular}{|c|c|c|c|}
\hline \multicolumn{5}{|c|}{ Minimum Net Density Standards for Transit Core of Station Area } \\
\hline TOD Place Type & Heavy Rail & Commuter/Light Rail & BRT/Bus \\
\hline Regional Center & $85 \mathrm{du} / \mathrm{ac}$ & $55 \mathrm{du} / \mathrm{ac}$ & $30 \mathrm{du} / \mathrm{ac}$ \\
\hline Community Center & $60 \mathrm{du} / \mathrm{ac}$ & $40 \mathrm{du} / \mathrm{ac}$ & $20 \mathrm{du} / \mathrm{ac}$ \\
\hline Neighborhood Center & $15 \mathrm{du} / \mathrm{ac}$ & $12 \mathrm{du} / \mathrm{ac}$ & $10 \mathrm{du} / \mathrm{ac}$ \\
\hline
\end{tabular}

Minimum Net Intensity Standards for Transit Core of Station Area

\begin{tabular}{|c|c|c|c|}
\hline TOD Place Type & Heavy Rail & Commuter/Light Rail & BRT/Bus \\
\hline Regional Center & 4.0 FAR & 2.0 FAR & 1.5 FAR \\
\hline Community Center & 4.0 FAR & 2.0 FAR & 1.0 FAR \\
\hline Neighborhood Center & 1.5 FAR & 1.0 FAR & 0.5 FAR \\
\hline
\end{tabular}

Source: Florida TOD Guidebook (20) 
Practice Notes: Decisions on the location of land uses can impact service costs and transit ridership. If land uses that generate transit ridership are located along key transit routes, then route productivity increases, and transit service can be offered more frequently. Locating transit compatible land uses outside an existing service area may require routes to be altered or extended, leading to longer headways and less convenient service - both disincentives to transit use. Transitcompatible land use decisions are one way to build transit ridership and reduce headways, without the risk and uncertainty of major capital outlays.

\section{I dentify and discuss parking management issues relative to public transportation and the multimodal environment, including park and ride facility locations, capacities, average usage/ vacancy, and transit connections.}

Parking management involves managing parking resources efficiently, while accommodating the needs of the community and furthering community goals. Providing a large supply of parking to accommodate peak demand promotes use of the automobile, and results in large surface parking areas that are unattractive to pedestrians, increases the length of the pedestrian trip, and discourages walking.

Establishing appropriate limits on parking in urban cores and centers reinforces non-auto modes by making it safer and more convenient to circulate on foot or by bicycle. It also leads to more compact urban development and allows denser and more diverse land use activities, making these areas a destination that can be more efficiently served by transit.

Emphasis could be placed on short-term parking (e.g. parking duration limits, time-of-day limits, restricted parking zones) over long-term parking in urban cores or major activity centers. Some popular parking management strategies include parking maximums, shared use parking, increasing the capacity of existing parking facilities, remote parking with shuttle services, and pricing (21). Maps of on-street and off-street parking are illustrated in BP 2-10. Appendix C includes examples of parking management and funding strategies that support transit.

\section{I dentify and discuss freight movement issues relative to the existing and planned multimodal environment.}

Freight mobility is critical to the economic success of any community. Efficient freight movement ensures that stores and restaurants are stocked appropriately, small manufacturers get the raw materials that they need, and local businesses receive packages, office supplies, and other goods.

The urban multimodal environment creates a number of challenges for freight activity. Complete streets policies, context sensitive solutions, and traditional neighborhood developments can result in narrower streets, traffic calming, and compact intersections that impact the operational needs of delivery trucks and cause more regular encroachment of turning vehicles into opposing lanes. Communities need to balance the need for access by large trucks, freight rail, and other modes of freight transportation with the circulation needs of autos, bicycles, pedestrians, and transit users. 


\section{BP 2-10. Parking Management Maps}

The City of Delray Beach Parking Management Plan notes that the success of a city-wide parking system does not only depend on the adequate provision of parking facilities but on how well those parking facilities are connected to both the ultimate destinations and other modes of transportation.

Delray Beach Off-Street and On-Street Parking Maps

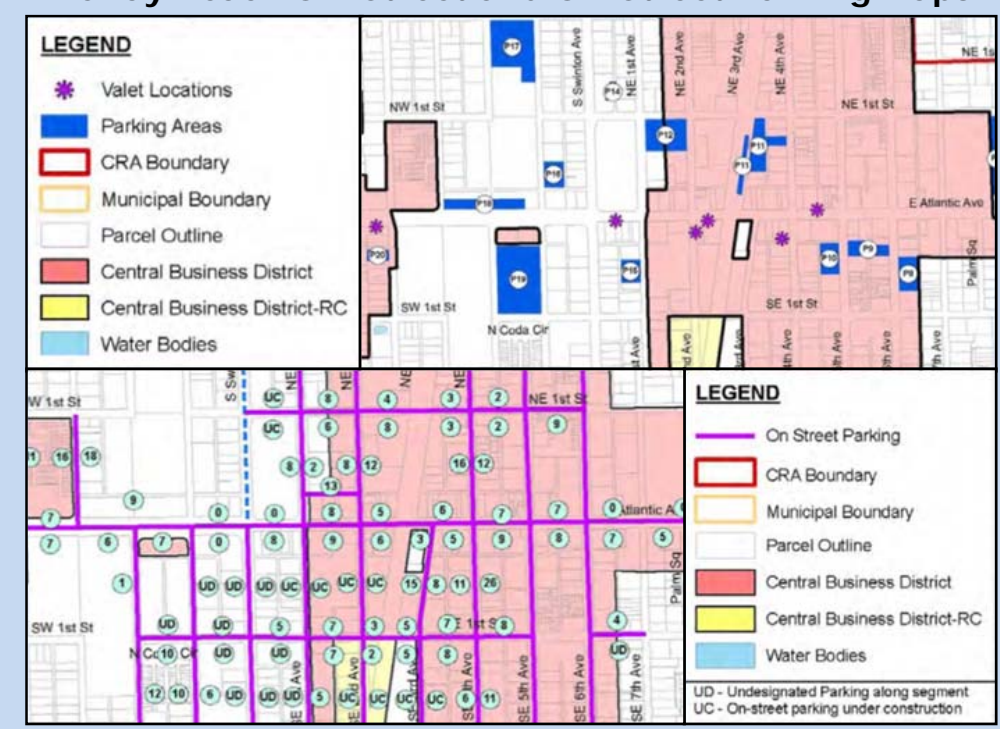

Source: Delray Beach Parking Management Plan (22)

In addition, urban freight distribution has smaller volumes with time sensitive freight necessary to replenish stock as inventory levels in urban stores, particularly smaller stores, tend to be lower than those of suburban or urban fringe "big box" retail environments. In urban core areas, little to no storage space is available so goods are brought in from distribution centers on the outskirts of the community. This repeated pattern must be maintained in spite of peak hour congestion and often creates conflicts. E-commerce, such as online shopping, is creating additional demands with growth in home deliveries.

Considerations with regard to the freight movement in the multimodal environment include:

- Modal conflicts due to the presence of bicycle and pedestrian facilities;

- Frequency of access by freight vehicles and accessibility due to road channelization, parking and loading zone restrictions, vehicle size limits, and noise and time restrictions;

- Urban truck regulations - route restrictions, parking regulations/curbside access delivery window/time-of-day restrictions, and emission controls; and

- Opportunities to separate freight-related uses from compact urban areas through freight consolidation centers (freight villages), (see BP 2-11) and/or regional connectors to intermodal facilities, such as ports or airports.

The Institute of Transportation Engineers recommends that transportation planners facilitate freight movement in urban "smart growth" environments by improving rail-freight service and commercial vehicle access, circulation, loading, and unloading, as follows (23):

- Designate and design priority truck routes in corridors where high-volume truck traffic exists or is anticipated; 
- Locate freight terminals and intermodal facilities convenient to major transportation routes of all freight modes, outside of activity centers, and away from areas likely to be congested;

- Provide efficient rail access and strategically locate yards to serve major industrial and distribution centers; and

- Provide off-street loading docks for all commercial, industrial, and institutional buildings and medium- to high-density residential complexes and provide alleys for service access in both commercial and residential areas.

\section{BP 2-11. Urban Freight Villages}

An urban freight village is an intermodal or freight staging facility where access is provided to rails, trucks, ports, and/or airports. As part of the Year 2030 Long Range Transportation Plan (LRTP) update, MetroPlan Orlando developed an Urban Freight Village Land Use Plan/Strategy. Proposed locations for freight villages were identified using GIS software to collect detailed land use information and analyze development patterns. Specific strategies suggested for use by FDOT and local jurisdictions in supporting the growth and development of urban freight villages include:

- FDOT monitoring of existing roadway conditions, identifying transportation impacts of new development or redevelopment, implementing future roadway designs for greater freight mobility, and assisting local agencies in identifying funding sources.

- Cities and counties directing development of warehousing and distribution centers in and around proposed freight villages by requiring buffers and/or transitional zones between incompatible land uses, protecting undeveloped land, or preventing encroachment of incompatible land uses through zoning, easements or purchase.

- All jurisdictions incorporating a review of existing roadway networks, planning in an integrated manner (comprehensively and long-range), adoption of design standards (intensities, site layout, and building guidelines) in and around urban freight villages, and involvement of the private sector through advisory committees and technical planning processes.

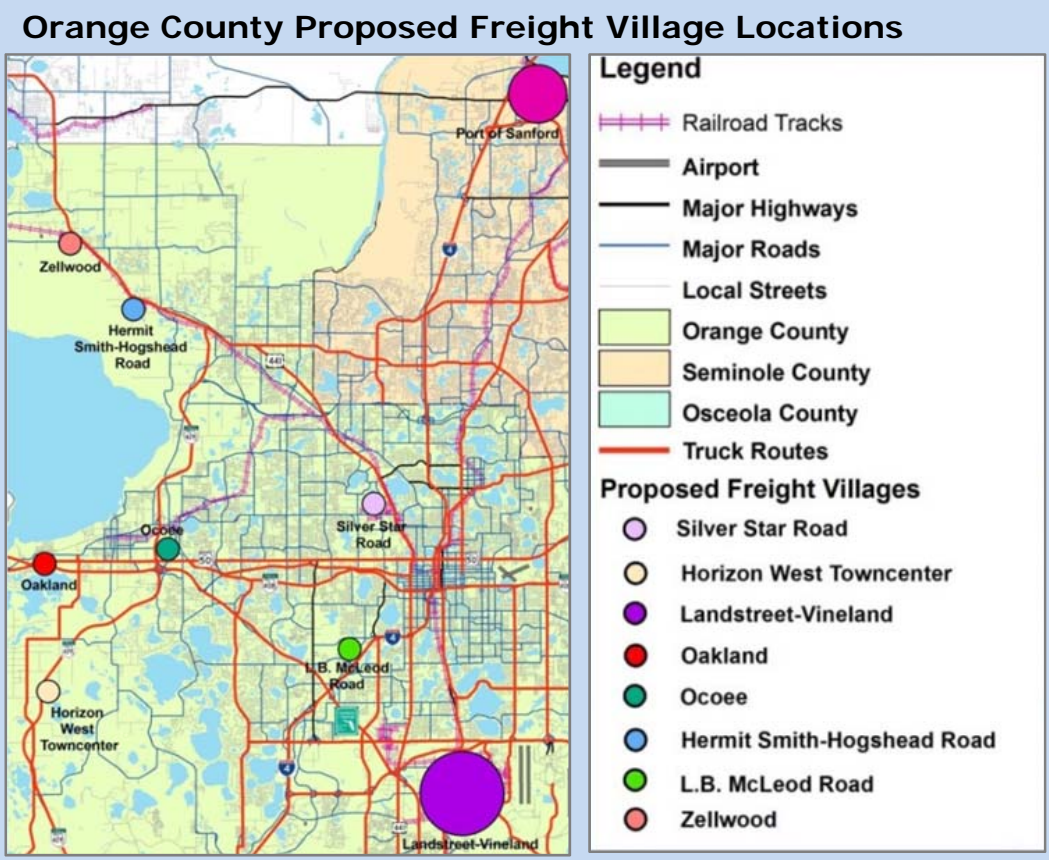

Source: MetroPlan Orlando 2030 LRTP (24) 


\section{Public Transportation Routes and Conditions}

The 2011 Community Planning Act calls for an emphasis on public transportation systems, where feasible. Fixed route systems operate in urban areas, whereas rural areas are predominately served by demand-responsive paratransit systems and are part of Florida's Coordinated Transportation System. The term public transportation encompasses a variety of modes of service, including, but not limited to automated guideway, bus, cable car, commuter rail, ferry boat, heavy rail, light rail, monorail, paratransit, trolleybus, and vanpool or demand response systems.

Appendix $D$ defines public transportation options that may be present or planned in urban areas. Table 2-2 identifies how different public transportation modes perform in varioussized communities according to criteria such as travel market, economic development, speed, right of way, and construction disruption. In addition to public transportation service, private "luxury" bus charters are increasingly filling the demand for intercity long distance travel in Florida. The transportation element should note the locations of any such services in the community and consider accessibility and public transportation connections to these key station areas.

Table 2-2. Public Transportation Modes of Service and Market Characteristics

\begin{tabular}{|c|c|c|c|c|c|c|}
\hline \multirow[b]{2}{*}{ Criteria } & Bus & BRT & Streetcar & Light Rail & $\begin{array}{c}\text { Commuter } \\
\text { Rail }\end{array}$ & $\begin{array}{c}\text { Heavy Rail/ } \\
\text { High Speed Rail }\end{array}$ \\
\hline & & & & & & \\
\hline $\begin{array}{l}\text { Travel Market } \\
\text { (Trip market served) }\end{array}$ & $\begin{array}{l}\text { Local/ } \\
\text { Commuter }\end{array}$ & $\begin{array}{l}\text { Local/ } \\
\text { Commuter }\end{array}$ & Local & $\begin{array}{l}\text { Local/ } \\
\text { Commuter }\end{array}$ & Commuter & $\begin{array}{l}\text { Long Distance } \\
\text { (Intercity) }\end{array}$ \\
\hline $\begin{array}{l}\text { Economic Development } \\
\text { (Impact on business) }\end{array}$ & Minimal & Moderate & Significant & Significant & Significant & Significant \\
\hline $\begin{array}{l}\text { Speed } \\
\text { (Operating speed in MPH) }\end{array}$ & $10-25$ & $20-50$ & $7-15$ & $20-30$ & $30-50$ & $30-70$ \\
\hline $\begin{array}{l}\text { Right of Way } \\
\text { (Shared/dedicated) }\end{array}$ & Shared & Dedicated & $\begin{array}{l}\text { Shared/ } \\
\text { Dedicated }\end{array}$ & Dedicated & Dedicated & Dedicated \\
\hline $\begin{array}{l}\text { Construction Disruption } \\
\text { (Impact on traffic and } \\
\text { business during } \\
\text { construction) }\end{array}$ & Minimal & Minimal & Minimal & Significant & Significant & Significant \\
\hline $\begin{array}{l}\text { - Density is a critical c } \\
\text { required to support } \\
\text { - } \quad \text { Rail investment is ge }\end{array}$ & $\begin{array}{l}\text { cern in transit } \\
\text { min bus head } \\
\text { rally more ca }\end{array}$ & $\begin{array}{l}\text { planning - min } \\
\text { vay } \\
\text { ital intensive a }\end{array}$ & 7 dwelling un & $\begin{array}{l}\text { per acre or } 5 \\
\text { us investment }\end{array}$ & & per acre are \\
\hline
\end{tabular}

Source: FDOT Transit Oriented Development Workshop Sketchbook (25)

Bus rapid transit (BRT), rapidly gaining the interest of Florida communities, is defined as a "flexible, permanently-integrated package of rapid transit elements with quality image and distinct identity" (26 p. 2.1). BRT has been described as a more flexible form of light rail because an express bus is much smaller in comparison to a train and can travel anywhere there is pavement rather than relying on a fixed rail system (26 p. 1.1). In general, BRT relies on a few basic principles including, "dedicated transitways/busways, limited stop and express service, and exclusive bus lanes" (26 p. 1.2). Although these basic principles are present in all BRT systems, the flexibility of BRT systems allows them to be tailored to 
specific community needs. Jacksonville and Gainesville are among Florida communities planning BRT systems.

When planning for BRT, the location of the running way within the transportation system is crucial. The running way defines exactly where the BRT vehicle will travel and is the most critical determinant of system speed and reliability (1 p. 2.3). BRT vehicles can operate using the public right of way in what is considered "on street" operation that is open to all forms of traffic. Alternatively, they can operate on "off street" facilities which are on restricted rights-of-ways like expressways (open to all traffic types) or transitways (open to transit vehicles only) (1 p. 2.3). BRT running ways are differentiated from other travel lanes through a variety of techniques like pavement markings, lane delineators, alternate pavement color, and alternate pavement texture (1 p. 2.3). TCRP Report 90 Bus Rapid Transit Volume 2: Implementation Guidelines provides state of the art implementation guidelines for bus rapid transit system (27).

LYMMO, in downtown Orlando, is a premium bus circulator (bus rapid transit) running on an exclusive running way. The service is under expansion to include additional BRT serving the area west of I-4 (28). LYMMO service will complement SunRail, Orlando's new commuter rail system. These actions work toward the fulfillment of Objective 1.3 in Orlando's Growth Management Plan which states: "By 2020, 5 percent of work trips shall be accommodated by public transit" (29). When complete, the 61.5 mile SunRail system will serve nearly 15 percent of Florida's population and the region's largest employers (30). The first phase of the project will extend from DeBary to Sand Lake Road in Orlando while the second phase of the project will extend the rail line from DeBary to DeLand and from Sand Lake Road to Poinciana in Polk County.

SunRail is a commuter rail service operating in Central Florida beginning in 2014. Recognizing the need for careful planning around SunRail stations, two SunRail Transit Oriented Development Sketchbooks were developed and are available on the SunRail website (business.sunrail.com/welcome/page/projectdocuments). Five different TOD typologies were "planned and developed within the context of the entire high capacity transit corridor to ensure that each TOD compliments, rather than competes, with another" (25 p. 12). The typologies, from largest to smallest, are downtown, urban center, town center, village center, and neighborhood center (25 p. 12).

The downtown and urban center TOD typologies support the highest densities and the greatest mix of uses creating pedestrian-oriented environments with limited parking options that encourage walking and the use of public transit options. Town centers are characterized by a medium-high density that includes "mostly residential with local-supporting commercial and employment" land uses (31 p. 15). Town centers should offer some structured parking integrated into development and surface parking should occur behind development to encourage pedestrian activity (31 p. 15). The village and neighborhood centers should have medium and low densities respectively with primarily residential land uses. Although these TOD typologies are primarily comprised of residential land use, it is still suggested that the surface parking be located behind development making pedestrians the focus. Central Florida has committed to encourage this type of TOD around each of the proposed SunRail stations. Figure 2-5 shows new TOD residential construction in Downtown Orlando near the new SunRail station. 


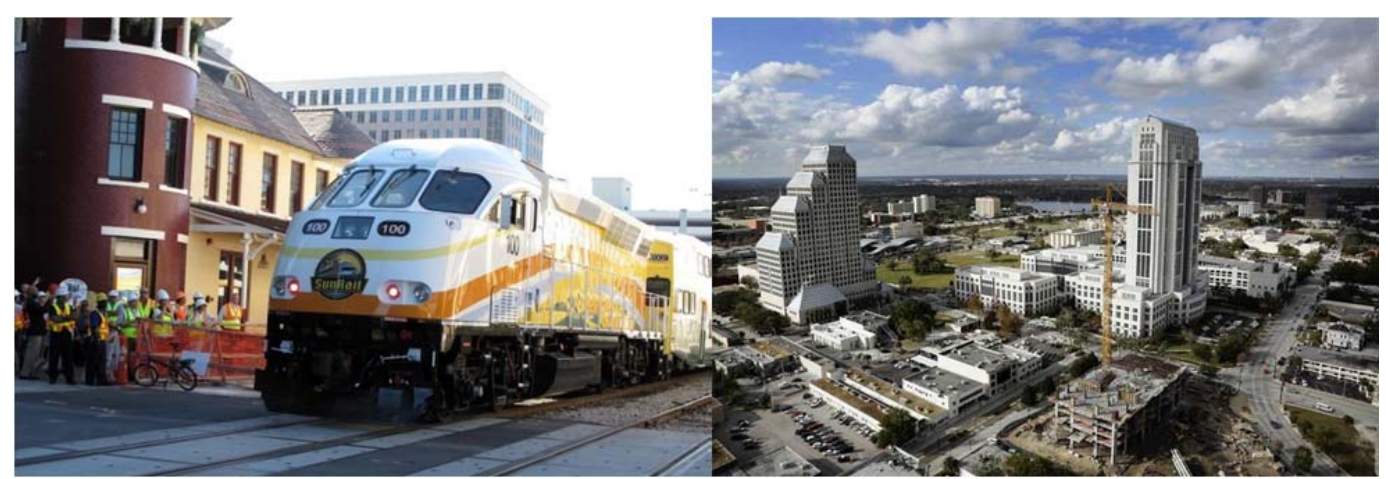

Figure 2-5. New construction surrounding SunRail stations

Source: www.trbimg.com/img-50f2ec44/turbine/os-realestate4.jpg-20130113/600

Light rail is gaining in popularity in large- and medium-size cities across the U.S., in part due to federal funding availability. Phoenix, Arizona has the $12^{\text {th }}$ most used light rail system in the United States (32 p. 3). Between 2001 and 2013, the 20.3-mile Central Phoenix/East Valley Light-Rail Transit project connecting Phoenix, Tempe, and Mesa was completed. Since its construction, the Valley Metro system has experienced an increase in ridership every year and there are plans of expanding the system further.

Tri-Rail is Southeast Florida's commuter rail line that has been in operation since 1989. The 72-mile system links three counties, Palm Beach, Broward and Miami-Dade. The system began as a temporary traffic mitigation measure for people affected by construction of I-95 and the Florida Turnpike (33). Tri-Rail is operated by the South Florida Regional Transportation Authority (SFRTA). The Authority's mission is to coordinate, develop and implement a viable regional transportation system in South Florida that endeavors to meet the desires and needs for the movement of people, goods and services. The SFRTA develops and maintains a Transit Development Plan (TDP). The comprehensive plans of two of the three counties (Palm Beach and Broward) also support the development of Tri-Rail with specific objectives and policies (see GOP 2-11).

Coordinating TDPs with the transportation element and comprehensive planning as a whole provides an opportunity to guide transit-supportive land use along transit corridors and anticipate transit systems needs particularly beyond the planning horizon of the TDP. Adopted transit plans, transit disadvantaged service plans, transit development plans, MPO long-range transportation plans, and regional transportation authority plans provide a wealth of information for use by local governments in the existing conditions analysis, as well as on future agency plans for public transportation. TDPs also include a system performance evaluation of the existing services primarily using data reported to the National Transit Database (NTD) and a financial plan that outlines how future transit services will be provided and funded. Specific information to obtain from these plans is noted below. ITR 22 identifies a number of additional transit planning resources to aid in the analysis.

\section{I dentify and map public transportation routes by type and exclusive transit rights-of-way or corridors and facilities, such as bus and rail stops and station areas, transfer locations and system connections.}

Maps of existing and planned public transportation systems are required in the transportation element (see BP 2-12). For example, the Pinellas County MPO LRTP includes 
a map series that depicts the existing transit systems routes, park-and-ride centers, and intermodal facilities followed by an example of the cost feasible premium bus network and the cost feasible rail network. The map series provides an example of what the transit system could potentially look like in the future for Pinellas County if funding becomes available. This can be a useful tool in understanding the connectivity of different modes of transit (bus and rail in this case) as well as the connectivity to neighboring transit systems (Pinellas County to Hillsborough and Pasco Counties in this case).

\section{BP 2-12. Map Public Transportation}

The Lakeland, FL 2010-2020 Comprehensive Plan includes a map series that depicts bus routes (express and fixed route), the city bus terminal, regional bus terminal, train terminal, park-and-ride centers (existing and committed), and pertinent land uses.

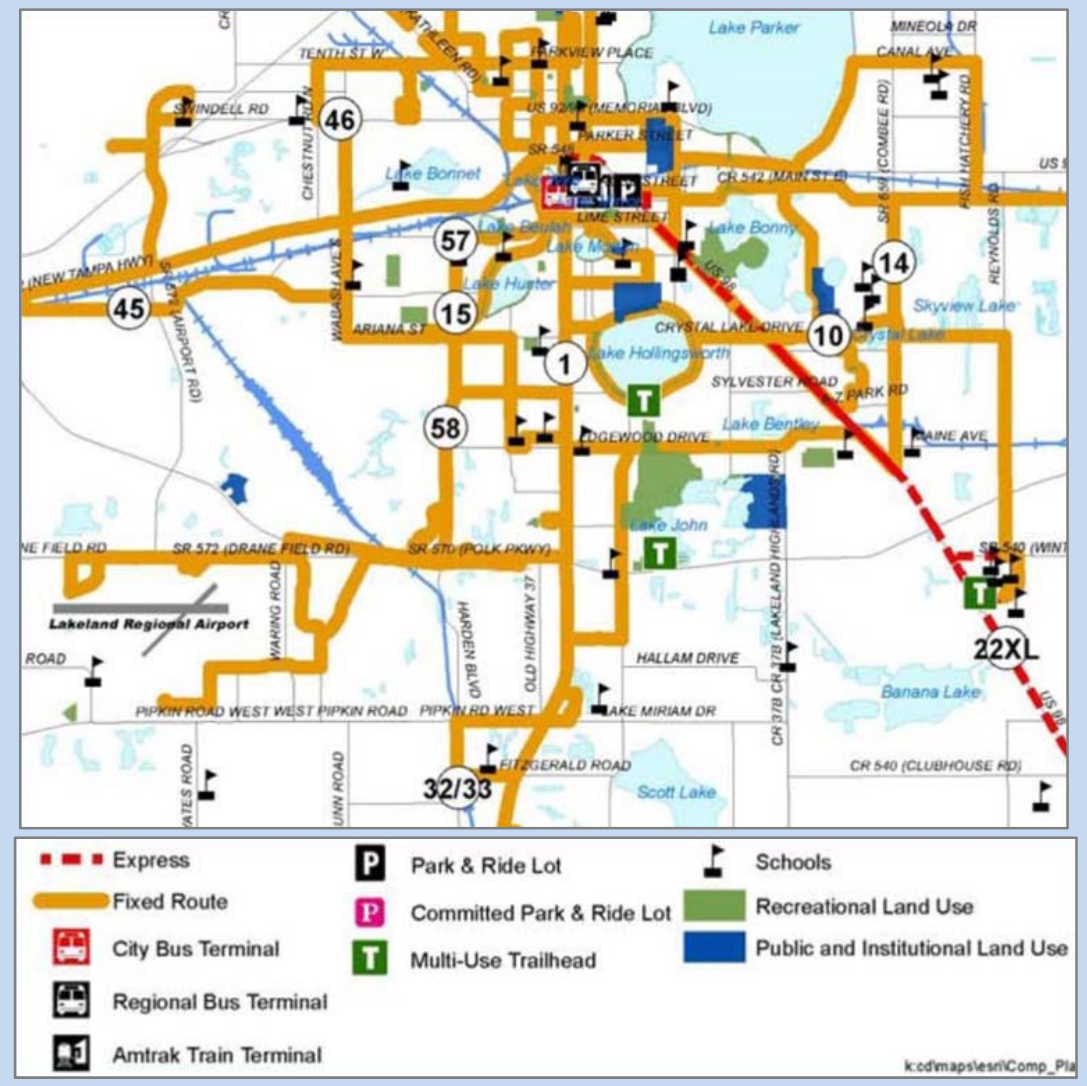

Source: Lakeland, FL 2010-2020 Comprehensive Plan (34)

Practice Notes: The situation appraisal of a transit development plan (TDP) provides useful information for local comprehensive planning. Factors addressed may include land use and development, roadway level of service, pedestrian access, coordination with neighboring transit systems, addressing the increased demand for varying modes of transit, the impact of rising fuel costs on transit systems, and the funding and resources required to provide a successful transit system. By addressing the factors identified in the applicable TDP, a local 
government will establish a strong connection between the TDP and the comprehensive plan.

\section{ITR 2-2. Transit Planning Resources}

- Transit planning - Transit Development Plan Resource Center is a central location providing easy access to a variety of tools and information to assist in the preparation of ten-year TDPs including complete plans - planfortransit.com/resources-2/download-center/?category $=7$

- FDOT Guidance for Producing a Transit Development Plan - planfortransit.com/wpcontent/TDP Materials/FDOT Guidance for Preparing a TDP 2009.pdf

- MPO long-range transportation plans www.mpoac.org

- Accessing Transit Design Handbook for Florida Bus Passenger Facilities www.dot.state.fl.us/transit/Pages/2013AccessingTransitFinal.pdf

- National Center Transit Research's (NCTR) website - www.nctr.usf.edu.

- FDOT State Park-and-Ride Guide www.dot.state.fl.us/transit/Pages/FinalParkandRideGuide20120601.pdf

\section{Describe transit service area and operating characteristics, including quality of service for public transportation as detailed in transportation disadvantaged service plans, transit development plans, MPO long-range transportation plans, and regional transportation authority plans.}

A variety of plans may include information for this analysis. Transit development plans (TDPs) can be particularly useful and MPO long-range transportation plans are increasingly addressing public transportation needs and investment. ITR 2-3 illustrates information that may be obtained from the TDP. TDPs typically begin by defining the service area characteristics, such as population size and demographics, and the existing transit services provided. The existing state of the transportation system is described highlighting areas that are working well and areas in need of attention.

Using the TDP and other plans, identify transit system characteristics including types of service, quality of service, network coverage, mode split, and convenience of modal connections. Determine future plans for further investment to help guide additional local transit and land use planning decisions (see BP 2-13). Also, document any safety concerns that may warrant additional attention in the comprehensive plan, such as crash indicators, transit fatalities and injuries, and security at terminals. Note any transit operating issues identified in the modal plans, such as:

- transit routes not serving community needs in terms of frequency and span of service;

- transit capacity/overcrowded routes;

- missing and sub-standard (size and condition) bus shelters;

- areas not accessible by sidewalks within $1 / 4$ mile of transit;

- high crash locations; and

- areas with high crime that may require improved amenities, visibility, or other strategies. 


\section{BP 2-13. I dentify and Plan for Premium or High Capacity Transit Routes}

The Broward MPO Long Range Transportation Plan has a vision to "transform transportation in Broward County to achieve optimum mobility with emphasis on mass transit while promoting economic vitality, protecting the environment, and enhancing quality of life." The plan includes an illustration of premium transit projects planned for the future system, and identifies two premium transit options for additional investment - Premium High Capacity and Premium Rapid Bus. Measures used for the regional transit quality of service assessment were: service frequency, hours of service, and transit-auto travel time.

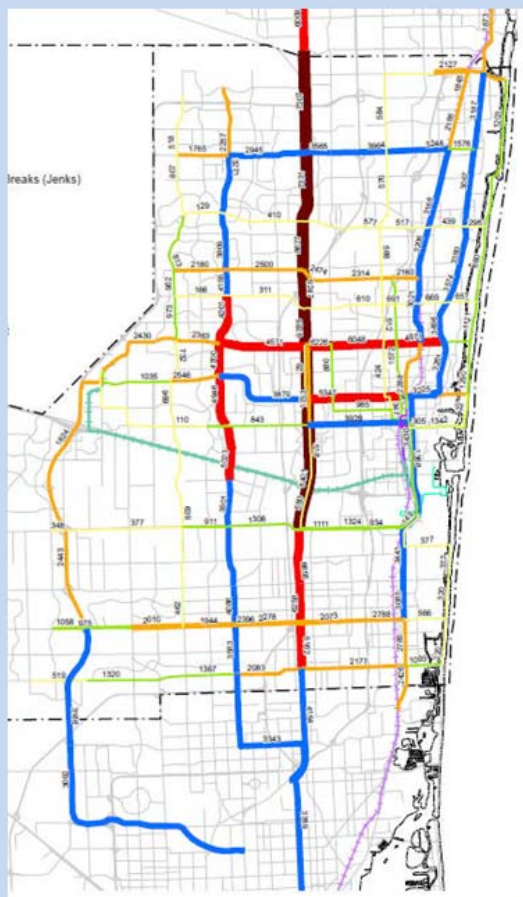

LEGEND

PREMIUM TRANSIT

\section{PROJECTS}

(Link Volume 2035)

6856-9789

$4201-6855$

$2851-4200$

$1696-2850$

$811-1685$

$22-810$

Classification based on Natural Breaks (Jenks)

Standard Deviation: 2114.38

Mean: 2387.64

Median: 1850

ILLUSTRATIVE PROJECTS

Peoplemover-SunPort

(Airport/Seaport)

Central Broward Transit

(not final routing)

South Florida East Coast

Corridor (FEC)

\section{Characteristic}

\section{Type of guideway}

\section{Peak/Off-peak headway}

Transit Signal Priority

Off-board fare collection system

Articulated low-floor transit vehicles

Real-time passenger information

Potential federal funding
Premium High Capacity

$\mathbf{5 0 \%}$ or more operates in fixed guideway (dedicated transit lane)

5-7.5 minutes

Yes

Yes

Yes

Yes

New Starts

Project cost $>\mathbf{\$ 2 5 0}$ million

Small Starts

Project cost $<=\$ 250$ million
Premium Rapid Bus

Operates in mixed traffic

10-15 minutes

Yes

Yes

Yes

Yes

Very Small Starts

$<\$ 50$ million per project

Source: Broward Metropolitan Planning Organization, 2014 (35). 


\section{ITR 2-3. Transit System I nformation Found in the TDP}

Transit development plans provide a wealth of information for the transportation element. For example, information may include:

- Fixed route vehicle information (including number of vehicles, age of vehicle, capacity, length, etc.)

- Paratransit vehicle information (including number of vehicles, age of vehicle, lift type, seats, wheelchair capacity, etc.)

- Summary of transit operating characteristics for city routes, campus routes, and weekend routes (including route number and description, cycle times, on and off-peak headways, service span, etc.)

- Route length and stops by location (including length of route, number of stops on each route, and location of stop in reference to within the city, county, or a portion of both) (36 pp. 3.2-3.14).

3. I dentify and evaluate issues associated with land use and accessibility (e.g., bicycle/ pedestrian access to transit stops and stations, densities/ intensities on transit corridors or key destinations, park and ride facility locations and transit connections, etc.)

As noted previously, the land use and multimodal environment is an important aspect of efficient transit service. For example, BP 2-14 describes how Altamonte Springs has addressed these issues in its comprehensive plan. BP 2-16 provides guidance on pedestrian and bicycle travel sheds relative to transit oriented developments. 


\section{BP 2-14. Address Transit Planning and Land Use I ssues}

The Altamonte Springs Transportation Element includes a section on Multimodal Issues and Opportunities that address transit and land use issues. Accessibility and the importance of "maximizing accessibility, convenience, and safety particularly in areas adjacent to proposed stations" is stressed (37 p. 2.40). Key land use characteristics mentioned include "higher densities and intensities, minimal building setbacks, joint development and dedicated pedestrian connections between stations and adjacent buildings" (37 p. 2.40). With the addition of light rail, a flex bus system, and the Seminole-Wekiva Trail to the area, the City notes that system-wide access and intermodal connectivity are important considerations. Activity centers are being considered to serve as intermodal transfer locations providing access to public transportation and daily shopping and service needs.

Altamonte Springs also noted the importance of developing a locally-oriented transit service to increase access to transit for residential areas that are not near the current transit corridors through their FlexBus service. The FlexBus service picks up passengers at their nearest station location in response to their request and transports them to their destination location. Since FlexBus does not run on a fixed route system, trips are much shorter and more direct. Long term bus transit development plans are being created with the focus of connecting these residential areas to activity centers, which will eventually become intermodal connection centers as well (37 p. 2.41). Along with the addition of locally-oriented transit, the City also plans to enhance bicycle and pedestrian facilities on a system-wide level. Modifications to the bicycle and pedestrian facilities, including interconnected sidewalks, off road bike trails, and transit shelters, will be highest priority near schools, parks, and activity centers (37 p. 2.41).

The addition of SunRail has created a change in land uses around each of the newly constructed stations, including the station and surrounding El Centro area of Altamonte Springs. El Centro is designed focusing on transit oriented development (TOD) through GIS analysis of non-residential intensity, residential intensity, population distribution, and vacant land within $1 / 4$ and $1 / 2$ mile from the SunRail Station. The image below depicts the GIS analysis.

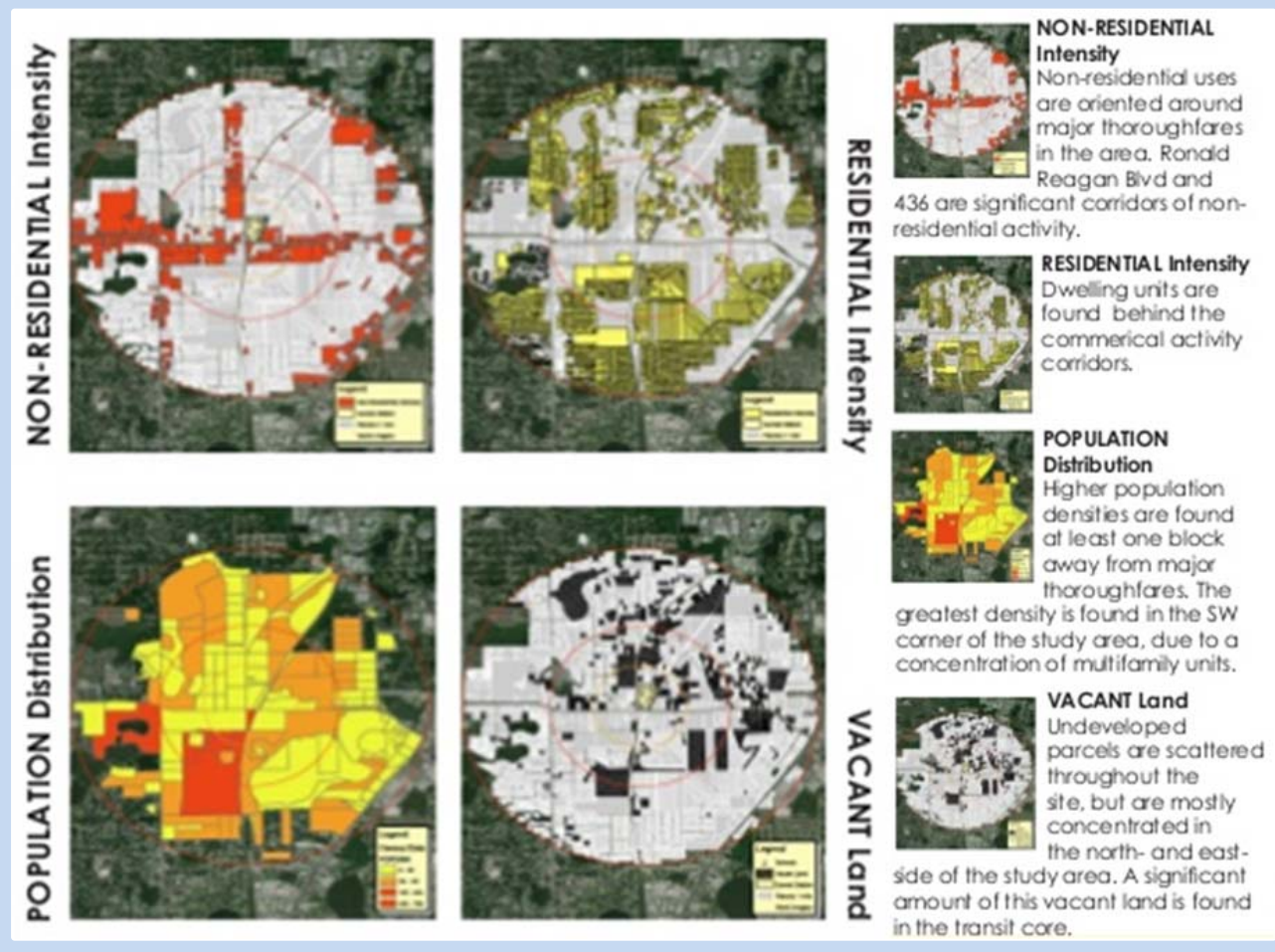

Source: www.slideshare.net/JoseCAyalaCNUA/altamonte-to-dbookletfinal 


\section{BP 2-15. Minimum Density per Type of Transit Service}

When addressing access to transit service, it is important to note what types of transit are supported by the density of that particular area. Areas with 4-5 dwelling units per acre, for example, is not considered TOD supportive in the Florida TOD Guidebook and should not be provided with any more than local bus service at 1 bus per hour. An area with 20-30 dwelling units per acre however, is considered TOD supportive and light rail services would be acceptable in these areas. The table below outlines the minimum density per type of transit service as provided by the Florida TOD Guidebook.

\begin{tabular}{|c|lc|}
\hline \multicolumn{2}{|c}{ Type of Transit Service } & $\begin{array}{c}\text { Density Threshold } \\
\text { (Dwelling Units/Acre) }\end{array}$ \\
\hline $\begin{array}{c}\text { Not TOD- } \\
\text { Supportive }\end{array}$ & Local Bus (1 bus per hour) $^{1}$ & $4-5$ \\
\hline & ${\text { Intermediate Bus (1 bus every 30 minutes) })^{1,2}}^{2}$ & 7 \\
$\begin{array}{c}\text { TOD- } \\
\text { Supportive }\end{array}$ & Premium Bus Service (1 bus every 10 minutes) $^{1,2}$ & 15 \\
& Light Rail Services $^{2}$ & $20-30$ \\
\hline
\end{tabular}

Source: A Framework for TOD in Florida (12)

\section{BP 2-16. Determine Travel Shed for TOD Stations}

Travel sheds maximize pedestrian activity and increase access to transit stations. According to A Framework for Transit Oriented Development in Florida (12), one-quarter mile and one-half mile represent a 5 to 10 minute walk time, which is the amount of time most people are willing to walk to a destination. The most intense and dense development is typically located within the one-quarter mile radius (transit core). Intensities and densities gradually decrease out to the one-half mile radius (transit neighborhood) and the one mile radius (transit supportive area). Bicycles and bike on bus programs can extend the travel sheds to a mile or more.

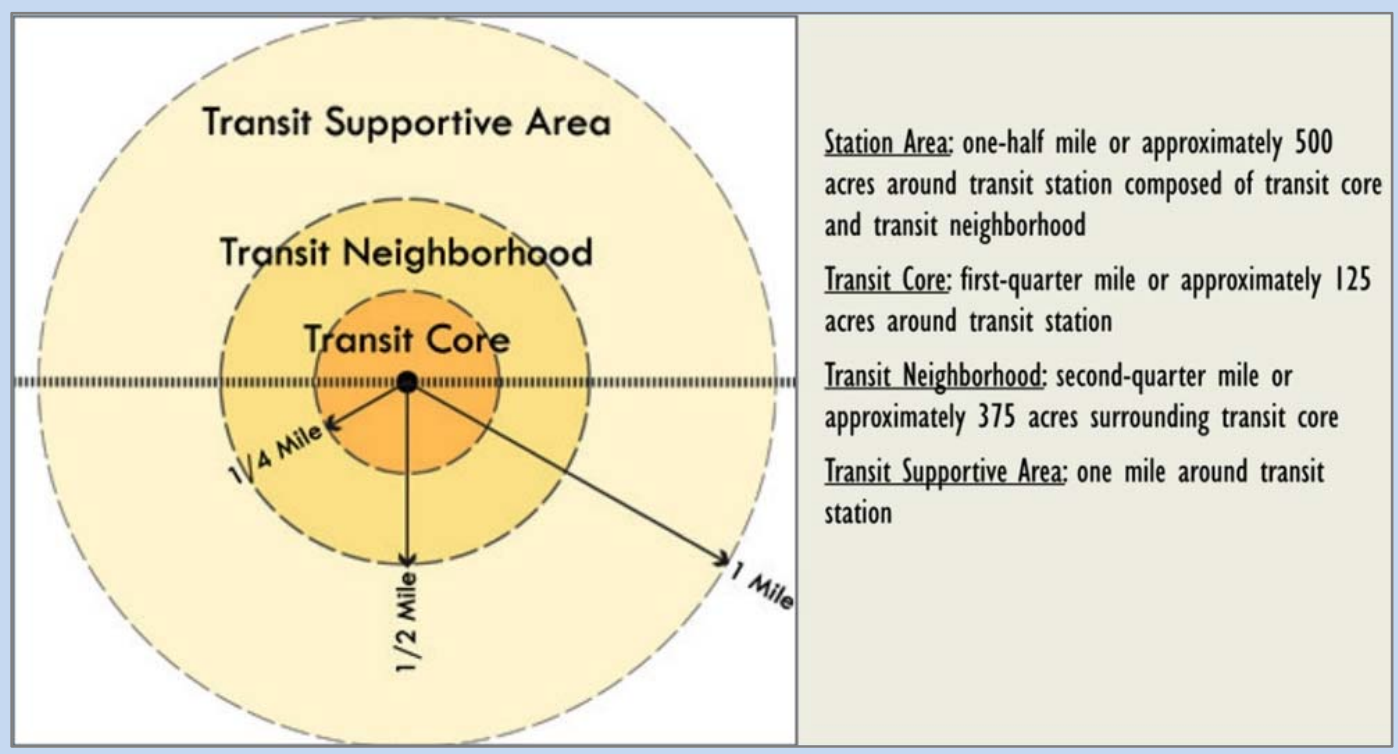

Source: A Framework for TOD in Florida (12) 


\section{Major Roadways, Evacuation Routes, and Conditions}

Below is an overview of the existing conditions inventory and analysis for the major roadway system. Much of the information may be obtained from the inventory of agency and modal plans, particularly the MPO long-range transportation plan, with supplemental data sources identified in ITR 2-4. Further information on estimating future travel demand and planning for the future roadway system is contained in Sections 2.3 and 2.4.

1. Develop a list and/ or map series to identify the following:

a. Major existing and programmed/ committed roadways

b. Current functional classification and maintenance responsibilities

c. Special corridor designations, such as:

- Strategic I ntermodal System (SIS)

- hurricane evacuation routes

- demand management corridors, such as managed lanes

- bus rapid transit corridors (see Public Transportation)

- regional goods movement corridors and local truck routes (see Rail, Ports, Airports, and I ntermodal Facilities)

Identify roadway and public transportation projects on the State Highway System (SHS) that are planned and programmed/committed (i.e., have funding committed to them in the next three years). These will be detailed in the Florida SIS Plan and the FDOT Adopted FiveYear Work Program. Roadway data sources for number of lanes, functional classification, and maintenance responsibilities are listed in ITR 2-4. BP 2-17 is an example; several others are provided throughout the model.

Florida's Strategic Intermodal System is a statewide network of transportation facilities, including the state's largest and most significant airports, spaceports, deep water seaports, freight rail terminals, interregional rail and bus terminals, rail corridors, urban fixed guideway transit corridors, waterways, and highways. SIS facilities provide the primary means of interstate, intrastate, and international movement of people and freight. The SIS is Florida's highest statewide priority for transportation capacity improvements. § 339.64, F.S., concerns the SIS Strategic Plan which "sets policies to guide decisions about which facilities are designated as part of the SIS, where future SIS investments should occur, and how to set priorities among these investments given limited funding." The SIS Strategic Plan is updated every five years. Per $\S 163.3180(5)(h) a$, F.S., states that "local governments that continue to implement a transportation concurrency system, whether in the form adopted into the comprehensive plan before the effective date of the Community Planning Act, or as subsequently modified, must consult with the Department of Transportation when proposed plan amendments affect facilities on the Strategic Intermodal System."

FDOT uses the Highway Classification System adopted by the Federal Highway Administration (FHWA) and identifies federal system assignments used for funding purposes in its Roadway Characteristics Inventory (RCI) database. The FHWA system classifies roadways as Principal Arterial, Minor Arterial, Major and Minor (or Urban) Collector, or Local streets based upon traffic movement and land access characteristics. Two area types, urban and rural, are used to differentiate context. Urban areas are those designated as urbanized areas by the U.S. Census Bureau, with the remaining areas being designated as rural. 
Practice Notes: Local governments may choose to use conventional functional definitions for arterial, collector, and local roadways in their comprehensive plan. Best practice is to supplement these definitions with more detailed statements of purpose and function for each roadway classification. This can be accomplished using either traditional functional classification terms or "complete streets" categories that relate to functional classifications. Similarly, modal priority routes, such as truck routes, should be designated in the plan to help guide roadway design and land use planning. Whatever the approach used, it is important to provide more adequate guidance on land use context for street network planning and design than provided by the broad FHWA "urban/rural" distinctions. See Section 2.3 (Categorize the Future Roadway Network) for further information.

\begin{tabular}{|c|c|c|}
\hline Description & Source & How To Obtain I nformation \\
\hline $\begin{array}{l}\text { Mean travel time to } \\
\text { work and commuting } \\
\text { trends }\end{array}$ & US Census Bureau & $\begin{array}{l}\text { factfinder2.census.gov/faces/nav/jsf/pages/index. } \\
\text { xhtml\#\#\# }\end{array}$ \\
\hline \multirow{2}{*}{$\begin{array}{l}\text { Roadway } \\
\text { Characteristics } \\
\text { Inventory }\end{array}$} & \multirow[t]{2}{*}{ FDOT Statistics Office } & Contact FDOT District Planning Office \\
\hline & & www3.dot.state.fl.us/videolog/default.asp \\
\hline $\begin{array}{l}\text { Web-Based Crash } \\
\text { Mapping and Analysis }\end{array}$ & University of Florida & www.geoplan.ufl.edu/projects.shtml \\
\hline $\begin{array}{l}\text { Highway/traffic data } \\
\text { for the SHS and } \\
\text { selected off-system } \\
\text { roads }\end{array}$ & FDOT Statistics Office & $\begin{array}{l}\text { www.dot.state.fl.us/planning/statistics/trafficdata/ } \\
\text { fti.shtm }\end{array}$ \\
\hline \multirow[t]{4}{*}{ Traffic counts } & MPO & Consult with MPO or MPO Website \\
\hline & FDOT Statistics Office & $\begin{array}{l}\text { www2.dot.state.fl.us/FloridaTrafficOnline/viewer.ht } \\
\text { ml } \\
\text { www.dot.state.fl.us/planning/statistics/tmh/ }\end{array}$ \\
\hline & City Government & Consult with City and City Website \\
\hline & County Government & Consult with County and County Website \\
\hline $\begin{array}{l}\text { Maps of existing } \\
\text { rights-of-way }\end{array}$ & $\begin{array}{l}\text { FDOT Surveying and } \\
\text { Mapping Office }\end{array}$ & $\begin{array}{l}\text { www.dot.state.fl.us/surveyingandmapping/rowma } \\
\text { p.shtm }\end{array}$ \\
\hline $\begin{array}{l}\text { SIS Maps and Lists of } \\
\text { Designated Facilities }\end{array}$ & FDOT Systems Planning & www.dot.state.fl.us/planning/sis/atlas/ \\
\hline \multirow[t]{3}{*}{$\begin{array}{l}\text { Hurricane evacuation } \\
\text { and vulnerability } \\
\text { assessments }\end{array}$} & $\begin{array}{l}\text { Florida Division of } \\
\text { Emergency } \\
\text { Management }\end{array}$ & www.floridadisater.org \\
\hline & $\begin{array}{l}\text { Regional Evacuation } \\
\text { Studies }\end{array}$ & $\begin{array}{l}\text { www.floridadisaster.org/res/ } \\
\text { www.trb.org/main/blurbs/168631.aspx }\end{array}$ \\
\hline & $\begin{array}{l}\text { Vulnerability } \\
\text { Assessment Webinars }\end{array}$ & $\begin{array}{l}\text { www.fhwa.dot.gov/environment/climate cha } \\
\text { nge/adaptation/webinars/ }\end{array}$ \\
\hline Sea level rise & University of Florida & sls.geoplan.ufl.edu/ \\
\hline $\begin{array}{l}\text { Performance } \\
\text { indicators }\end{array}$ & University of Florida & $\begin{array}{l}\text { www.dot.state.fl.us/research- } \\
\text { center/Completed Proj/Summary PL/FDOT BDK7 } \\
7 \text { 977-14 rpt.pdf }\end{array}$ \\
\hline $\begin{array}{l}\text { Electric vehicle } \\
\text { charging stations }\end{array}$ & ChargePoint & www.chargepoint.com/driver-assistance.php \\
\hline
\end{tabular}




\section{BP 2-17. Map and Discuss Major Thoroughfares and Related Characteristics}

A variety of maps may be helpful to understanding the major thoroughfare system. They may be identified in different ways and combined in final documents with future plans to illustrate both the existing and planned future transportation system, as shown in the example below. They might also be combined with land use and/or across modes to address land use and intermodal relationships, as shown in several examples throughout the model element. The most common items mapped for the existing conditions analysis of major thoroughfares include:

- Major Roadway System

- Roadway Functional Classification

- Strategic Intermodal System/Regional Goods Movement Corridors

- Managed Lanes

- Hurricane Evacuation Routes

- Transit Routes (various types)

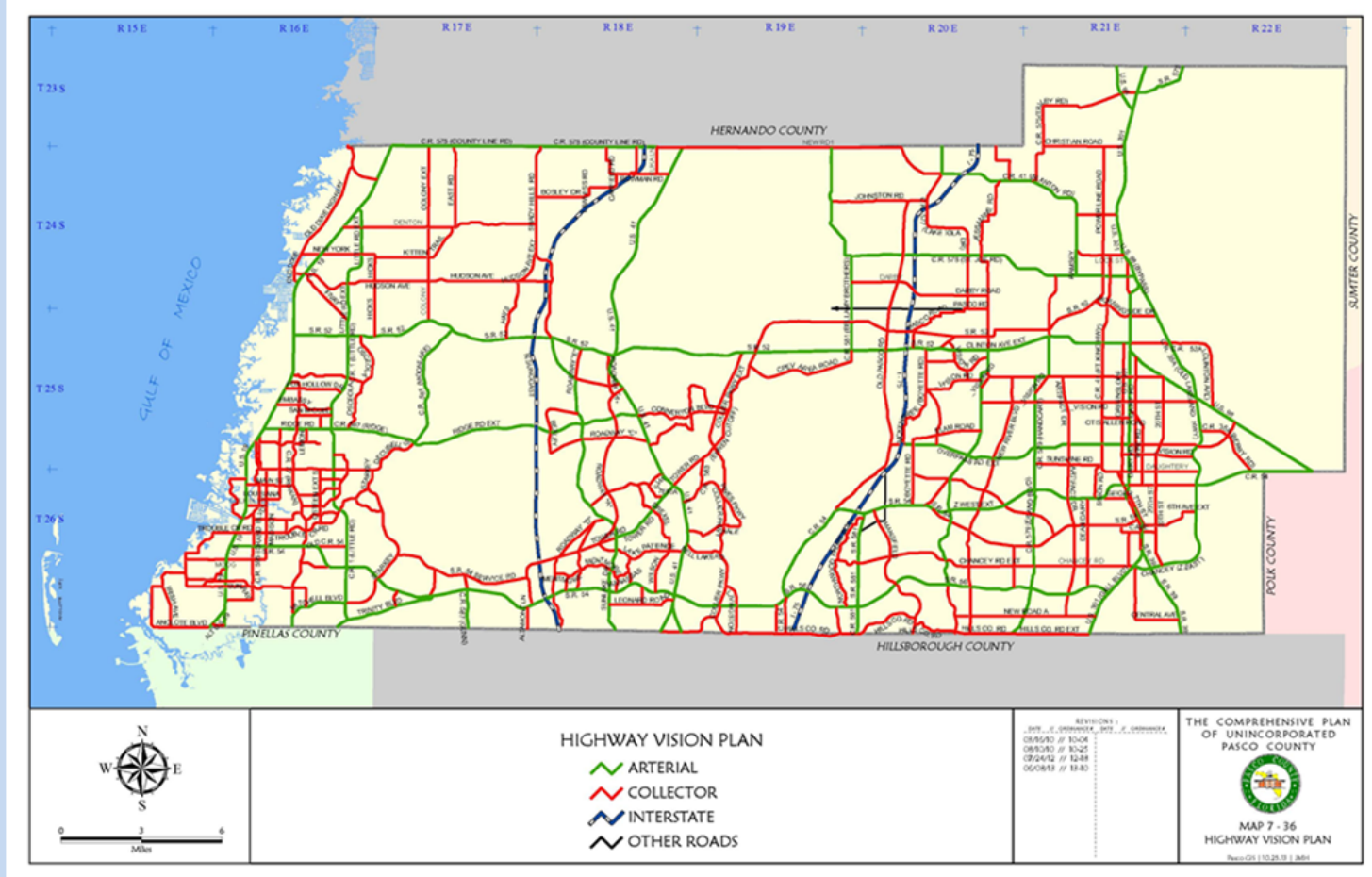

Source: Pasco County Highway Vision Plan (11)

2. Note or map and evaluate information on travel patterns, characteristics, and issues. Considerations include:

a. mode split

b. origin-destination (O-D) patterns

c. average commute times and lengths

d. average trip length

e. vehicle and person miles traveled (VMT, PMT)

Some travel data will flow from the long-range transportation planning process of the MPO, and some will be produced via local analysis. 
Table 2-3 is an example of the type of mode choice and related travel information that may be obtained from an MPO long-range transportation plan. Evaluating this information over time provides insight into how travel behavior is changing and possible strategies to address that change. Quality/level of service analysis and sketch planning analysis to forecast future travel demand and network spacing needs are addressed in Section 2.3. ITR 2-5 notes some of the specific data sources to consult in this effort.

\section{TR 2-5. Commuting Patterns and Characteristics}

- MPO long-range transportation plans www.mpoac.org

- Modal split and vehicle occupancy rates. US Census J ourney to Work data www.census.gov/hhes/commuting/data/commuting.html

- U.S Census Bureau Longitudinal Employer-Household Dynamics - lehd.ces.census.gov/

- Florida Statistical Abstract - www.bebr.ufl.edu/bebrproducts/series/Florida\%20Statistical\%20Abstract

- Commuter assistance program websites - www.commuterservices.com/

Practice Notes: One way to reduce VMT is to increase residential density. Research indicates that an area with a population density of 4,000 persons per square mile produces approximately 39\% less VMT per capita than an area of 500 persons per square mile (38). 
Table 2-3. Example of Mode Choice Information in a Long-Range Transportation Plan

\begin{tabular}{|c|c|c|c|c|c|c|c|c|c|}
\hline & \multicolumn{4}{|c|}{ Highway Trips } & \multicolumn{4}{|c|}{ Transit Trips } & \multirow[b]{2}{*}{ Total } \\
\hline & Person Trips & Drive Alone & $\begin{array}{c}\text { One } \\
\text { Passenger }\end{array}$ & $\begin{array}{c}\text { Two+ } \\
\text { Passengers }\end{array}$ & $\begin{array}{l}\text { Walk to } \\
\text { Local }\end{array}$ & $\begin{array}{l}\text { Walk to } \\
\text { Premium }\end{array}$ & $\begin{array}{l}\text { Park- } \\
\text { Ride }\end{array}$ & $\begin{array}{l}\text { Kiss- } \\
\text { Ride }\end{array}$ & \\
\hline $\begin{array}{l}\text { Zero Car } \\
\text { Households }\end{array}$ & 131,217 & 50,977 & 36,263 & 31,722 & 10,580 & 2 & 524 & 1,149 & 12,256 \\
\hline $\begin{array}{l}\text { One Car } \\
\text { Households }\end{array}$ & $2,957,840$ & $1,208,784$ & 858,586 & 871,247 & 16,541 & 2 & 1,342 & 1,343 & 19,228 \\
\hline $\begin{array}{c}\text { Two+ Car } \\
\text { Households }\end{array}$ & $3,958,012$ & $2,129,674$ & $1,265,472$ & 546,862 & 12,250 & 1 & 2,123 & 1,633 & 16,006 \\
\hline Total & $7,047,067$ & $3,389,433$ & $2,160,316$ & $1,449,832$ & 39,370 & 5 & 3,988 & 4,123 & 47,487 \\
\hline Can Walk & $2,329,210$ & $1,108,448$ & 757,261 & 421,155 & 39,370 & 5 & 1,142 & 1,830 & 42,346 \\
\hline Must Drive & $1,686,285$ & 794,869 & 487,278 & 399,005 & 0 & 0 & 2,845 & 2,295 & 5,139 \\
\hline No Access & $3,031,572$ & $1,486,119$ & 915,779 & 629,675 & 0 & 0 & 0 & 0 & 0 \\
\hline Total & $7,047,067$ & $3,389,433$ & $2,160,316$ & $1,449,832$ & 39,370 & 5 & 3,988 & 4,123 & 47,487 \\
\hline \multicolumn{10}{|c|}{ Productions: } \\
\hline CBD & 112,093 & 54,763 & 33,305 & 19,976 & 4,019 & 0 & 10 & 23 & 4,051 \\
\hline Exurban & $3,887,492$ & $1,851,835$ & $1,188,737$ & 830,136 & 11,231 & 1 & 2,519 & 3,032 & 16,782 \\
\hline Other & $3,047,482$ & $1,482,835$ & 938,275 & 599,716 & 24,122 & 4 & 1,461 & 1,069 & 26,654 \\
\hline \multicolumn{10}{|l|}{ Attractions: } \\
\hline CBD & 229,985 & 108,352 & 68,472 & 42,398 & 9,064 & 0 & 715 & 984 & 10,766 \\
\hline Exurban & $3,173,414$ & $1,603,462$ & $1,021,874$ & 535,222 & 10,482 & 0 & 1,014 & 1,365 & 12,861 \\
\hline Other & $3,643,668$ & $1,677,620$ & $1,069,974$ & 872,212 & 19,826 & 4 & 2,261 & 1,775 & 23,865 \\
\hline Total & $7,047,067$ & $3,389,433$ & $2,160,316$ & $1,449,832$ & 39,370 & 5 & 3,988 & 4,123 & 47,487 \\
\hline
\end{tabular}

Source: MetroPlan Orlando 2030 LRTP (39)

\section{I dentify and discuss transportation demand management services, programs, and impacts, such as:}

a. Services (vanpool/ rideshare, carshare, bike share)

b. Parking management

c. Employee transportation coordinators for large employers

Transportation demand management (TDM) consists of strategies that foster increased efficiency of the transportation system by influencing travel behavior by mode, time of day, frequency, trip length, regulation, route or cost. Examples of TDM strategies include public transit services, carpooling, compressed work weeks, telecommuting, limited parking, and provision of bike and locker facilities by employers. The Florida Department of Transportation has a policy to ensure the consideration of TDM strategies "in all studies, plans, programs, functional areas, and in employee benefit programs (Topic No.: 000-725050-h) (40)."

Sponsored in whole or in part by the Florida Department of Transportation, several commuter assistance programs serve various regions of Florida. They are sometimes housed within a transit agency or managed by a private entity. These commuter assistance programs offer specialized mobility services and support programs to encourage alternatives to single occupancy vehicle travel. Examples include subsidized employee/employer 
vanpools, carpool matching, guaranteed ride home, and reduced transit fare programs. Vanpool or rideshare services can provide a way for local residents to access employment, as well as longer distance travel options. Managed lanes are a comprehensive TDM strategy for congested highway corridors (see BP 2-40). Commuter assistance programs collect data that is useful for understanding commuting needs and patterns and that monitors impacts of interventions on travel demand. TDM resources can be found in ITR 2-6.

There is a state discretionary grant program, known as the Transit Corridor Program, which is for the purpose of relieving congestion and improving capacity through use of highoccupancy vehicles. Transit agencies, counties and municipalities are eligible for this grant, and it can be applied toward planning, land acquisition, capital facilities, construction and operating costs of transit. Examples of specific transit facilities that might be found in a transportation management program for transit corridors include bus-pullout lanes, HOV lanes, access improvements along the corridor, park-and-ride lots, traffic controls and TDM strategies targeting corridor employers.

\section{ITR 2-6. Transportation Demand Management}

- National TDM and Telework Clearinghouse contains over 100 case studies of work site trip reduction programs on the Helpdesk - www.nctr.usf.edu/clearinghouse

- TDM in Florida - www.commuterservices.com

- Victoria Transport Institute - www.vtpi.org/tdm/

- Incorporating TDM into the Land Development Process includes a review of available literature and planning/regulatory policies, analyzes relevant case studies that highlight negotiations between local governments and land developers, and provides general recommendations as a result of the research (41) - www.nctr.usf.edu/pdf/576-11.pdf

- Land Developer Participation in Providing for Bus Transit Facilities/Operations documents various regulatory and non-regulatory strategies that Florida's local governments and transit agencies can use to generate public transportation funding (42) www.nctr.usf.edu/pdf/Land\%20Developer.pdf

Popularity of on-demand transportation options is on the rise due to increasing transit availability and the lack of automobile-ownership in segments of the population. These options include community-wide car rental and bicycle rental systems that enable users to rent vehicles by the hour. Demand for bike- and car-sharing services will grow as more and better transit options are developed with the accompanying increase in residential options located close to the transit service. The transportation element should address these options including their location as well as convenient access to them.

Rental cars located in urban neighborhoods and transit locations are prevalent in many large cities across the nation and are in a few locations in Florida. Foregoing car payments and the accompanying insurance costs while still having access to an automobile when needed provides quite an incentive for a car-less lifestyle especially to the next, younger generation of urban dwellers and aging residents. Due to popularity among the Millennial Generation, car sharing is perhaps most prevalent on Florida's university campuses.

Bike sharing systems are currently located in Miami, Orlando, Tampa, and Broward County and are expected to spread throughout the state. Community-wide bike rental systems that increase local mobility options are provided by local governments in large cities such as New 
York and Chicago. Broward County has been operating a successful bike sharing system since 2011 that has been expanded annually due to demand through increased ridership.

4. Document safety and operational concerns noted in other reports (MPO congestion management process, corridor studies, safety audits or reports), such as:
a. high crash locations and crash indicators (3- to 5-year timeframe)
b. bottlenecks (locations subject to frequent congestion, compare to crash data)

An understanding of crash locations can assist in supporting future land use policies, access management policies, and the provision of infrastructure to improve safety within the community. Addressing a 3-5 year timeframe in the inventory of crash-related data will identify areas where crashes occur more frequently, as opposed to isolated instances. High crash locations are often an indicator that the area requires additional access management strategies and/or bicycle/pedestrian infrastructure projects, such as raised medians, signalized midblock crossings, local streets, parking lot cross access, and other treatments. BP 2-18 illustrates information obtained from a pedestrian safety action plan that relates to roadway and land use conditions on transit routes.

Specific changes to existing local traffic circulation patterns may also need to be considered to improve safety and advance other community objectives. For example, converting certain one-way streets back to two-way streets in core areas and activity centers is one means to increase roadway safety, as well as accessibility. Such conversions may "improve vehicular access and reduce driver confusion" (43). Literature on urban street network design concludes that two-way streets create higher levels of economic activity and improve the livability of downtown areas (43). From a safety perspective, one-way streets contribute to driver inattentiveness and higher travel speeds (43). 


\section{BP 2-18. Document Safety Conditions}

According to the MetroPlan Orlando Pedestrian Safety Action Plan, arterial roads tend to exhibit attributes that contribute most to pedestrian exposure, crash risk, and fatality risk. These roads tend to host centers of commerce, low-wage jobs, transit stops, and low-income housing which are all factors that generate pedestrian activity. The following map displays pedestrian crashes as they relate to various land uses and transit routes.

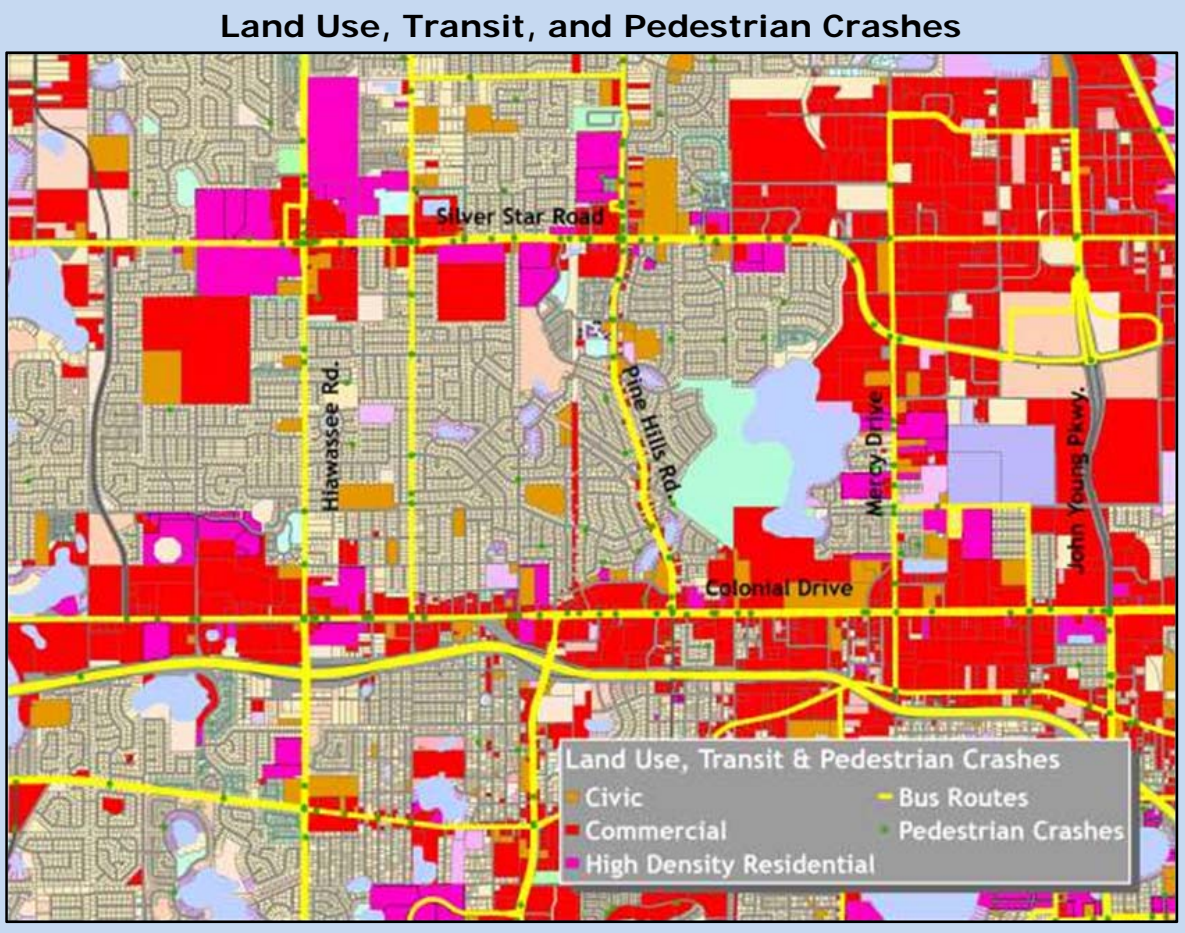

Source: MetroPlan Orlando Pedestrian Safety Action Plan (44)

Transportation elements should include information documenting crash locations, any contributing factors, and possible countermeasures. Goals, objectives and policies can then be established to increase safety with regard to those issues. Guidance for planning efforts is available in the following report:

- Florida Strategic Highway Safety Plan www.dot.state.fl.us/safety/SHSP2012/StrategicHwySafetyPlan.pdf

- NCHRP Report 546 - Incorporating Safety into Long-Range Transportation Planning

Crash data sources are noted in ITR 2-4 and ITR 2-7. Safety audit studies are another important source of information. Guidance is also available on various websites including:

- Federal Highway Administration (FHWA) Safety program - safety.fhwa.dot.gov/

- Florida Department of Transportation State Safety Office website www.dot.state.fl.us/safety/

An important consideration with regard to Florida's growing aging population is the safety and mobility needs of aging road users. The ability of aging adults to participate in community life depends on the available transportation options. FDOT has established the following program to provide guidance in this area. 
- Florida Department of Transportation Safe Mobility for Life Program www.dot.state.fl.us/trafficoperations/operations/safetyisgolden.shtm.

\section{ITR 2-7. Crash Mapping}

Signal Four Analytics is an interactive web-based crash mapping and analysis program that was developed by the GeoPlan Center at the University of Florida. Upon completion of its pilot applications, Signal Four Analytics is expected to supply users with real time crash and street data that is paired with interactive analysis and visualization tools (45). When this system is fully functional it will prove to be an excellent resource for tracking, mapping, and analyzing crashes across the state. More information about Signal Four Analytics can be found at - s4.geoplan.ufl.edu/

The following resources are useful for further crash analysis and mapping:

- Florida Department of Safety and Motor Vehicles - www.flhsmv.gov/html/safety.html

o Provides individual crash reports and county crash and fatality rates

- Local Police Departments

o Provides high crash locations

\section{Evaluate system needs with regard to hurricane evacuation routes, as well as planned projects and infrastructure vulnerability to storm surge.}

Hurricane evacuation routes and roadway vulnerability to flooding and storm surge may be found in the coastal management element and/or the applicable Regional Evacuation Study. In addition, a preliminary assessment of transportation infrastructure vulnerable to sea level rise may be determined using the Florida Sea Level Scenario Sketch Planning Tool, which includes a Map Viewer, GIS data layers, and a Sea Level Change Inundation Surface Calculator (see BP 2-19). Local governments should consult the coastal management element, applicable plans, and resources for:

- evacuation times and critical transportation projects needed to improve those times,

- information that promotes disaster readiness in terms of the transportation system's ability to be inventoried after a disaster event and function as part of the recovery effort, and

- the purpose of evaluating land use decisions in terms of evacuation clearance times and functional ability of the transportation network to achieve projected clearance times.

Local governments should consider the need for making future land use changes and upgrading transportation facilities for improved hurricane evacuation times and hazard resiliency. 


\section{BP 2-19. Consider Vulnerability to Hazards in I nfrastructure I nvestments}

As an FHWA Adaptation Pilot Project, Hillsborough County developed a series of disaster scenarios based on different sea level rise projections in combination with different categories of hurricane to determine vulnerable areas and infrastructure. The map below depicts a "high" sea level rise scenario during Category 1 and Category 3 hurricanes. Roadways and other infrastructure within the areas in blue are considered vulnerable to the sea level rise and storm surge during these conditions.

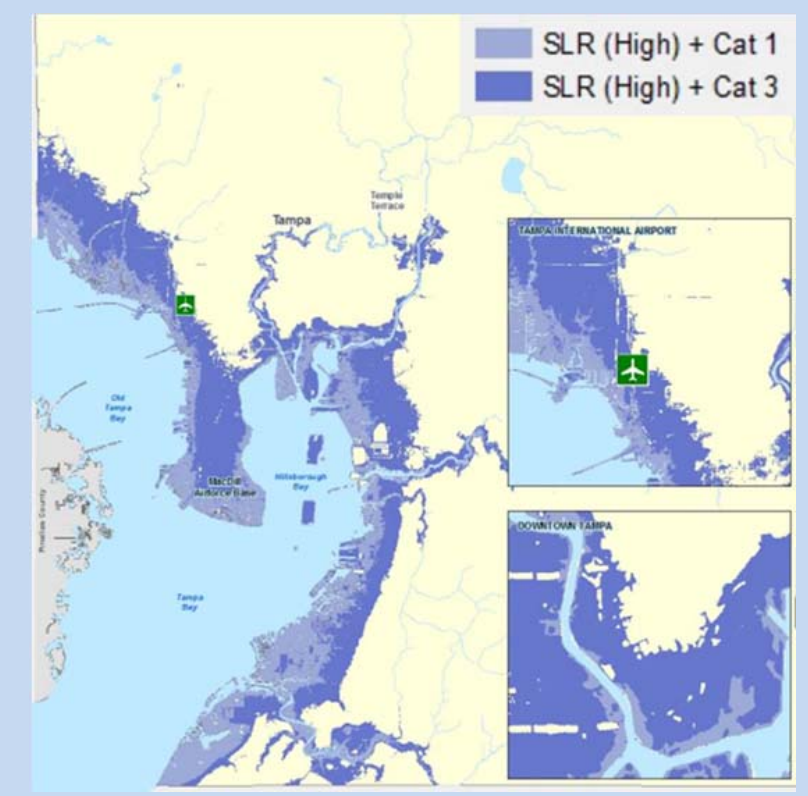

Source: Hillsborough Transportation Vulnerability Assessment (46)

\section{Bicycle and Pedestrian Conditions}

Florida's Community Planning Act requires all communities to plan for bicycle and pedestrian travel. The ability of bicycle riders and pedestrians to safely and conveniently travel to desired destinations for daily needs, such as work and shopping, is an important component of a multimodal transportation system. In addition to active transportation, bicycle and pedestrian systems support recreation and offer increased opportunities for exercise - a critical issue given today's obesity epidemic.

Many areas have bicycle and pedestrian plans and safety action plans that contain extensive information on existing conditions and future needs and plans. For example, local and regional bicycle and/or pedestrian master plans may have been completed that can provide information for the transportation element on existing conditions, needs, and planned projects, including sidewalks, bicycle facilities, and multi-use trails. Appendix B identifies many of the bicycle and/or pedestrian plans and safety action plans that have been produced in Florida. ITR 2-8 identifies other plans and resources that can inform the analysis. 
ITR 2-8. I dentification of Existing Bicycle and Pedestrian Conditions

- Bicycle and/or pedestrian master plans - see Appendix B

- MPO long-range transportation plan - www.mpoac.org

- Transportation disadvantaged service plan, transit development plan- access to transit

- Bicycle and/or pedestrian safety action plans

- Bicycle and Pedestrian Information Center www.pedbikeinfo.org/

- Adventure Cycling Association - www.adventurecycling.org/routes-and-maps/us-bicycle-routesystem/

- FDOT criteria for selecting routes for the U.S. Bicycle Route System is in Chapter 8 of the Plans and Preparations Manual - www.dot.state.fl.us/rddesign/ppmmanual/2012PPM.shtm

- FDOT Bicycle and Pedestrian Partnership Council website www.dot.state.fl.us/planning/policy/bikeped/

Using these resources, document the existence and conditions of bicycle and pedestrian facilities and analyze the current and potential use of the facilities. An inventory of existing bicycle infrastructure will include bicycle parking, transit stops that accommodate bicycle use, street lighting, bicycle-related signs, bicycle facilities on roadways (bike lanes), and multi-use trails. In addition to sidewalks, pedestrian infrastructure includes street lighting, pedestrian-related signs, pedestrian signalization, and crosswalks. Suggested data to document or map and evaluate for the existing conditions analysis is noted below.

Practice Notes: Surveys are helpful in identifying existing bicycle and pedestrian conditions. They provide answers to questions regarding activity use, demographic data, and barriers that impede bicycling and walking (47). Section 2.3 includes information on system analysis techniques for bicycle and pedestrian needs.

1. Document locations and characteristics of bicycle and pedestrian ways and facilities, such as:

a. lane miles of arterials and collectors along with the lane miles (or linear feet) of sidewalk on both sides and only one side of these streets;

b. Iane miles of exclusive pedestrian ways and/ or multi-use trail system (physically separated from roadway network) high use area/ facilities;

c. lane miles of bike lanes on arterials and collectors;

d. lane miles of exclusive bicycle ways and/ or multi-use trail system ( physically separated from roadway network);

e. special facilities, such as bike boulevards (a continuous through street for bicycles, but short distance travel (local access) for motor vehicles);

f. bicycle parking - requirements and types and characteristics of facilities available (see www.ibike.org/ engineering/ parking.htm for further information);

g. bicycle accommodations on public transportation (e.g., bikes on bus); 


\section{h. high use areas/ facilities.}

2. Document and identify deficiencies in the multi-use trail network and those relative to other bicycle and pedestrian facilities, such as:

a. accessibility to major generators and gaps in the bicycle and pedestrian network where bike and pedestrian travel is most likely, such as:

- along arterial or collector streets serving areas of relatively high residential density or commercial intensity;

- areas with a compact, mixed land use pattern (residential and non-residential) within a 1 mile biking distance; and

- areas in proximity to transit routes/ stops, public schools, public parks, and other major demand generators.

The fact base will help a community identify needs such as gaps in the existing network (see BP 2-20), facility needs in bike- or pedestrian-focused areas, or other needs based on the community's vision (see BP 2-21). Section 2.3 provides additional analysis methods for identifying local bicycle and pedestrian needs and deficiencies. When the gaps have been identified, they can be mapped and prioritized for future improvement.

Practice Notes: MPO bicycle and pedestrian plans focus on the regional transportation system and may not address local pedestrian and bicycle needs or projects. Local governments should consider appropriate linkages to regional networks and public transportation stops along their roadways and within areas where pedestrian and bicycle movement is desired over automobile movement.

\section{BP 2-20. I dentify Pedestrian Facility Deficiencies}

The City of Fort Lauderdale Transportation Element includes a map of sidewalk gaps developed by Broward County.

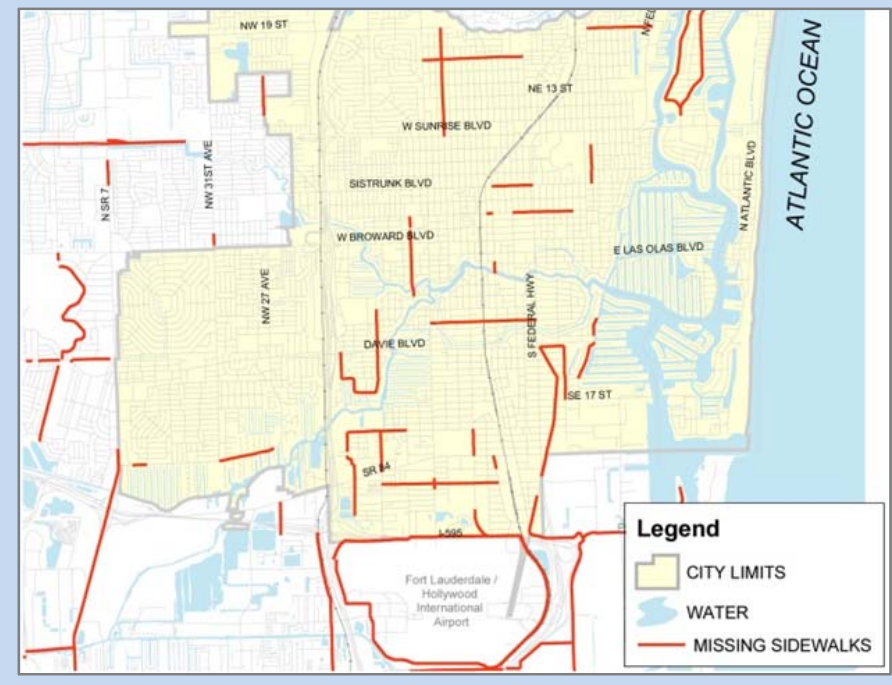

Source: Broward County Comprehensive Plan (48) 


\section{BP 2-21. I dentify and Map the Bicycle and Pedestrian Network}

The Alachua County Transportation Element provides a color map of both existing and planned pedestrian/bicycle facilities within the County's "Urban Cluster" planning area.

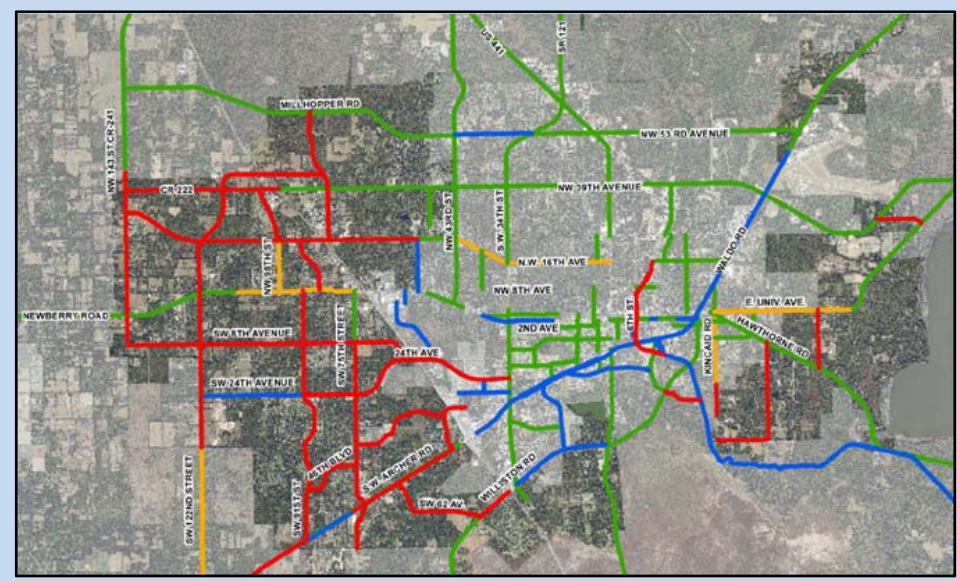

Source: Alachua County Comprehensive Plan (49).

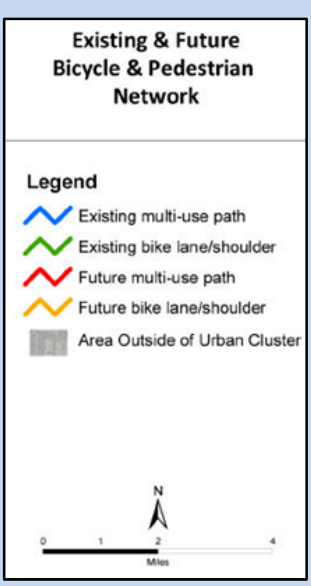

\section{Pedestrian and bicycle safety}

\section{a. I dentify issues related to crosswalks, including mid-block crossing locations (controlled and uncontrolled)}

\section{b. I dentify safety data, including crash indicators, injuries, and fatalities}

The League of American Bicyclists Bicycle Friendly America (BFA) program is a resource tool for private and public entities to use for integrating bicycle needs into the transportation infrastructure. The BFA provides a list of five basic elements of essential bicycle planning: engineering, education, encouragement, enforcement, and evaluation and planning. More information can be found at the BFA website - www.bikeleague.org/bfa.

Another important data source for bicycle and pedestrian planning is crash data that can direct efforts to specific locations in need of attention (see BP 2-22). In some areas, bicycle and pedestrian safety action plans will provide a wealth of information on this topic (See Appendix B). Even in areas without such a plan, it is helpful to consult those that have been prepared for other areas for ideas and information. For example, MetroPlan Orlando, the MPO for the Orlando urbanized area, developed a Pedestrian Safety Action Plan "...to address the clear need to improve both the physical environment for pedestrians and the behaviors necessary to reduce crashes" (44). The plan identifies the most pressing pedestrian crash problems and solutions, sets a course to implement those solutions, and outlines how to monitor progress on the implementation and effectiveness of those efforts (see also BP 2-18).

As noted in the MetroPlan Orlando Pedestrian Safety Action Plan: "The most effective method to improve pedestrian safety is to completely redesign the road environment and adjacent land uses to support and encourage safe walking. Lowering vehicular speeds is the most effective way to reduce pedestrian fatalities. Reducing vehicular speeds involves building setbacks, providing street trees and on-street parking" (44 p. 38). The plan also 
emphasizes the importance of ongoing support for educational and enforcement efforts to improve driver and pedestrian behavior.

\section{BP 2-22. Document Bicycle and Pedestrian Crash Locations}

The City of Largo Multimodal Plan provides maps of bicycle and pedestrian crash densities.

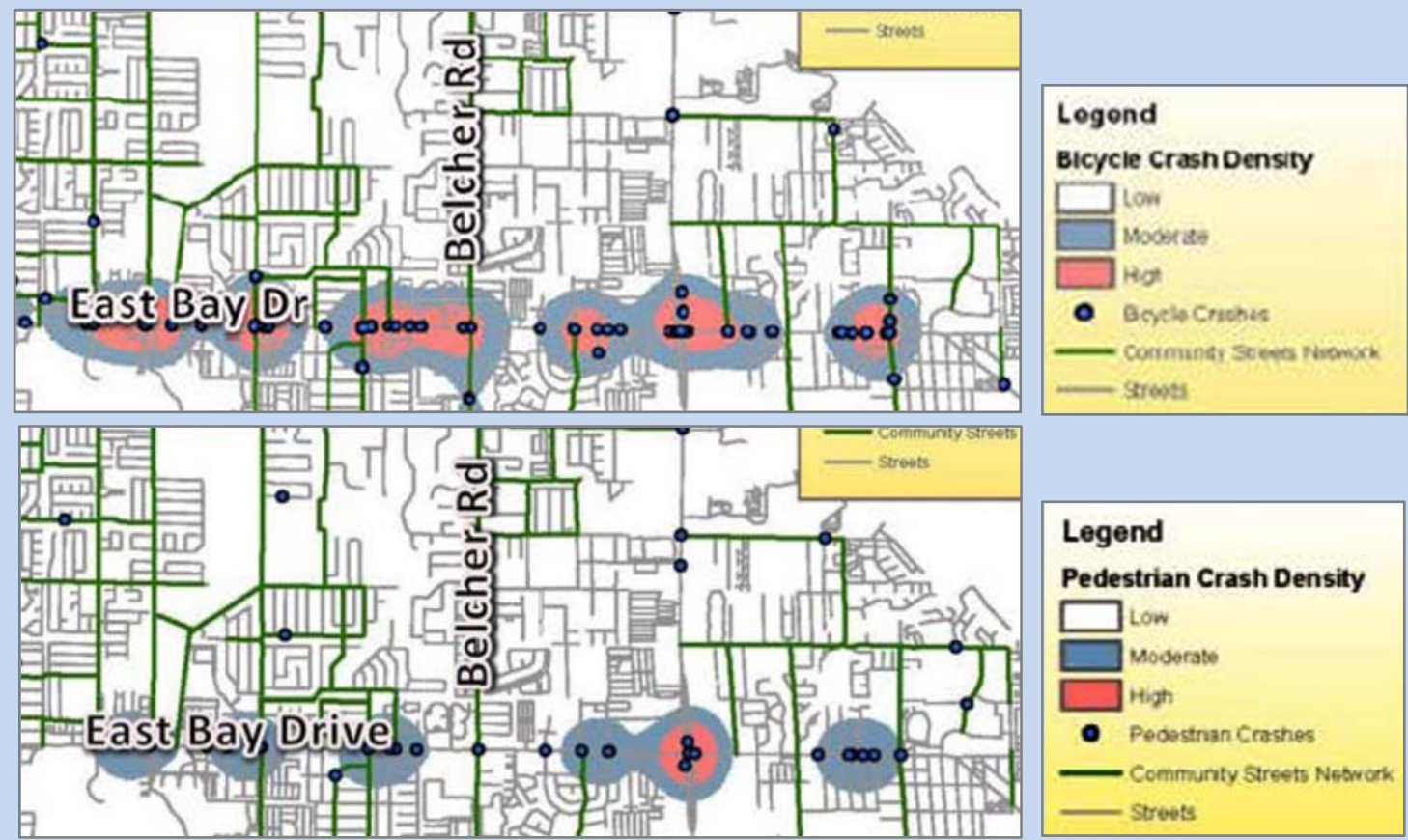

Source: City of Largo Multimodal Plan (50)

MetroPlan Orlando developed a list of priority projects to help convert existing streets into "multimodal corridors". The corridors were mapped, evaluated and ranked based on the number of pedestrian crashes and fatalities, with fatal crashes given extra weighting. Projects include studies for conventional widening projects, intersection improvements, multimodal and context-sensitive improvements, bus rapid transit (BRT) projects, and streetcar projects. Possible multi-modal enhancements include bus bays, transit shelters, wider sidewalks, landscaping, and intersection improvements (44 p. 38).

Ongoing efforts to improve pedestrian safety in the region include filling sidewalk gaps, adding medians, and adding street lighting. Other needs identified by the plan include the need to provide more frequent, safe crossings between signalized intersections. Funding for these projects is anticipated through the continuous, comprehensive, and cooperative (the 3 $C^{\prime}$ s) transportation planning process of MetroPlan Orlando, FDOT, and local governments (44 p. 38).

\section{Ports, Aviation, Rail, and Related Conditions}

Transportation elements for local governments with a population greater than 50,000 must address ports, aviation, and related facilities. Details regarding the transportation system that supports freight mobility, including regional goods movement corridors, local truck routes, and hot spots (locations with high crash rates or difficulty in truck maneuvering), 
should be identified and provided in the transportation element along with intermodal connections including ports, airports, rail, and trucking. Information sources for this effort are noted in ITR 2-9.

Practice Notes: Chapter 163, Part II, F.S., requires local governments to address ports, aviation, and related facilities as follows:

- Identify aviation and seaport facilities and access to those facilities. Identify all airports, projected airport and aviation development, and land use compatibility around airports.

- Cities larger than 50,000 population and counties larger than 75,000 population should also coordinate plans for port, aviation, and related facilities with the general circulation and transportation element.

- Include applicable airport master plan (optional).

\section{I dentify and map the waterway network, existing ports, and port facilities.}

2. I dentify roadway facilities providing access, rail corridors, transit services, intermodal terminals, and related circulation needs for people and freight.

3. I dentify and map existing airports, related facilities, and areas subject to land use compatibility requirements around airports. I dentify noise contours and runway protection zones.

The movement of goods largely occurs on the state and regional transportation network and related information is available in modal plans that address freight. ITR 2-9 includes some freight-specific plans and resources in Florida to consult in the analysis. The Florida Freight Mobility and Trade Plan and other regional goods movement studies guide statewide policies and investments for the movement of goods. County Freight and Logistics Overviews provide county-specific freight infrastructure maps and statistics on industry and employment, imports and exports, trade partners, and SIS infrastructure (spaceports, airports, seaports, rail). A map illustrates the freight infrastructure within each county.

Goods movement information in MPO LRTPs often comes from various regional freight studies and plans throughout the state with information available at the following websites and webpages:

- MetroPlan Orlando Freight Webpage - metroplanorlando.com/modes/freight/

- North Florida Transportation Planning Organization (TPO) Freight \& Passenger Mobility Webpage www.northfloridatpo.com/transportationplanning/freight passenger mobility/

- Southeast Florida Transportation Council (SEFTC) Regional Freight Plan seftc.org/pages/regional-information\# regional-freight-information

- Tampa Bay Regional Goods Movement Website - tampabayfreight.com 


\section{ITR 2-9. Rail, Ports, Airports, and Freight Planning I nformation Sources}

- FDOT Strategic Intermodal System Plan/Maps and adopted Five-Year Work Program www.dot.state.fl.us/planning/systems/programs/mspi/pdf/1st\%205\%202013.pdf

- MPO long-range transportation plan - www.mpoac.org

- Regional transportation authority plans

- FDOT Freight Mobility and Trade Plan - www.freightmovesflorida.com/freight-mobility-and-tradeplan/freight-mobility-and-trade-plan-overview

- Regional goods movement studies - www.mpoac.org/freightpage/index.shtml

- County Freight and Logistics Overviews. www.freightmovesflorida.com/resources-freightinfrastructure/freight-county-infrastructure

- Florida Seaport System Plan - www.dot.state.fl.us/seaport/ (Publications)

- Florida Department of Transportation. Intermodal System Handbook www.dot.state.fl.us/planning/systems/documents/brochures/default.shtm\#brochures

- Port master plans - www.flaports.org/

- Airport master Ppans - airport-authority.com/browse-US-FL

- NCFRP 23: Synthesis of Freight Research in Urban Planning

- NCFRP 24: Smart Growth and Urban Goods Movement

- NCFRP 14: Guidebook for Understanding Urban Goods Movement

- Volvo Research and Education Foundation Center of Excellence for Sustainable Urban Freight Systems - coe-sufs.org/

- European Commission Best Urban Freight Solutions (BESTUFS) I \& II - www. bestufs.net/

\section{Describe future need for ports and related facilities as detailed in port master plans.}

\section{Describe future need for airports and related facilities as detailed in airport master plans or as identified in the system analysis.}

6. I dentify issues impacting freight movement into and out of the community, including key points of access to rail, ports, airports, and intermodal centers and connections. Note freight hot spots.

Generally, each seaport and airport has a master plan that guides its activities and development and provides much of data and analysis necessary for a transportation element. Consistency of the transportation element with port and airport plans is the focus of objectives and policies in many transportation elements.

According to the Florida Ports Council, fifteen seaports operate in Florida (51). Transportation elements should provide detailed information of any port within the jurisdiction, as well as if the jurisdiction is affected by traffic generated by a port. Such information is readily available from the applicable port master plan. Ports should also be noted in a map of transportation facilities or other map. BP 2-23 is an example of how major truck routes, rail lines, and freight activity centers might be mapped. BP 2-24 illustrates an airport facilities map. BP 2-25 and BP 2-26 are examples of maps, data, and analysis to consider in the local transportation element. 


\section{BP 2-23. Freight Activity Centers}

The red circles in the map below illustrate emerging freight activity centers in Polk County. Note "Emerging Freight Activity Center Number 4" is the CSX Intermodal Logistics Center (ILC) - a major source of truck and rail movement within the county.

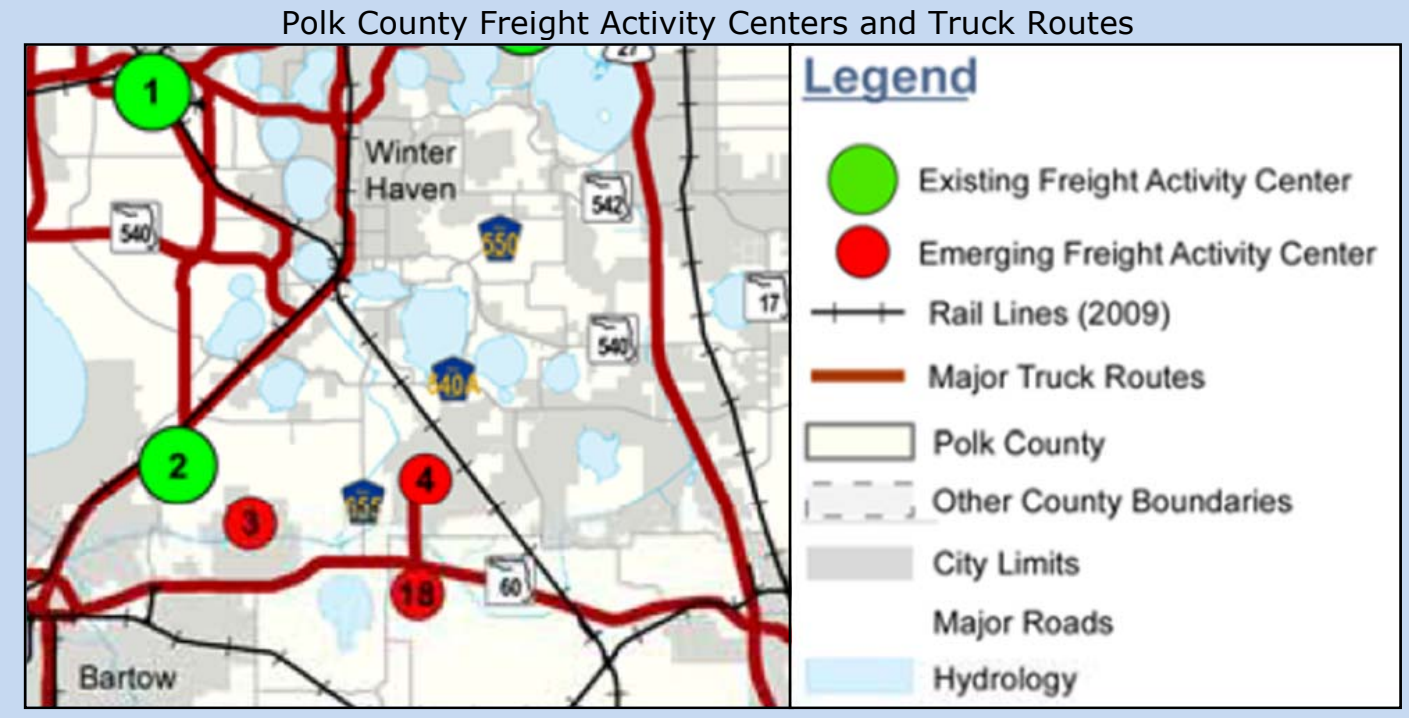

Source: Polk 2035 Mobility Vision Plan (52)

\section{BP 2-24. Airport Facilities Map}

The City of J acksonville Transportation Element includes an airport facilities map that illustrates airports, runways, and aprons (noted with red circles).

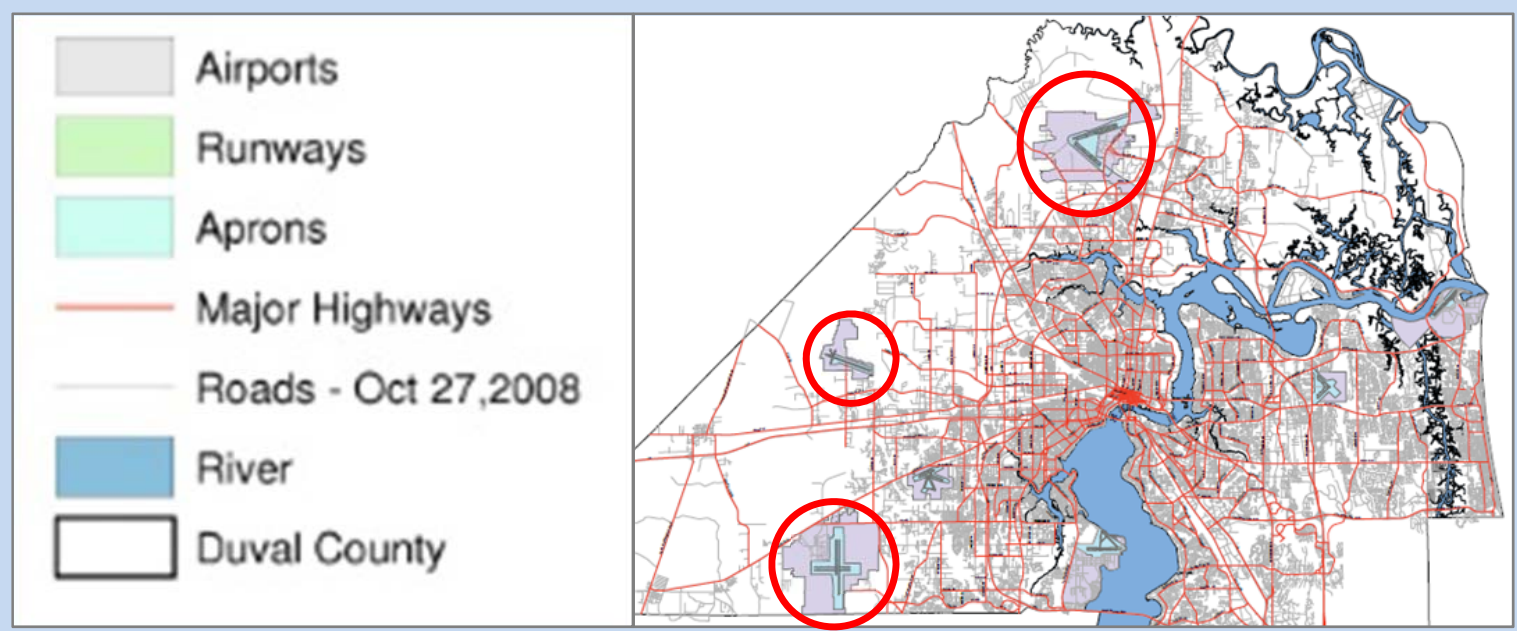

Source: City of J acksonville 2030 Comprehensive Plan (53)

Railroads have not always been addressed in transportation elements likely because they are privately owned and operated. Yet, rail plays an important role in goods movement and an increasing role in the movement of people. Some passenger service on railroads in Florida is currently provided by Amtrak and a proposed new passenger service along the east coast is All Aboard Florida (54). The higher-speed rail service will initially service from 
Miami north to the Space Coast and eventually to the Orlando International Airport. Longer term plans extend service north to Jacksonville and possibly further west to Tampa. Details of the service are available on the All Aboard Florida website - www.allaboardflorida.com.

\section{BP 2-25. I dentify Existing Rail, Ports, Airports, and Related Facilities}

Hillsborough County: The Transportation Element of the Hillsborough County Comprehensive Plan draws upon information and future trends obtained from existing master seaport plans or Port Authority staff. An inventory and analysis of the seaport facilities located in the County along with a general description of each facility, the number of jobs, the amount of cargo, surrounding land use, heavy truck and rail trips, and the primary corridors used to access the facility.

The supporting data and analysis addresses each of the Port of Tampa's four industrial districts along with a description of the materials and products associated with the district including any known plans for expansion (10 p. 53). Rail and roadway access to each district is described in detail along with recently completed and planned projects. For example, key roadway corridors that serve the Port of Tampa are listed in the Transportation Element (10).

The Transportation Element also discusses the inland intermodal facilities throughout the County. One example is the East Central Tampa Industrial Area that includes several large industrial operations, major distribution centers, trucking firms, warehouses, and a recycling center (10 p. 57). The major roadway corridors serving this diverse group of industrial uses include "I-4, I-75, Harney Road, 56th Street, 50th Street, and Hillsborough Avenue" (10 p. 58). These roadway corridors are supported by the "CSXT NEVE Spur, which has several rail sidings used for intermodal transfers and shipping of manufactured products" (10 p. 58).

Miami: The City of Miami has one of the largest ports in the state. In its Transportation Element Data Inventory and Analysis report, the City of Miami describes access to the Port of Miami:

o Port is illustrated on a map that identifies "Intermodal Centers and Access to such Facilities" (55 p. 7);

o Identifies existing public transit facilities and routes that serve the port along with specific route details including headways, operating periods, and ridership (55 p. 47);

- Identifies the port as a major trip generator and attractor in the "Retail and Commercial Facilities" category (55 p. 52);

o Identifies the port in a list of existing intermodal facilities (55 p. 55); and

- In a section on projected traffic conditions, it is noted that an "East-West Corridor rapid transit line," is a transit project identified in a community transportation plan as well as the downtown master transportation plan (55 pp. 121, 131). 


\section{BP 2-26. I dentify Access to Airports and Related Data}

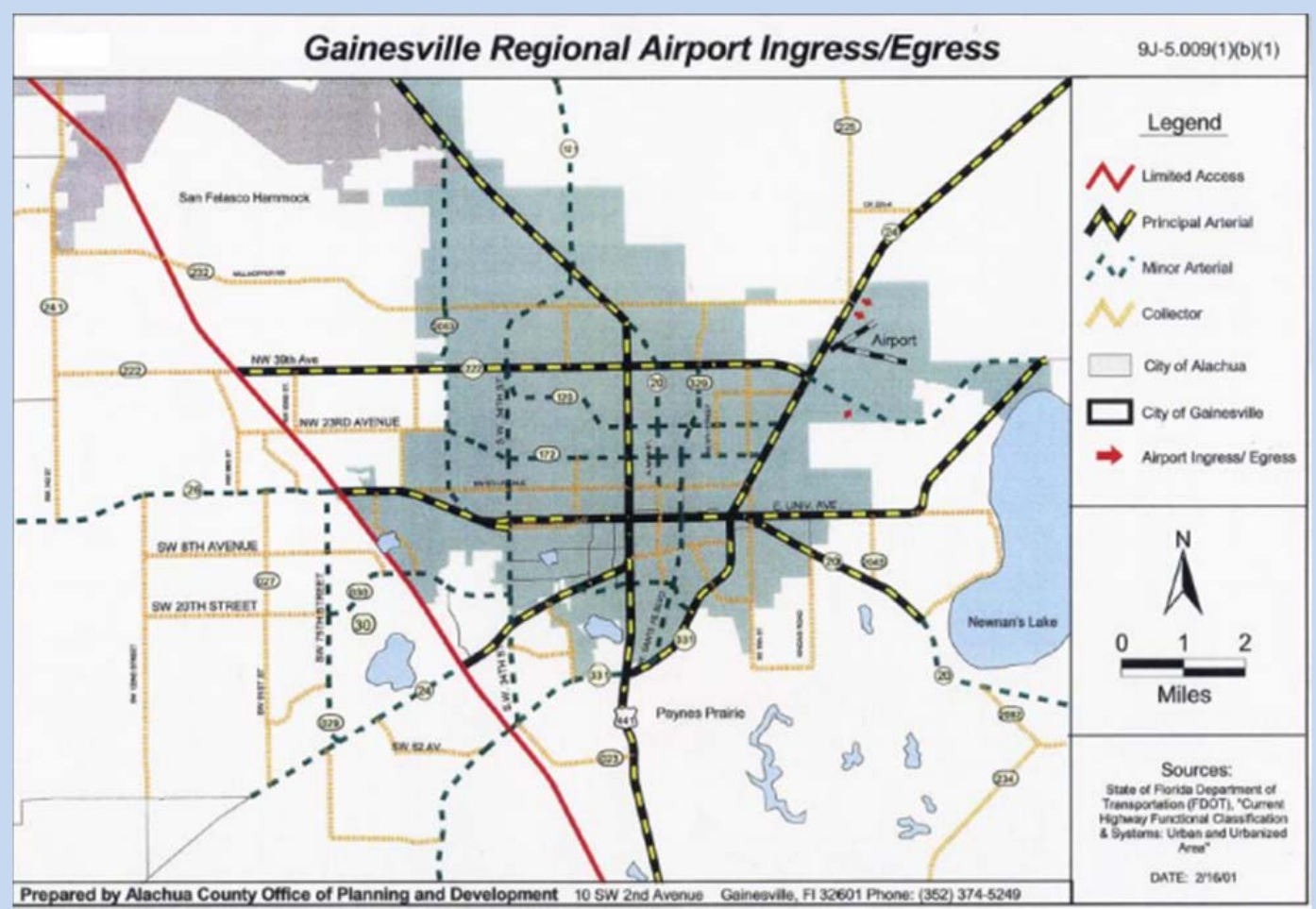

Source: Alachua County Comprehensive Plan: 2011-2030

As an example of transportation element content relative to a small airport within an MPO area, the City of Gainesville Comprehensive Plan Transportation Mobility Element (TME) includes the following data and analysis (56):

- Airports and freight rail lines

- Airport use (i.e., military use, commercial use, and private use)

- Graph of number of airport passengers over nearly 40 years

- Table of total airport freight, mail, and express cargo in tons

- Table of airport deplanements and enplanements

- Table of enplaned passenger demand forecast

- Table of general aviation operations forecast

- Locations of helipads

- Population (including socio-economic factors) served by the airport, natural area surrounding the airport; land use and the City's Airport Hazard Zoning regulations; airport noise impacts; airport clear zones and obstructions; obstructions to local air traffic; traffic circulation

- Maps: airport and rail facilities, airport natural features; airport land use; airport clear zones and obstructions; existing airport traffic circulation

- Table of programmed capital improvements

\section{Identify and document existing conditions information or airport land use compatibility studies relative to compatibility of land uses around airports.}

Land use compatibility around airports must be addressed consistent with Chapter 333, F.S. An overview of general land use compatibility considerations to include in the comprehensive plan is provided in Table 2-4. FDOT's Airport Compatible Land Use Guidebook provides detailed guidance for the consideration of "land development in the 
vicinity of public use airports and military airfields" in light of "federal, state, local government laws, statutes, rules, and regulations" (57 p. v.). The Guidebook includes (57 p. ii.):

- Principles underlying land use compatibility requirements;

- Statutes, regulations, and processes governing land use compatibility;

- Process for reviewing development applications; and

- Strategies to prevent or correct land use incompatibilities.

In addition, the Federal Aviation Administration issued expanded guidance on land uses within the airport runway protection zones (RPZ) in September of 2012. FAA guidance clarifies that transportation facilities such as rail facilities, public roads/highways, and vehicular parking facilities are among land uses considered not compatible with RPZs (see Appendix E). Planning staff should be aware that additional coordination steps are required when building new or expanding existing facilities of this type within the vicinity of the airport.

Table 2-4. Addressing Airports in the Comprehensive Plan

\begin{tabular}{|l|l|l|l|l|}
\hline Technique & Description & Key Value & $\begin{array}{l}\text { Primary } \\
\text { Shortcoming }\end{array}$ & When to Use \\
\hline $\begin{array}{l}\text { Comprehensive } \\
\text { Plan }\end{array}$ & $\begin{array}{l}\text { Long term } \\
\text { techniques } \\
\text { with goals, } \\
\text { objectives, } \\
\text { maps, charts, } \\
\text { and text }\end{array}$ & $\begin{array}{l}\text { Provide for } \\
\text { organized } \\
\text { community } \\
\text { growth and } \\
\text { development } \\
\text { including land } \\
\text { use and } \\
\text { (sometimes) } \\
\text { airport elements }\end{array}$ & $\begin{array}{l}\text { Airports and } \\
\text { communities do } \\
\text { not always plan } \\
\text { growth together, } \\
\text { thus allowing the } \\
\text { encroachment of } \\
\text { incompatible land } \\
\text { uses into airport } \\
\text { environs }\end{array}$ & $\begin{array}{l}\text { Comprehensive plans } \\
\text { must be completed by } \\
\text { local communities and } \\
\text { updated periodically, } \\
\text { and preferably, in } \\
\text { conjunction with the } \\
\text { airport master plan/ } \\
\text { airport layout plan }\end{array}$ \\
\hline
\end{tabular}

Source: ACRP Report 27: Enhancing Airport Land Use Compatibility (58 p. 1.149)

\section{Intermodal Facilities and Conditions}

The traffic circulation component of the transportation element must address "existing and projected intermodal deficiencies and needs." Intermodal transportation has been generally defined as "the shipment of cargo and movement of people involving more than one mode of transportation in a single, seamless journey" (59). Smooth and timely connections between transportation modes are key to an efficient multimodal system. Transportation elements should identify the location and type of intermodal centers within the local government as well as the activities of the center (see BP 2-27, for example).

1. Intermodal facilities to identify in a map or list and describe in the plan include:

a. key connections to ports, airports, rail, and trucking,

b. intermodal logistics centers and roadway connectors,

c. key existing and planned connections between automobile, transit, bicycle, and pedestrian modes (e.g., park-and-ride lots, bus transfer locations/ centers, bike share locations, major bicycle parking areas, pedestrian networks surrounding transit stops, passenger terminal/ stations, etc.),

d. other facilities, such as electric vehicle charging infrastructure. 


\section{BP 2-27. Document I ntermodal Facilities}

The transportation element should include text in the plan that identifies and describes intermodal facilities and connections. For example, the Miami Intermodal Center (MIC) is located across from the Miami International Airport (MIA) and includes a rental car center, a Tri-Rail Station, and the MIA Mover connecting the MIC to MIA. In 2014, an intercity bus terminal, intercity rail terminal, regional commuter rail platform, metro-rail station, metro-bus station will open to complete the MIC (60 p. 7). The main purpose of the MIC is to provide connectivity between all forms of ground transportation and alleviate the congested streets around the airport. Upon completion, the MIC will serve as a safe, efficient, and seamless intermodal center. The MIC is meant to serve all of Miami-Dade County by providing connectivity between MIA, business areas, and activity centers as well as serve as a transfer station for commuters.
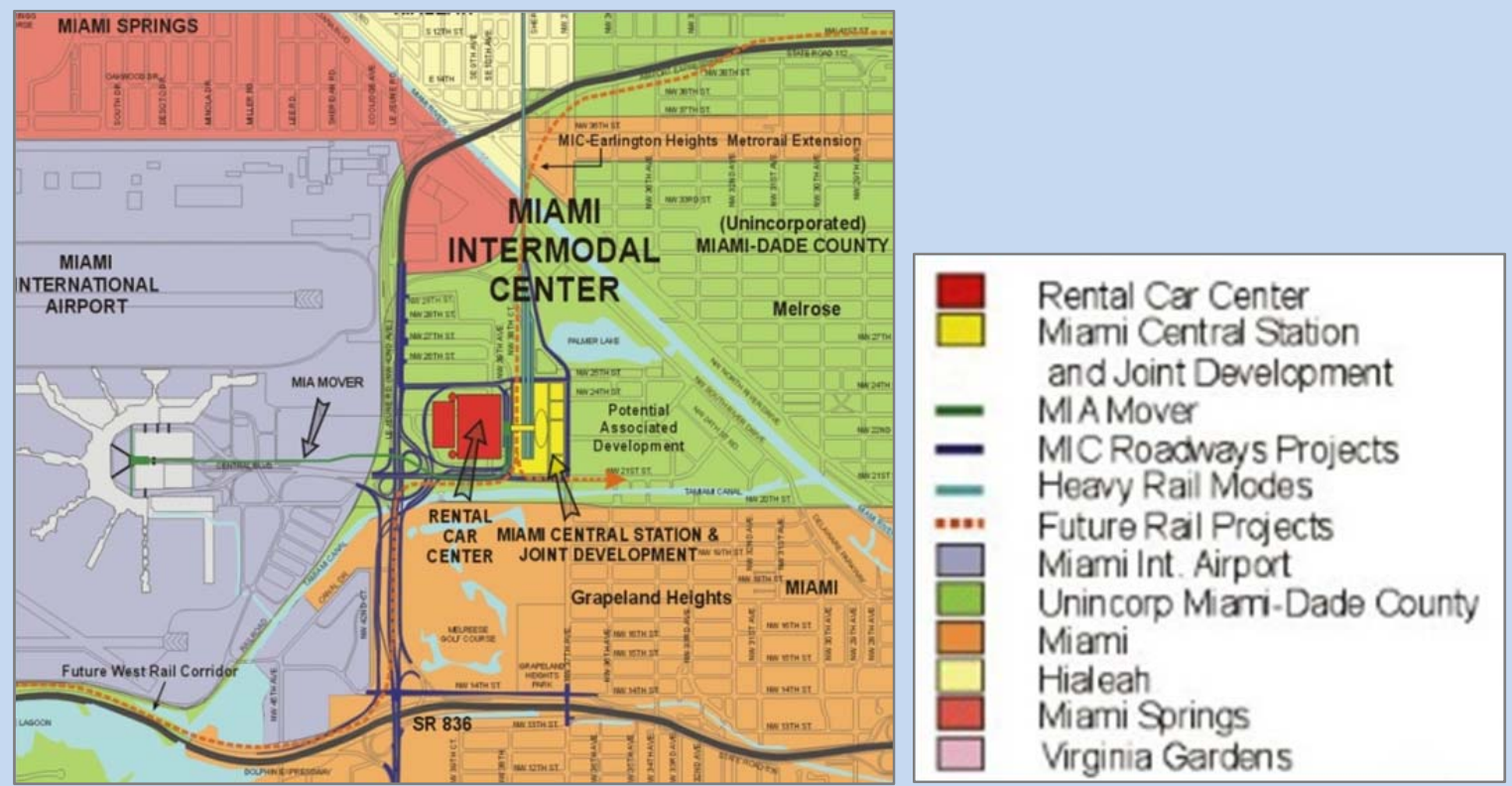

Source: Miami Intermodal Center Project Overview, FDOT (60). 


\subsection{System Analysis and Future Needs}

Transportation system needs include improvements consistent with other plans, to accommodate new growth, increase safety, and/or increase connectivity and mobility. Determining transportation system needs and appropriate multimodal strategies and capital improvement projects is an iterative process. Information and findings obtained in the inventory of modal and agency plans/visions and existing transportation and land use conditions provides a starting point to analyze the transportation system. The analysis must consider the system's relationship to land use, existing and future system performance, and system needs.

The analysis of existing conditions for all modes will reveal opportunities to improve upon the system in light of the local vision and multimodal objectives. Future transportation system demand must also be analyzed in light of anticipated future growth and land use, as identified in the Future Land Use Element. This information will help identify whether demand for transportation system may exceed supply and where modal options and programmatic strategies could be applied to manage that demand and improve mobility. . ITR 2-10 identifies tools and information sources for this effort. A broad range of actions should be considered in addressing future demand such as policies, institutional and operational strategies, pricing, infrastructure projects, special studies, regulations, education and awareness, financing strategies, and a host of collaborative undertakings.

Practice Notes: Chapter 163, Part II, F.S., requires local governments to:

1) Identify projected transportation system levels of service and system needs based upon the future land use map.

2) Identify how the local government will correct existing facility deficiencies and meet the identified needs of the projected transportation system. 


\section{ITR 2-10. System Analysis Tools and Resources}

- Travel demand modeling - Florida Standard Urban Transportation Model Structure (FSUTMS) through FDOT or an MPO

- TBEST - a tool used to forecast transit ridership and accessibility at the individual route and stop level, project changes in transit ridership based on socioeconomic characteristics, test alternative route configurations, and determine the impacts of service changes on stop level ridership and transit performance (61).

- Florida Department of Transportation, 2013 Quality/Level of Service Handbook - provides tools to quantify multimodal transportation service inside the roadway environment (essentially inside the right-of-way) www.dot.state.fl.us/planning/systems/programs/sm/los/pdfs/2013\%20QLOS\%20Handbook.pdf

- Transportation Research Board, Transit Capacity and Quality of Service Manual (TCQSM). www.trb.org/Main/Blurbs/169437.aspx

- Transportation Research Board, 2010 Highway Capacity Manual

- FDOT Transportation Statistics Office and Webpage - www.dot.state.fl.us/planning/statistics

- U.S Census Bureau Longitudinal Employer-Household Dynamics - lehd.ces.census.gov/

- MPO long-range transportation plans - www.mpoac.org

- Commuter assistance program websites

- NCHRP Report 446: A Guidebook for Performance-Based Transportation Planning

- Population projections - University of Florida Bureau of Economic and Business Research (BEBR)

- Sketch planning

- Safety audits

\section{Quality/Level of Service Analysis for all Modes}

Quality/level of service (LOS) analysis is used in planning to determine available capacity based on existing and anticipated travel demand. Communities may obtain information on existing and future roadway level of service from their respective MPO's long-range transportation plan, as well as from FDOT in rural areas (see Chapter 3). Florida legislation no longer mandates transportation concurrency or establishes minimum level of service standards for roadways. Local government comprehensive plans must include roadway level of service standards for capacity planning and prioritizing purposes based on professionally accepted methodologies.

In addition, although no longer required to adopt FDOT established level of service standards for the state highway system, local governments should continue to coordinate with FDOT on level of service for state maintained roadways. In April of 2012, FDOT adopted the following policy regarding LOS standards for the State Highway System (62):

"It is the Department's intent to plan, design and operate the State Highway System at an acceptable level of service for the traveling public. The automobile level of service standards for the State Highway System during peak travel hours are " $D$ " in urbanized areas and "C" outside urbanized areas. See Procedure No. 525-000-00, Level of Service Standards and Highway Capacity analysis for the State Highway System for more information. No specific level of service standards are established for other highway modes (e.g., bus, pedestrian, bicycle). Quality/level of service for these modes is determined on a case by case basis."

\section{Identify and describe future needs on major roadways as detailed in the Florida SIS Plan, MPO LRTPs, and TDPs.}




\section{Forecast future travel demand on local thoroughfares. Determine existing and future transportation system performance (e.g. Q/ LOS, bottlenecks) for the identified thoroughfares and transportation routes.}

Travel demand modeling in Florida is performed using the Florida Standard Urban Transportation Model Structure (FSUTMS) by metropolitan planning organizations and performed by FDOT in areas not covered by MPOs. Larger urban area transportation models may include transit and freight components. As discussed in Section 2.1, some MPOs also perform scenario planning to determine the effect of various land use scenarios on future travel demand, often in coordination with local governments. The results of such scenario planning efforts are important inputs to local government multimodal system analysis (see BP 2-3, for example).

Local governments in urbanized areas may choose to engage in additional evaluation of quality of service across the various transportation modes to further identify system needs in relation to those modes. Figure 2-6 is an example of quality/level of service criteria applied across the various modes of transportation. BP 2-28 is an example map of deficient state and county roadways. Annual documentation of roadway capacity deficiencies based upon adopted level of service standards provides insight into deficient roadways in need of capital improvements and other multimodal strategies (see BP 2-29).

\section{BP 2-28. I dentify Deficiencies on the Major Thoroughfares and Transportation Routes}

Technical documentation in support of the Hillsborough County Comprehensive Plan includes a map identifying deficient roadways in the unincorporated County. Deficient state maintained roads are shown in red and deficient county roads are shown in yellow.

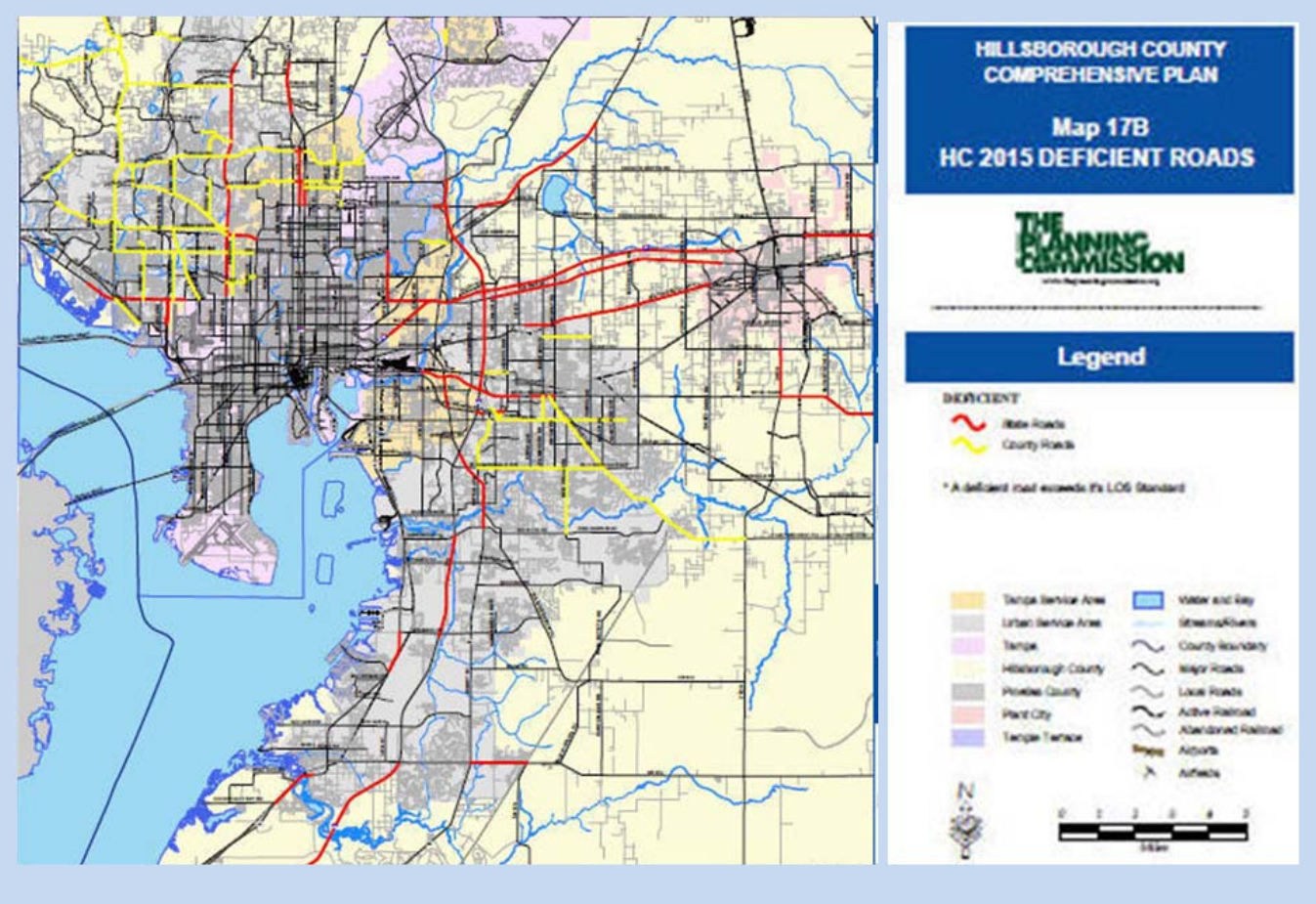

Source: Hillsborough County Comprehensive Plan (63) 


\section{BP 2-29. Orange County's Annual Capacity and Availability Report}

Orange County produces an Annual Capacity and Availability Report as provided in its concurrency management ordinance. The report uses the level of service (LOS) standards set forth in the Orange County Comprehensive Plan. The 2012-2013 report notes the number of roadways and roadway segments that fail to meet the defined LOS and states that these deficiencies will be addressed in the next update to the Capital Improvements Element. This annual report allows Orange County to keep a detailed record of which roads are in need of more attention and can more easily rectify concurrency issues through updates to the Capital Improvements Element of the Comprehensive Plan.

Source: www.orangecountyfl.net/Portals/0/Library/Development-Planning/docs/20122013\%20Annual\%20Capacity\%20Availability\%20Report.pdf

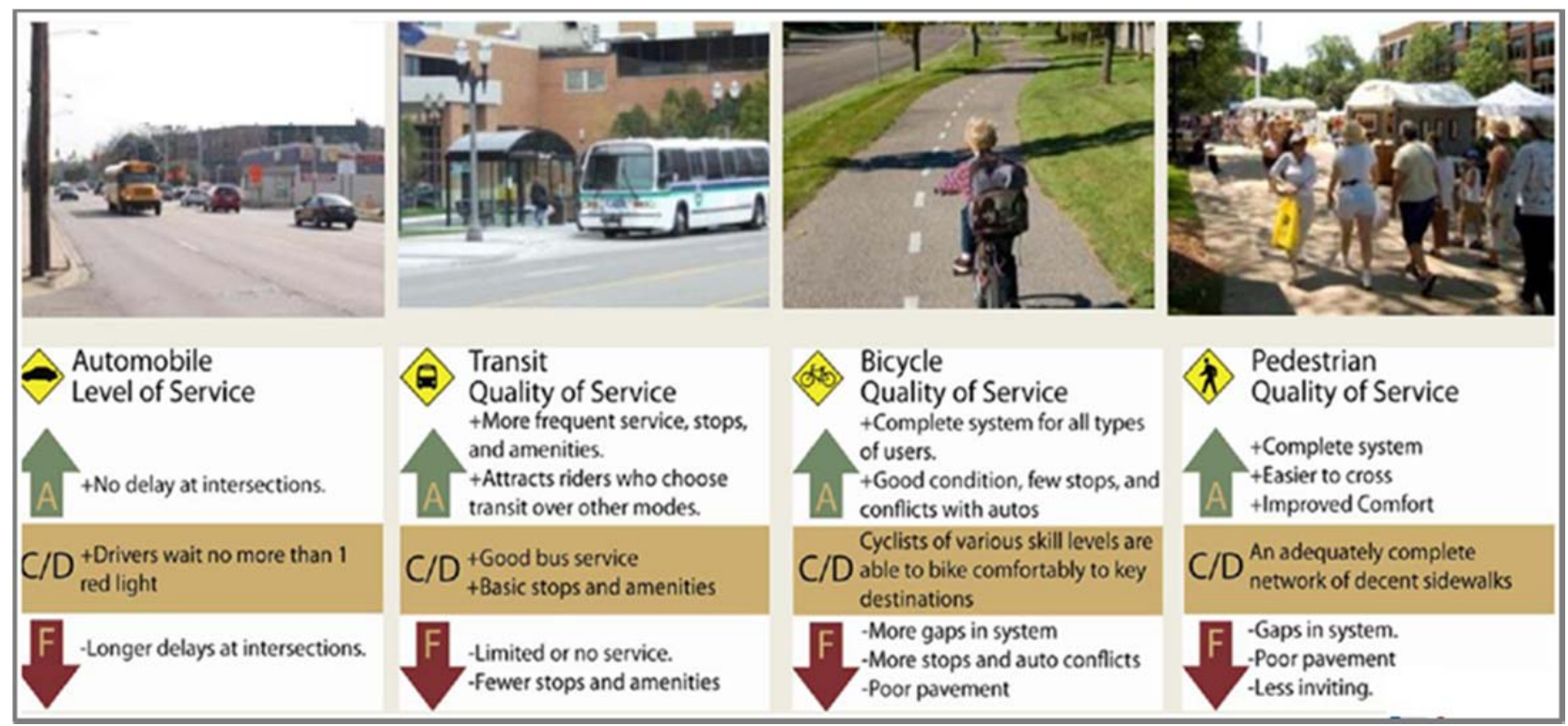

Figure 2-6. Multimodal quality of service illustration

Source: Multimodal Q/LOS Webinar (64)

FDOT's 2013 Quality/Level of Service Handbook and the accompanying software includes techniques from the 2010 Highway Capacity Manual and is designed to provide "a foundation for high quality, consistent capacity and LOS analyses and review in the State of Florida" (65). The 2010 Highway Capacity Manual integrates level of service analysis for four modes (bicycle, pedestrian, transit, automobile), enabling analysis across the modes and allowing adjustments based on policy objectives (66). Procedures for analysis of intersections, midblock pedestrian crossing, shared-use trails, and rural highways are also included. The analysis culminates in four LOS grades (one per mode). Table 2-5 indicates criteria found to be statistically significant by mode in relation to LOS that are used in the analysis. An understanding of these criteria is also useful in establishing simpler analysis methods, as well as in setting performance measures for the future system. 
Table 2-5. Statistically Significant LOS Criteria for Non-Automobile Modes in HCM 2010

\section{Pedestrian LOS}

- Presence and width of sidewalks

- Lateral separation of pedestrians and motorized vehicles

- Presence of barriers and buffers, such as parked cars and trees

- Volume and speed of motorized vehicles
Bicycle LOS

- Proximity of bicyclists to motorized vehicles

- Presence of a paved shoulder or marked bicycle lane

- Volume and speed of motorized vehicles and percentage of trucks

- Pavement condition

- Availability of on-street parking
Transit LOS

- Frequency - headways or transit vehicles per hour

- Speed or travel time

- Reliability or excess wait time

- Stop amenities

- Crowding or perceived travel time adjustments

- Pedestrian LOS Source: Measuring Multimodal Mobility with the Highway Capacity Manual (66).

3. Describe future need for public transportation as detailed in transportation disadvantaged service plans, transit development plans, MPO long-range transportation plans, and regional transportation authority plans, and examine potential alternative strategies to address that need

Information on future public transportation needs will have been documented in the evaluation of existing conditions and review of agency and modal plans discussed in Sections 2.1 and 2.2. These plans will also suggest various land use, housing, capital improvement, and transportation strategies that could be applied to address future needs. Some of these options are detailed in Section 2.5. Others could include climate change adaptation strategies, integration of transportation planning across agencies, integrating mixed income housing with improved access to public transportation, and so on.

4. Estimate additional future local public transportation system needs, such as circulators, additional routes, headways, service hours, etc. Work with transit service providers to use tools such as TBEST to evaluate the effectiveness of transit alternatives and for prioritization purposes.

Transit system demand in Florida is commonly forecasted using the Transportation Boardings Estimation and Simulation Tool (TBEST) to project a 10-year ridership forecast (available at www.tbest.org). TBEST is a tool developed for FDOT that is used to forecast transit ridership and accessibility at the individual route and stop level, project changes in transit ridership based on socioeconomic characteristics, test alternative route configurations, and determine the impacts of service changes on stop-level ridership and transit performance (61). The 10-year ridership forecasted using TBEST along with other applicable analyses is used to develop a series of alternative transit system projects and routes changes designed to meet the projected demand and resolve other system issues.

In addition to forecasting ridership, a local government may also need to perform additional evaluations to address issues unique to the area. For example, the Gainesville Regional Transit System TDP describes the difficulty in planning for future transit service because of drastic ridership fluctuations that occur between times when the University of Florida is in session and when the students are on summer, winter, and spring breaks. To examine this fluctuation, the City of Gainesville and Alachua County performed a transit market assessment. The transit market assessment included a traditional market assessment, a choice market assessment, and a regional market assessment to account for various different types of transit users. 
The traditional market assessment includes potential transit users which include elderly populations, youth populations, low-income populations, and no-vehicle populations. The choice market assessment includes potential transit users that live in more densely populated areas and choose to use transit rather than other modes of transportation for reasons of convenience, time, or cost effectiveness. The regional market assessment includes potential transit users who are interested in accessing various destinations across a region through a connected regional transit system (36 p. 8.3). Through understanding the different potential transit markets, the City of Gainesville and Alachua County were able to define where those populations are located and the type of transit service to which they have access as well as what type of new transit service should be made available in specific areas. BP 2-30 illustrates how transit needs may be documented. 


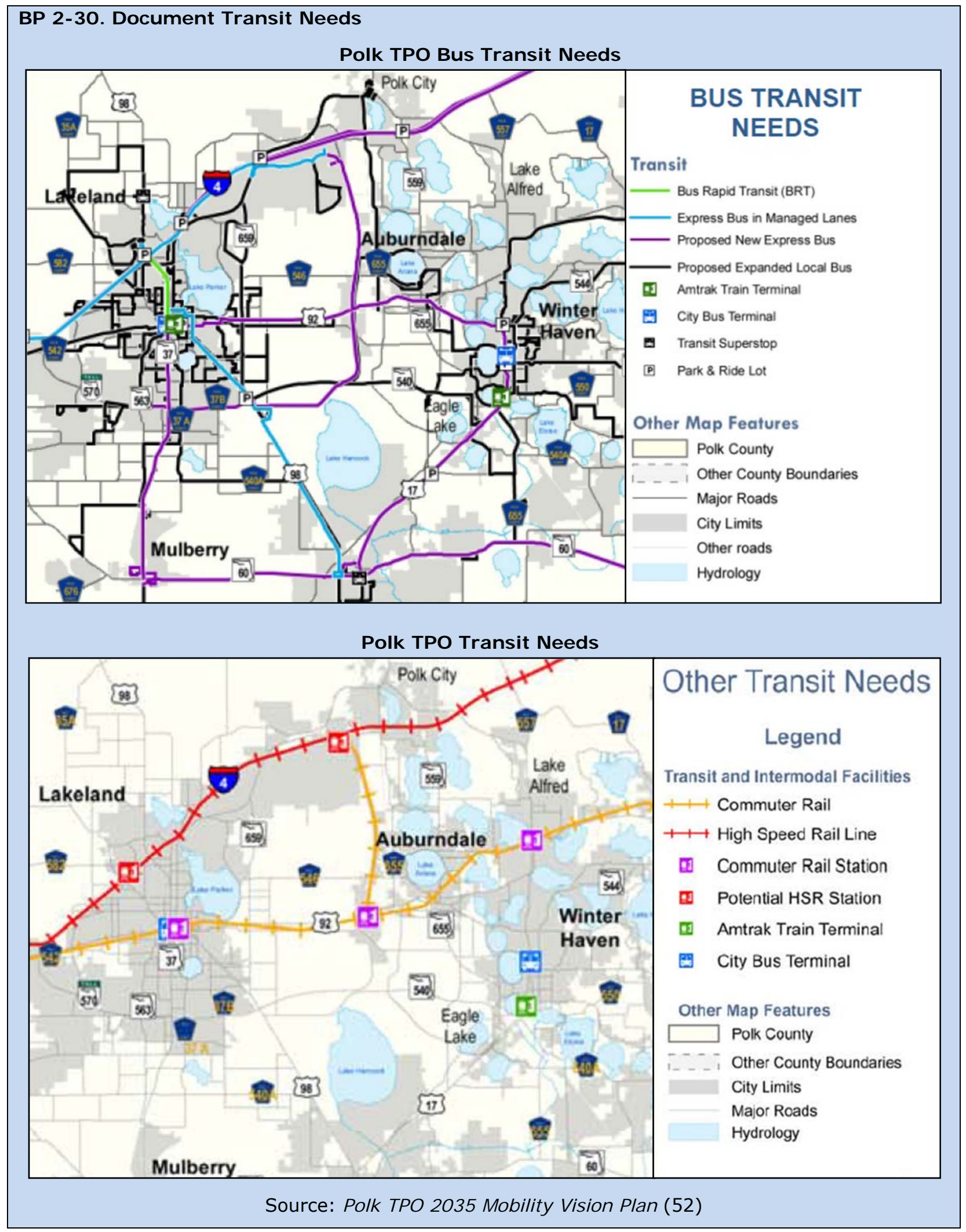




\title{
Sketch Planning Analysis for Network Planning
}

Sketch planning methods can be used in addition to travel forecasting to estimate the spacing and capacity needs for major urban thoroughfares in relation to the future land use plan.

\section{Estimate future transportation system needs for locally identified thoroughfares and transportation routes, including connectivity, continuity, access, spacing, and capacity needs.}

\begin{abstract}
Practice Notes: As stated in the TRB Access Management Manual, 2nd ed., "Many, if not most, 6-lane roadways have resulted from widening of existing roadways because of the absence of an effective supporting circulation system, resulting in the roadway serving a collector function in addition to the arterial function. The conflict between vehicles entering and leaving the roadway consumes the capacity of one (or more) lanes in each direction of travel." (17)
\end{abstract}

Among the easiest sketch planning methods to apply is that suggested by ITE, which allows for adjustments to variables such as trip by private automobile, trip length, service volume (vehicles per hour per lane), and dwelling unit occupancy (67). NCHRP 15-43 adapted this method for use in estimating the spacing and number of lanes that can be accommodated by a given gross population density (17). The resulting curves reveal that holding capacity (persons per square mile) of the thoroughfare network increases as the service volume (vehicles per hour per lane) increases and the percentage of trips on the principal arterial system decreases (see Figure 2-7).

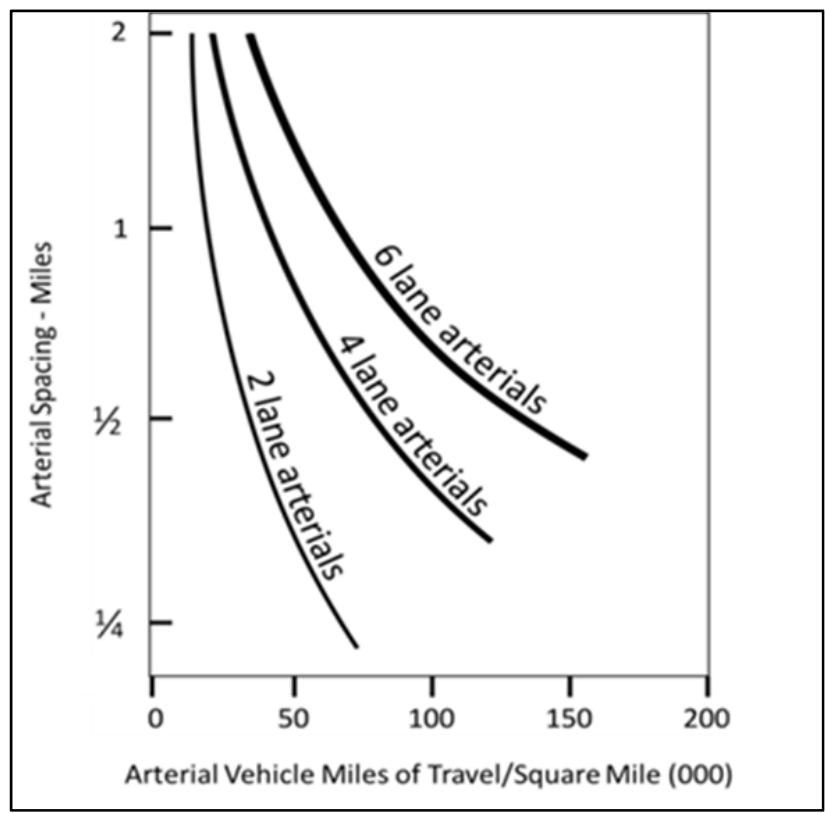

Figure 2-7. Spacing of urban arterial streets based on travel demand Source: NCHRP 15-43, as adapted (17). 
This method demonstrates that "a network of 4-lane principal arterials with a supporting circulation system of minor arterials/major collectors, together with inter-parcel circulation and service roads to support non-residential development, can support a gross population density of 3900 to 6000 or more persons per square-mile." (17). As population density increases, the spatial distribution of land use activities will also change. This will result in different trip generation rates (fewer trips by auto and more by walking and public transit). Auto trip length may also change. Such variations can be considered in selecting values for vehicular trip generation, average trip length, and percentage of trips on principal arterials for the sketch planning analysis.

\section{I dentify needs for other locally identified thoroughfares and transportation routes, including connectivity, continuity, spacing, capacity, and safety needs.}

Building upon the sketch planning and future travel demand analysis, consider whether additional thoroughfares and routes may be needed to support the future land use and multimodal transportation plan. These will primarily include routes that generally function as arterials or collectors. However, it is also important to consider local networks, including local streets and bicycle and pedestrian routes and crossings for a clear picture of the overall circulation network (see BP 2-31). Local street network density and connectivity is a primary determinant of the quality of the multimodal environment. People can walk and bike more easily where streets provide relatively short blocks and multiple connections to shops or services from the surrounding residential areas.

Practice Notes: Identify locations lacking sufficient roadways that function primarily as collector streets. Provide for additional collector routes in these areas. In the absence of adequate and connected supporting networks, the capacity from adding new lanes to major roadways may be counteracted by excessively long signal cycles and delay at major intersections. Long signal cycles at intersections indicate a need for other corrective actions such as grade separations, rerouting left turns, or improving the density and connectivity of the secondary street system to reduce arterial left-turn volumes. 
BP 2-31. Apply Spacing and Connectivity Guidelines to the Transportation Network

ITE offers the following network spacing and connectivity guidelines for different contexts, including local network planning guidelines to improve walkability:

- The basic form of the major thoroughfare system is shaped by the spacing and alignment of arterial thoroughfares. The system of arterials should be continuous and networked in a general rectilinear form. In lower density suburban and general urban areas, arterial spacing may need to be one-half mile or less. In denser urban centers and core areas, arterials may need to be spaced at one-quarter mile or less.

- In more conventional suburban areas that intend to remain so, arterial spacing of up to one mile may suffice if facilities of up to six lanes are acceptable to the community. The arterial thoroughfares should be supplemented by thoroughfares spaced at most one-quarter-mile apart. Such areas typically are interspersed with areas of mixed-use and walkable activity, such as commercial districts and activity centers. These centers require more frequent and connected networks of local streets.

- Closer spacing of thoroughfares (one-eighth mile for collectors) may be needed depending on pedestrian activity levels, desired block patterns and continuity. Natural features, preserved lands, or active agriculture may break up the pattern.

- The network should include a system of bicycle facilities with parallel routes generally no more than one-half-mile apart, and with direct connections to major trip generators such as schools, retail districts, and parks. Bicycle facilities may include on-street bike lanes, separated paths, or shared lanes on traffic-calmed streets with low motor vehicle volumes.

- Local streets should be configured in a fine grained, multimodal network internally to the neighborhood, with multiple connections to the system of major thoroughfares. Where streets cannot be fully networked, they should be supplemented by pedestrian and/or bike-pedestrian facilities to provide the desired connectivity.

- Pedestrian facilities should be spaced so block lengths in less dense areas (suburban or general urban) do not exceed $600 \mathrm{ft}$. (preferably 200 to $400 \mathrm{ft}$.) and relatively direct routes are available. In the densest urban areas (urban centers and urban cores), block length should not exceed $400 \mathrm{ft}$. (preferably 200 to $300 \mathrm{ft}$.) to support higher densities and pedestrian activity.

Source: ITE Designing Walkable Urban Thoroughfares (68).

\section{Evaluating Bicycle and Pedestrian Needs}

Many tools are available to help local governments evaluate the quality of the bicycle and pedestrian system and identify deficiencies and possible improvement strategies. ITR 2-11 provides an overview of some of the tools and techniques used for this analysis. Some of the more popular tools are discussed in this section. 


\section{ITR 2-11. Bicycle and Pedestrian Planning Analysis Tools and Resources}

Transportation element policies should include or call for establishing design principles and procedures that support walking and bicycling. Various states including Washington, California, and Florida provide planning and design handbooks that can be applied to bicycle and pedestrian infrastructure. For example, Florida's two handbooks, Florida Pedestrian Planning and Design Handbook (69) and Florida Bicycle Planning and Design Handbook (70), contain a range of information on bicycle- and pedestrian-supportive modifications such as installing bicycle lanes, sidewalks, and street lighting.

In an August 2013 memorandum, the Federal Highway Administration (FHWA) supports "taking a flexible approach to bicycle and pedestrian facility design" noting primary resources provided by the American Association of State Highway and Transportation Officials (AASHTO) (71) -

www.fhwa.dot.gov/environment/bicycle pedestrian/guidance/design guidance/design flexibility.cfm.

Two AASHTO guides provide resources for planning, designing, and operating bicycle and pedestrian facilities:

- "Guide for the Planning, Design, and Operation of Pedestrian Facilities, July 2004, (AASHTO Pedestrian Guide) provides guidelines for the planning, design, operation, and maintenance of pedestrian facilities, including signals and signing. The guide recommends methods for accommodating pedestrians, which vary among roadway and facility types, and addresses the effects of land use planning and site design on pedestrian mobility" (71).

- "Guide for the Development of Bicycle Facilities 2012, Fourth Edition (AASHTO Bike Guide) provides detailed planning and design guidelines on how to accommodate bicycle travel and operation in most riding environments. It covers the planning, design, operation, maintenance, and safety of on-road facilities, shared use paths, and parking facilities. Flexibility is provided through ranges in design values to encourage facilities that are sensitive to local context and incorporate the needs of bicyclists, pedestrians, and motorists" (71).

Other tools and resources include:

- FDOT PLOS model for signalized intersections for pedestrians

- Walk Friendly Assessment Tool - www.walkfriendly.org/WFCAssessmentTool Nov2011.pdf

- Florida Pedestrian and Bicycle Strategic Safety Plan www.alerttodayflorida.com/resources/Florida PBSSP Feb2013.pdf

- Florida's Strategic Highway Safety Plan www.dot.state.fl.us/safety/SHSP2012/StrategicHwySafetyPlan.pdf

- AASHTO Highway Safety Manual - www.highwaysafetymanual.org/

- Gap analysis - mapping, equity analysis, neighborhood access

- Bicycle and pedestrian surveys and audits

- National Bicycle and Pedestrian Documentation Project - bikepeddocumentation.org/

Practice Notes: The National Bicycle and Pedestrian Documentation Project aims to provide a universal method for data collection and modeling of bicycle/pedestrian demand (http://bikepeddocumentation.org/). Spreadsheet data inputs include: two-hour count total, a count date, count time, the type of bicycle/pedestrian path, and climate zone. Data is extrapolated using existing formulas to calculate average week day and weekend total, average weekly volumes, annual totals, monthly volumes, and average monthly and daily figures. 


\section{Walk Friendly Community (WFC) Assessment Tool}

This assessment tool helps communities evaluate existing pedestrian infrastructure and policies using a questionnaire. Detailed questions are divided into eight sections:

community profile, status of walking, planning, education and encouragement, engineering, enforcement, evaluation, and additional questions. The questions cover a range of topics that include population, pedestrian planning and policies; levels of walking; public education of walking programs; design standards; enforcement programs such as enforcing pedestrian yield laws; types of evaluation tools used to assess pedestrian programs; and general questions covering a community's strengths and weaknesses (72).

\section{Walkability Rating System}

Observation and experience have shown that certain characteristics contribute to the pedestrian experience. A walkability rating system is based on key characteristics of the street environment that support "walkability"; the more that are present, the more pleasant and attractive the environment to pedestrian activity. The factors include narrow streets, street trees, less traffic, sidewalks, interconnected streets, on-street parking, lower traffic speeds, a variety of land uses, buildings near the street, and small blocks. The walkability rating system may be applied to evaluate the degree to which these characteristics need to be applied in a given area to achieve walkable streets:

* (one star) - The fewest walkable factors tend to be found in the most suburban places.

** (two stars) - Transportation-only factors can be added to achieve some walkability even in a drivable setting.

*** (three stars) - A moderate number of these factors will create an oasis of walkability even in a drivable setting.

**** (four stars) - When many of these factors are present, a very favorable pedestrian environment has been provided.

$* * * * *$ (five stars) - When all of these factors are present, an ideal pedestrian environment has been provided. Local residents and tourists are drawn to these areas. Land values are at their highest (6 p. 4.35).

\section{Bicycle and Pedestrian Count Tools}

The National Bicycle and Pedestrian Documentation Project website contains instructions, count forms, and volunteer training resources. The tools "provide guidance on the systematic measurement of existing levels of walking and bicycling at specific locations" (73). Counting Bicyclists and Pedestrians to Inform Transportation Planning describes types of technologies available for counting bicyclists and pedestrians and the benefits and challenges associated with different approaches. The brief also explains how bicyclist and pedestrian count data can be used to inform transportation planning and present trends in levels of bicycle and pedestrian activity (74).

\section{Gap Analysis}

Bikeway/sidewalk gap analysis involves mapping gaps to highlight opportunities to improve the connectivity of bicycle and pedestrian networks. Equity gap analysis assesses geographic equity of bicycle or pedestrian facilities with respect to disadvantaged populations. The analysis overlays gaps in the network of interest (pedestrian, bicycle, 
and/or transit) with spatial data on income, race, and age in GIS. Neighborhood access mapping evaluates access to services such as grocery stores, neighborhood retail, schools, and transit stops within a short walk or bicycle ride. It may be based on a network distance/travel time analysis or a simple concentration of services. Walkscore.com provides one way to conduct this analysis.

\section{Sketch Planning}

Sketch planning requires public input from a range of ages, abilities, and geographic areas. Information gathered from this input guides the location of future pedestrian and bicycle facilities. In this method, the distance between origins and destinations is primarily considered in determining bicycling and walking trips. Bicycle route selection favors those that will potentially serve the highest population density and the greatest concentration of destination points. GIS is a useful tool for this approach (75). 


\subsection{Future Multimodal Transportation System}

This section of the model element suggests components and issues to consider when defining a plan for the future transportation system. The future plan will convey the results of the community vision and priorities, the analysis of transportation and land use conditions, and the identification of system needs and deficiencies into a plan. Estimates of future travel demand in relation to planned future land use will inform the planning effort, as will estimates of potential future changes in travel behavior based on land use and the availability of additional transportation modes. Local vision statements and supporting goals and objectives can provide a framework for evaluating alternatives and selecting appropriate projects and strategies for the community, as discussed in BP 2-32 and BP 247. ITR 2-12 identifies some example maps to consider when conveying future plans.

\section{ITR 2-12. Example Maps For the Future Transportation System}

- Future Land Use and Transportation Concept Maps (including relationship of activity centers to public transportation routes)

- Existing and Planned Roadway Functional Classification

- Priority Routes and Facilities by Mode (transit, truck, bicycle, pedestrian and related facilities, such as parking/park-and-ride)

- Thoroughfare Right of Way Needs Identification Map

- Existing and Planned Bicycle and Pedestrian Routes and Facilities (including multiuse trails and facilities)

- Port, Airport and Intermodal Facilities (and relationship to activity centers, key connectors)

- Priority Multimodal Transportation Projects

\section{BP 2-32. Evaluating Plan Alternatives}

Long-range planning goals and objectives provide an excellent framework for evaluation of plan alternatives and help to ensure consistency of the transportation element with the local government's vision for its future. The Hillsborough County, FL Comprehensive Plan, for example, evaluates plan alternatives on their ability to achieve 5 specific goals:

- Enhancing quality of life

- Creating supportive land use patterns

- Minimizing adverse or fostering positive environmental impacts

- Providing for mobility

- Providing cost-effective and efficient investment

Source: Hillsborough County, FL Comprehensive Plan (10 p. 84)

\section{Address Regional Coordination and Consistency}

\section{Elaborate on the extent to which the comprehensive plan integrates transportation needs and priorities identified in plans of other transportation agencies and local governments.}

The transportation element should identify local planning efforts that advance broader regional mobility objectives. Incompatibilities of other agency and modal plans with the vision and priorities of the local government should also be identified and addressed. Methods to address any incompatibilities, such as pursuit of a joint regional planning study 
or intergovernmental agreements, could be noted in the goals, objectives, and policies of the transportation and/or intergovernmental coordination element.

Practice Notes: Effective multimodal transportation planning involves a shift in focus from moving cars to moving people and goods. Investing in both motorized and non-motorized vehicle infrastructure is essential. The point is not to choose one over the other, but to distinguish the appropriate location and contexts for each, thereby enabling travel options.

For the state highway system and major arterials, place lower priority on preventing future congestion through widening and fringe highways (that induce exurban growth) and higher priority on managing the existing system (e.g., managed lanes, access management, intelligent transportation systems).

For urban cores or activity centers, place lower emphasis on relieving congestion (a sign of vitality) and greater emphasis on expanding and reinforcing mode choice, improving walkability, and promoting a diverse and compatible mix of land uses.

\section{Integrate Future Land Use and Transportation}

Chapter 163, Part II, F.S., requires local governments to coordinate the proposed transportation map or map series with the future land use map or map series. This can be achieved by preparing an integrated transportation and land use vision or concept plan that is illustrated in a map. When developing this map series, local governments should consider the Rural-Urban Transect and the characteristics of each Transect Zone as they relate to the community. The Rural-Urban Transect is illustrated in Figure 2-8. BP 2-33 provides an example of a conceptual map series that relates the future land use plan to the transportation system by identifying multimodal nodes, districts, and other place types in relation to key transportation facilities (see also BP 2-34). BP 2-35 identifies the many steps taken in Broward County to improve the multimodal environment and create an improved sense of place.

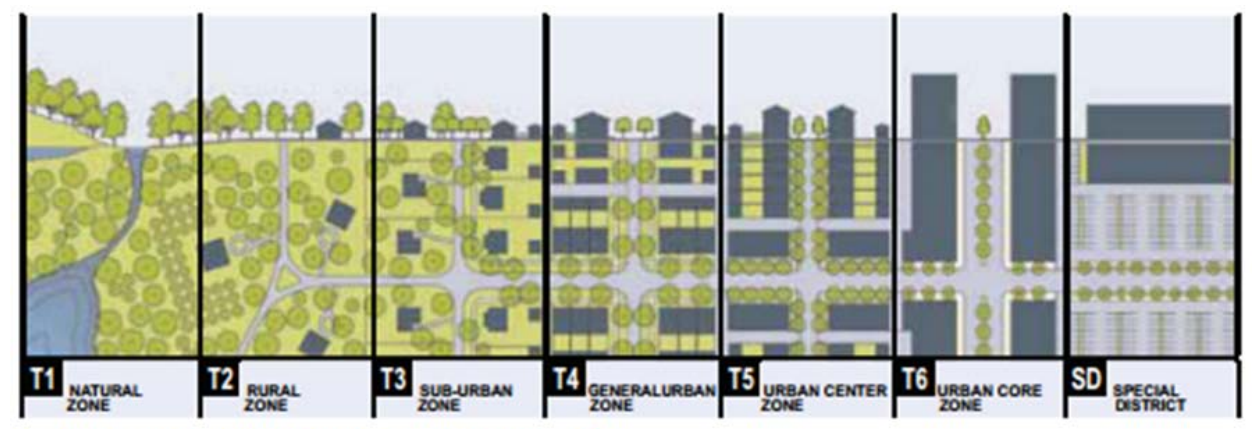

A Typical. Rural-Uraun Transect, with Transect Zones

Figure 2-8. Rural-urban transect

Source: New Urbanism: Best Practices Guide, 4th Ed. (76)

Practice Notes: Begin by identifying which centers in the metropolitan area have the most potential to accommodate non-auto modes and focus investment on 
enhancing walkability and connecting pedestrian, bicycle, and transit facilities within those centers.

\section{BP 2-33. Designate Areas I ntended for Compact Development}

Limitations of the FHWA "urban" and "rural" designations in conventional functional classification led EI Paso, Texas to adopt an additional area type called "Compact Urban" and to rename the urban category as "Driveable Suburban", while retaining the "Rural" designation (6). Developers of the plan note that the Texas Department of Transportation finds these designations helpful in clarifying local intentions and uses them in its roadway classification and design determinations for El Paso, rather than the broader FHWA urban/rural categories (77). The City has also identified a number of subcategories within each area type to identify its various planning areas. As noted in the Transportation Element of the El Paso Comprehensive Plan (6 p. 1.32):

"The Urban/Rural distinction [of conventional functional classification] is essential for designing thoroughfares, yet it suffers from a fundamental oversight. The Census Bureau's "Urban" designation is simply so broad that it encompasses vastly different types of land development - different physical contexts that must be respected when thoroughfares are designed or redesigned."

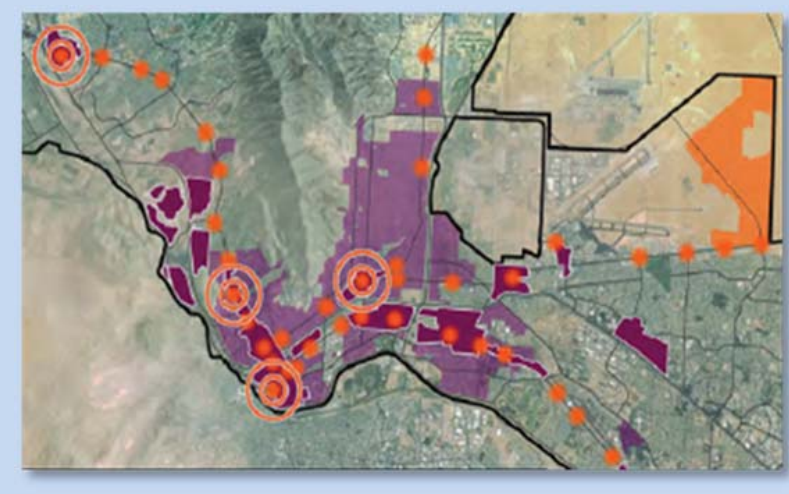

\section{LEGEND}
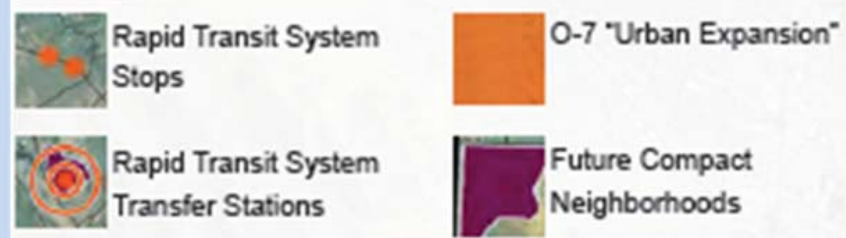

Rapid Transit System Transfer Stations

Future Compact Neighborhoods

G-1 "Downtown" and G-2"Traditional Neighborhood"

Source: City of El Paso, Texas Transportation Element (6)

For integrated transportation and land use, focus on accomplishing the following:

- Activity centers of varying sizes and intensities throughout the community, including a strong central core;

- A diverse and complementary mix of land uses in activity centers that promotes activity during peak and non-peak hours and brings daily activities within walking distance of residences and offers streets and squares that are safe, comfortable, and attractive for the pedestrian;

- An interconnected network of streets and paths within activity centers that connect to surrounding neighborhoods, with traffic calming where appropriate; and

- Increased densities and intensities of land uses within activity centers and within walking distance of transit stops. 
The transportation element should connect major activity centers, such as urban core areas, with thoroughfares and premium public transportation service (e.g., express bus, bus rapid transit, light rail, commuter rail). Transit oriented developments and transit compatible uses (see Table 2-1 for examples) should be located along or in close proximity to public transportation routes.

\section{BP 2-34. Include a Map Series Relating the Transportation and Land Use Elements}

Chapter 163.3177 (b)1, F.S., requires that the transportation element "include a map or map series showing the general location of the existing and proposed transportation system features and shall be coordinated with the future land use map or map series." The Broward County I-95 Corridor Mobility Planning Project includes a series of maps that illustrate transportation and land use relationships with place types identified in relation to the corridors. Land use characteristics are generally mapped and place types identify multimodal districts and nodes, as well as freight districts and centers. The third map identifies aspirational future scenarios that match transit oriented development to key transit corridors. Other place types identified and matched to transit and/or roadway corridors include local and regional activity centers and multimodal corridors and nodes.

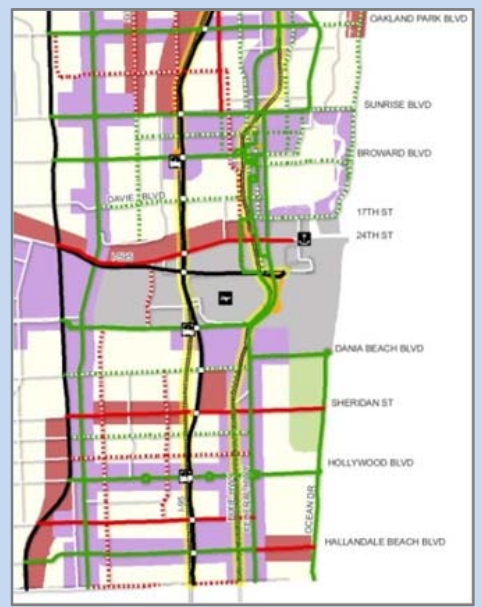

Facility Types and Generalized Future Land Use Vision

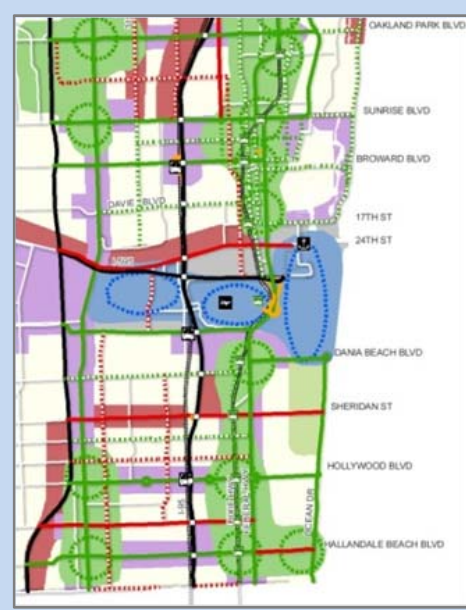

Facility Types and Place Types

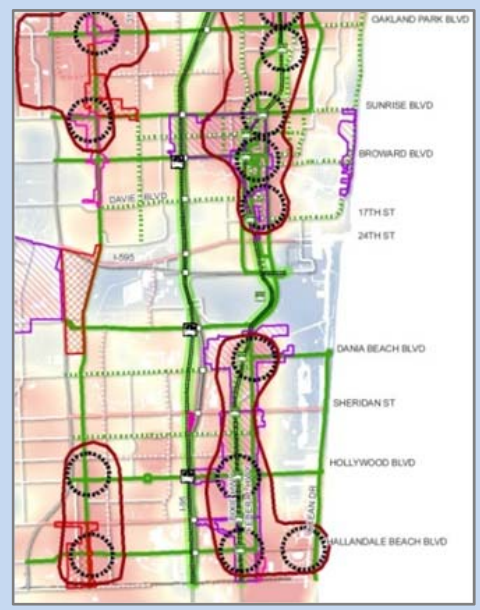

Aspirational Future Scenario

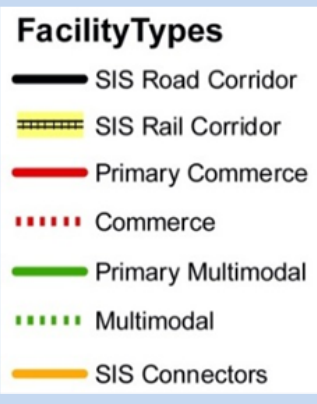

Generalized
Future
Land Use
$\quad$ Residential
Commercial
Industrial
Mixed
Other

㘣 Tri Rail

졍 FEC Rail

Place Types

Multimodal $\quad$ Nodes

Freight/Goods

District

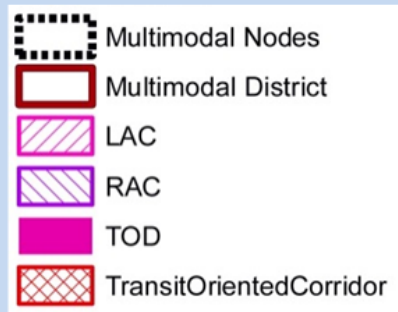

Source: I-95 Corridor Mobility Plan (78)

Local governments should consider the location of major activity centers in relation to major thoroughfares with the primary function of serving long distance, high speed travel (see Figure 2-9). If not properly located, centers can result in hazardous conflicts between local 
circulation and through traffic movement and major roadways can have a barrier effect on pedestrian activity. The element should provide supporting networks for activity centers to maximize internal circulation, support transit service, and minimize traffic conflicts on thoroughfares. Generally, a minimum of two safe pedestrian crossings per mile is recommended.

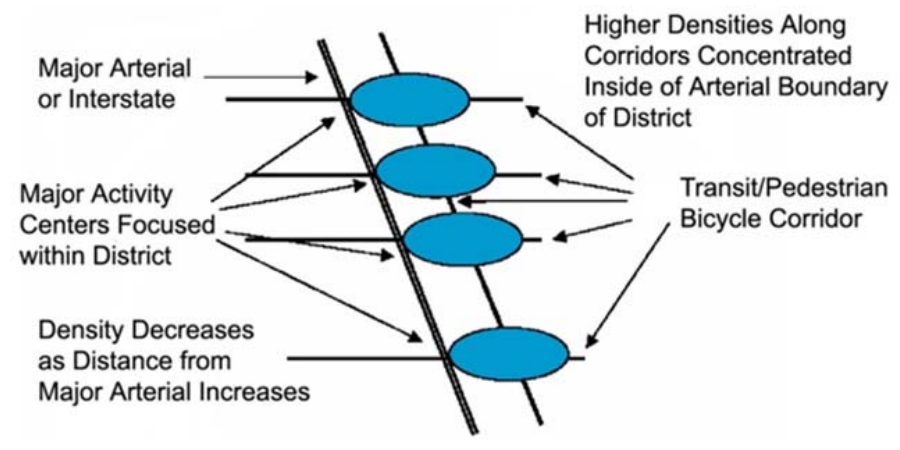

Figure 2-9. Locating activity centers along major arterial corridors

Source: Florida Multimodal Transportation Districts and Multimodal Areawide Quality of Service Handbook (79).

\section{BP 2-35. Broward County's Steps to I mprove the Multimodal Environment}

Broward County has taken a number of steps to prepare for transit oriented land use patterns.

- During the 2004 Evaluation and Appraisal Report (EAR) process, the County developed a Technical Report - Major Issue \#6 - Developing Transit Oriented Land Use Patterns (TOLUPS) that set the course for future growth combining mixed-use development with transit improvements. Based on the Report, the Planning Council adopted changes to the Land Use Plan creating three new mixeduse land use designations: Transit Oriented Corridor (TOC), Transit Oriented Development (TOD), and Mixed Use Residential (MUR).

- The Broward MPO adopted the 2030 LRTP as a tool to guide development of multi-modal transportation and prioritize transportation spending. The LRTP, with its focus on non-automobile modes of transportation, contains a Transit Cost-Feasible Plan that identifies Premium Transit improvements, such as light rail transit, bus rapid transit (BRT), rapid bus, and express bus options.

- The Broward County Commission adopted the Community Design Guidebook providing guidance to improve "sense of place" (a community goal) through transit and pedestrian oriented redevelopment and advances the following principles:

o Making Broward County one of the nation's most visually attractive counties;

o Creating a more pedestrian/transit friendly environment;

o Providing for a mix of uses and housing types; and,

o Enhancing redevelopment and economic opportunity.

The Guidebook identifies standards and patterns to achieve a sense of place through land use patterns, street layouts, streetscapes, wayfinding systems, and pedestrian and transit linkages, along with prevailing development patterns and design of the built environment. Urban design concepts address building design and orientation, density/intensity of development, architectural typology, mobility, and the pedestrian environment. Finally, the Guidebook includes recommendations for comprehensive plan amendments, land development code amendments, and revisions to traffic engineering standards. Demonstration projects allow the County to show how it is accomplishing transit oriented redevelopment.

Source: Broward County Transit Investment Plan (80). 
Mobility plans in Florida have sometimes been developed in support of a mobility fee - a transportation system charge to recoup the proportionate cost of transportation demand generated by all new development. The fee focuses on new development due to its association with transportation concurrency systems and is used to fund planned transportation facilities and services. It is also sensitive to the vehicle miles of travel (VMT) generated by new development, thereby incentivizing development closer to urban centers.

A mobility fee may have both a regional and local tier. The local tier may address localized transportation improvement priorities identified in local mobility plans. Examples include collector roadways, local transit routes or circulators, and bicycle and pedestrian facilities. The regional tier addresses project priorities of countywide or multi-county benefit identified in interlocal agreements. Mobility plans establish transportation improvement priorities for expenditure of the mobility fee. A prioritized schedule of transportation projects is implemented in planned growth areas. Mobility plans aimed at advancing walking, bicycling and transit use through coordinated policies and impact fee systems have been adopted in Jacksonville-Duvall County, Pasco County, Alachua County (see BP 2-36). 


\section{BP 2-36. Apply Multimodal Strategies to I ntegrate Land Use and Transportation}

Jacksonville: The Jacksonville 2030 Mobility Plan established five development areas with separate vision plans focusing on mobility-friendly communities. The City implemented various measures to facilitate the multimodal transportation system and lower overall vehicle miles of travel and emissions. For example, development can earn trip reduction units for net residential density, mix of uses, transit service, pedestrian and bicycle friendliness, affordable and senior housing, and parking supply.
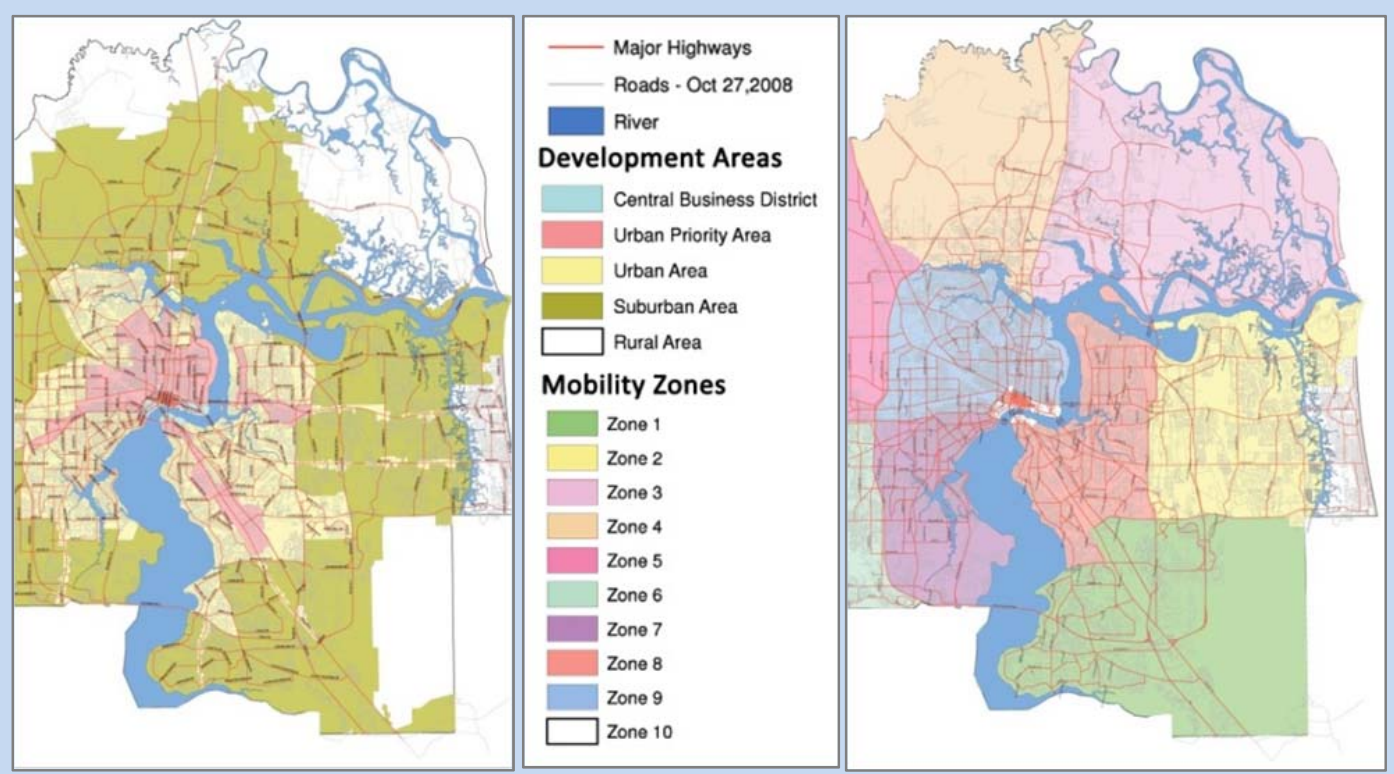

Source: Jacksonville 2030 Mobility Plan (81)

Alachua County: The Alachua County Mobility Plan includes land use strategies to enhance traditional neighborhood development (TND) and introduce transit oriented development (TOD) along BRT corridors. These developments are granted more units per acre and must be mixed use with emphasis on walking, bicycling, and transit use. Multimodal transportation strategies encourage efficient use of the urban cluster. Policies address level of service, roadway parameters, guidance for developing transit, and specific plans for each facility on the Strategic Intermodal System.
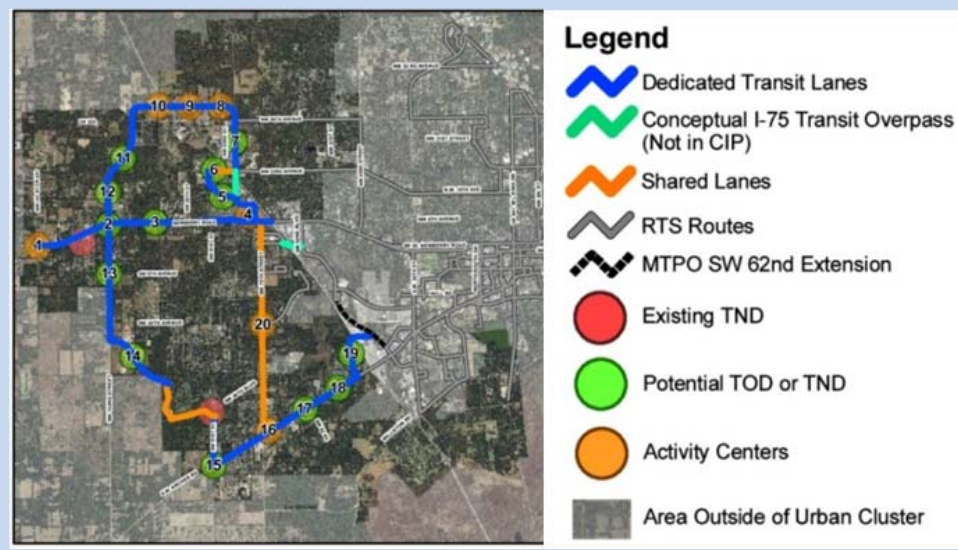

Source: growthmanagement.alachuacounty.us/transportation planning/documents/Ex2 TODPotMapAmended.pdf 


\section{Categorize and Manage Future Corridors}

Many communities in Florida and nationally are adopting or seeking to adopt "complete streets" policies and guidelines in an effort to achieve changes in local and regional practice. The design of a "complete street" will differ depending upon the context in which it is located, as well as the activities that occur on the roadway and within the right-of-way (17). Table 2-6 compares activities accommodated on a principal arterial versus a local street.

Table 2-6. Comparison of Principal Arterial and Local Street

\begin{tabular}{|c|c|}
\hline Principal Arterial & Local Street \\
\hline $\begin{array}{l}\text { - } \text { movement of motor vehicles } \\
\text { - } \text { movement of pedestrians } \\
\text { - } \text { movement of bicyclists } \\
\text { transit, light rail transit) } \\
\text { - } \text { freight movement } \\
\text { utility location (e.g., major water } \\
\text { distribution lines) } \\
\text { - } \text { storm water collection and conveyance } \\
\text { landscaping, street furniture and other } \\
\text { aesthetic enhancements }\end{array}$ & $\begin{array}{ll}\text { - } & \text { direct access to residences } \\
\text { - } & \text { vehicular movement incidental to } \\
\text { - } & \text { reaching a collector street } \\
\text { - } & \text { service and delivery } \\
\text { - } & \text { social interaction } \\
\text { - } & \text { utility location (water, sanitary sewer, gas } \\
\text { and, in some cases, television cable, } \\
\text { - } \\
\text { nelephone and electric) }\end{array}$ \\
\hline
\end{tabular}

The context sensitive solutions (CSS) approach was advanced to help overcome limitations of conventional functional classification for street design. A goal of CSS is to reduce the dominance of roadway capacity in roadway design decisions. The approach strives to maintain an optimal balance between desired roadway operations and roadside context. It uses context zones to orient roadway types and design to specific land use patterns, as proposed in the ITE Recommended Practice Designing Walkable Urban Thoroughfares: A Context Sensitive Approach (82). Emphasis is placed on design details critical to supporting non-auto modes. Some areas use this approach as a basis for local government "formbased" codes that integrate building design and layout with street design.

Basic elements of the approach are as follows (82):

- $\quad$ Seven context zones (Table 2-7) are defined to correspond to Rural-Urban Transect (Figure 2-8) that categorize land use contexts according to character, density of activities and intensity of development, ranging from "natural" to "urban core" or "assigned district"

- Thoroughfares may also be categorized into types using functional class to determine role and using design characteristics tailored to each roadside context that they pass through (see Figure 2-10). The thoroughfare type is governed by design elements and features that fit within a particular context, such as sidewalks, planting strips, medians, bike lanes, on-street parking, and access location.

- The context zone and community vision are matched to desired characteristics for a thoroughfare. This may result in tradeoffs between automobile capacity and multimodal design elements.

The CSS approach is most applicable to the development of a local multimodal transportation element during two key activities: 
1. Identification, description, and mapping of functional classifications for thoroughfares and other major routes.

a. This involves determining the functions, modal emphasis, and operational features of various segments of the roadway network, along with general alignments and spacing considerations, access control, number of lanes/cross-section, and designation of freight and transit corridors, where applicable. The determination of function or typology sets the stage for design of each segment of the network.

2. Development of goals, objectives, and policies.

Table 2-7. Context Zone Descriptions

\begin{tabular}{|c|c|c|}
\hline Context Zone & Distinguishing Characteristics & General Character \\
\hline C-1 Natural & Natural landscape & Natural features \\
\hline C-2 Rural & $\begin{array}{l}\text { Agricultural with scattered } \\
\text { development }\end{array}$ & $\begin{array}{l}\text { Agricultural activity and } \\
\text { natural features }\end{array}$ \\
\hline C-3 Suburban & $\begin{array}{l}\text { Primarily single family } \\
\text { residential with walkable } \\
\text { development pattern and } \\
\text { pedestrian facilities, dominant } \\
\text { landscape character }\end{array}$ & $\begin{array}{l}\text { Detached buildings with } \\
\text { landscaped yards }\end{array}$ \\
\hline C-4 General Urban & $\begin{array}{l}\text { Mix of housing types including } \\
\text { attached units, with a range of } \\
\text { commercial and civic activity } \\
\text { at the neighborhood and } \\
\text { community scale }\end{array}$ & $\begin{array}{l}\text { Predominantly detached } \\
\text { buildings, balance between } \\
\text { landscape and buildings, } \\
\text { presence of pedestrians }\end{array}$ \\
\hline C-5 Urban Center & $\begin{array}{l}\text { Attached housing types such } \\
\text { as townhouses and apartments } \\
\text { mixed with retail, workplace and } \\
\text { civic activities at the community } \\
\text { or sub-regional scale. }\end{array}$ & $\begin{array}{l}\text { Predominantly attached buildings } \\
\text { landscaping within the public } \\
\text { right of way substantial } \\
\text { pedestrian activity }\end{array}$ \\
\hline C-6 Urban Core & $\begin{array}{l}\text { Highest-intensity areas in } \\
\text { sub-region or region, with } \\
\text { high-density residential and } \\
\text { workplace uses, entertainment, } \\
\text { civic and cultural uses }\end{array}$ & $\begin{array}{l}\text { Attached buildings forming } \\
\text { sense of enclosure and } \\
\text { continuous street wall } \\
\text { landscaping within the public } \\
\text { right of way, highest } \\
\text { pedestrian and transit activity }\end{array}$ \\
\hline Districts & \multicolumn{2}{|c|}{$\begin{array}{l}\text { To be designated and described locally, districts are areas that are } \\
\text { single-use or multi-use with low-density development pattern. } \\
\text { These may be large facilities such as airports, business parks } \\
\text { and industrial areas. }\end{array}$} \\
\hline
\end{tabular}

Source: New Urbanism: Best Practices Guide, 4th Ed. (76) 


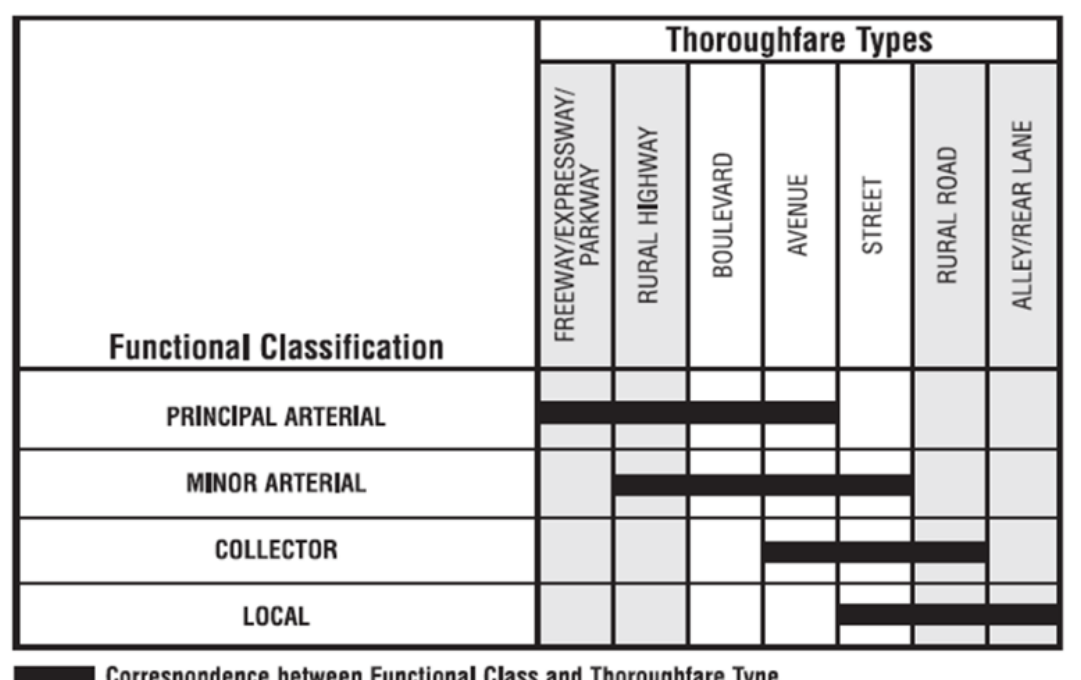

Figure 2-10. ITE context sensitive thoroughfare typologies

Source: Designing Urban Thoroughfares for Walkable Communities (82)

Local governments interested in applying the CSS approach in network planning, should adhere to the following general guidelines (82 p. 31):

- Consider organizing the network according to the context zones, functional classifications and thoroughfare types;

- Ensure that each major thoroughfare is designed to support transit and pedestrian travel, as well as private and commercial vehicles;

- Emphasize design for through movement needs on limited access and principal arterial roadways;

- Plan transit oriented developments (TODs) on transit corridors or take advantage of TODs that are already there (see Table 2-8);

- Plan for right-of-way needs "based on network performance measures that are multimodal and that allow capacity and level-of-service to be considered in conjunction with other measures, both quantitative and qualitative.... [and] be open to the selection of decision criteria that balance community character and capacity enhancement or congestion relief. 
Table 2-8. TOD Place Types

\begin{tabular}{|c|c|c|c|}
\hline TOD PLACE TYPES & $\begin{array}{l}\text { COMMUNITY } \\
\text { CONTEXT }\end{array}$ & $\begin{array}{c}\text { SMARTCODE } \\
\text { TRANSECT ZONE }\end{array}$ & $\begin{array}{c}\text { CSS } \\
\text { CONTEXT ZONES }\end{array}$ \\
\hline Regional Center - Heavy Rail & \multirow{3}{*}{ Urban } & \multirow{3}{*}{$\begin{array}{l}\text { Urban Core (T6) } \\
\text { Urban Center (T5) }\end{array}$} & \multirow{3}{*}{$\begin{array}{l}\text { Urban Core (C6) } \\
\text { Urban Center (C5) }\end{array}$} \\
\hline Regional Center - Light Rail & & & \\
\hline Community Center - Heavy Rail & & & \\
\hline Regional Center - BRT/Bus & \multirow{3}{*}{ Transitional } & \multirow{3}{*}{ Urban General (T4) } & \multirow{3}{*}{ General Urban (C4) } \\
\hline Community Center - Light Rail & & & \\
\hline Neighborhood Center - Heavy Rail & & & \\
\hline Community Center - BRT/Bus & \multirow{3}{*}{ Suburban } & \multirow{3}{*}{ Suburban (T3) } & \multirow{3}{*}{ Suburban (C3) } \\
\hline Neighborhood Center - Light Rail & & & \\
\hline Neighborhood Center - BRT/Bus & & & \\
\hline
\end{tabular}

Source: A Framework for Transit Oriented Development in Florida (12)

1. Define the functional categories or typologies to be used and prepare purpose and function statements describing each category, including modal priorities and access versus through movement characteristics. I dentify desired alternative cross-section types for each roadway category.

Functional classification is a process for categorizing roadways according to their planned function. Commonly used categories are principal and major arterial (including freeways, expressways and other major arterial roadways), minor arterial, major collector, minor collector, local streets, and alleys. The number, details, and character of roadway categories will depend upon the population size, planning objectives, and complexity of the local planning area. Some areas prepare separate thoroughfare plans that are adopted by reference into the comprehensive plan. A suggested approach is to integrate thoroughfare plans directly into the multimodal transportation element. ITR 2-13 includes resources to consult in this effort.

A trend in contemporary thoroughfare planning practice is to define street functions and roles in more detail. The context sensitive solutions (CSS) approach has given rise to a number of new functional "typologies" in recent years. These typologies build upon the rationale of functional classification, while more explicitly considering the pedestrian and providing additional guidance to street design and modal emphasis in varying land use contexts. Best practice is to include purpose and function statements and example crosssections or design types for each roadway classification. Commonly used categories are parkway, boulevard, avenue, street, and alley/lane (see BP 2-38 and BP 2-39).

The roadway functional categories may be supplemented with layers that identify priority modes - for example, a transit priority corridor may have a special designation aimed at reinforcing network design and operational features that relate to the type of transit provided (see BP 2-37). Layered roadway networks have been proposed as appropriate in situations where providing priority to a particular mode can improve safety and efficiency (83 p. 18). Such an approach is particularly applicable in addressing the special needs of pedestrians, bicyclists, transit and trucks on certain roadways and can be addressed as an overlay as discussed in BP 2-37. 


\section{ITR 2-13. Traffic Circulation (Thoroughfare) Planning}

- Functional classification - U.S. DOT Highway Statistics www.fhwa.dot.gov/policyinformation/statistics/2011/; NCHRP Project 15-43 : Second Edition of the TRB Access Management Manual (17); FHWA Urban Boundary and Federal Functional Classification Handbook 2003 (84)

- Network and corridor Planning - ITE Recommended Practice: Designing Walkable Urban Thoroughfares: A Context Sensitive Approach (68) - www.ite.org/css/RP-036A-E.pdf

- Access Management and Network and Corridor Planning. TRB Access Management Manual, 2003 and NCHRP Project 15-43: Second edition of the TRB Access Management Manual (publication pending)

- Street design standards - American Association of State Highway and Transportation Officials (AASHTO) Green Book (85) and its companion resource, commonly known as the Florida Greenbook (86) - www.dot.state.fl.us/rddesign/FloridaGreenbook/FloridaGreenbook.pdf

- Context sensitive solutions - FDOT Traditional Neighborhood Design Handbook (87) and ITE Designing Walkable Urban Thoroughfares: A Context Sensitive Approach (68) www.ite.org/css/RP036A-E.pdf

- $\quad$ Layered networks - ITE Planning Urban Roadway Systems (83)

- Complete streets - National Complete Streets Coalition of Smart Growth America (Coalition), The Best Complete Streets Policies of 2012 (88)

\section{BP 2-37. Establish Modal Priority Routes}

The ITE report Planning Urban Roadway Systems notes: "Well planned roadway systems should offer a variety of modal choices appropriate to the community being served and typically would include pedestrian, bicycle, transit, automobile, and truck on the same roadway network. Each of these subsystems will have its own network that overlays the others and offers the potential user choices and tradeoffs in terms of user cost, travel time, reliability, availability, safety and accessibility" (83 p. 2). The island town of Alameda, California in the San Francisco Bay area uses a "layered network" approach in its transportation plan. The transportation element identifies roadways by classification, function, and the degree of priority placed on non-automobile modes. These layers each include pedestrian facilities and are mapped as a series of "overlays" as follows:

- Roadway Classification: island arterial, regional arterial, transitional arterial, collector, local;

- Function: gateway, industrial/general commercial, residential, school and recreation zone;

- Transit: transit priority streets;

- Bicycle: bicycle priority streets; and

- Truck: truck routes
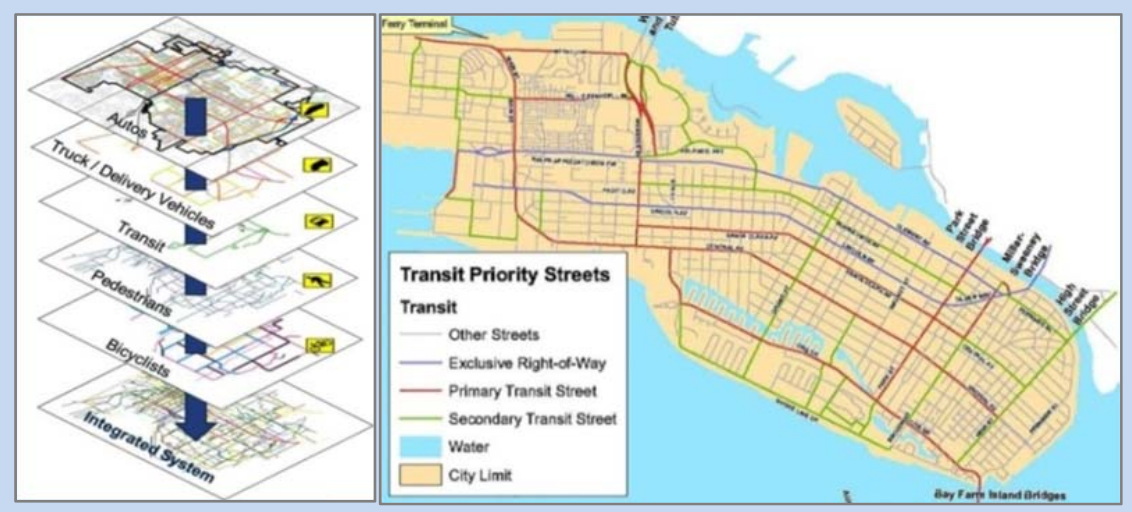

Source: ITE Designing Walkable Urban Thoroughfares (68) 


\begin{tabular}{|c|c|c|}
\hline \multicolumn{3}{|c|}{$\begin{array}{l}\text { BP 2-38. Functional Typologies for Context Sensitive } \\
\text { Broward County Complete Streets Typologies (89): }\end{array}$} \\
\hline $\begin{array}{l}\text { Common } \\
\text { Street } \\
\text { Types }\end{array}$ & Description & Comment \\
\hline Boulevard & $\begin{array}{l}\text { Walkable, moderate speed divided arterial } \\
\text { in urban environments that traverses and } \\
\text { connects districts and cities. Primarily a } \\
\text { longer distance route for all vehicles } \\
\text { including transit, goods movement, and } \\
\text { emergency response. Design speeds } \\
\text { should be } 35 \text { mph or less. }\end{array}$ & $\begin{array}{l}\text { Serves as primary transit routes. Should } \\
\text { have bike lanes and sidewalks standard. } \\
\text { May have shared-use paths. Often has a } \\
\text { planted median. May have on-street } \\
\text { parking when passing through urban } \\
\text { centers and urban cores. }\end{array}$ \\
\hline Avenue & $\begin{array}{l}\text { Walkable, low speed collector or minor } \\
\text { arterial that serves as a short-distance } \\
\text { connector between districts or urban } \\
\text { centers and provides access to abutting } \\
\text { land. Links streets with boulevards. For all } \\
\text { vehicles including transit. Design speeds } \\
\text { should be } 30 \mathrm{mph} \text { or less; strong } \\
\text { consideration should be given for } 25 \mathrm{mph} \\
\text { or less when on-street parking is provided. }\end{array}$ & $\begin{array}{l}\text { Serves as primary pedestrian and bicycle } \\
\text { routes. Should have local transit routes. } \\
\text { May or may not have a median. May or } \\
\text { may not have on-street parking depending } \\
\text { on context. }\end{array}$ \\
\hline Street & $\begin{array}{l}\text { Walkable, low speed facility that primarily } \\
\text { serves as access to abutting properties and } \\
\text { local traffic in neighborhoods. Connects to } \\
\text { adjoining neighborhoods. Serves local } \\
\text { function for vehicles and transit. Design } \\
\text { speeds should not exceed } 25 \mathrm{mph} \text {. }\end{array}$ & $\begin{array}{l}\text { Can be commercial or residential. Bicycles } \\
\text { are served by shared space. Commercial } \\
\text { streets should always have sidewalks. } \\
\text { Residential streets should have sidewalks } \\
\text { unless traffic volumes are less than } 1,200 \\
\text { per day and speeds are } 25 \mathrm{MPH} \text { or less. }\end{array}$ \\
\hline Alley/Lane & $\begin{array}{l}\text { Walkable link between streets; allows } \\
\text { access to garages. }\end{array}$ & $\begin{array}{l}\text { Narrow space characterized by walking } \\
\text { speeds. }\end{array}$ \\
\hline $\begin{array}{l}\text { Special } \\
\text { Street } \\
\text { Types }\end{array}$ & Description & Comment \\
\hline Main Street & $\begin{array}{l}\text { Slower vehicle speeds, favors pedestrians } \\
\text { most, contains the highest level of } \\
\text { streetscape features, typically dominated } \\
\text { by retail and other commercial uses }\end{array}$ & $\begin{array}{l}\text { Functions differently than other streets in } \\
\text { that it is a destination }\end{array}$ \\
\hline Drive & $\begin{array}{l}\text { Located between an urbanized } \\
\text { neighborhood and park or waterway }\end{array}$ & Can be a local street or an alley \\
\hline Transit Mall & $\begin{array}{l}\text { The traveled way is for exclusive use by } \\
\text { buses or trains, typically dominated by } \\
\text { retail and other commercial uses }\end{array}$ & $\begin{array}{l}\text { Excellent pedestrian access to and along } \\
\text { the transit mall is critical. Bicycle access } \\
\text { may be supported. }\end{array}$ \\
\hline $\begin{array}{l}\text { Bike } \\
\text { Boulevard }\end{array}$ & $\begin{array}{l}\text { A continuous through street } \\
\text { for bicycles, but short distance travel (local } \\
\text { access) for motor vehicles }\end{array}$ & $\begin{array}{l}\text { Usually a local street with low } \\
\text { traffic volumes and low speeds }\end{array}$ \\
\hline $\begin{array}{l}\text { Festival } \\
\text { Street }\end{array}$ & $\begin{array}{l}\text { Contains traffic calming, flush } \\
\text { curbs, sidewalks separated by } \\
\text { bollards, and streetscape features that } \\
\text { allow for easy conversion to public uses } \\
\text { such as farmers' markets and music } \\
\text { events }\end{array}$ & $\begin{array}{l}\text { Often a commercial street in a } \\
\text { downtown context that has the special } \\
\text { design features listed to the left }\end{array}$ \\
\hline $\begin{array}{l}\text { Shared } \\
\text { Space }\end{array}$ & $\begin{array}{l}\text { Slow, curbless street where } \\
\text { pedestrians, motor vehicles, and bicyclists } \\
\text { share space }\end{array}$ & $\begin{array}{l}\text { May support café seating, play areas, and } \\
\text { other uses }\end{array}$ \\
\hline
\end{tabular}




\section{BP 2-39. Functional Classification and Complete Streets Typologies}

This example from Deerfield Beach shows a table and a map with the FDOT functional classification and the Complete streets functional classification for roadways within the municipality.

\begin{tabular}{|c|c|c|c|c|}
\hline \multicolumn{5}{|c|}{ Existing Road System - Functional Classificaitons } \\
\hline \multicolumn{5}{|c|}{ City Streets } \\
\hline $\begin{array}{c}\text { FDOT Classification, } \\
\text { Complete Streets } \\
\text { Classification }\end{array}$ & From & To & Existing Lanes & $\begin{array}{c}\text { Roadway } \\
\text { Length (Miles) }\end{array}$ \\
\hline City Collector, Avenue & & & & 12.20 \\
\hline NE 12TH AVE & HILLSBORO BLVD & SOUTH CITY LIMIT & 2 & 1.25 \\
\hline NE 20TH AVE & HILLSBORO BLVD & \begin{tabular}{|l|} 
SE 10TH ST \\
\end{tabular} & 2 & 0.92 \\
\hline NE 2ND ST & NW 3RD AVE & DIXIE HWY & 2 & 0.45 \\
\hline NE 2ND ST & DIXIE HWY & FEDERAL HWY & 2 & 0.57 \\
\hline NE 3RD AVE & SW 15TH ST & NE 48TH ST & 2 & 0.51 \\
\hline City Minor Arterial, Boulevard & & & & 3.27 \\
\hline MILITARY TRL & HILLSBORO BLVD & SW 10TH ST & 4 & 0.98 \\
\hline MILITARY TRL & SW 10TH ST & SW 15TH ST & 4 & 0.73 \\
\hline SW 10TH ST & $1-95$ & SW 11TH WAY & 6 & 0.14 \\
\hline SW 10TH ST & SW 11TH WAY & DIXIE HWY & 6 & 0.65 \\
\hline $\begin{array}{l}\text { County/State Minor } \\
\text { Arterial, Boulevard }\end{array}$ & & & & 12.62 \\
\hline DIXIE HWY & SAMPLE RD & NE 48TH ST & 4 & 1.05 \\
\hline HILLSBORO BLVD & FEDERAL HWY & $\mathrm{A} 1 \mathrm{~A}$ & 4 & 0.87 \\
\hline MILITARY TRL & NORTH CITY LIMIT & HILLSBORO BLVD & 4 & 0.72 \\
\hline MILITARY TRL/NW 9TH AVE & GREEN RD & SAMPLE RD & 4 & 1.13 \\
\hline NE 2ND ST/DIXIE HWY & N RIVER AVE & NE 2ND AVE & 4 & 0.05 \\
\hline NW 48TH ST & MILITARY TRL & $1-95$ & 4 & 0.76 \\
\hline $\begin{array}{c}\text { County/State Principal } \\
\text { Arterial, Boulevard }\end{array}$ & & & & 13.23 \\
\hline FEDERAL HWY/US 1 & NORTH CITY LIMIT & HILLSBORO BLVD & 6 & 0.54 \\
\hline FEDERAL HWY/US 1 & HILLSBORO BLVD & SE 10TH ST & 6 & 0.90 \\
\hline POWERLINE RD & NW 48TH ST & SAMPLE RD & 6 & 1.02 \\
\hline SAMPLE RD & WEST CITY LIMIT & POWERLINE RD & 6 & 0.38 \\
\hline SAMPLE RD & POWERLINE RD & MILITARY TRL & 6 & 1.02 \\
\hline State Collector, Avenue & & & & 1.18 \\
\hline SR A1A/OCEAN BLVD & NORTH CITY LIMIT & HILLSBORO BLVD & 2 & 0.55 \\
\hline SR A1A/OCEAN BLVD & HILLSBORO BLVD & SOUTH CITY LIMIT & 2 & 0.63 \\
\hline
\end{tabular}
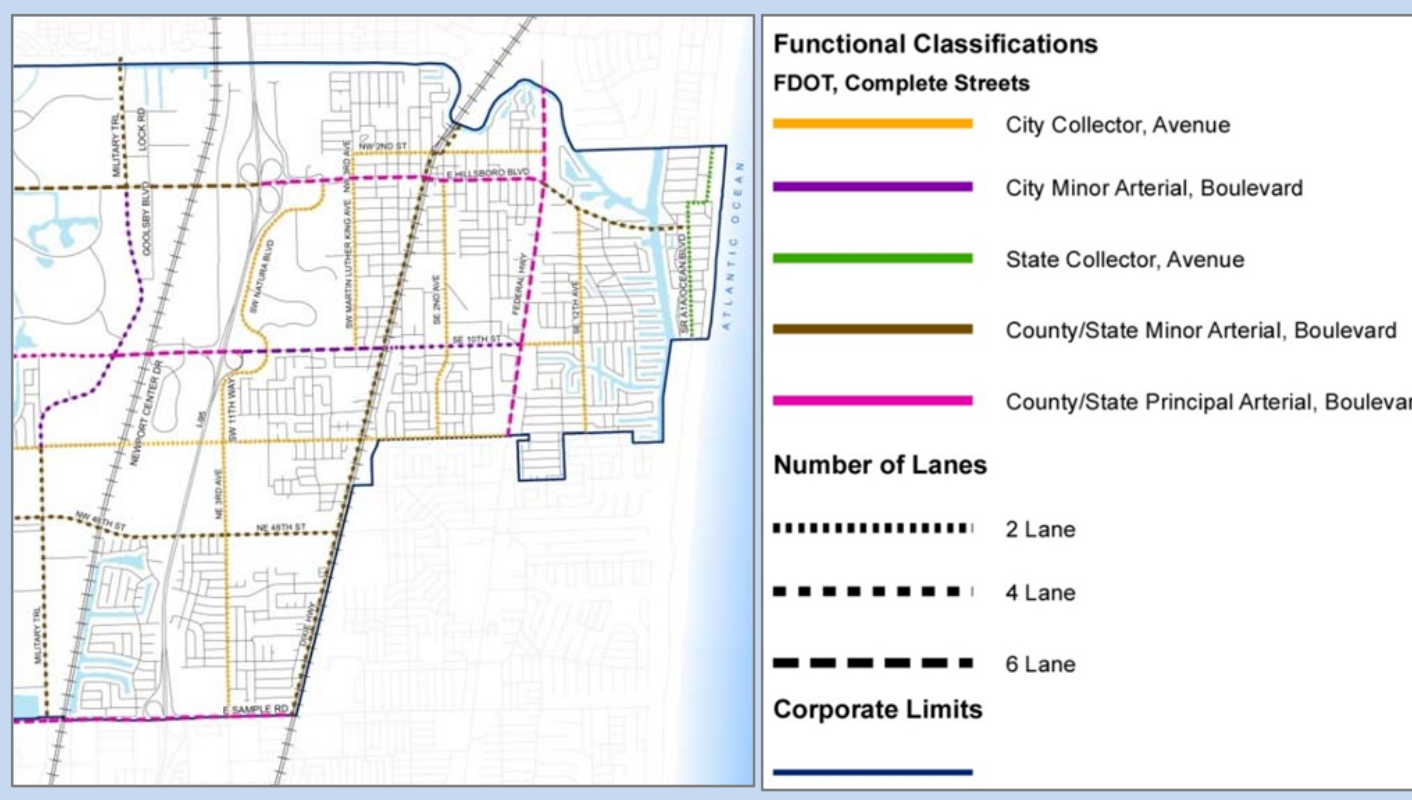

Source: Deerfield Beach Complete Streets Guidelines 


\section{Assign roadway categories to each segment of the existing and planned network, through maps and/ or lists. I dentify any special corridor designations.}

The transportation element should include maps and/or lists indicating the classification assigned to roadways in the transportation element (see BP 2-39). Various typical designs can be applied to each of these categories to address local needs and preferences. These can include topics such as median width and design, number of travel lanes, sidewalk location and width, and utility placement. Some transportation corridors will be planned for special treatment as it relates to local and regional multimodal plans and design standards. Examples may include: SIS roadways, roadways with adopted access management plans, corridors designated for managed lanes (see BP 2-40), bus rapid transit corridors, and so on. Identifying these in the transportation element helps to ensure appropriate coordination of planning and implementation actions with the objectives of these designations.

Information specific to corridor designation for right-of-way preservation is provided in the next topic of this section.

\section{BP 2-40. Designate and/ or Reinforce Managed Lanes on Major Thoroughfares}

A managed lane involves active management of a travel lane on an interstate highway or expressway. It typically involves limiting the use of the lane to specific classes of vehicles (e.g., carpools, buses, and trucks), often in concert with congestion pricing or tolls. The purpose is to decrease congestion on the highway system. The principal operational strategies for managed lanes are pricing, vehicle eligibility, or access control (90).

The Florida Department of Transportation is actively promoting managed lanes as a strategy to alleviate congestion on the freeway system. In 2012, legislation was adopted to assist FDOT in implementing the strategy ( $\$ 338.151$, F.S.). FDOT includes truck lanes, high occupancy vehicle (HOV) lanes, high occupancy toll (HOT) lanes, dedicated bus rapid transit (BRT) lanes, reversible lanes, and express lanes in its description of managed lanes.

FDOT's interest in advancing managed lanes grew from the success of the I-95 Express Lanes Project. All users either register or pay a toll to use the express lanes using an electronic tolling device. Carpools of three or more, hybrid vehicles, South Florida Vanpools, and buses may all register to use the express lanes free of charge. Motorcycles and emergency vehicles need not register to use the express lanes free of charge. Operational

Map of Florida Managed Lanes Projects

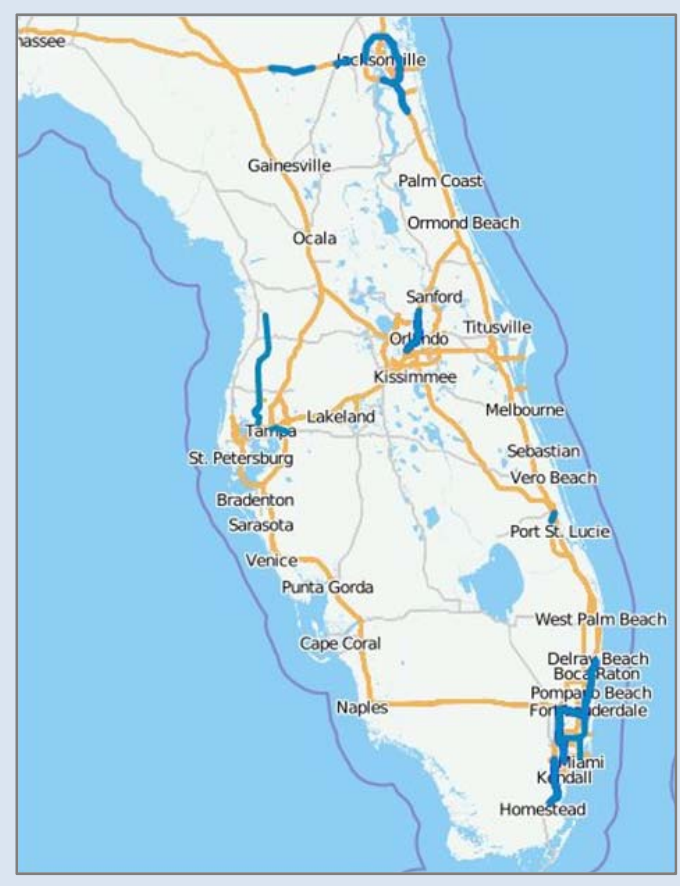
performance of I-95 in both the express and regular travel lanes significantly improved with average travel speeds which went from about $20 \mathrm{mph}$ before the express lanes to an average of $41 \mathrm{mph}$ (northbound peak) and $51 \mathrm{mph}$ (southbound peak) (91 p. 3). Express bus ridership increased "an average of $22 \%$ between the first three months of 2009 and the first three months of 2010 despite a decrease of $12 \%$ in overall Miami-Dade Transit ridership" (91 p. 3).

Source: www.floridamanagedlanes.com 


\section{I dentify generalized right-of-way needs for future thoroughfares and collector roadways, and assign through maps, policies, and/ or lists (e.g. right-of-way needs identification map)}

Right-of-way costs often represent the single largest expenditure for a transportation project, particularly in growing urbanized areas. Therefore, it is essential to carefully consider the right-of-way needed for each planned roadway. Preserving an adequate amount of right-of-way will be one determinant of the ability to cost-effectively accommodate modal alternatives, utility needs, and design amenities.

Section 337.273(1)(d), F.S., establishes authority for local governments to designate corridors for right-of-way preservation and management. Regarding the process of designating transportation corridors, §337.273(6), F.S., states: "A local government may designate a transportation corridor by including the corridor in the entity's comprehensive plan traffic circulation or transportation element...." Thereafter, a transportation management ordinance may be adopted for designated transportation corridors, pursuant to the criteria contained in statute.

The plan should identify transportation projects expected to be completed in the planning horizon, particularly those projects that are part of the MPO Cost-feasible Plan, the State Transportation Improvement Program (STIP), the FDOT Five-Year Work Program, and the local Capital Improvements Program. Local governments are encouraged to take a longerterm approach and also designate future transportation corridors that are not "financially constrained," including corridors in the MPO "Needs" Plan and other collector or arterial roadways deemed locally important to the efficiency of the transportation network based upon the analysis of spacing, continuity, and connectivity needs.

Right-of-way needs for each planned roadway can be determined based upon typical or corridor-specific cross-sections and design objectives for that category of roadway. Common practice is to use generalized widths and refine them as more detailed engineering studies are completed. The right of way needs are then mapped, along with the functional classification or typology of the roadway corridor. Finally, goals, objectives, and policies for corridor preservation and management are included in the transportation element (BP 2-41 and GOP 2-6). Preservation of future transportation right-of-way is accomplished through a variety of strategies, such as on-site density transfers, clustering options, overlay requirements, and impact fee credits. Appendix $\mathrm{F}$ provides corridor management policies and objectives from the Tallahassee-Leon County Comprehensive Plan that reflect contemporary best practices. A detailed review of corridor preservation options and legal considerations in Florida is available in the report Corridor Preservation Best Practices available at www.cutr.usf.edu/wp-content/uploads/2012/07/BestPracticesReport.pdf. 


\section{BP 2-41. Thoroughfare Right-of-way Needs I dentification Maps}

The Palm Beach County, Florida Thoroughfare Right-of-Way Identification Map is used to avoid development encroachment in future corridors and preserve right of way in the development process. Goals, objectives, and policies for corridor preservation and management are included in the transportation element. Palm Beach County is one of several counties in Florida that preserve and manage right of way along major corridors based on the authority granted in Florida law.
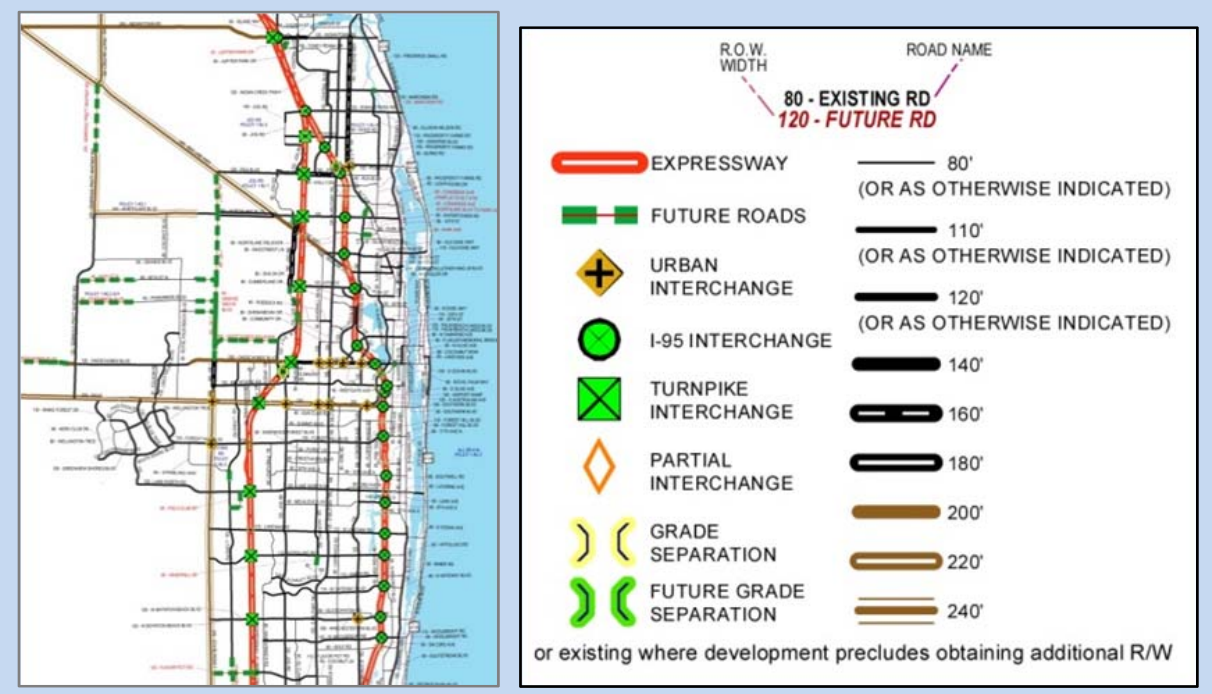

Source: Palm Beach County Comprehensive Plan (92)

The Broward County Trafficways Plan was developed in the early 1960s for the purpose of right-ofway preservation. The plan is implemented through the land (re)development process. Parcels required to plat, and in some cases those exempt from platting, must dedicate, by deed or easement, right-of-way consistent with the Plan. Recent updates include a new "context sensitive corridor" overlay designation denoted in green to guide ROW and building setback decisions in these areas.

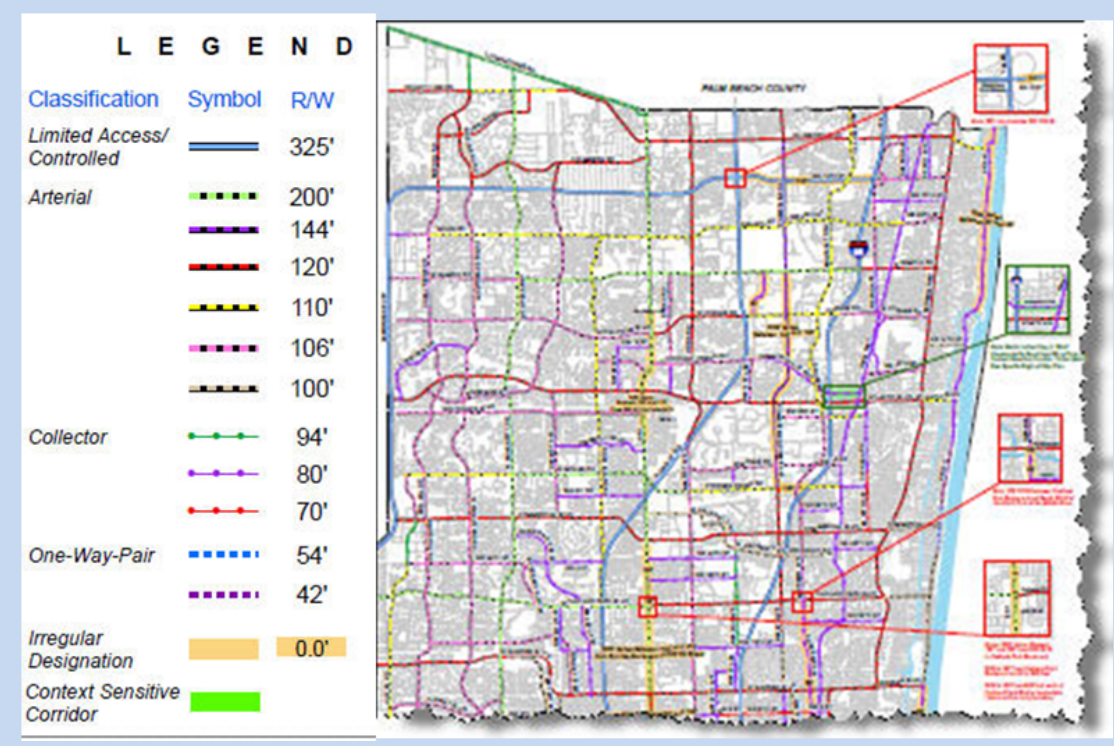

Source: Broward County Trafficways Plan 


\section{Integrate Connections to Aviation, Rail, Ports, and I ntermodal Facilities}

An important aspect of local government planning for ports and airports is ensuring the accessibility of these facilities through the surface transportation system for the efficient movement of people and freight. Access to major airports and ports is generally via the SIS, SIS connectors, or other regional roadways.

FDOT has committed to become more multimodal and intermodal by providing more choices for moving freight and people with seamless transfers across mode choices through the SIS (93 p. 2). Intermodal connectors - highways, rail lines, and waterways connecting hubs to corridors - are a core element of the statewide transportation system and are eligible for funding (93 p. 6). Intermodal logistics centers (ILCS), a SIS facility created to aid in the shipment of goods through a seaport, are an important connection (94). BP 2-46 describes Polk county's planning efforts for an intermodal logistics center.

The transportation element should identify all rail and roadway corridors used to access a port or airport facility. Corridor management plans or strategies should be applied to these facilities where necessary to improve truck operations or throughput.

\section{BP 2-42. Planning for I ntermodal Logistics Centers}

The Central Florida Intermodal Logistics Center (CFILC) opened in 2014 in Winter Haven, Florida just off of SR 60. The CFILC is a 318-acre intermodal terminal serving as a centralized hub for transportation, logistics, and distribution to Orlando, Tampa, and South Florida. This facility is expected to provide comparable or improved service to all existing points that are currently served by the Orlando facility. Polk County incorporated a selected area plan into its Comprehensive Plan to plan for the future growth anticipated to occur due to the CFILC. It is the goal of the selected area plan to promote economic development opportunities by centralizing the development in key areas where infrastructure and urban services can best accommodate it. To minimize traffic congestion due to the increased through traffic generated by the CFILC, the selected area plan establishes that Polk County will increase roadway capacity where necessary and construct new collector roads forming a grid system to maximize access and reduce congestion.

Source: Polk County Comprehensive Plan (95)

\section{Integrate Bicycle and Pedestrian Networks}

Bicycle and pedestrian networks and enhancements should be carefully integrated into the overall transportation plans (see BP 2-43). Consider connectivity needs between activity centers and surrounding residential areas, as well as with public transportation. In planning for bicycles, it is important to understand the diversity of options. As noted in a study of bicycle and pedestrian mobility and safety in Europe (96 p. 6):

"To maximize bicycling opportunities, cities must build a network of safe and comfortable routes using a mix of bike lanes, bike boulevards, cycle tracks, and bike paths that connect residents to potential destinations. Infrastructure that maximizes the separation between bicyclists and motor vehicles, without making bicyclists travel too far out of their way, may be more effective for encouraging new bicyclists than on-street pavement markings." 
BP 2-43. Steps for Integrating Bicycle and Pedestrian Needs into Transportation Planning

1. Facilitate public participation

2. Determine a community vision and objectives

3. Create a fact-base: document locations of existing facilities and their use

4. Identify and prioritize locations needing improvement

5. Evaluate alternatives and determine solutions

6. Review, revise, and recommend transportation and land use policies

7. Establish key design procedures; and

8. Evaluate and revise plans

Source: Pedestrian and Bicycle Information Center (47).

A variety of alternative approaches can be considered for improving the connectivity, continuity and safety of bicycle and pedestrian routes (see BP 2-44, for example). Key considerations in establishing the bicycle plan, include:

- Bicycles extend access to transit to a larger area. Look for opportunities to enhance the connections between bicycles and buses and provide for bicycle parking as needed at both ends of the trip.

- Good locations for bicycle parking are high demand bus stop and station areas. These locations can be identified through consultations with local bicycle groups and transit rider surveys and will include all bus rapid transit stops.

- Make sure the area around existing and proposed transit stops is highly accessible by bicycle (as well as by foot).

- Provide adequate bicycle parking facilities as discussed in www.pedbikeinfo.org/planning/facilities.cfm.

- Bicycle lanes should be placed to the left of bus travel lanes where possible, as buses stop and start and bicyclists need to maintain momentum.

- Connect key travel destinations as directly as possible with bicycle lanes, paths, or shared streets (see BP 2-45 and BP 2-46).

Practice Notes: Creating bicycle and pedestrian-friendly environments is key to encouraging choice of these modes over the automobile, particularly for short trips. Bicyclists are capable of traveling greater distances; however, sidewalks are essential to pedestrian travel within urban cores and activity centers. Those not using motor vehicles should be able to safely circulate throughout the planning area and access land uses. Ample bicycle and pedestrian connections within and between residential areas and supporting community facilities and services, such as shopping areas, employment centers, transit stops, neighborhood parks, and schools provide for this circulation. Such connections may be sidewalks, bicycle facilities, and/or shared use paths and connections between cul-de-sacs. 


\section{BP 2-44. I dentify Alternative Strategies for I mproving Bicycle and Pedestrian Ways}

The City of Largo, Florida prepared a citywide multimodal plan in 2012 aimed at implementing a strategic action plan for improving the City's multimodal network. The plan addresses existing deficiencies and establishes multimodal level of service (LOS) targets. A list of recommended multimodal projects for the next 25 years is provided, including several that address pedestrian and bicycle mobility. The City's goal is to have 100 percent sidewalk coverage on both sides of the streets in places where it is possible. The city's latest inventory found that approximately 35 percent of the city's 200-mile road network has sidewalk gaps. The plan also calls for enhancing bicycle facilities, particularly on arterial and collector roads, with five possible recommendations for doing so. Those recommendations are to: 1 ) do nothing because there is an existing on-road bicycle facility; 2) a roadway restripe to reduce existing lane widths to create space for bicycles; 3 ) a road diet to reduce the number of lanes to make room for bicycles; 4) add paved shoulders; and 5) add shared lane markings after a detailed corridor study.

Source: City of Largo Multimodal Plan (97)

\section{BP 2-45. Plan a Bicycle Network That Connects to Transit and Key Destinations}

The City of Tallahassee and Leon County work with local cycling groups to identify potential bicycle routes and connections to existing cycling facilities. The long term goal of this effort is to establish a comprehensive bicycle network throughout the urban areas of Leon County. The map below reflects the first step of this effort and represents a marked bicycle network that provides access to key destinations within the Tallahassee Mobility District. The proposed county-wide system is "based on 'feeder routes' recommended and tested by Capital City Cyclists (CCC) and Committee for Bikeable Community (CBC) members." Interactive maps were posted on line for the overall network and the public is encouraged to view the maps and provided additional input. Information is also included on connecting bicycle and transit routes, including schedules for StarMetro - the regional transit provider. Additional considerations to include in such a map are key land use destinations that may benefit from improved bicycle accessibility.

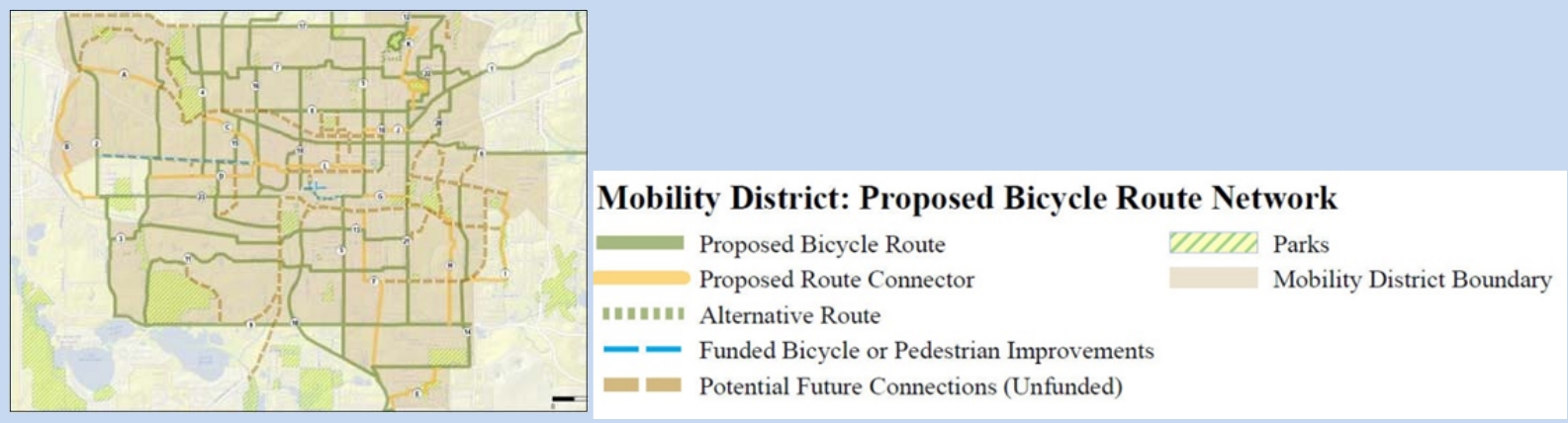

Source: Tallahassee-Leon County Planning Department 


\section{BP 2-46. Redesigning I ntersections to I mprove Bicycle Safety}

Intersections can be redesigned in a manner that promotes safety for bicycle users. For years, the Dutch have used the intersection design illustrated below to keep the cyclist separated from automobile traffic to minimize conflict points in right turning situations. The intersection design does not require any more space than a typical intersection and can be implemented as new construction or as a retrofit. A video describing the design can be found at -

www. youtube.com/watch?v=FIApbxLz6pA.

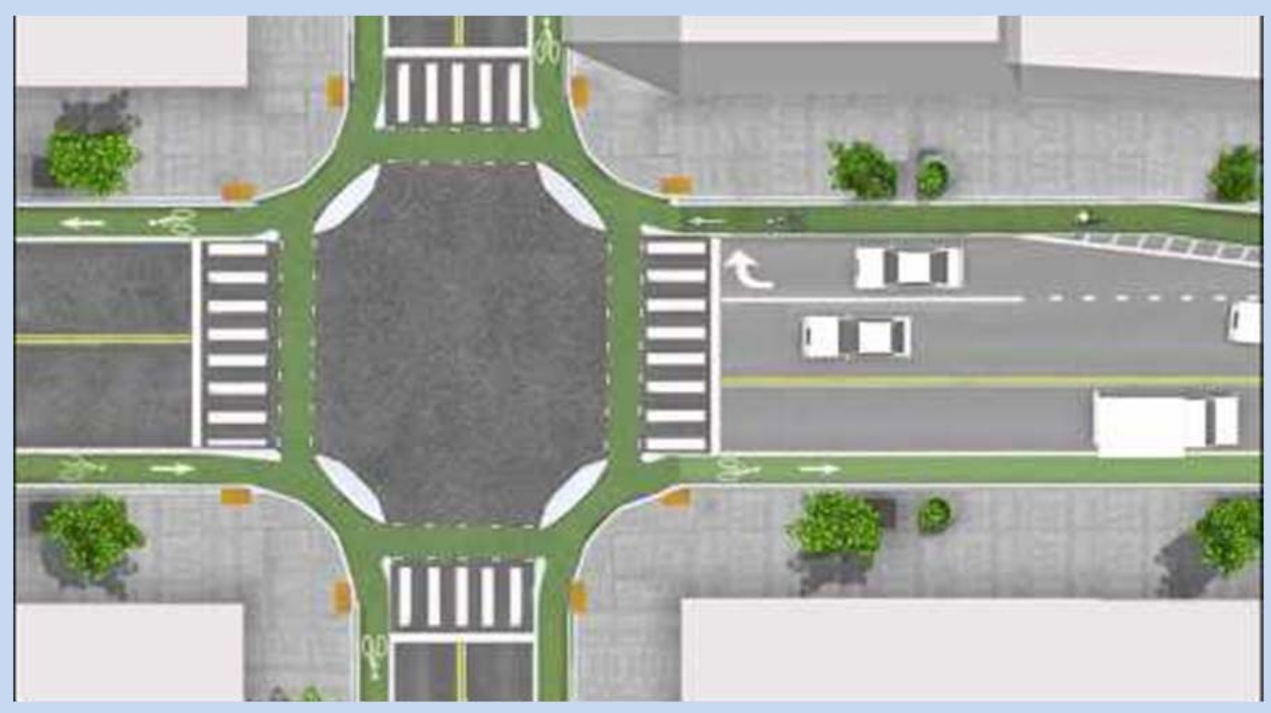

Source: img.youtube.com/vi/FIApbxLz6pA/hqdefault.jpg

\section{I dentify Desired Safety and Operational Projects}

The future transportation element will identify a number of potential adjustments to the existing transportation system. These may include safety and operational/capacity projects, programs, and services across the various transportation modes. The plan should identify and strategically prioritize and phase projects for inclusion in the capital improvements element. Examples may include medians, intersection redesign, mid-block crossings and so on. An effective way to do so is to establish a point system that is tied to the community vision, priorities and planning goals and objectives, as discussed in BP 2-47. Some strategies may require partnerships with other agencies, creating an opportunity to link the transportation and intergovernmental coordination elements. In addition, BP 2-48 illustrates a comprehensive approach to improving bicycle and pedestrian safety. 


\section{BP 2-47. Prioritize Multimodal Projects and Strategies}

In the City of Largo Multimodal Plan, a prioritization methodology was developed and applied to transportation corridors within the city. The following categories were used to prioritize each segment of the applicable corridors:

- Level of Service

- Pedestrian Needs

- Community Resource Connectivity

- Transit Connectivity
- Bicycle Needs

- Safety

- Public Support

- Supports Local Plans

Each roadway corridor was evaluated according to these eight categories and assigned a point value that was used to determine the priority of that corridor. For example, corridors served by more than two transit routes earned three points in the Transit Connectivity category, while corridors served by one or two transit routes only earned two points. Corridors with a pedestrian level of service (LOS) below the target LOS by more than one earned three points while those with pedestrian LOS below the target by less than 0.5 only earned one point. Projects proposed on corridors located in high hazard areas earned three points while projects on corridors with an average of four or more bicycle crashers within the last five years earned two points. Projects on the corridor segments with the highest overall score became the top ranked city projects as illustrated in the following map.

\section{Identified Top Ranked City Projects}

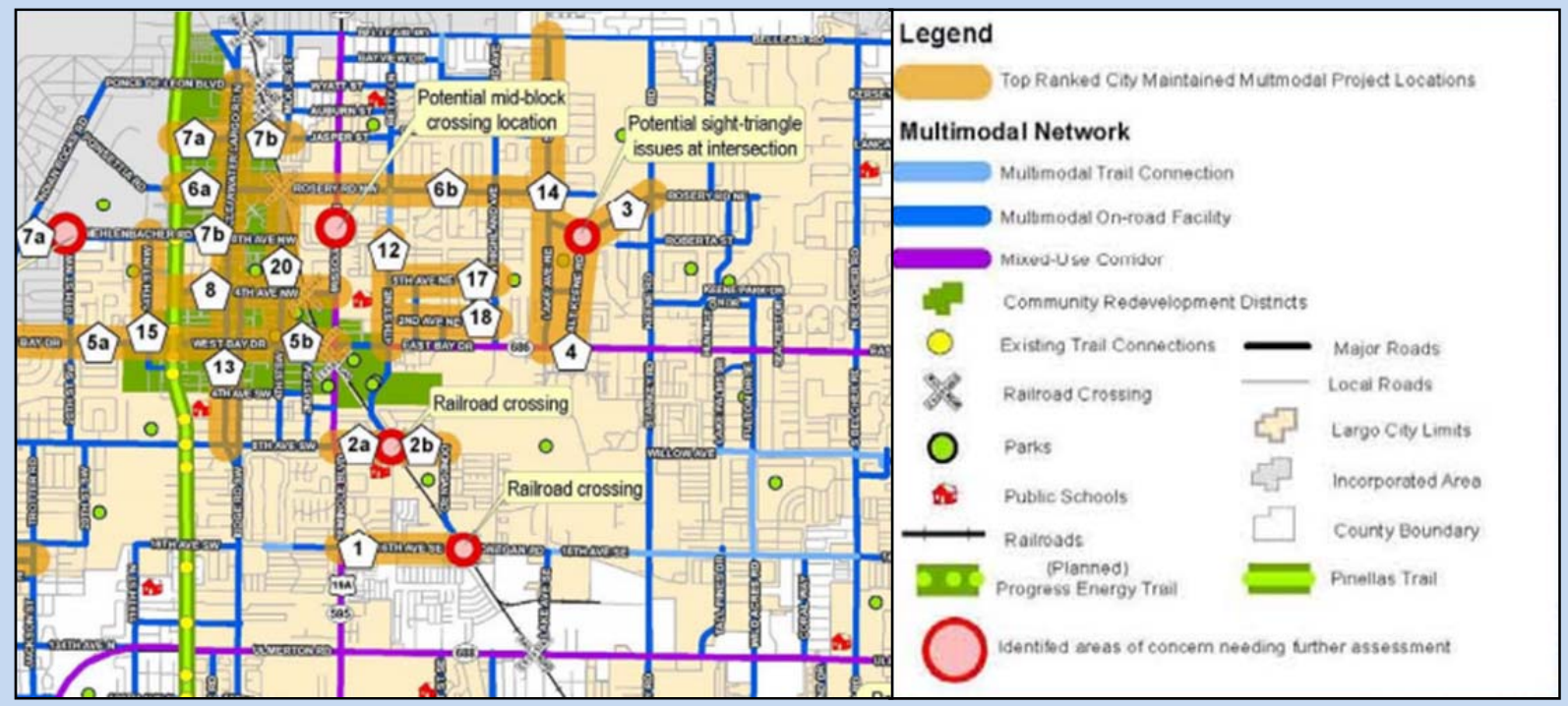

Source: City of Largo Multimodal Plan (97) 


\section{BP 2-48. I dentify Desired Safety Projects}

CityTrails $^{\mathrm{TM}}$, the City of St. Petersburg's bicycle pedestrian master plan, creates a vision for how to improve pedestrian and bicycle safety. The plan calls for projects under the following categories: bicycle facilities, sidewalk program, crosswalk safety, education and enforcement.

- The city's bicycle infrastructure has been enhanced significantly with the addition of on-street bicycle lanes, independent recreational trails, and marked bike routes. In addition, bicycle parking spaces and new bicycle racks have been installed at key locations throughout the city.

- A comprehensive program has been undertaken to complete construction of sidewalks on all collector and arterial roadways. Data has been collected of missing links and funding has been prioritized to complete at least one sidewalk along all designated bicycle routes.

- An extensive program was developed and implemented to enhance all crosswalks and signalized intersections. All mid-block crosswalks on minor roadways and all school crosswalks were enhanced with additional signs and markings. A total of 32 crosswalks on major roadways were additionally enhanced with rectangular rapid flashing beacons. Signalized intersection pavement marking and countdown pedestrian signals were installed.

- The educational efforts were multi-faceted and included activities such as brochure development and distribution, interactive displays at appropriate events and festivals, and conducting workshops and presentations solely focused on bicycle and pedestrian safety. The educational efforts were conducted across a broad spectrum of the population as well, with programs developed for adults, youths, and children. In addition, the City sought and obtained grants to provide bicycle helmets to kids and adults at no charge.

- The primary methods of enforcement included weekly deployment of police enforcement details to monitor all major crosswalk locations and also providing training videos to all police officers.

\section{Proposed Bicycle Pedestrian Facilities}

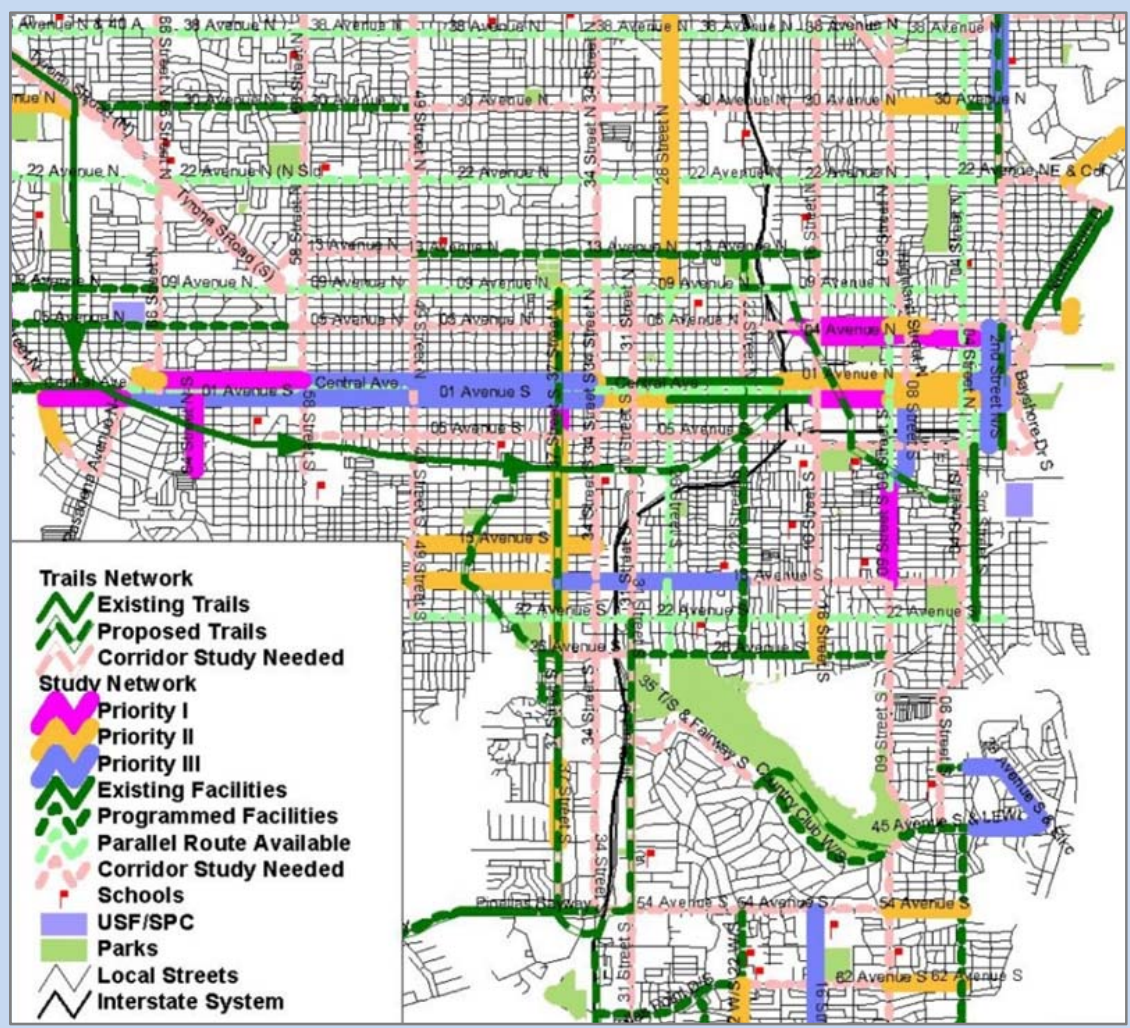

Source: City of St. Petersburg, FL, www.stpete.org/bicycle/ 
Rightsizing techniques, such as a road diet, are useful in promoting safety and accessibility by updating streets to more appropriately fit their context. As the needs of a community evolve over time, the streets should also change to best serve those needs. Rightsizing may involve a complete redesign of a street to include new infrastructure or could be as simple as restriping the road to change parking or add bicycle lanes (98). A road diet is a type of rightsizing treatment performed that reduces the number of automobile traffic lanes by replacing one or more of the existing lanes with any combination of landscaping treatments, wider sidewalks, bicycle lanes, etc.

\section{Set Future Q/ LOS Standards, Performance Measures, and Benchmarks}

Chapter 163, Part II, F.S., requires local governments to determine projected system level of service. To accomplish this, level of service standards/performance measures should be established, to the extent applicable, as described below:

- roadway level of service (LOS)

- public transportation quality of service standards

- bicycle and pedestrian quality of service or performance standards, targets, or benchmarks

ITR 2-14 notes various resources to consult in this effort. BP 2-50 provides a variety of sample measures that could be considered in relation to specific multimodal strategies. ITR 2-15 identifies level of service standards common to fixed route public transportation systems. An example of transit oriented level of service standards adopted in Broward County is provided in BP 2-50.

Although LOS is defined in $\S 163.3164$, F.S., in terms of capacity, both quantity and quality of service are considered appropriate measures of service for non-automobile modes of transportation, such as transit, bicycle, and pedestrian modes. A variety of performance standards, targets, or benchmarks may be considered for modes other than the automobile. Such standards could be developed or adopted by reference from the plans of other modal providers within the community. Specific Q/LOS targets could be set for each mode and facility, based on their long term objectives, roadway function and so on. Future quality/level of service standards or performance measures should be set for the following based on the community vision:

- major roadway network

- transit system

- bicycle network

- pedestrian network

- $\quad$ special treatment areas (i.e. transportation concurrency exception areas, area-wide transportation concurrency, multimodal transportation districts)

Practice Notes: Level of service standards technically must appear in the capital improvements element. Including them in the transportation element is an opportunity to establish consistency between the elements. 


\section{ITR 2-14. Establishing Level of Service Standards and/ or Performance Measures}

- Florida Department of Transportation 2013 Quality/Level of Service Handbook

- Transportation Research Board, 2010 Highway Capacity Manual

- Performance measures for all modes - Expanded Transportation Performance Measures to Supplement Level of Service (LOS) for Growth Management and Transportation Impact Analysis (65)

- Transit capacity and quality of service - TCRP Report 165: Transit Capacity and Quality of Service Manual, 2013 - www.trb.org/main/blurbs/169437.aspx

- MPO long-range transportation plans www.mpoac.org

- Plans of other modal providers 


\begin{tabular}{|c|c|c|}
\hline \multicolumn{3}{|c|}{ BP 2-49. Example Multimodal Strategies and Corresponding Indicators/ Measures } \\
\hline & Example Strategies & $\begin{array}{l}\text { Indicators } \\
\text { / Measures }\end{array}$ \\
\hline \multirow{7}{*}{ 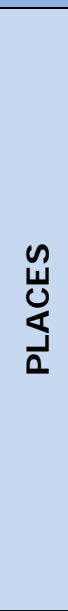 } & $\begin{array}{l}\text { Multimodal Districts - Encourage a mix of uses to make destinations closer } \\
\text { and within walking distance. }\end{array}$ & \multirow{7}{*}{$\begin{array}{l}\text { Population Density } \\
\text { Population-to- } \\
\text { Employment Ratio } \\
\text { Sidewalk Coverage } \\
\text { Jobs and Housing } \\
\text { Near Transit } \\
\text { Pedestrian Q/LOS } \\
\text { Bicycle Crashes, } \\
\text { Injuries \& Fatalities } \\
\text { Amount of Goods } \\
\text { Moved }\end{array}$} \\
\hline & $\begin{array}{l}\text { Multimodal Nodes - Encourage transit-ready densities and intensities of } \\
\text { development or redevelopment. }\end{array}$ & \\
\hline & Freight/Goods Districts - Preserve and strengthen connections to SIS & \\
\hline & $\begin{array}{l}\text { Freight/Goods Centers - Implement strategies/projects in airport and } \\
\text { seaport master plans }\end{array}$ & \\
\hline & $\begin{array}{l}\text { Lower Intensity Residential Areas - Stabilize and protect established } \\
\text { neighborhoods. }\end{array}$ & \\
\hline & $\begin{array}{l}\text { Lower Intensity Commercial Areas - Optimize safe and easy access points } \\
\text { for all modes. }\end{array}$ & \\
\hline & $\begin{array}{l}\text { Lower Intensity Mixed Use Areas - Encourage horizontal and vertical } \\
\text { mixed use. }\end{array}$ & \\
\hline \multirow{6}{*}{$\begin{array}{l}\text { U } \\
\underline{\mathbf{E}} \\
\bar{\Xi} \\
\overline{\mathbf{U}}\end{array}$} & SIS Facilities - Implement managed lanes & \multirow{6}{*}{$\begin{array}{l}\text { Auto LOS } \\
\text { Travel Time } \\
\text { Reliability } \\
\text { Intersection Delay } \\
\text { Transit Q/LOS } \\
\text { Bicycle Q/LOS } \\
\text { Pedestrian Q/LOS } \\
\text { Crashes Involving } \\
\text { Pedestrians and } \\
\text { Bicyclists } \\
\text { Sidewalk Coverage }\end{array}$} \\
\hline & Primary Multimodal Facilities - Adopt multimodal Q/LOS standards. & \\
\hline & $\begin{array}{l}\text { Multimodal Facilities - Prioritize bicycle and pedestrian improvements to } \\
\text { facilities. }\end{array}$ & \\
\hline & Primary Commerce Facilities - Limit access to major intersections. & \\
\hline & $\begin{array}{l}\text { Commerce Facilities - Address potential safety conflicts between } \\
\text { pedestrians/bicyclists and autos/trucks. }\end{array}$ & \\
\hline & $\begin{array}{l}\text { Freight Connections - Prioritize and implement intersection improvements } \\
\text { to better accommodate trucks and enhance efficiency. }\end{array}$ & \\
\hline \multirow{7}{*}{$\frac{\sum_{u}}{\frac{n}{n}}$} & $\begin{array}{l}\text { Develop a designated network of "Complete Streets" consistent with the } \\
\text { map of Multimodal Facilities to identify and prioritize specific } \\
\text { improvements. }\end{array}$ & \multirow{7}{*}{$\begin{array}{l}\text { Transit Mode Share } \\
\text { Bicycle Mode Share } \\
\text { Pedestrian Mode } \\
\text { Share } \\
\text { Average Commute } \\
\text { Trip Length } \\
\text { Countywide VMT } \\
\text { Per Capita } \\
\text { Truck Miles } \\
\text { Traveled } \\
\text { \% Miles Severely } \\
\text { Congested }\end{array}$} \\
\hline & Continue to strengthen congestion management processes and programs & \\
\hline & $\begin{array}{l}\text { Assess the effectiveness of existing transportation demand management } \\
\text { (TDM) programs and refine the programs accordingly. }\end{array}$ & \\
\hline & $\begin{array}{l}\text { Create a common communication venue for local governments and } \\
\text { agencies to share information. }\end{array}$ & \\
\hline & Secure a dedicated funding cource for trancit onerating cocts & \\
\hline & & \\
\hline & Periodically report on system status and trends. & \\
\hline \multicolumn{3}{|c|}{ Source: I-95 Corridor Mobility Plan (78) } \\
\hline
\end{tabular}




\begin{tabular}{|ll|}
\hline BP 2-50. Transit-Oriented Q/ LOS Standards \\
\hline North Central District & - Achieve Headways of 30 minutes or less on $90 \%$ of routes. \\
& - Establish at least one neighborhood transit center. \\
& - Expablish at least one additional community bus route. \\
\hline Central District & - Achieve headways of 30 minutes or less on $80 \%$ of routes. \\
& - Establish at least one neighborhood transit center. \\
\hline Port/Airport District & Establish at least two additional community bus routes. \\
\hline Overall & - Increase number of bus stop shelters by $30 \%$. \\
& - Maintain the maximum service volumes on arterial roadways within \\
& each District \\
\hline & Source: Broward County Code of Ordinances (99) \\
\hline
\end{tabular}

Performance measures for the fixed route transit service are either considered operational or financial and those selected for reviewing Broward's system are listed in ITR 2-15.

\begin{tabular}{|l|l|}
\hline \multicolumn{2}{|l|}{ ITR 2-15. Selected Performance Review Measures Fixed Route Transit Services } \\
\hline Operational Measures & Financial Measures \\
\hline Service & Expenses and Revenue \\
Service Area Population & Operating Expenses \\
Service Area Density & Maintenance Expenses \\
Passenger Trips & Local Revenue \\
Passenger Miles & Local Contribution \\
Average Passenger Trip Length & Passenger Fare Revenue \\
Revenue Miles & Other Non-Fare Revenue \\
Revenue Hours & Average Fare \\
\hline Vehicle & Efficiency \\
Vehicles Available in Maximum Service & Operating Expense per Capita \\
Vehicles Operated in Maximum Service (VOMS) & Operating Expense per Passenger Trip \\
Revenue Miles per Vehicle in Max. Service & Operating Expense per Revenue Mile \\
Average Age of Fleet (in years) & Operating Expense per Revenue Hour \\
\hline Employee & Maintenance Expense per Revenue Hour \\
Total Employee FTEs & Maintenance Expense per VOMS \\
Revenue Hours per Employee FTE & Farebox Recovery \\
Passenger Trips Per Employee FTE & \\
\hline Effectiveness & \\
Vehicle Miles per Capita & \\
Passenger Trips per Capita & \\
Passenger Trips per VOMS & \\
Passenger Trips per Revenue Mile & \\
Passenger Trips per Revenue Hour & \\
\hline \multicolumn{2}{|c|}{ Source: Broward County Transit Development Plan (80 p. 3.3) } \\
\hline
\end{tabular}

\section{Establish Desired Multimodal Strategies and Services}

The plan should incorporate a variety of multimodal strategies and policies. Section 2.5 identifies a broad range of strategies that may be considered by topic. Example goals, objectives, and/or policies relative to the various strategies are also provided. 


\subsection{Goals, Objectives, and Policies}

Chapter 163.3177(1), F.S., requires principles and strategies - commonly listed as goals, objectives, and policies - to reflect "community commitments to implement the plan..." In addition, reflection of the community vision and priorities in goals, objectives, and policies ensures that they are addressed through the comprehensive planning process. Chapter 163, Part II, F.S., defines these terms as follows:

- Goal means the long-term end toward which programs or activities are ultimately directed;

- Objective means a specific, measurable, intermediate end that is achievable and makes progress toward a goal;

- Policy means the way in which programs and activities are conducted to achieve an identified goal.

The community's future vision and priorities will typically require revisions and additions to existing goals, objectives, and policies. For example, if the community desires travel alternatives to the single occupancy vehicle (SOV), the plan goals and objectives should address how the other modes of travel will be promoted. ITR 2-16 illustrates the planning process from citizen input through performance measurement.

As defined in Florida Statutes, objectives should be measurable. Establishing measures of effectiveness and a means of measurement along with each objective will ensure that this requirement is met. GOP 2-15 is an example from the Pasco County MPO LRTP that illustrates the application of measures to specific objectives.

Goals, objectives, and policies should also be consistent with applicable transportationrelated plans such as regional transportation plans, transit agency plans, and neighboring local government comprehensive plans. Because of the complex nature of the comprehensive plan, some goals, objectives, and policies may be contradictory. Additional policies may be necessary "to establish how best to resolve those conflicts" (100 p. 98). BP 2-51 is an example of achieving consistency between the region's transit development plan and a countywide transportation element. 


\begin{tabular}{|c|c|c|c|c|}
\hline $\begin{array}{l}\text { Citizen } \\
\text { Input }\end{array}$ & Goals \& Policies & $\begin{array}{l}\text { Inventory } \\
\text { Baseline }\end{array}$ & $\begin{array}{l}\text { I mplementation } \\
\text { Step }\end{array}$ & Measurement \\
\hline $\begin{array}{l}\text { I want to feel } \\
\text { safe when I } \\
\text { go out for a } \\
\text { bicycle ride }\end{array}$ & $\begin{array}{l}\text { Increase the safety of } \\
\text { bicycling in the } \\
\text { community. }\end{array}$ & $\begin{array}{l}\text { Inventory of } \\
\text { bicycle } \\
\text { crashes, } \\
\text { facilities and } \\
\text { routes. }\end{array}$ & $\begin{array}{l}\text { New bicycle lanes } \\
\text { and other facilities on } \\
\text { key routes. }\end{array}$ & $\begin{array}{l}\text { Number of key } \\
\text { destinations or } \\
\text { areas of the city } \\
\text { that can be } \\
\text { reached using } \\
\text { designated } \\
\text { bicycling facilities; } \\
\text { number of bicycle- } \\
\text { related crashes. }\end{array}$ \\
\hline $\begin{array}{l}\text { The bus } \\
\text { should go } \\
\text { where I need } \\
\text { to go. }\end{array}$ & $\begin{array}{l}\text { Fixed route bus } \\
\text { service should go to } \\
\text { major activity and } \\
\text { employment centers. }\end{array}$ & $\begin{array}{l}\text { Examine the } \\
\text { relationship } \\
\text { of existing } \\
\text { bus routes to } \\
\text { activity and } \\
\text { employment } \\
\text { centers. }\end{array}$ & $\begin{array}{l}\text { Redesign bus routes } \\
\text { or add new routes as } \\
\text { necessary. }\end{array}$ & $\begin{array}{l}\text { Number of routes } \\
\text { and frequency of } \\
\text { service to activity } \\
\text { and employment } \\
\text { centers. }\end{array}$ \\
\hline $\begin{array}{l}\text { I want a } \\
\text { grocery store } \\
\text { within } \\
\text { walking } \\
\text { distance of } \\
\text { my home. }\end{array}$ & $\begin{array}{l}\text { Provide for compatible } \\
\text { food, education, retail } \\
\text { and service uses on a } \\
\text { neighborhood level } \\
\text { within or in close } \\
\text { proximity to } \\
\text { residential areas. } \\
\text { Ensure adequate } \\
\text { pedestrian facilities. }\end{array}$ & $\begin{array}{l}\text { Inventory } \\
\text { existing } \\
\text { pedestrian } \\
\text { facilities. }\end{array}$ & $\begin{array}{l}\text { Adjust LDRs to allow } \\
\text { for activity centers in } \\
\text { close proximity to } \\
\text { residential areas. } \\
\text { Fill gaps in the } \\
\text { pedestrian network. }\end{array}$ & $\begin{array}{l}\text { Number of } \\
\text { residential units } \\
\text { within walking } \\
\text { distance of urban } \\
\text { core areas or } \\
\text { activity centers. }\end{array}$ \\
\hline
\end{tabular}

\section{BP 2-51. Ensuring Consistency Between Transportation Plans}

The following table illustrates some of the consistencies between the Broward County Transportation Element and the Broward County TDP.

\begin{tabular}{|l|l|}
\hline \multicolumn{1}{|c|}{ Broward County Transportation Element } & \multicolumn{1}{c|}{ Broward County TDP } \\
\hline $\begin{array}{l}\text { Objective 3.1: Broward County shall continue to } \\
\text { participate in cooperative intergovernmental plans and } \\
\text { programs that will continuously improve safety and } \\
\text { security through 2011 }\end{array}$ & $\begin{array}{l}\text { Goal 1: Continuously improve the delivery } \\
\text { of mobility services for customers to } \\
\text { increase ridership }\end{array}$ \\
\hline $\begin{array}{l}\text { Objective 3.5: Broward County shall coordinate its } \\
\text { transportation system with the plans and programs of } \\
\text { any applicable MPO, transportation authority, Florida } \\
\text { transportation plan, FDOT's Adopted Work Program, and } \\
\text { the SIS }\end{array}$ & $\begin{array}{l}\text { Objective 8-1: Coordinate service } \\
\text { development with surrounding counties to } \\
\text { address customer travel needs and } \\
\text { connectivity }\end{array}$ \\
\hline $\begin{array}{l}\text { Objective 3.3: Broward County shall continue to } \\
\text { participate in cooperative intergovernmental plans and } \\
\text { programs that will maintain energy efficiency as well as } \\
\text { incorporate transportation strategies to reduce the } \\
\text { production of greenhouse gases }\end{array}$ & $\begin{array}{l}\text { Objective 3-2: Increase the role of public } \\
\text { transportation to support the reduction of } \\
\text { greenhouse gas effects and provide } \\
\text { alternatives to lessen the overall carbon } \\
\text { footprint within Broward County }\end{array}$ \\
\hline \multicolumn{2}{|c|}{ Source: Broward County Comprehensive Plan (48) Broward County TDP (80) } \\
\hline
\end{tabular}

The following are planning best practices and strategies for consideration in the development of effective multimodal transportation goals, objectives, and policies. 


\section{Regional and Internal Consistency}

Intergovernmental coordination at a regional level plays a particularly important role in multimodal transportation planning. Plan consistency is essential when addressing regional transportation facilities to ensure appropriate timing and coordination of facility modifications. Each local government comprehensive plan, including the transportation element, should be consistent, to the extent feasible, with the plans and programs of the metropolitan planning organization, transportation authorities, transit agencies, and the Florida Department of Transportation as they relate to the jurisdiction (see GOP 2-1, for example). Strategies may include:

1) Support the Florida Transportation Plan, the Strategic Intermodal System Plan, and other applicable state plans and guidelines.

2) Be consistent with adopted regional mobility plan or regional vision plan, such as that established through a regional collaborative, including the MPO Long-range Transportation Plan, Transit Development Plan, and Strategic Regional Policy Plan (see BP 2-51).

3) Coordinate with land use, transportation, corridor management, mobility plans, and programs of adjacent local governments.

4) Strive for internal consistency of local comprehensive plan objectives and policies, as well as with those of specialized plans.

\section{GOP 2-1. I ntergovernmental Coordination}

The City of Boca Raton established goals with supportive objectives and policies for intergovernmental coordination in its comprehensive plan transportation element. The first goal is broadly stated providing safe, efficient, and affordable mode choices for local and regional travel - but relevant to intergovernmental coordination in order to develop a regional multimodal transportation system. The fourth goal is specific to working with the Boca Raton Airport Authority on transportation planning, and the fifth goal explicitly mentions working with different transit agencies to provide local transit service (101). Some objectives and the related policies addressed the following:

Objective Tran.1.3.0 is to collaborate with various agencies including the Florida Department of Transportation, the local school district, and the Palm Beach Metropolitan Planning Organization (MPO) on creating strategies for developing multimodal transportation systems

Policy Tran.1.3.7 is to collaborate with the Intergovernmental Plan Amendment Review Committee to develop criteria for maintaining a minimum level of service across jurisdictions

Policy Tran.1.3.8 addresses sharing socio-economic data with the MPO

Policy Tran.3.1.6 encourages work with neighboring communities to develop bicycle and pedestrian facilities

Policies Tran.4.1.2 and Tran.4.1.3 involve working with the Boca Raton Airport Authority, Tri-Rail, and Palm Tran to provide transit facilities at the airport

Policies Tran.5.1.1 through Tran.5.1.6 cover a range of topics from developing transitaccessible communities to promoting ride sharing programs

Source: Boca Raton Comprehensive Plan Transportation Element (101) 


\section{Land Use and Multimodal Environment}

Land use organization, location, mix, and density/intensity paired with multimodal policy contribute to a multimodal environment (see GOP 2-2). For example, the organization of land uses into a compact urban core and urban activity center nodes of varying sizes having relatively high densities and a mix of uses near transit stops creates destinations where people can come by bus and/or interact with the environment outside of the automobile. The location of these nodes, and other transit compatible land uses (e.g. schools, hospitals, major employers, etc.) on corridors served by transit helps reinforce ridership. The location and design of the nodes is also important, as discussed in Section 2.4. The following strategies will help to create a multimodal environment:

1) Establish appropriate densities and intensities along designated urban cores, major activity center areas, station areas, and transit oriented corridors.

2) Designate and reinforce strong urban core(s) and urban activity centers of varying sizes and compositions.

3) Define transit-compatible land uses and locate on existing or planned transit corridors with direct access to transit (e.g., transit oriented development).

4) Provide for a complementary and integrated mix of retail, services, residential, institutional, cultural, recreational, and employment opportunities within urban cores and major activity centers.

5) Provide for a vertical mix of uses that encourage active uses at the street level and promote pedestrian/transit oriented urban design concepts within urban cores, major activity centers, transit station areas, and along transit oriented corridors.

6) Provide for accessible food, health, education, retail, and service uses on a neighborhood level within or in close proximity to residential areas.

7) Establish urban design criteria for urban cores, major activity centers, transit station areas, and transit oriented corridors to preserve or improve livability.

8) Establish priority on enhancing bicycle and pedestrian mobility within existing and proposed activity centers, urban core areas, transit station areas, and transit oriented corridors.

9) Include automobile parking management strategies for urban cores, activity centers, and transit corridors to reduce surface area parking and promote nonautomobile travel.

10) Provide for, and require new development to contribute to, pedestrian-friendly facilities on the public streetscape (see GOP 2-3).

11) Provide for, and require new development to contribute to, facilities at existing and proposed transit stations and stops including covered shelters, trash receptacles, benches, landing pads, lighting, bicycle parking, transit information displays, and real time transit information where available (see GOP 2-3). 
12) Call for transportation impact assessment procedures that address development impacts on all modes of transportation and minimize vehicular, transit, bicycle, and pedestrian conflicts.

\section{GOP 2-2. Linking Transportation and Land Use through Planned Mobility}

The Boca Raton Comprehensive Plan Transportation Element incudes policies that (101):

- require mixed uses, pedestrian-friendly design, and higher density for places served by transit

- address higher density and intensities and mixed uses

- require street connectivity, short blocks, and mixed land uses to reduce travel distances

- require that developments be safe and convenient for walking, biking, and transit use

The Future Land Use Element includes policies that (102):

- require the City to enforce density regulations for residential units dependent upon the land use

- provide guidance on how land uses should be distributed for mixed use development

- allow flexibility in the distribution and encourage mixed uses that support the comprehensive plan's mobility strategies

The plan links transportation and land use by including the Planned Mobility (PM) land use designation which allows mixed-use development to occur at higher density and intensity with a goal of creating "vibrant" places and reducing the need to travel large distances. There is no predetermined formula for deciding the land use mix; the appropriate mixture of uses, density, and intensity will depend upon factors that include site conditions and the character of adjacent neighborhoods

Source: Boca Raton Comprehensive Plan Transportation Element (102).

GOP 2-3. Developer Contributions to the Multimodal Environment

Goal/ Objective
Objective: Contributions to Multimodal Environment. New
developments or redevelopment projects shall contribute to
providing a safe, convenient, comfortable and aesthetically
pleasing transportation environment that promotes walking,
cycling, and transit use. Appropriate improvements or
enhancements to the multimodal network may be required
as a condition of development approval, such as the
following:

- Full accommodations for pedestrian access and movement, including shaded sidewalks, benches and enhanced crossings;

- Full accommodations for bicycles, including lockers, showers, and racks;

- Direct connections between the MMTD and the regional bicycle/pedestrian network;

- Installation of shared use paths;

- Well-designed accommodations for transfer of passengers at designated transit facilities;

- Preferential parking for rideshare participants;

- Well-designed access for motor vehicle passenger drop-offs and pick-ups at designated transit facilities and at commercial and office development sites;

- Full accommodation for the mobility impaired, including parking spaces, sidewalks and ramps for handicapped access;

- Weather protection at transit stops. 


\section{Multimodal Quality/ Level of Service}

Multimodal level of service standards go beyond roadway level of service to ensure that the operating characteristics of other modes are maintained or improved to a locally desirable level. Standards may relate to a variety of operational characteristics of importance to each mode, and may be simple or complex depending upon the planning capacity of the community. Section 2.3 discussed the topic of multimodal quality/level of service (Q/LOS) analysis. Examples of Q/LOS policies in local comprehensive plans are provided in GOP 2-4 and GOP 2-5.

\section{GOP 2-4. Multimodal Level of Service Standards}

Policy 1.1.4 of the Alachua County Transportation Mobility Element provides level of service (LOS) standards for multimodal transportation within Urban Cluster Transportation Mobility Districts (49). LOS standards were adopted for roadways, bicycle, pedestrian, and express transit facilities. The LOS standards for pedestrian, bicycle, and express transit were adopted as part of an overall strategy to link land use and multi-modal transportation in the area designated as Urban Cluster in a Mobility Plan which was adopted as an amendment to the Comprehensive Plan in January 2010, and became effective in April 2010.

Policy 1.1.4. Within the Urban Cluster, the County adopts multi-modal level of service (LOS) standards for the following:

\begin{tabular}{|l|c|l|}
\cline { 2 - 3 } \multicolumn{1}{c|}{} & $\begin{array}{l}\text { Level of Service } \\
\text { (LOS) }\end{array}$ & Standard of Measure \\
\hline Pedestrian & B & Based on Presence of a pedestrian facility \\
\hline Bicycle & B & $\begin{array}{l}\text { Based on Presence of a bike lanes / paved } \\
\text { shoulders }\end{array}$ \\
\hline $\begin{array}{l}\text { Express } \\
\text { Transit }\end{array}$ & B & $\begin{array}{l}\text { Based on Peak Hour Frequency of 15 minutes or } \\
\text { less }\end{array}$ \\
\hline $\begin{array}{l}\text { Motor } \\
\text { Vehicle* }\end{array}$ & D & Professionally Accepted Traffic Analysis \\
\hline $\begin{array}{l}\text { Motor } \\
\text { Vehicle* } \\
\text { SIS** }\end{array}$ & C & $\begin{array}{l}\text { Professionally Accepted Traffic Analysis in } \\
\text { consultation with FDOT }\end{array}$ \\
\hline
\end{tabular}

* Standard applies to Collector and Arterial Roads

** Strategic Intermodal System 


\section{GOP 2-5. Multimodal Performance Targets}

Multimodal performance measures and targets provide a means to determine policy effectiveness. The City of Temple Terrace established the Temple Terrace Multimodal Transportation District (TT MTD) in the Mobility Element of the 2025 Comprehensive Plan. Policy 2.1.5 defines measurable minimum performance targets as follows:

A. The City of Temple Terrace shall coordinate with HART and the Metropolitan Planning Organization (MPO) to apply the transit quality of service framework as found in the Second Edition of the Transit Capacity and Quality of Service Manual (TCQSM) and required as part of the MPO'S long-range transportation plan.

B. The City of Temple Terrace establishes the following performance targets as minimum quality/level of service standards for transit, bicycle and pedestrian facilities and roadways within the TT MTD, as follows:

- $80 \%$ of all the bicycle and pedestrian facilities within the TT MTD network shall function at LOS C or better;

- All parcels within $1 / 4$ mile of a transit stop should be served by pedestrian facilities operating at LOS C or better;

- $80 \%$ of the employees and dwelling units in the TT MTD will be located within $1 / 2$ mile of a transit stop; and

- $70 \%$ of the employees and dwelling units in the TT MTD will be located within the service area of transit operating at LOS D or better

Source: City of Temple Terrace 2025 Comprehensive Plan (103)

\section{Major Roadway Network}

Major roadways serve mobility at a regional and local level. They include roadways functionally classified as arterials, as well as major collectors. The regional roadway system in urbanized areas is planned by the MPO in coordination with FDOT and local governments. Local governments may work within the MPO planning process to facilitate consistency with local comprehensive plan objectives. Some major roadways deemed locally important may also be planned, funded and maintained by local governments. In coordinating with other agencies or planning additional local roadways, keep in mind the following strategies:

1) Adopt a complete streets policy and guidelines to guide the functional classification of roadways and their design (see Appendix G for Fort Lauderdale's complete streets policy. See also ITR 2-17 and BP 2-52).

2) Designate transportation corridors requiring additional right of way and/or corridor management and include corridor management policies to preserve right-of-way needed for all transportation modes and to provide for dedication of land or conveyance of easements to local governments for planned transportation projects as provided in §337.273(6), F.S. (see Appendix F and GOP 2-6).

3) Provide for construction of parallel relievers or service roads along major highway corridors or within interstate interchange quadrants.

4) Provide for construction of new interstate highway overpass crossings to preserve continuity of street networks. 
5) Include grade separated intersection improvement(s) when appropriate for major roadway intersections.

6) Provide for construction of additional travel lanes and/or turn lanes to address existing or anticipated motor vehicle traffic volume where appropriate.

7) Establish priority for critical projects related to hurricane evacuation.

8) Include new arterial or major collector roadways to relieve motor vehicle traffic congestion and increase network connectivity.

9) Include design elements to increase bicycle and pedestrian safety and mobility.

10) Include network enhancements and design elements in support of managed lanes and modal priorities (e.g. truck routes, bus rapid transit routes, complete streets).

11)Provide park-and-ride facilities that accommodate carpooling and/or regional transit service.

12) Direct appropriate departments to perform safety audits as needed.

Practice Notes: Given the dramatically higher costs of delaying pavement maintenance, a growing number of large cities are choosing to enact a "fix it first" policy. Los Angeles did so after estimates indicated that it would cost the City $\$ 64,000 /$ lane mile for immediate repair versus $\$ 900,000$ per lane mile for delayed repair. (104) Other cities that have adopted this approach include St Louis, Honolulu, Philadelphia and San Francisco.

\section{ITR 2-17. Elements of an I deal Complete Streets Policy}

- Includes a vision for how and why the community wants to complete its streets

- Specifies that 'all users' includes pedestrians, bicyclists and transit passengers of all ages and abilities, as well as truck, buses, and automobiles.

- Applies to both new and retrofit projects, including design, planning, maintenance, and operations, for the entire right of way.

- Makes any exceptions specific and sets a clear procedure that requires high-level approval of exceptions.

- Encourages street connectivity and aims to create a comprehensive, integrated, connected network for all modes.

- Is adoptable by all agencies to cover all roads.

- Directs the use of the latest and best design criteria and guidelines while recognizing the need for flexibility in balancing user needs.

- Directs that Complete Streets solutions will complement the context of the community.

- Establishes performance standards with measurable outcomes.

- Includes specific next steps for implementation of the policy

Source: Smart Growth America's National Complete Streets Coalition (105) 


\section{BP 2-52. Measure the Success of a Complete Streets Policy}

"Complete streets" is a national movement oriented toward reducing the dominance of automobiles in street planning and design by ensuring consideration of all users. A complete streets policy is a relatively simple method of achieving greater attention to the full range of modes in street network planning and design. The design of a complete street will differ depending upon the context in which it is located, as well as the activities that occur on the roadway and within the right-of-way (17). The following City of Indianapolis Complete Streets Implementation Policy focuses on measurable results and implementation.

"The City shall measure the success of this Complete Streets policy using, but not limited to the following performance measures:

- Total miles of bike lanes

- Linear feet of new pedestrian accommodations

- Number of new curb ramps installed along city streets

- Crosswalk and intersection improvements

- Percentage of transit stops accessible via sidewalks and curb ramps (beginning in June 2014)

- Rate of crashes, injuries, and fatalities by mode

Rate of children walking or bicycling to school (beginning in June 2014)"

Source: National Complete Streets Coalition of Smart Growth America (106) 


\section{GOP 2-6. Tallahassee-Leon County Corridor Preservation Policies}

Policy 1.6.3: [M] (Effective 12/15/11) Future right-of-way needs for selected transportation corridors designated for improvement in the Tallahassee-Leon County Comprehensive Plan are generally depicted in the table below and in the Future Right-of-Way Needs Map and the Long-range Transportation Plan.

\begin{tabular}{|c|c|}
\hline \multicolumn{2}{|c|}{$\begin{array}{l}\text { Future Right-of-Way Needs } \\
\text { WI THOUT an Existing Corridor Alignment }\end{array}$} \\
\hline Functional Classification & ROW (ft.) ${ }^{1-3}$ \\
\hline $\begin{array}{l}\text { Blueprint Principal Arterial }^{4} \\
\text { Principal Arterial } \\
\text { Minor Arterial Major } \\
\text { Collector } \\
\text { Minor Collector }\end{array}$ & $\begin{array}{l}230 \\
200 \\
176 \\
146 \\
100\end{array}$ \\
\hline
\end{tabular}

Notes:

1) Widths represent maximum anticipated ROW needs for generalized corridors; not precise alignments. Where a specific alignment is established through alignment studies, engineering studies or design, such alignment shall apply for the purpose of development review. Actual road location and design will be determined by specific corridor and design studies.

2) Alternative widths may be established by the local government, in consultation with other affected agencies, pursuant to an adopted Critical Area Plan or based upon an analysis of existing constraints, community planning objectives, and other considerations unique to the roadway or surrounding land development.

3) In addition to the number of travel lanes, the following are important considerations in the determination of right-of-way needs for future corridors:

a. Space for sidewalks to provide safe and convenient movement of pedestrians.

b. The provision of bike lanes or separate bike paths.

c. Space for current or future location of utilities so that, when necessary, they can be safely maintained without undue interference with traffic. The utility strip needs to be of sufficient width to allow placement of a water main so that in the case of rupture, neither the roadway pavement nor adjacent property will be damaged.

d. Accommodation of stormwater at the surface or in storm drains.

e. Accommodation of auxiliary lanes at intersections.

f. Placement of trees to improve the aesthetic qualities of the roadway, to shade pedestrians, and improve community appearance. The space needs to be adequate to accommodate tree growth without damaging sidewalks, abutting development, or curb and gutter.

g. Allowing for changes in the paved section, utilities, or other modifications, that may be necessary in order to meet unseen changes in vehicular, pedestrian, bicycle, or other transportation needs as a result of changes in land use and activity patterns.

4) Planned ROW needs for Capital Circle from Centerview to W. Tennessee, as accepted by the Blueprint Intergovernmental Agency on November 19, 2001.

Policy 1.6.4: [M] (Effective 12/15/11)

All proposed development plans on designated future transportation corridors shall be reviewed for consistency with the Future Right-of-Way Needs Map, the Long-range Transportation Plan, and any specific alignment or engineering studies and shall be consistent with identified right-of- way needs for designated future transportation corridors as a condition of development approval.

Source: Tallahassee-Leon County Comprehensive Plan (107) 


\section{Access Management}

Access management is the coordinated planning, regulation, and design of access between roadways and land development. Careful control of access along major roadway corridors reduces traffic conflicts and flow interruptions, while improving safety for drivers, pedestrians, and bicyclists. Keep in mind the following policies and strategies to advance access management objectives for major roadways and around freeway interchanges:

1. Include policies and strategies to provide alternative access to development on arterial roadways, such as parallel relievers, service roads, parking lot cross access, and requirements for unified on-site circulation (see GOP 2-7, for example).

2. Include policies and strategies to close excessive or unsafe driveway connections or to redesign overly-wide or poorly designed connections.

3. Include policies and strategies to replace continuous two-way left turn lanes with medians on multi-lane arterials.

4. Require conformance of new signals with signal coordination plans and FDOT signal spacing standards for the state highway system.

5. Restrict access in the functional area of highway interchanges.

6. Control access in the functional area of roadway intersections.

7. Require adequate, uninterrupted throat length for driveways and frontage roads that connect to arterial roadways.

8. Include measures to close or redesign inadequately designed median openings.

Practice Notes: Access levels for the state highway system are established by the Florida Department of Transportation. Local governments may assign access levels to locally maintained thoroughfares or establish access location, spacing and design criteria in roadway functional categories. Goals, objectives and policies, plus roadway and access design standards and land development regulations, are used to implement the access management program. 
GOP 2-7. Access Management

Objective 1.4 Connectivity and Access Management: Reduce vehicle trip demand, increase access and safety for cyclists and pedestrians, and preserve the integrity of the transportation system with effective connectivity and access management programs.

Policy 1.4.8: The City of Tallahassee and Leon County shall adopt and maintain access management ordinances and supporting design standards to control the location, spacing, operation, and design of access connections and median openings. Development access shall be designed to protect the maximum service volume, safety, and operating characteristics of transportation facilities that it impacts, considering impacts to all modes and users.

Policy 1.4.10: Properties under the same ownership, consolidated for development, or part of phased development plans shall be considered one property for the purposes of access management. Access points to such developments shall be the minimum necessary to provide reasonable access, rather than the maximum available for that property frontage.

Source: Tallahassee-Leon County Comprehensive Plan (107)

\section{Minor Street Network}

The minor street network serves to provide connectivity from land use to the major roadway network. It includes roadways functionally classified as minor collectors and local streets or alleys. The following criteria are aimed at improving the connectivity and availability of local and collector street networks and promoting increased connection of activity centers to surrounding neighborhoods to enhance local mobility and reduce local trips on major roadways.

1) Include network-enhancing local and minor collector street projects.

2) Promote direct connections between activity centers and surrounding residential areas.

3) Include policies and strategies to increase street network connectivity.

4) Include measures to increase pedestrian safety at intersections, mid-block crossings, and while walking along the road.

5) Include measures to increase bicycle safety.

6) Include measures to provide safe routes to schools. Coordinate with school board and local law enforcement regarding Safe Routes to Schools within a two-mile walking distance from schools. Effort should focus on physical improvements as well as educational and enforcement activities.

Practice Notes: A connectivity index is a network walkability measure used to quantify how well a street network connects destinations (70 p. 14). To measure a connectivity index, count the number of street segments (links) and intersections and cul-de-sacs (nodes) within the study area. Divide the number of links by the number of nodes to calculate the index. Areas with a score of 1.4 or higher are considered walkable (70 p. 14). In suburban residential areas, bicycle and pedestrian connections can be provided independent of the street network by connecting cul-de-sacs or providing shared pathways linked to destinations. 
GOP 2-8. Street Network and Connectivity

Goal/ Objective

Measure of

Means of

Effectiveness

Measurement

Goal: Street Network and Connectivity. The [local government] shall provide a dense, interconnected network of local and collector streets that supports walking, bicycling and transit use, while avoiding excessive through traffic in residential neighborhoods.

Objective: The street network shall be comprised of a system of interconnected and direct routes with a connectivity index of 1.4 or higher.

M.O.E.: Is the
connectivity index of 1.4
or higher?

M.O.E.: Is the
connectivity index of 1.4 or higher?
Yes or No?

Policy: Missing links in the street network shall be identified and eliminated where feasible through the development and capital improvement process.

Objective: Urban cores and activity centers shall be subject to a maximum block (length or perimeter) requirement to advance connectivity as development M.O.E: Has maximum block length been established in the LDRs? and redevelopment occurs (Coordinated with FLUE).

Policy: Connections of new local and collector streets and driveways with arterial streets shall conform to adopted access spacing intervals of the agency with jurisdiction.

Policy: The local street circulation pattern shall maximize access to individual lots and activity center destinations (e.g. schools, commercial areas, parks). At the same time, the circulation pattern shall discourage cut-through traffic in residential areas through designs such as curving roads, jogs, Tintersections, roundabouts, gateway treatments, and traffic calming techniques (e.g. chicanes, speed tables, raised intersections, on-street parking, etc.).

\section{Public Transportation Network}

Public transportation in urban areas may consist of a variety of modes, services and routes ranging from demand response systems to commuter rail. Goals, objectives and policies may focus on coordination of land use decisions with public transportation and a variety of service enhancements and priority investments. Another key issue for transit is providing adequate connections to/from one's origin and destination, also known as "first mile/last mile" connectivity. Small-scale services such as local circulators may be beneficial for this purpose and thus a focus for future planning efforts. Funding is another challenge, in particular funding for ongoing operations (see GOP 2-9, GOP 2-11, and GOP 2-10). Strategies include:

1) Identify and use land use strategies to reinforce statewide/regional transit and express transit service traveling through or with endpoints within plan boundaries.

2) Address existing and planned local transit within plan boundaries, including route locations, headways, span of service, and infrastructure and land use strategies.

3) Improve the quality of service for transit, considering the potential for enhanced route and destination connectivity via locally provided transit circulators that connect to the larger transit system. Shelter amenities, safety and security at transit stops, and quality of maintenance at transit stops are other important issues in this regard. 


\section{GOP 2-9. Addressing Transit Operating Needs}

Many communities struggle to fund transit operations. The City of Boca Raton defines transit operations as a capital improvement to allow for greater latitude in establishing creative funding options for transit. The following objective and definitions are included in the City of Boca Raton Capital I mprovements Element:

OBJ ECTI VE CI E.1.1.0. Define types of public facilities, establish standards for levels of service for each type of public facility, and determine what capital improvements are needed in order to achieve and maintain the adopted standards for levels of service. (9J-5.016[3][b](1)

(A) "Capital improvement" means land, improvements to land, structures (including design, permitting, and construction), and initial furnishings and selected equipment. Capital improvements have an expected useful life of at least 3 years. For the purposes of the Comprehensive Plan, capital improvements also include the cost of transit operations...

(B) "Category of public facilities" means a specific group of public facilities, as follows:

(B) (1) Category A public facilities are transportation facilities (e.g. arterial and collector roads, sidewalks, bike lanes, shared use pathways/trails, and transit infrastructure and operations), arterial and collector roads, stormwater management, potable water, sanitary sewer, solid waste, and parks and recreation facilities owned or operated by the City of Boca Raton, all of which are addressed in other elements of this Comprehensive Plan.

Source: City of Boca Raton Capital Improvements Element (108)

\section{GOP 2-10. Transit}

Goal: Transit. The [local government] shall work with the [local transit agency] to ensure that the community is well-connected via transit to major trip generators and attractors, that transit stops and waiting areas are safe and comfortable, and to enhance intermodal connections.

Objective: Identified needs shall be reflected in the [transit development plan (TDP)] and/or the [local government] capital improvements program and priority shall be given to funding of improvements that increase the availability, speed, frequency, duration, and reliability of transit.

Objective: The [local government] shall coordinate with the [local transit agency] regarding the provision of transit centers and other facilities for the transfer of passengers to and from the community via the regional transit system.

Policy: The [local government] shall coordinate with the [local transit agency] regarding the provision of benches, signage, lights, and covered or enclosed waiting areas for transit stops.

Policy: The [local government] shall coordinate with [local transit agency] regarding the provision of bicycle parking at transit stops and bicycle racks on buses as a means to interface bicycle travel with public transit. 


\section{GOP 2-11. Transit Networks}

The Palm Beach County Comprehensive Plan presents the following goal, objective, and policy:

Goal 1: Provide an interconnected multimodal transportation system which moves people, goods, and services in a safe, efficient, convenient, and economical manner with minimal adverse impacts to the environment

Objective 1.5: The County shall encourage the use of transit within Palm Beach County. The measurement of the success of this objective shall be through increased usage of transit services within Palm Beach County

Policy 1.5-c: Palm Tran shall continue to provide and plan for bus service to Tri-Rail stations and to major traffic generators and attractors in the County

Source: Palm Beach County Comprehensive Plan (92)

\section{Transportation Demand Management}

Transportation demand management (TDM) consists of strategies that foster increased efficiency of the transportation system by influencing travel behavior by mode, time of day, frequency, trip length, regulation, route, and/or cost. TDM discourages drive-alone travel through management of existing transportation infrastructure, services, and resources. TDM strategies include carpooling, compressed work weeks, telecommuting, limited parking, and provision of bike and locker facilities by employers. The Florida Department of Transportation has a policy to ensure the consideration of TDM strategies "in all studies, plans, programs, functional areas, and in employee benefit programs (Topic No.: 000-725050-h) (40)." Example TDM programs and ordinances can be found for Boca Raton at bocatmi.com/section/BOCA TDM/23/interior.php and Washington State at www.wsdot.wa.gov/Transit/CTR/. See GOP 2-12 for an example TDM policy for local transportation plans.

Local planning strategies that could be considered in the development of goals, objectives, and policies for TDM include:

1. Provide for high quality transit service operating in managed lanes.

2. Incorporate intelligent transportation systems (ITS) strategies.

3. Establish institutional strategies such as a transit use/carpooling incentive program for employees.

4. Establish commuter financial incentives.

5. Provide infrastructure, policies, and financial incentives designed to encourage alternatives to single occupant vehicle travel.

6. Establish pricing strategies.

7. Provide for safer travel for all modes, through engineering, enforcement, and education.

8. Establish a commute trip reduction strategy to be implemented via a commute trip reduction ordinance. 
9. Provide for on-demand transportation options such as car- and bike-sharing. Ensure space availability for car-sharing slots in public parking facilities or reserved space for bicycle stations in public areas as well as transit locations.

\section{GOP 2-12. Transportation Demand Management}

TDM strategies are generally established and implemented in specialized plans such as transportation management association (TMA) plans; however, objectives and policies in the transportation element should guide the establishment of such strategies. The following example policy, suggested for Multimodal Transportation Districts (MMTD), could also be adapted in the transportation element for broader application.

Policy 17: Vehicle Trip Reduction/Transportation Demand Management. Transportation demand management strategies shall be incorporated into the transportation planning process for MMTDs to alleviate congestion. A range of techniques will be considered, such as vanpool/ridesharing programs, parking management, pricing, transit vouchers, pre-tax incentives, telework, flextime, and/or other appropriate trip reduction strategies. The local government will identify and work with other service providers, as appropriate, to implement the selected strategies.

Source: Model Regulations and Plan Amendments for Multimodal Transportation Districts (13)

\section{Bicycle and Pedestrian Network and Safety}

A safe and continuous bicycle and pedestrian network comprised of a system of interconnected and direct routes is an important part of a multimodal transportation system. Local planning strategies and issues to consider in the development of goals, objectives, and policies include:

1. Identify opportunities to implement bicycle lanes and ADA accessible sidewalks of appropriate width on or near all collector and arterial routes where appropriate.

2. Include planned projects to address gaps in the bicycle and pedestrian network and improve connectivity (see GOP 2-13).

3. Address the continuation of, or establish new, shared use paths.

4. Require new development to maintain continuous pedestrian networks, including connections to transit stops, adjacent lots, and between building entrances and the internal and external sidewalk network.

5. Require new development to maintain continuous bicycle networks, including connections to transit stops and adjacent properties, and to provide bicycle parking at all non-residential uses, multi-family uses and other key destinations.

6. Adopt bicycle and pedestrian quality of service standards and/or performance measures. 
GOP 2-13. Bicycle/ Pedestrian Network Connectivity

Goal/ Objective

Measure of

Effectiveness

Means of Measurement

Goal: Bicycle/Pedestrian Network and Connectivity. The [local government] shall provide direct bicycle and pedestrian connections within and between residential areas and supporting community facilities and services, such as shopping areas, employment centers, transit stops, neighborhood parks, and schools.

Policy: Missing links in the bicycle and pedestrian network shall be identified and eliminated where feasible through the development and capital improvement process. Missing links may include locations between cul-de-sacs, through walls or fences, mid-block where block length exceeds 660 feet, or where bicycle pedestrian routes would otherwise be "excessively" circuitous. Consider contraflow lanes in situations where criteria are met.

Policy: Highest priority for improvements shall be given to locations with high concentrations of pedestrian activity and where connections are needed to ensure easy access between transportation modes, with particular attention to bicycle and pedestrian access to schools, transit stops, and regional greenway or trail systems.

Objective: Urban cores and activity centers shall be subject to a maximum block (length or perimeter) requirement to advance connectivity as development and redevelopment occurs.

Objective: Consideration for Schools. The [local government] shall give special consideration to schools and their multimodal needs to provide a safe, accessible environment for students by giving high priority to bicycle and pedestrian facilities within a two-mile radius of all schools in both new development and redevelopment.

\begin{tabular}{|l|l|}
$\begin{array}{l}\text { M.O.E: Has maximum } \\
\text { block length been } \\
\text { established in the LDRs? }\end{array}$ & Yes or No? \\
\hline $\begin{array}{l}\text { M.O.E: Has high priority } \\
\text { been given to bicycle and } \\
\text { pedestrian facilities within } \\
\text { a two-mile radius of all } \\
\text { schools? }\end{array}$ & Yes or No? \\
\hline
\end{tabular}

\section{Ports, Aviation, Rail, and I ntermodal Facilities}

A freight system based on rail, ports, aviation and the intermodal connections between each of these modes is crucial to an effective multimodal transportation system.

1. Align planning for ports, aviation, rail, and intermodal connections with the future land use element.

2. Coordinate with applicable plans (airport master plan, port master plan, etc.).

3. Address existing SIS facilities, necessary improvements to those facilities, and the intermodal connections on the SIS network.

4. Designate local routes intended for freight movement by large trucks and establish appropriate roadway design and operational measures for their efficiency.

GOP 2-14 provides an example objective and policies. An example goal and supporting objectives that address the integration of rail, ports, aviation, and related intermodal facilities into Pasco County's transportation system appear in GOP 2-15. In anticipation of the Central Florida Intermodal Logistics Center, the City of Winter Haven developed the objective and supporting policies listed in GOP 2-16. 


\section{GOP 2-14. Access to Ports and Airports}

Manatee County adopted the Port Manatee Master Plan as a "subelement" of the Manatee County Comprehensive Plan thereby expressing its support for the goals, objectives and policies of the Port Authority. Below are some examples:

Objective 2.3: Off-Port access and connectivity. The Port shall collaborate with other governmental agencies and private interests to protect and enhance vehicular access and the flow of commodities between the Port and regional transportation facilities. These entities include FDOT, the SarasotaManatee MPO, and the CSXT.

Policy 2.3.1: Vehicular access improvements. To maintain and expand the high-speed intermodal access and connections needed for the efficient movement of goods to and from its facilities, the Port shall work with FDOT and the MPO to gain priority funding for needed improvements to roads over which Port truck traffic must travel. Such roads include the Port's SIS connector ...as well as potential cargo corridors connecting the Port with the Encouragement Zone to facilitate the transfer of containerized and non-containerized commodities between the sites.

Policy 2.3.2: U.S. 41 Corridor. The Port shall pursue contacts with the FDOT District 1 access management staff to configure existing median openings and driveways to higher access management standards appropriate for the segment of U.S. 41 from the Port south to I-275. In addition, the Port shall coordinate with the FDOT to provide input regarding planning for the U.S. 41 corridor between the Port and I-275 from a freight and goods movement standpoint, including consideration of grade separations at the intersections of U.S. 41 with Piney Point Road and with South Dock Street.

Policy 2.3.3: Direct Port to I-75 Connection. The Port shall collaborate with the FDOT in the ongoing study of the proposed direct Port to I-75 connector to ensure that the eventual corridor alignment and design are consistent with the Port's planned future expansion and accommodates the needs of Encouragement Zone property owners as well as those in the North County Gateway Overlay District.

Policy 2.3.4: Rail service and connectivity. The Port shall work with the CSXT to identify and pursue improvements to the off-Port rail infrastructure and operations, which could facilitate goods movement by maximizing rail service and interchanges for the Port and its related industries, including access to adjacent Encouragement Zone properties. 


\section{GOP 2-15. Port, Airport, Rail, and I ntermodal I ntegration}

\section{\begin{tabular}{l|l|l}
\hline Goal/ Objective & Measure of Effectiveness & Means of Measurement
\end{tabular}}

Goal 1.1.0: The plan will effectively address the integration of port, airport, and rail modes of transportation, and associated intermodal facilities into a cohesive intermodal system that will enhance travel for all users of Pasco County's transportation system.

Objective 1.1.1: The transportation $\quad$ MOE 1.1.1.1: LOS on roads system will provide for the safe and carrying a high truck traffic efficient movement of people and freight via the highway, port, airport, and rail systems.

Objective 1.1.2: The plan will consider the enhancement and protection of existing intermodal facilities and, in general, linkages between modes.

Objective 1.1.3: Project prioritization will consider new intermodal facilities and improvements to existing intermodal facilities. percentage.

MOE 1.1.1.2: LOS on designated access roads serving intermodal facilities. MOE 1.1.2.1: Are park-andride lots utilized in the intermodal system? MOE 1.1.2.2: Does a public airport master plan exist? MOE 1.1.3.1: Does the prioritization process consider intermodal facilities? Source: Pasco County 2035 Long Range Transportation Plan (110)

\section{GOP 2-16. I ntermodal Connectivity}

Objective 1.11: Coordinate the Expansion of existing or siting of new air, rail, road, or related transportation facilities of the Future Land Use and Conservation Elements of this Comprehensive Plan. Coordinate proposed road, airport, and non-motorized improvements with the plans and programs of adjacent cities, the Polk County TPO, Polk County, FDOT, and other appropriate agencies.

Supporting policies require:

- that transportation projects be reviewed for consistency with applicable plans,

- $\quad$ strategies are developed that mitigate adverse impacts on adjacent natural resources, and

- intermodal management of surface and air transportation is managed in an effort to support the overall transportation system. 


\section{Chapter 3. Model Element for Small Communities and Rural Areas}

The model element for rural areas includes guidance for local governments outside of MPO planning areas with less than 50,000 in population (municipalities) and less than 75,000 in population (counties). These jurisdictions are identified as Categories A and B in Appendix A, Table A-1. In developing a multimodal transportation element, local governments that meet these criteria are required to plan for traffic circulation (i.e., the types, locations, and extent of existing and proposed major thoroughfares and transportation routes), as well as bicycle and pedestrian ways.

Communities in non-urbanized areas of Florida often emphasize different issues than those in metropolitan areas, particularly economic development including access to jobs and, more recently, intermodal logistics centers. Public transportation is usually limited to ondemand paratransit service. Bicycle and pedestrian modes of travel may be intermixed on the roadway network with little funding to provide separate facilities. Local governments may apply this model element to more fully develop transportation planning efforts through data collection, analysis, and community vision.

The local government has the opportunity to address many aspects of transportation and land use within the transportation element. The transportation system may be discussed in the context people and goods/freight mobility, affordable housing, environmental justice, societal issues, economic development, livability, walkability, healthy lifestyles, etc. Small communities and rural areas should address the availability of transportation facilities and services to provide mobility, access land uses, and connect to urban areas.

Practice Notes: Interpretation of the guidance in the model element involves professional judgment as to the appropriate level of analysis or treatment feasible or appropriate for a given mode or issue, in light of local conditions and priorities.

\subsection{Community Vision and Priorities}

Transportation has a direct impact on the quality of life in a community. It affects the way an area grows, the ability of businesses to move freight and retain employees, the ability of residents to move about safely and easily without a car, the quality of the natural environment, and even the health and wellbeing of local residents. Because the transportation system has many quality of life implications, it is a central issue in advancing a community's overall vision for its future.

A key step in the transportation planning process is to create a community vision that reflects the "interaction between desired states of prosperity, environmental quality, and social equity/quality of life"
"The intent of this Comprehensive Plan is to satisfy [future travel] demand through proactive planning, such as:

- Creating self-contained communities with

- Internally connected street networks, and

- Corridor preservation throughout the County to the communities externally."

- Taylor County, FL Traffic Circulation Element 
and to identify issues that need to be addressed to achieve that vision (2). Planning is an iterative process, and the vision and priorities will flow from the existing conditions analysis discussed in later sections, other local planning efforts, and the overall public involvement process. The visioning step involves extensive community outreach and is generally the most interactive step of the planning process.

Practice Notes: Chapter 163. 3177(2), F.S., notes that coordination of the several elements of the local comprehensive plan shall be a major objective of the planning process. The elements must be consistent. Each map depicting future conditions must reflect the principles, guidelines, and standards within all elements and must be contained within the comprehensive plan. The community vision and priorities are important criteria to use in evaluating and selecting plan alternatives. Doing so helps to maintain coordination and consistency of the transportation element with other elements of the comprehensive plan.

Developing a community vision and priorities may occur before or after the existing conditions inventory and should address the roles that the various components of the transportation system play within the community to achieve the community vision, as follows:

\section{Briefly describe the community's vision and priorities for transportation as drawn from public meetings and other local and/ or regional plans or visions and prepare a conceptual vision or mission statement.}

Synthesize strategic areas of importance to the community into categories for future improvement to be addressed in the plan. These categories help to provide focus in defining the community's future vision and priorities for planning purposes:

- widen and/or pave existing roads

- consider alternative corridor improvements

- reserve and connect transportation corridors

- analyze freight movement, speed, and reliability

- support employment and school commuting patterns

- focus on compact development

- examine walking and bicycling environments

- provide a variety of transportation choices

2. Discuss principal findings and identify strategic areas of improvement from the existing conditions analysis as they relate to the vision and priorities. Prepare a visionary map identifying the local vision and priorities.

3. Look at the state transportation vision and the regional vision for the area. Consider preferred scenarios and any incompatibilities resulting from differences in visions and priorities from those of other plans and agencies.

The Florida Transportation Plan (www.2060ftp.org/) and Florida Strategic Intermodal System (SIS) Strategic Plan (www.dot.state.fl.us/planning/sis/Strategicplan/) contain visions for the future transportation system including future corridors 
(www.flfuturecorridors.org/) deemed critical to the state's economic competitiveness and quality of life. Local governments potentially affected should consider connectivity to and land use implications of such future corridors and SIS facilities.

Regional visions can play an important role in increasing regional land use and transportation coordination in multimodal planning. Several agencies and organizations, notably regional planning councils, have undertaken regional visioning efforts to make collective decisions about each region's future (see Figure 2-1. Regional visioning initiatives in Florida). Local governments often participate in these efforts and may also engage in local visioning efforts that can further inform the analysis.

Using these visions, the local government should analyze the effects of the various future land use scenarios on the transportation system. Are these scenarios compatible with the locally defined vision and strategic priorities? Are they different? Is further intergovernmental coordination required? These are questions that should be addressed in the analysis. In addition, the local government should begin to consider strategies to advance preferred scenarios as detailed in local and regional vision plans. Ideas for achieving local government multimodal transportation and land use visions and planning objectives are provided in Sections 3.4 and 3.5, including methods to evaluate and monitor success.

A visionary land use concept map may be useful to guide official decisions on land use map changes in keeping with the intended community vision and priorities. BP 3-1 contains a land use and transportation vision for Taylor County that included the identification of key issues and evaluation of alternative development approaches described in BP 3-2. 


\section{BP 3-1. Prepare a Land Use and Transportation Vision Plan}

The Vision 2060 Plan for Taylor County lays out a land use and transportation vision that discourages sprawl and focuses on an urban district around Perry, a coastal district, and a rural district.
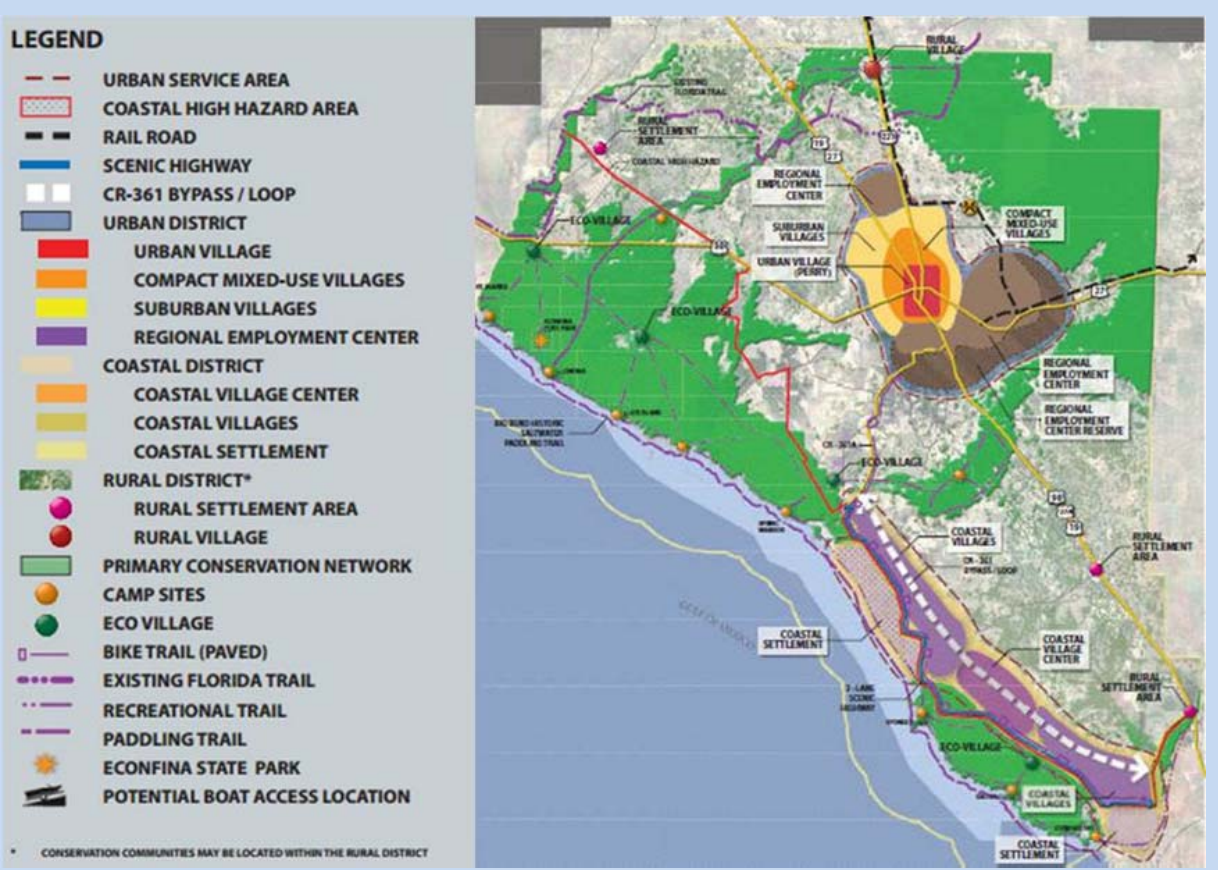

Source: Vision 2060 Plan for Taylor County - www.taylorcountyvision.org/web-content/

Future transportation concepts developed by University of South Florida Graduate Students included visionary designs of urban, suburban, and rural corridors. The rural corridor (Figure 3-1) illustrates the incorporation of high speed rail and new technologies such as piezoelectric generators along with sustainability features such as rain gardens and green energy farming. The City of Altamonte Springs illustrated the vision for their future transportation system employing a variety of policies found in their Mobility Plan (Figure 32). Policies addressed transit-oriented development connections to the SunRail station, transit stops, parking management, shade trees, and many other strategies. 


\section{BP 3-2. Key I ssues and Scenario Planning}

Taylor County developed the Vision 2060 Plan in 2009 as a proactive planning tool "...that guides future decisions that protect, sustain, and enhance our quality of life." Key issues identified through a public involvement process included:

- Major development allowed outside the City of Perry may cause it to lose its historic importance as the urban and commercial center for the County and the region. Unplanned growth that is dispersed and low density in character:
o Consumes more land
o Increases commuting time
o Increases fire and emergency response time
o Provides little opportunity for future public transit
o Provides little opportunity for quality workforce housing
o Is more expensive to build and maintain

- Unplanned growth may encroach into recreational lands and existing hunting leases, reducing opportunities for hunting, fishing, and other outdoor recreational activities important to maintaining the quality of life.

- The agricultural and silvicultural heritage may be adversely affected as new development occurs.

The vision planning effort involved the analysis of three alternative development patterns:

- Alternative 1: Centers featured two urban service areas. The first around the City of Perry and the Regional Employment District Center and the second along the coastline.

- Alternative 2: Coastal Corridor connected the two urban villages with suburban village development that consumed portions of the rural area. A bypass of CR-361 was envisioned to maintain the rural character of the main facility.

- Alternative 3: US-27 Alt Corridor focused development along US 27 with three urban centers connected by a commuter rail line serving Tallahassee and Gainesville.

Alternatives were compared using land use data and estimated cost of new infrastructure. A modification of the Centers Alternative was chosen due to anticipated lower lifetime costs of infrastructure capital and operating costs. In addition, $16 \%$ of the land area is within the urban service area and $84 \%$ remains in the rural service area.

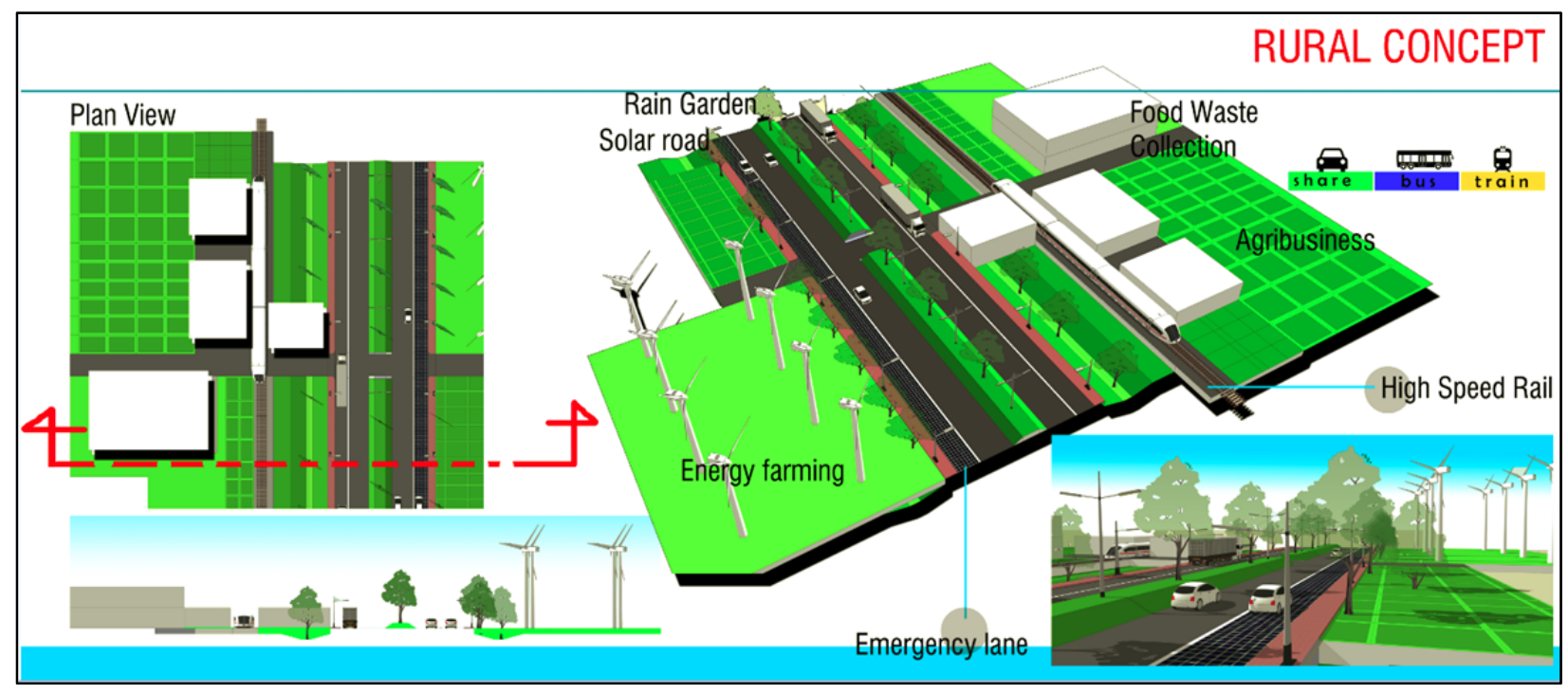

Figure 3-1. Rural concept

Source: USF Graduate Student Future Corridor Visioning Presentation 


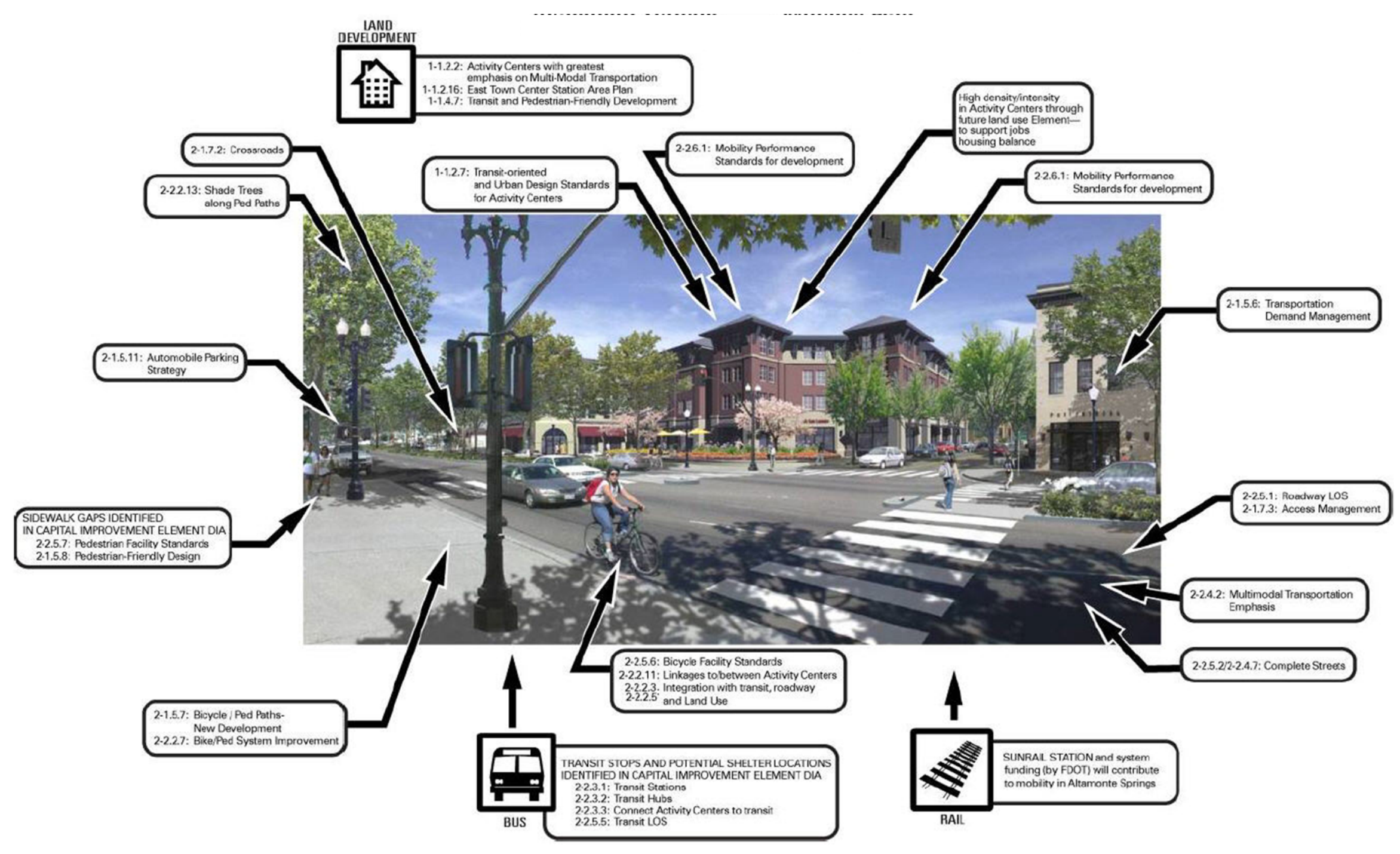

Figure 3-2. Altamonte Springs vision

Source: City of Altamonte City Plan 2030 (37) 


\title{
3.2 I nventory and Analysis of Transportation and Land Use Conditions
}

A detailed inventory and analysis of existing transportation and land use conditions provide the necessary foundation for the future transportation plan. The inventory will draw heavily from the supporting data and analysis in the inventory of modal and regional plans or visions noted above, as well as from the inventory of existing transportation and land use conditions within the local jurisdiction. This section describes data needs and information sources for this inventory and provides guidance on the analysis of existing conditions.

\begin{abstract}
Practice Notes: Chapter 163.3177(1)(f), F.S., notes that the comprehensive plan must be based on appropriate data. Data and analysis may include, but is not limited to: surveys, studies, community goals and vision, and other available data. Copies of key studies and data used in preparing the plan should be included in the plan or they "may not be deemed a part of the comprehensive plan." Other supporting studies, data, or supporting documents may still be used in determining compliance and "must be made available to the public."
\end{abstract}

Local governments of all sizes must document existing conditions including interactions between land use and transportation. Land use and transportation are interdependent dimensions, and coordination of the two is essential to achieving a variety of transportation and growth management goals. Reducing traffic congestion, improving roadway safety, lowering greenhouse gas emissions, containing public costs, sustaining economic growth, promoting livable communities, preserving natural areas and resources - these public goals require effective land use and transportation coordination. Focus on the multimodal aspect of the transportation circulation system can begin with a multimodal analysis of existing conditions including key intermodal connections and the system's relationship to existing land uses.

\section{I nventory of Regional and Modal Plans}

An initial step in the planning process is to collect the transportation plans of various modal providers and entities and to inventory the information in each plan that relates to the local government transportation system. Issues of importance include identified needs, planned and prioritized improvements by mode, adopted quality/levels of service, land use and transportation issues and recommendations, and maps of existing and proposed facilities. A goal of the inventory is to document the projects that are being planned in the community by other agencies and to ensure compatibility of local plans with other regional and state transportation planning efforts. Inconsistencies in planning efforts should also be documented and addressed, as noted in Section 2.4. Below is an overview of some items to document.

1. I nventory agency and modal plans and document data and information on all issues of importance to the local multimodal element, such as, but not limited to:
a. quality/ level of service for various modes and identified needs
b. crash analyses
c. land use issues related to the transportation system
d. access conditions along major thoroughfares 


\section{e. network continuity and gaps}

f. freight movement objectives and needs

g. projects with committed funding within the next three years

h. funding commitments, prioritization, and partnering opportunities

i. inconsistencies with exiting state, regional, and local government plans

ITR 2-1 (Plans and Programs of State and Regional Agencies and Modal Providers) includes some of the state, regional, and modal transportation plans to collect and review in this analysis. Subsequent sections of the model element address these issues in more detail by topic or mode, including additional steps for evaluating the local transportation system.

Modal plans, including public transportation plans, contain important information for multimodal transportation planning efforts. Transit plays a role in the mobility of Florida's residents and visitors through both urban and rural transit systems. Figure 3-3 provides a map of Florida's fixed route transit systems and notes the counties that operate rural systems. Fixed route systems operate in urban areas while rural areas are predominately served by demand-responsive paratransit systems and are part of Florida's Coordinated Transportation System.

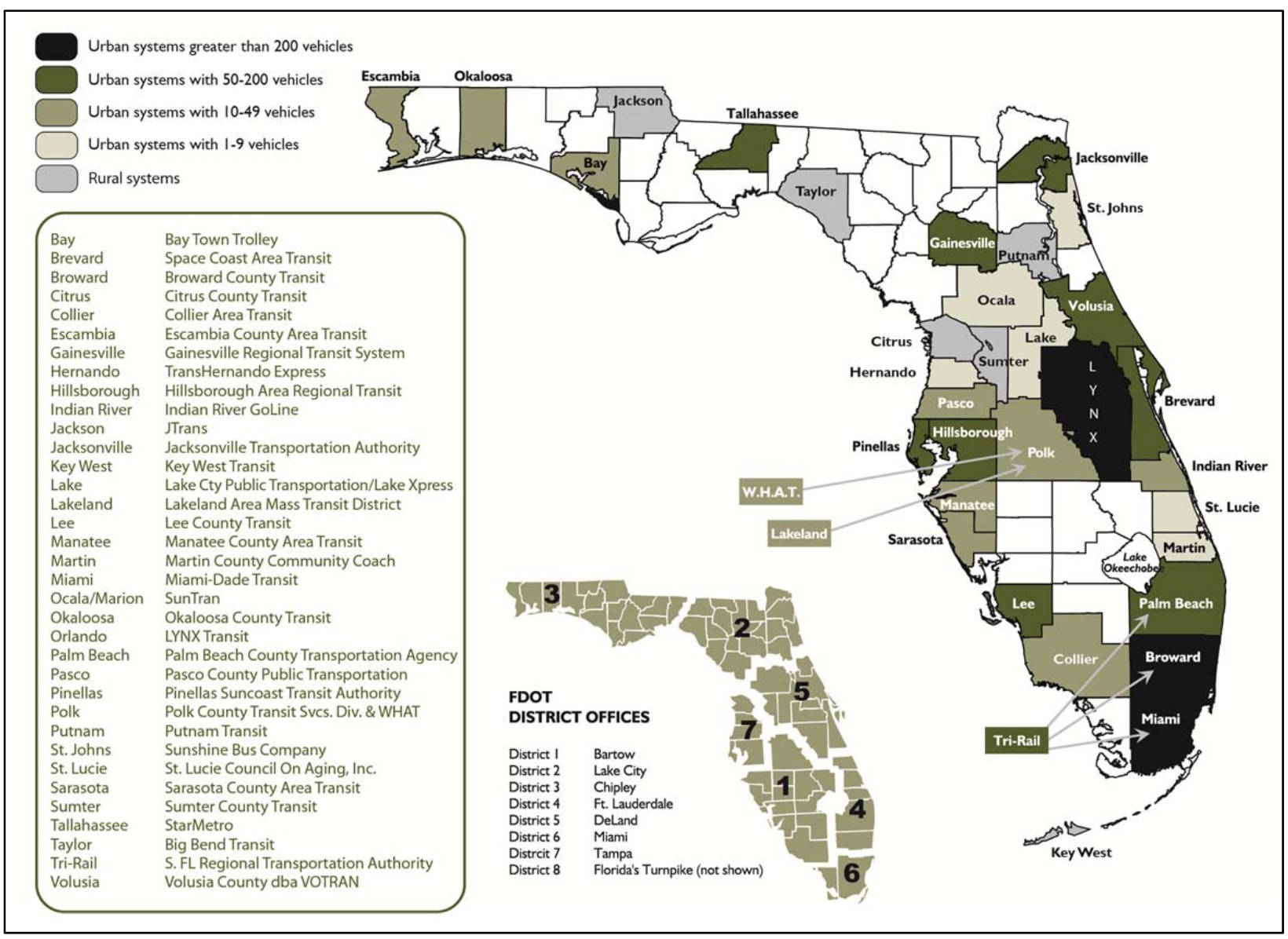

Figure 3-3. Map of Florida fixed route transit systems

Source: National Center for Transit Research. 


\section{I dentify priorities related to economic development plans and programs, including those related to rural areas of critical economic concern (RACEC).}

Efficient transportation systems are critical to economic growth and economic development plans commonly contain strategies to facilitate development that affect the transportation system. Efforts to create regional employment centers, industrial complexes, educational institutions, or increase tourism are reliant on mobility and accessibility. Economic development assistance is available for areas designated as RACEC. RACECs are described in $\$ 288.0656$, F.S., as "a rural community, or a region composed of rural communities, designated by the Governor, that has been adversely affected by an extraordinary economic event, severe or chronic distress, or a natural disaster or that presents a unique economic development opportunity of regional impact" (§288.0656 F.S.).

BP 3-3 maps the region and describes a catalyst site. These regions are targets for rural economic development initiatives (REDIs) which are meant to encourage economic development in RACECs through the implementation of catalyst projects. FDOT is one of the state agencies that provides programs and services for RACECs. Local governments seeking transportation projects for economic development through a REDI should contact their FDOT District office.

\section{Land Use and Multimodal Environment Conditions}

Understanding how existing land uses relate to the transportation system is key to planning for their integration. Building on the findings of the regional planning inventory, local governments should document existing land uses and land use conditions that relate to the multimodal transportation system and to system management strategies. Below are items to address in the detailed local land use and transportation inventory and analysis.

1. Map existing land use in relation to existing roadways and public transportation, including major generators/ attractors (e.g., employment centers, shopping centers, hospitals, schools, parking facilities, airports, ports, intermodal centers, etc.); town center(s); activity centers, and density and intensity of uses.

Building on the findings of the state, regional, and modal planning inventory, a local government should document land uses and land use conditions that relate to the multimodal transportation system and to system management strategies (e.g., access management, transportation demand management). A transportation element addresses trip generators (e.g., residential areas) and attractors (e.g., employment, retail, services) to gain a better understanding of travel patterns that may impact roadway needs, as well as what populations are using transit service (if available), where those populations are coming from, and where they are going. What constitutes a major traffic generator is subject to local interpretation and context - those in a small community or rural area will likely differ from those in a metropolitan area.

Practice Notes: While an existing land use map may indicate general land uses, those uses, centers, or districts that require greater accessibility should be mapped to facilitate this understanding. For the transportation element, future land use concepts should identify areas where walkable and compact urban development is 
desired. This guides future street design and the application of context sensitive solutions on major corridors, as well as planning and investment decisions relative to public transportation, pedestrian/bicycle services, and facilities.

BP 3-3. Rural Areas of Critical Economic Concern and Catalyst Sites

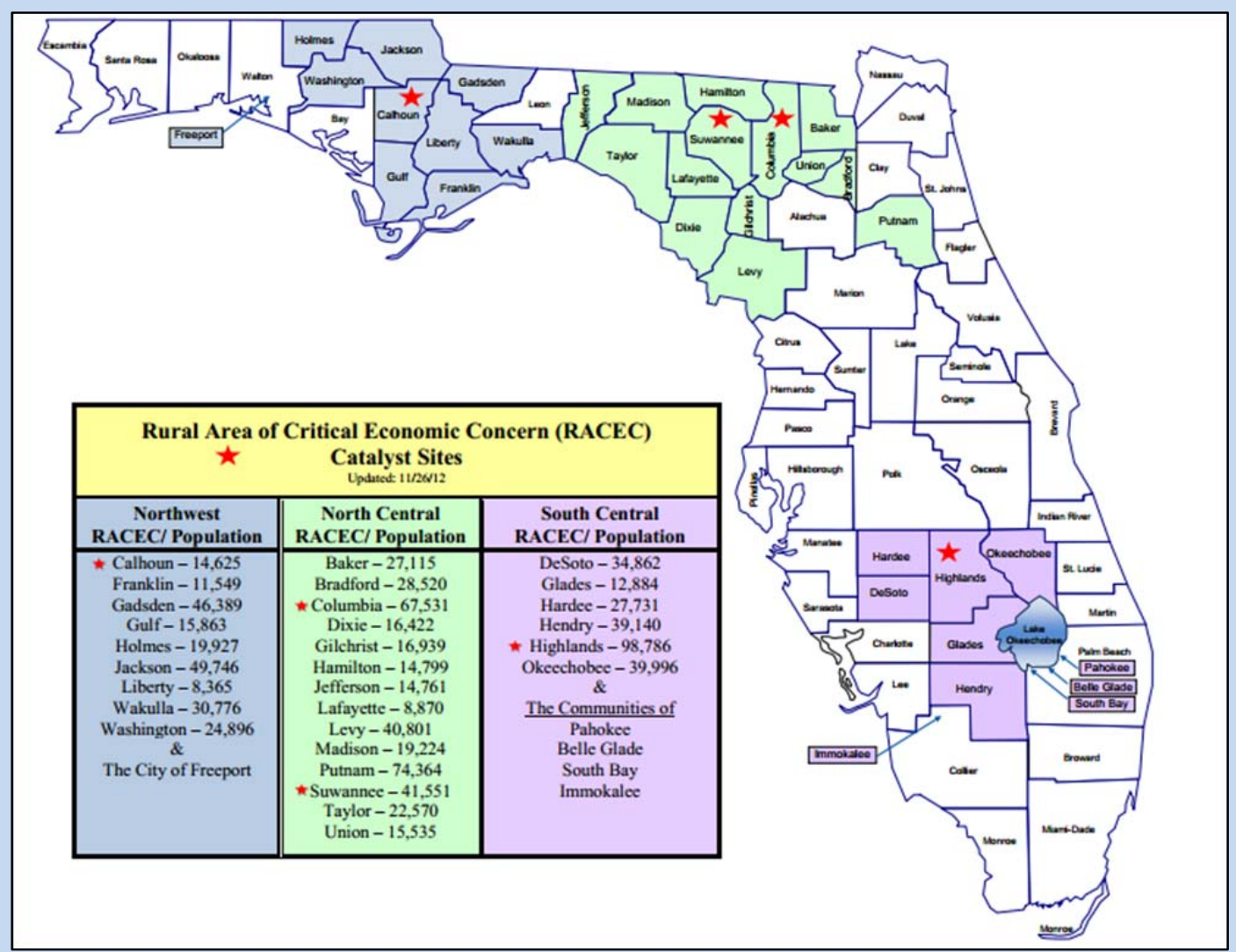

This map illustrates rural areas of critical economic concern designations in Florida with catalyst sites denoted by red stars. In the FY 2013 Florida Department of Transportation REDI Report, FDOT reported on its efforts to support a catalyst project (112). The Suwannee County Catalyst Site attracted a lumber company, Klausner Group, and a new sawmill facility is under construction. It is estimated that the sawmill will employ nearly 350 people and create an additional 600 jobs for suppliers and other indirect economic impacts.

FDOT programmed Economic Development Transportation Fund (EDTF) dollars to assist with improvements to the county road $\left(169^{\text {th }}\right.$ Road) that connects the sawmill to US 90 as well as ingress and egress to and from the site. Also, FDOT provided approximately $\$ 1.75$ million dollars to Suwannee County to extend the 4-lane section of US 90 for the purposes of providing left and right turn lanes onto $169^{\text {th }}$ Road as a public safety benefit. At the intersection of US 90 and $169^{\text {th }}$ Road, FDOT funded and coordinated the upgrade of a railroad crossing in support of the project. In addition, it is anticipated that there will be an increase in logging trucks using CR 250 coming out of Madison and Taylor counties and crossing the bridge over the Suwannee River at Dowling Park. FDOT is actively seeking funds to construct improvements to the bridge.

Source: www.floridajobs.org/REDI/RACECMap.pdf 
2. I dentify and discuss issues with the current transportation system with regard to existing land use and the multimodal environment, including the following ( Note: This I tem emphasizes land use issues related to placemaking and mode choice. I tems 3-6 address additional issues associated with access, public transportation, parking, and freight, respectively.):

a. land use organization/ location efficiency (e.g., key centers, land use separations)

b. land use mix/ balance (e.g., significant land uses, land use ratios, jobs to population ratios)

c. density/ intensity (e.g., residential, employment density, see BP 27. Documenting Population Density along Transit Corridors)

The local government should review the existing and proposed future land use map and consider whether it provides for an appropriate organization, mix, and density or intensity of land uses to support multimodal transportation options. In BP 3-2, the Taylor County Vision 2060 Plan noted how the effects of dispersed, low-density growth could impact the County. Specifically, local governments should look at the future land use map to ensure:

- a strong central core or activity center consisting of government centers, transit stations, or a town square surrounded by relatively high density/intensity residential and non-residential development;

- a compatible mix of land uses throughout each core or activity center and within individual sites and buildings that supports alternative modes of transportation and promotes activity during peak and non-peak hours (see Table 2-1. Land Use Compatibility Matrix);

- proximity of shopping, services, and employment centers to each other and to the surrounding residential uses to facilitate walking and bicycling, as an alternative to driving; and

- efficient freight and goods movement.

Practice Notes: For the transportation element, future land use concepts should identify areas where walkable and compact urban development is desired. This guides future street design and the application of context sensitive solutions on major corridors as well as planning and investment decisions relative to public transportation, pedestrian/bicycle services, and related facilities.

Land use strategies should be carefully integrated into the overall transportation planning scheme. An understanding of the land use characteristics needed to support public transportation, walking, and bicycling will be vital to this effort. These are characterized in the literature as the five-Ds of development (14 p. 52):

1) Density: population and employment by geographic unit (e.g., per square mile, per developed acre). 
2) Diversity: mix of land uses, typically residential and commercial development, and the degree to which they are balanced in an area (e.g., jobs-housing balance).

3) Design: neighborhood layout and street characteristics, particularly connectivity, presence of sidewalks, and other design features (e.g., shade, scenery, presence of attractive homes and stores) that enhance the pedestrian- and bicyclefriendliness of an area.

4) Destination accessibility: ease or convenience of trip destinations from point of origin, often measured at the zonal level in terms of distance from the central business district or other major centers.

5) Distance to transit: ease of access to transit from home or work (e.g., bus or rail stop within $1 / 4$ - to $1 / 2$-mile of trip origin).

Proximity of diverse land uses combined with intersection density are factors that promote walking. Transit use is supported by walkable environments and by proximity to the service and accessibility provided by public transportation to a range of destinations. Destination accessibility is the most statistically significant variable for reducing vehicle miles of travel (VMT). Alternatively, poor accessibility, single land use areas, and/or strip development are defining characteristics of urban sprawl that contribute to increased VMT (15).

Practice Notes: While an existing land use map may indicate general land uses, those uses, centers, or districts that require greater accessibility should be mapped to facilitate this understanding.

3. Identify and discuss issues regarding land development and access conditions on major routes, such as:

a. shallow commercial strip development and zoning;

b. presence/ absence of supporting street network and any gaps that should be connected;

c. possible changes to the supporting street and site circulation system to improve roadway safety and operations;

d. presence/ absence of internal access connections allowing circulation between properties and opportunities for joint access or interparcel circulation;

e. substandard driveway design conditions, such as driveways with excessive grades or slopes, inadequate widths or radii, or inadequate throat lengths; and

f. sites with open frontages or too many driveways and opportunities to reduce superfluous access points.

A typical land use and access management issue, which also reduces destination accessibility, is commercial strip development along major thoroughfares. In some cases, such development may be separated from residential areas by walls or barriers. Closely 
spaced driveways, a lack of unified circulation between sites, and sparse or disconnected local street networks increase local trip circulation on major travel routes. As a result, traffic conflicts multiply and crashes increase. This situation is common in small communities and rural areas where the state road providing access to a community is also the main street. Over time, the numerous driveways and traffic signals will intensify congestion and delay causing regional commute times, fuel consumption, and vehicular emissions to increase. Routes with poorly managed access have increased the potential for vehicular crashes involving bicyclists and pedestrians. Figure 2-4 (Visualization of multimodal access management benefits) illustrates the multimodal benefits of improved access management.

BP 2-8 (Strategies for Integration of Transportation and Land Use) identifies some of the strategies to consider when attempting to better integrate land use and transportation and advance access management objectives in the multimodal planning process. Many others are identified in Section 3.5, and in the TRB Access Management Manual, 2nd ed. (17).

Research has shown that destinations near the core of urban areas and job centers that are highly accessible with a diversity of uses and well-connected street systems tend to be among the most vibrant and livable places and also have the greatest potential to reduce driving (16). In turn, access management of major routes preserves their viability for through movement of people and freight, thereby protecting the market area of existing businesses and reducing delay and crashes for the driver (17). Rural and undeveloped areas may consider land use and zoning envelopes along new thoroughfares to cluster commercial activity at key nodal points and minimize strip development.

4. I dentify and discuss parking management issues relative to freight, public transportation, and the multimodal environment, including park and ride facility locations, capacities, average usage/ vacancy, and transit connections.

Parking management is about managing parking resources efficiently, while accommodating the needs of the community and furthering community goals (22 p. 23). Providing a large supply of parking to accommodate peak demand promotes use of the automobile. It also results in large areas of surface parking that are unattractive to pedestrians, increases the length of the pedestrian trip, and discourages walking.

Establishing appropriate limits on parking in town centers and supporting activity centers reinforces non-auto modes by making it safer and more convenient to circulate on foot or by bicycle. It also leads to more compact development and allows denser and more diverse land use activities, making these areas a destination that can be more efficiently served by fewer automobile trips or transit, if available.

Parking on major thoroughfares in small towns may negatively impact through movement of traffic while, at the same time, providing a buffer between the sidewalk and fast-moving vehicles. When traffic volumes on major thoroughfares through small towns exceed capacity for the adopted level of service, communities may consider using one or both of the parking lanes to accommodate peak directional movements. The City of Newberry has employed this approach as a temporary solution on SR 26.

5. I dentify and discuss freight movement and parking issues relative to the existing and planned multimodal environment. 
Freight mobility is critical to the economic success of any community. Efficient freight movement ensures that stores and restaurants are stocked appropriately, small manufacturers get the raw materials that they need, and local businesses receive packages, office supplies, and other goods.

A multimodal environment creates a number of challenges for freight activity. Complete streets policies, context sensitive solutions, traditional neighborhood developments, and existing grid street systems can include narrower streets, traffic calming, and compact intersections that impact the operational needs of delivery trucks and cause more regular encroachment of turning vehicles into opposing lanes. Communities need to balance the need for access by large trucks, freight rail, and other modes of freight transportation with the circulation needs of autos, bicycles, pedestrians, and transit users.

Considerations with regard to the freight movement in the multimodal environment include:

- Modal conflicts due to the presence of bicycle and pedestrian facilities;

- Frequency of access by freight vehicles and accessibility due to road channelization; parking and loading zone restrictions, vehicle size limits, and noise and time restrictions;

- Urban truck regulations - route restrictions, parking regulations/curbside access delivery window/time-of-day restrictions, and emission controls; and

- Opportunities to separate freight-related uses from compact urban areas through freight consolidation centers (freight villages) (see BP 2-11. Urban Freight Villages), and/or regional connectors to intermodal facilities, such as ports or airports.

The Institute of Transportation Engineers recommends that transportation planners facilitate freight movement in urban "smart growth" environments by improving rail-freight service and commercial vehicle access, circulation, loading, and unloading, as follows (23):

- Designate and design priority truck routes in corridors where high-volume truck traffic exists or is anticipated;

- Locate freight terminals and intermodal facilities convenient to major transportation routes of all freight modes, outside of activity centers, and away from areas likely to be congested;

- Provide efficient rail access and strategically locate yards to serve major industrial and distribution centers; and

- Provide off-street loading docks for all commercial, industrial, and institutional buildings and medium- to high-density residential complexes and provide alleys for service access in both commercial and residential areas.

Commercial truck parking has become a major issue not only in Florida but nationally. Hours of service (HOS) rules require that truck drivers rest after long periods of driving (generally truck drivers are permitted to drive for 10 consecutive hours before being required to take off for 8 consecutive hours) has revealed the severe lack of parking facilities for trucks (113 p. 5). Truck parking may be an issue along the right of way of major thoroughfares in rural areas.

A study by the Federal Highway Administration provided the following series of suggestions for solving commercial truck parking shortfalls (113 p. 38): 
- Expand or improve public rest areas

- Expand or improve commercial truck stops and travel plazas

- Encourage the formation of public-private partnerships

- Educate or inform drivers about available spaces

- Change parking enforcement rules

- Conduct additional studies

\section{Major Roadways, Evacuation Routes, and Conditions}

Below is an overview of the existing conditions inventory and analysis for the major roadway system. Much of the information may be obtained from the inventory of agency and modal plans, with supplemental data sources identified in ITR 2-4 (Roadway Data Sources). ITR 3-1 contains a list of potential maps that may be included in the map series documenting existing conditions. Further information on estimating future travel demand and planning for the future roadway system is contained in Sections 3.3 and 3.4.

\section{Develop a list and/ or map series to identify the following:}

a. Major existing and programmed/ committed roadways

b. Current functional classification, pavement condition, and maintenance responsibilities

c. Special corridor designations, such as:

- Strategic I ntermodal System (SIS)

- hurricane evacuation routes

- regional goods movement corridors and local truck routes (see Ports, Aviation, Rail, and I ntermodal Facilities)

Identify roadway and public transportation projects on the State Highway System (SHS) that are planned and programmed/committed (i.e., have funding committed to them in the next three years). These will be detailed in Florida SIS Plan and FDOT Adopted Five-Year Work Program. Roadway data sources for number of lanes, functional classification, and maintenance responsibilities are listed in ITR 2-4 (Roadway Data Sources).

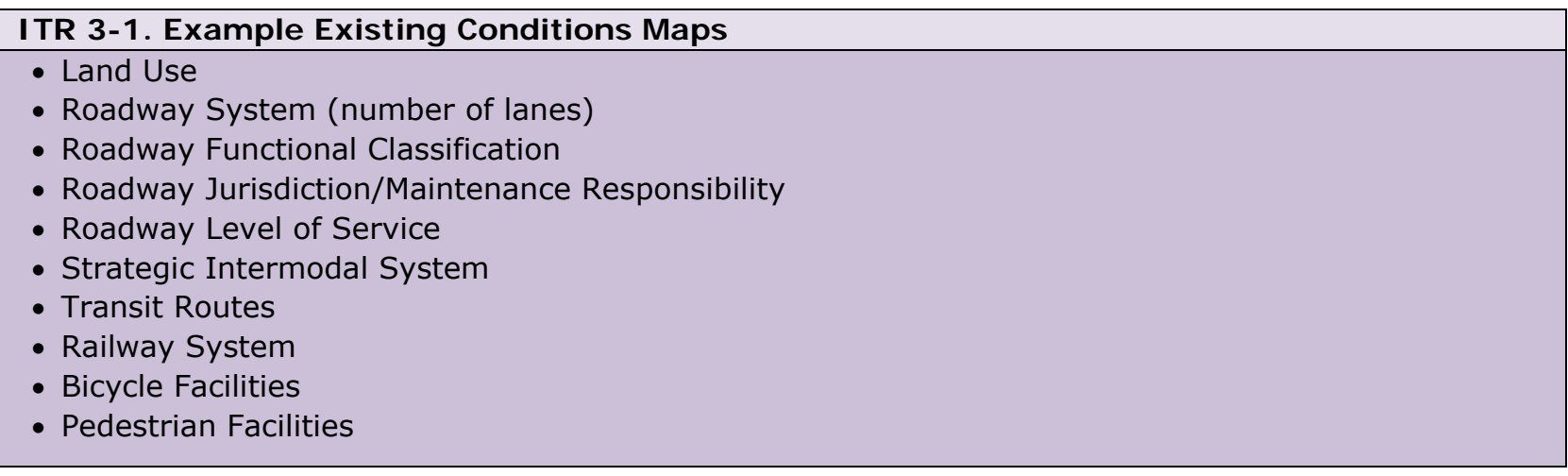

Florida's Strategic Intermodal System is a statewide network of transportation facilities, including the state's largest and most significant airports, spaceports, deep water seaports, freight rail terminals, interregional rail and bus terminals, rail corridors, urban fixed guideway transit corridors, waterways, and highways. SIS facilities provide the primary means of interstate, intrastate, and international movement of people and freight. The SIS is Florida's highest statewide priority for transportation capacity improvements. §339.64, F.S., concerns the SIS Strategic Plan which "sets policies to guide decisions about which 
facilities are designated as part of the SIS, where future SIS investments should occur, and how to set priorities among these investments given limited funding." The SIS Strategic Plan is updated every five years. Per $\S 163.3180(5)(h) a$, F.S., states that "local governments that continue to implement a transportation concurrency system, whether in the form adopted into the comprehensive plan before the effective date of the Community Planning Act, or as subsequently modified, must consult with the Department of Transportation when proposed plan amendments affect facilities on the Strategic Intermodal System."

FDOT uses the Highway Classification System adopted by the Federal Highway Administration (FHWA) and identifies federal system assignments used for funding purposes in its Roadway Characteristics Inventory (RCI) database. The FHWA system classifies roadways as Principal Arterial, Minor Arterial, Major and Minor (or Urban) Collector or Local streets based upon traffic movement and land access characteristics. Two area types, urban and rural, are used to differentiate context. Urban areas are those designated as urbanized areas by the U.S. Census bureau, with the remaining areas being designated as rural. BP 35 illustrates how roadway characteristics may be documented in a table. Each major roadway may also be described in terms of how it is used and its relationship to land uses in the corridor as in BP 3-4.

\section{BP 3-4. Description of Major Thoroughfare}

The City of Palatka Comprehensive Plan includes this description (114 p. B10): U.S. 17 (S.R. 15/20 (Reid Street)) is a principal arterial which runs north-south through Putnam County merging with S.R. 100 at Madison Street, and running east-west as Reid Street through Palatka. This arterial roadway is a four-lane facility from C.R. 209 to San Mateo. As an arterial, the roadway serves to connect the urban service areas of Palatka, Pomona Park, and Welaka. Locally, running east-west as Reid Street, U.S. 17/ S.R. 15/20 serves as the principal access to shopping and service areas within the City's central business district. In 2005, the roadway was handling approximately 11,000 trips per day in both directions north of S.R. 100, while on Reid Street, the east-west segment of the roadway, traffic volumes increase to approximately 32,500 trips per day. Reid Street within the Central Business District (CBD) of the City of Palatka is described as an "interrupted" principal arterial. This distinction between operation of a rural and an urban facility is created by the added frequency of friction due to turning movements, pedestrians, and signalized intersections. Traffic signal control at the intersections is normally the capacity-controlling factor. 
BP 3-5. Existing Roadway Characteristics

Glades County Existing Roadway Network Characteristics, 2010

\begin{tabular}{|c|c|c|c|c|c|c|c|}
\hline Roadway Name & From & To & $\begin{array}{l}\text { Number } \\
\text { of Lanes }\end{array}$ & $\begin{array}{l}\text { Length } \\
\text { (miles) }\end{array}$ & $\begin{array}{c}\text { Daily Service } \\
\text { Volume }\end{array}$ & SIS & $\begin{array}{c}\text { FDOT } \\
\text { Standard LOS }\end{array}$ \\
\hline \multicolumn{8}{|l|}{ State Road } \\
\hline \multirow[t]{6}{*}{ US $27 /$ SR 25} & Highland County Line & SR 29 & $4 \operatorname{Ln}$ & 7.79 & 23,800 & YES & B \\
\hline & SR 29 & SR 78 West & $4 \mathrm{Ln}$ & 10.48 & 23,800 & YES & B \\
\hline & SR 78 West & SR 78 East & $4 \mathrm{Ln}$ & 3.97 & 23,800 & YES & B \\
\hline & SR 78 East & First Street & $4 \mathrm{Ln}$ & 1.85 & 23,800 & YES & B \\
\hline & First Street & CR 720 & $4 \operatorname{Ln}$ & 1.84 & 23,800 & YES & B \\
\hline & CR 720 & Hendry County Line & $4 \operatorname{Ln}$ & 3.06 & 23,800 & YES & B \\
\hline \multirow[t]{3}{*}{ SR 29} & US 27 & CR 74 & $2 \operatorname{Ln}$ & 0.76 & 11,360 & YES & $\mathrm{C}$ \\
\hline & CR 74 & SR 78 & $2 \operatorname{Ln}$ & 9.17 & 11,360 & YES & C \\
\hline & SR 78 & Hendry County Line & $2 \mathrm{Ln}$ & 2.51 & 11,360 & YES & C \\
\hline \multirow[t]{6}{*}{ SR 78} & US 27 & Tobias Avenue & $2 \operatorname{Ln}$ & 0.49 & 11,360 & No & C \\
\hline & Tobias Avenue & CR 74 & $2 \operatorname{Ln}$ & 9.26 & 11,360 & No & C \\
\hline & CR 74 & Loop Road & $2 \operatorname{Ln}$ & 1.08 & 11,360 & No & C \\
\hline & Loop Road & CR 721 & $2 \operatorname{Ln}$ & 2.47 & 11,360 & No & C \\
\hline & CR 721 & Access Road & $2 \mathrm{Ln}$ & 13.83 & 11,360 & No & C \\
\hline & Access Road & Okeechobee County Line & $2 \mathrm{Ln}$ & 2.33 & 11,360 & No & C \\
\hline SR 78 West & SR 29 & US 27 & $2 \mathrm{Ln}$ & 14.86 & 11,360 & No & $\mathrm{C}$ \\
\hline \multicolumn{8}{|l|}{ County Road } \\
\hline \multirow[t]{2}{*}{ CR 721} & SR 78 & CR 721A & $2 \operatorname{Ln}$ & 5.54 & 8,450 & No & $\mathrm{D}$ \\
\hline & CR 721A & Okeechobee County Line & $2 \operatorname{Ln}$ & 9.57 & 8,450 & No & $\mathrm{D}$ \\
\hline \multirow[t]{3}{*}{ CR 74} & SR 29 & CR 731 & $2 \operatorname{Ln}$ & 7.71 & 8,450 & No & $\mathrm{D}$ \\
\hline & CR 731 & CR 731 West & $2 \operatorname{Ln}$ & 3.02 & 8,450 & No & $\mathrm{D}$ \\
\hline & CR 731 West & Charlotte County Line & $2 \mathrm{Ln}$ & 4.57 & 8,450 & No & $\mathrm{D}$ \\
\hline \multirow[t]{2}{*}{ CR 731} & CR 74 & CR 720 & $2 \mathrm{Ln}$ & 8.45 & 8,450 & No & D \\
\hline & CR 720 & SR 29 & $2 \mathrm{Ln}$ & 2.86 & 8,450 & No & $\mathrm{D}$ \\
\hline CR 720 & US 27/SR 25 & Hendry County Line & $2 \mathrm{Ln}$ & 9.29 & 8,450 & No & D \\
\hline
\end{tabular}

Source: Glades County Comprehensive Plan Transportation Element (115)

Pavement condition factors into local government transportation planning efforts for small communities and rural areas. Maintenance of these facilities consumes a significant portion of a community's budget and a pavement condition analysis can assist in prioritizing paving needs. An example is provided in BP 3-6.

Practice Notes: Local governments may choose to use conventional functional definitions for arterial, collector, and local roadways in their comprehensive plan. Best practice is to supplement these definitions with more detailed statements of purpose and function for each roadway classification. This can be accomplished using either traditional functional classification terms or "complete streets" categories that relate to functional classifications. Similarly, modal priority routes, such as truck routes, should be designated in the plan to help guide roadway design and land use planning. Whatever the approach used, it is important to provide more adequate guidance on land use context for street network planning and design than provided by the broad FHWA "urban/rural" distinctions. 


\section{BP 3-6. Pavement Conditions Analysis}

The City of Mukilteo, Washington developed a pavement condition index (PCI) for the purpose of evaluating the pavement conditions of each road segment throughout the City. Mukilteo was able to monitor the condition of the pavement and reported that in 2007 the average pavement condition was rated as 79 which was an overall improvement from the score of 73 in 1999 . The tables below indicate pavement condition categories by mile and roadway classification pavement status.

\begin{tabular}{|c|c|c|}
\hline PCI RANGE & CONDITION & MILES \\
\hline $90-100$ & Excellent & 23.6 \\
\hline $70-89$ & Very Good & 20.4 \\
\hline $50-69$ & Good & 13.1 \\
\hline $25-49$ & Poor & 4.7 \\
\hline $0-24$ & Very Poor & 0.0 \\
\hline
\end{tabular}

\begin{tabular}{|c|c|c|}
\hline $\begin{array}{c}\text { ROADWAY } \\
\text { CLASSIFICATION }\end{array}$ & $\begin{array}{c}\text { TRAVEL } \\
\text { MILES }\end{array}$ & Average PCI \\
\hline Principal Arterial & $1.3^{*}$ & 87 \\
\hline Minor Arterial & 5.0 & 71 \\
\hline Collector Street & 6.7 & 73 \\
\hline Local Road/Street & 48.9 & 81 \\
\hline
\end{tabular}

Source: City of Mukilteo, Washington Transportation Element (116)

The movement of goods - freight - largely occurs on the state and regional transportation network and related information is available in those modal plans. In addition, the Florida Freight Mobility and Trade Plan and other regional goods movement studies guide statewide policies and investments for the movement of goods (ITR 2-1. Plans and Programs of State and Regional Agencies and Modal Providers). Another resource for local government transportation elements are county freight and logistics overviews (ITR 2-9. Ports, Airports, and Freight Planning Information Sources). Each overview details industry and employment statistics, imports and exports, trade partners, SIS infrastructure (spaceports, airports, seaports, rail). A map in each overview illustrates the freight infrastructure within the county. BP 3-7 provides an example of how major truck routes, rail lines, and freight activity centers might be mapped. 
BP 3-7. Freight Activity Centers

Polk County Freight Activity Centers and Truck Routes

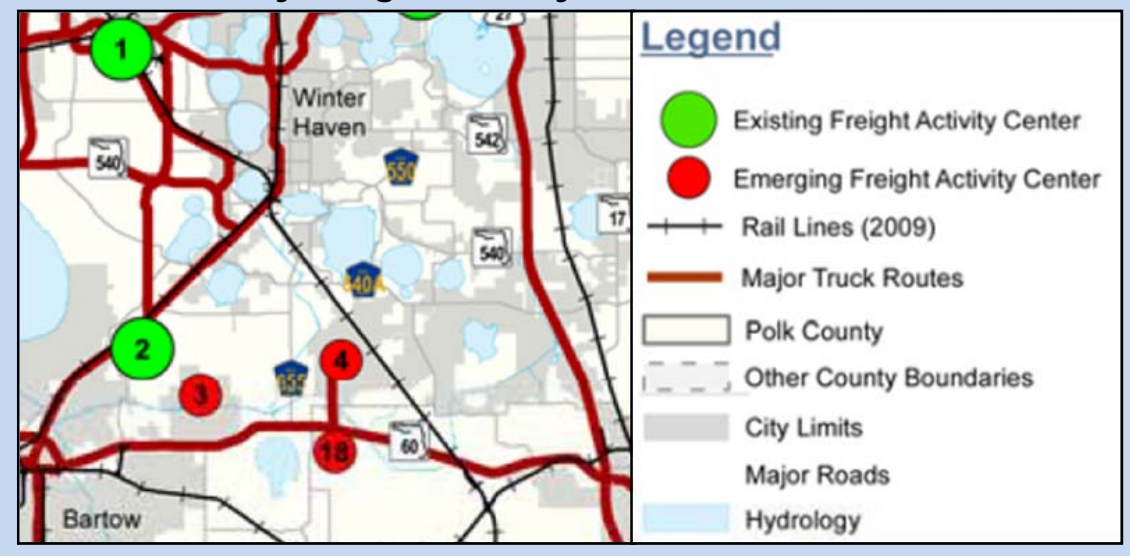

Source: Polk 2035 Mobility Vision Plan (52)

\section{Note or map and evaluate information on travel patterns, characteristics,} and issues. Considerations include:
a. mode split
b. origin-destination (O-D) patterns
c. average commute times and lengths
d. average trip length
e. vehicle and person miles traveled (VMT, PMT)

Residents of small communities tend to travel long distances for employment because fewer jobs are available within the community. Evaluating this information over time provides insight into how travel behavior is changing and possible strategies to address that change. Quality/level of service analysis and sketch planning analysis to forecast future travel demand and network spacing needs are addressed in Section 3.3. ITR 2-5 (Commuting Patterns and Characteristics) notes some of the specific data sources to consult in this effort. An example of how to illustrate the data is available in BP 3-8.

\begin{tabular}{|c|c|c|c|}
\hline \multicolumn{4}{|c|}{ BP 3-8. Workers by Transportation Mode } \\
\hline \multicolumn{4}{|c|}{ City of Belle Glade Workers by Transportation Mode } \\
\hline Mode & Workers (Belle Glade) & Workers (PBC) & Workers (Florida) \\
\hline All Means of Transportation & 4,985 & 475,570 & $6,910,170$ \\
\hline Drove Alone & 3,095 & 378,760 & $5,445,525$ \\
\hline 2-Person Carpool & 495 & 43,315 & 698,575 \\
\hline 3-Person Carpool & 160 & 7,655 & 117,465 \\
\hline 4-or- More Person Carpool & 230 & 5,785 & 77,725 \\
\hline Bus or Trolley Bus & 715 & 5,130 & 108,340 \\
\hline Streetcar, Trolley Car, Subway, or Elevated Car & 0 & 115 & 7,760 \\
\hline Railroad or Ferryboat & 0 & 645 & 4,270 \\
\hline Taxicab, Motorcycle, or Other Means & 90 & 5,790 & 58,740 \\
\hline Bicycle or Walked & 160 & 8,925 & 157,680 \\
\hline Worked at Home & 45 & 19,455 & 207,090 \\
\hline
\end{tabular}




\section{I dentify and discuss transportation demand management services, programs, and impacts, such as:}
a. Services (vanpool/ rideshare, carshare, bike share)
b. Parking management
c. Employee transportation coordinators for large employers

Transportation demand management (TDM) consists of strategies that foster increased efficiency of the transportation system by influencing travel behavior by mode, time of day, frequency, trip length, regulation, route or cost. Examples of TDM strategies include public transit services, carpooling, compressed work weeks, telecommuting, limited parking, and provision of bike and locker facilities by employers. The Florida Department of Transportation has a policy to ensure the consideration of TDM strategies "in all studies, plans, programs, functional areas, and in employee benefit programs (Topic No.: 000-725050-h) (40)."

Sponsored in whole or in part by the Florida Department of Transportation, several commuter assistance programs serve various regions of Florida. They are sometimes housed within a transit agency or managed by a private entity. These commuter assistance programs offer specialized mobility services and support programs to encourage alternatives to single occupancy vehicle travel. Examples include subsidized employee/employer vanpools, carpool matching, guaranteed ride home, and reduced transit fare programs. Vanpool or rideshare services can provide a way for local residents to access employment, as well as longer distance travel options. Managed lanes are a comprehensive TDM strategy for congested highway corridors (see BP 2-40. Designate and/or Reinforce Managed Lanes on Major Thoroughfares). Commuter assistance programs collect data that is useful for understanding commuting needs and patterns and that monitors impacts of interventions on travel demand. TDM resources can be found in ITR 2-6 (Transportation Demand Management).

There is a state discretionary grant program, known as the Transit Corridor Program, which is for the purpose of relieving congestion and improving capacity through use of highoccupancy vehicles. Transit agencies, counties and municipalities are eligible for this grant, and it can be applied toward planning, land acquisition, capital facilities, construction and operating costs of transit. Examples of specific transit facilities that might be found in a transportation management program for transit corridors include bus-pullout lanes, HOV lanes, access improvements along the corridor, park-and-ride lots, traffic controls and TDM strategies targeting corridor employers.

\section{Document safety and operational concerns noted in other reports (corridor studies, safety audits or reports), such as: \\ a. high crash locations and crash indicators (3- to 5-year timeframe) \\ b. bottlenecks (locations subject to frequent congestion, compare to crash data)}

An understanding of crash locations can assist in supporting future land use policies, access management policies, and the provision of infrastructure to improve safety within the community. Addressing a 3-5 year timeframe in the inventory of crash-related data will 
identify areas where crashes occur more frequently, as opposed to isolated instances. High crash locations are often an indicator that the area requires additional access management strategies and/or bicycle/pedestrian infrastructure projects, such as raised medians, signalized midblock crossings, parking lot cross access, network connections, and other treatments. BP 3-9 illustrates mapping of intersections of concern based on crash data.

Specific changes to existing local traffic circulation patterns may also need to be considered to improve safety and advance other community objectives. For example, converting certain one-way streets back to two-way streets in town centers and supporting activity centers is one means to increase roadway safety, as well as accessibility. Such conversions may "improve vehicular access and reduce driver confusion" (43). Literature on urban street network design concludes that two-way streets create higher levels of economic activity and improve the livability of downtown areas (43). From a safety perspective, one-way streets contribute to driver inattentiveness and higher travel speeds (43).

Transportation elements should include information documenting crash locations, any contributing factors, and possible countermeasures. Goals, objectives and policies can then be established to increase safety with regard to those issues. Guidance for planning efforts is available in the following reports:

- Florida Strategic Highway Safety Plan www.dot.state.fl.us/safety/SHSP2012/StrategicHwySafetyPlan.pdf

- NCHRP Report 546 - Incorporating Safety into Long-Range Transportation Planning

Crash data sources are noted in ITR 2-4 (Roadway Data Sources) and ITR 2-7 (Crash Mapping). Safety audit studies are another important source of information. Guidance is also available on various websites including:

- Federal Highway Administration (FHWA) Safety program - safety.fhwa.dot.gov/

- Florida Department of Transportation State Safety Office website www.dot.state.fl.us/safety/

An important consideration with regard to Florida's growing aging population is the safety and mobility needs of aging road users. The ability of aging adults to participate in community life depends on the available transportation options. FDOT has established the following program to provide guidance in this area:

- Florida Department of Transportation Safe Mobility for Life Program www.dot.state.fl.us/trafficoperations/operations/safetyisgolden.shtm. 


\section{BP 3-9. Safety Concerns and Crash Indicators}

The following resources are useful for further crash analysis and mapping:

- Florida Department of Safety and Motor Vehicles - www.flhsmv.gov/html/safety.html

o Provides individual crash reports and county crash and fatality rates

- Local Police Departments

o Provides high crash locations

The City of Mukilteo, Washington developed the map shown below indicating intersections of concern due to high crash rates to include in their transportation element.

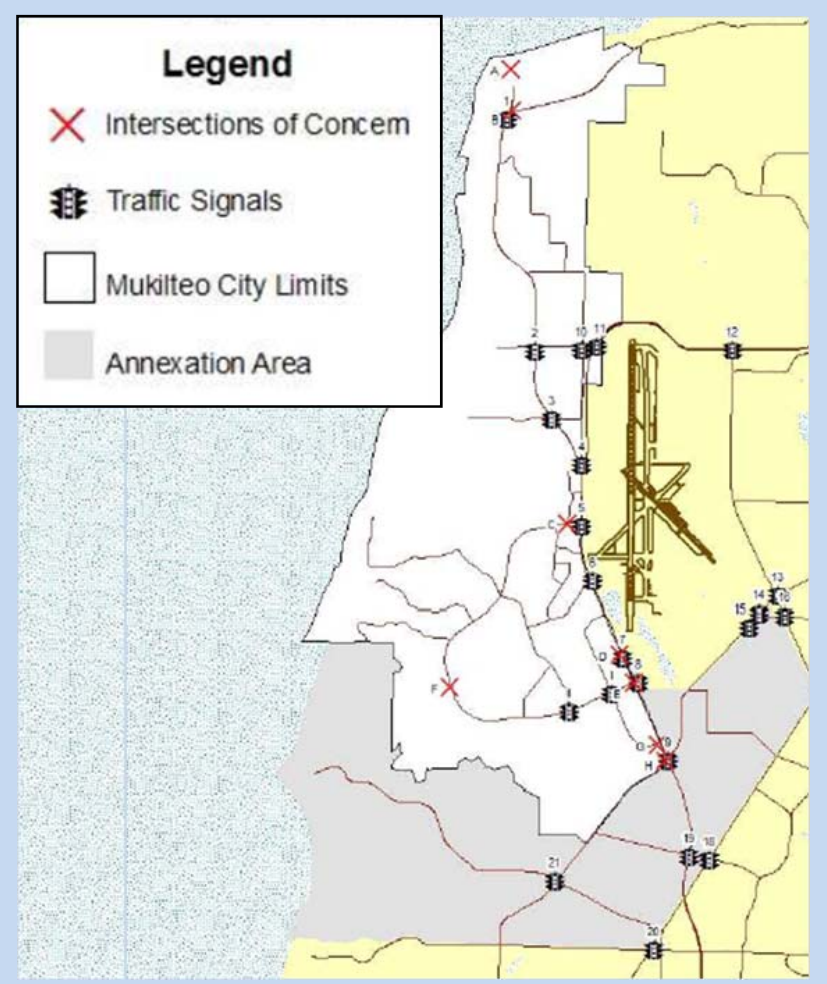

Source: City of Mukilteo, Washington Comprehensive Plan (116 p. 93)

\section{Evaluate system needs with regard to hurricane evacuation routes, as well as planned projects and infrastructure vulnerability to storm surge.}

Hurricane evacuation routes and roadway vulnerability to flooding and storm surge may be found in the coastal management element and/or the applicable Regional Evacuation Study. In addition, a preliminary assessment of transportation infrastructure vulnerable to sea level rise may be determined using the Florida Sea Level Scenario Sketch Planning Tool, which includes a Map Viewer, GIS data layers, and a Sea Level Change Inundation Surface Calculator (see BP 2-19. Consider Vulnerability to Hazards in Infrastructure Investments). Local governments should consult the coastal management element, applicable plans, and resources for:

- Evacuation times and critical transportation projects needed to improve those times, 
- Information that promotes disaster readiness in terms of the transportation system's ability to be inventoried after a disaster event and function as part of the recovery effort, and

- The purpose of evaluating land use decisions in terms of evacuation clearance times and functional ability of the transportation network to achieve projected clearance times.

Local governments should consider the need for making future land use changes and upgrading transportation facilities for improved hurricane evacuation times and hazard resiliency. Example objectives and policy strategies for hurricane evacuation from Monroe County are contained in GOP 3-2.

\section{Public Transportation and Conditions}

The 2011 Community Planning Act calls for an emphasis on public transportation systems, where feasible. Fixed route systems operate in urban areas, whereas rural areas are predominately served by demand-responsive paratransit systems and are part of Florida's Coordinated Transportation System. The term public transportation encompasses a variety of modes of service, including, but not limited to automated guideway, bus, cable car, commuter rail, ferry boat, heavy rail, light rail, monorail, paratransit, trolleybus, and vanpool or demand response systems.

Appendix $D$ defines public transportation options that may be present or planned in urban areas. Table 2-2 (Public Transportation Modes of Service and Market Characteristics) identifies how different public transportation modes perform in various-sized communities according to criteria such as travel market, economic development, speed, right of way, and construction disruption. In addition to public transportation service, private "luxury" bus charters are increasingly filling the demand for intercity long distance travel in Florida. The transportation element should note the locations of any such services in the community and consider accessibility and public transportation connections to these key station areas.

\section{If applicable, identify and map available public transportation by type and facilities, such as:}
a. Fixed transit routes (including passenger rail), span of service, average headways, populations served and ridership;

b. Paratransit service;

c. Intercity bus service;

d. Bus and rail stops, station areas, transfer locations, and system connections.

Maps of existing and planned public transportation systems are required in the transportation element. Small communities and rural areas can look to existing transit planning efforts within their jurisdiction for information to include in the multimodal transportation element.

In Florida, plans are already developed for fixed route transit and paratransit services in the form of transit development plans (TDPs), transportation disadvantaged service plans (TDSPs), and locally coordinated human services 
transportation plans (LCHSTPS). Paratransit and human services transportation provide transportation for those who cannot obtain their own transportation due to a disability, age, or income and at-risk children through a statewide coordinated system. Transportation disadvantaged services are overseen by the Florida Commission for the Transportation Disadvantaged and funded through the State Transportation Disadvantaged Trust Fund.

In some cases, the TDSP has been expanded to include requirements of the LCHSTP in order to access federal grants for expanding public transit and other transportation services, buying vehicles, improving access to information and services, and other efforts. Components of the TDSP include a service plan describing existing operational and administrative structure, a development plan describing long-term goals and objectives based on data and analysis, and quality assurance describing service evaluation. Also included is a consistency review of other transportation plans. The service analysis includes forecasts of the transportation disadvantaged population, a needs assessment, and barriers to coordination.

The situation appraisal of a transit development plan (TDP) provides useful information for local comprehensive planning. Factors addressed may include land use and development, roadway level of service, pedestrian access, coordination with neighboring transit systems, addressing the increased demand for varying modes of transit, the impact of rising fuel costs on transit systems, and the funding and resources required to provide a successful transit system. By addressing the factors identified in the applicable TDP, a local government will establish a strong connection between the TDP and the comprehensive plan.

ITR 2-4 (Roadway Data Sources) provides a list of resources for TDPs and TDSPs that can be used to assist communities in planning for transit. ITR 2-3 (Transit System Information Found in the TDP) details the type of route information that may be found in a TDP. BP 3-10 provides an illustration of transit service characteristics. Local governments may choose to include or reference the entirety of these plans within their transportation element, or include only applicable portions, such as planned services and routes, changes, or infrastructure. Key connections between modes in small communities and rural areas are likely to include park-and-ride lots or inter-city bus transfer locations/centers. The local transportation element should also clearly describe consistency with any transit plans for the area. Coordinating TDSPs and TDPs with the transportation element and comprehensive planning as a whole provides the opportunity to guide land use and anticipate future transit need.

Passenger rail stops may be determined by local knowledge. In small communities and rural areas, system connections may be limited to inter-city bus transfer locations/centers. Maps should illustrate bus and passenger rail routes (including direction), train stations, transit centers, and key transfer points as an overlay on the street network. 
BP 3-10. Transit Service Characteristics

Belle Glade Transit Service Characteristics

\begin{tabular}{|c|c|c|c|c|}
\hline Route & $\begin{array}{c}\text { Peak } \\
\text { Headway } \\
\text { (min) }\end{array}$ & $\begin{array}{c}\text { Off-Peak } \\
\text { Headway } \\
\text { (min) }\end{array}$ & $\begin{array}{c}\text { Total Peak } \\
\text { Hour Vehicles }\end{array}$ & $\begin{array}{c}\text { Total Off-Peak } \\
\text { Hour Vehicles }\end{array}$ \\
\hline $\mathbf{4 0}$ & 60 & 60 & 5 & 3 \\
\hline $\mathbf{4 7}$ & 60 & 60 & 2 & 2 \\
\hline $\mathbf{4 8}$ & 60 & 60 & 2 & 2 \\
\hline Lake Region & 120 & 120 & 2 & 2 \\
\hline
\end{tabular}

Source: City of Belle Glade Comprehensive Plan (117)

\section{Bicycle and Pedestrian Conditions}

Florida's Community Planning Act requires all communities to plan for bicycle and pedestrian travel. The ability of bicycle riders and pedestrians to safely and conveniently travel to desired destinations for daily needs, such as work and shopping, is an important component of a multimodal transportation system. In addition to active transportation, bicycle and pedestrian systems support recreation and offer increased opportunities for exercise - a critical issue given today's obesity epidemic.

Some small communities and rural areas may have bicycle and pedestrian plans and safety action plans that contain detailed information on existing conditions and future needs and plans. For example, local and regional bicycle and/or pedestrian master plans may have been completed that can provide information for the transportation element on existing conditions, needs, and planned projects, including sidewalks, bicycle facilities, and multi-use trails. Appendix B identifies many of the bicycle and/or pedestrian plans and safety action plans that have been produced in Florida. ITR 2-8 (Identification of Existing Bicycle and Pedestrian Conditions) identifies other plans and resources that can inform the analysis.

The transportation element should document the existence and conditions of bicycle and pedestrian facilities and analyze the current and potential use of the facilities. An inventory of existing bicycle infrastructure will include bicycle parking, transit stops that accommodate bicycle use, street lighting, bicycle-related signs, bicycle facilities on roadways (bike lanes), and multi-use trails. In addition to sidewalks, pedestrian infrastructure includes street lighting, pedestrian-related signs, pedestrian signalization, and crosswalks. Suggested data to document or map and evaluate for the existing conditions analysis is noted below.

Practice Notes: Surveys are helpful in identifying existing bicycle and pedestrian conditions. They provide answers to questions regarding activity use, demographic data, and barriers that impede bicycling and walking (47). Section 2.3 includes information on system analysis techniques for bicycle and pedestrian needs.

1. Document locations and characteristics of bicycle and pedestrian ways and facilities, such as,

a. lane miles (or linear feet) of bicycle lanes and sidewalks on arterials and collectors (note if facilities are on one or both sides of the road); 
b. lane miles of exclusive bicycle and pedestrian ways and/ or multiuse trail system (physically separated from roadway network);

c. bicycle accommodations on public transportation;

d. crosswalks, including mid-block crossing locations (controlled and uncontrolled); and,

e. high use areas/ facilities.

2. Document and identify deficiencies in the multi-use trail network and those relative to other bicycle and pedestrian facilities, such as:

a. accessibility to major generators and gaps in the bicycle and pedestrian network where bike and pedestrian travel is most likely, such as:

- along arterial or collector streets serving areas of relatively high residential density or commercial intensity;

- areas with a compact, mixed land use pattern ( residential and non-residential) within a 1 mile biking distance; and

- areas in proximity to transit routes/ stops, public schools, public parks, and other major demand generators.

The fact base will help a community identify needs such as gaps in the existing network (see BP 2-20. Identify Pedestrian Facility Deficiencies), facility needs in bike- or pedestrianfocused areas, or other needs based on the community's vision (see BP 2-21. Identify and Map the Bicycle and Pedestrian Network). Section 2.3 provides additional analysis methods for identifying local bicycle and pedestrian needs and deficiencies. When the gaps have been identified, they can be mapped and prioritized for future improvement.

Practice Notes: MPO bicycle and pedestrian plans focus on the regional transportation system and may not address local pedestrian and bicycle needs or projects. Local governments should consider appropriate linkages to regional networks and public transportation stops along their roadways and within areas where pedestrian and bicycle movement is desired over automobile movement.

\section{Pedestrian and bicycle safety}

a. I dentify issues related to crosswalks, including mid-block crossing locations (controlled and uncontrolled)

b. I dentify safety data, including crash indicators, injuries, and fatalities

Lane miles of bicycle lanes and sidewalks and crash indicators along state highways may be obtained from FDOT (ITR 2-4. Roadway Data Sources). Counties likely have this information for county roads. On local roads where no information on existing facilities is available, the local government may consider performing an inventory. BP 2-22 (Document Bicycle and Pedestrian Crash Locations) contains an example of how crashes might be mapped.

Bicycle/pedestrian access to transit and bicycle facilities on buses may be obtained from the applicable transportation disadvantaged service plan and/or transit development plan (ITR 2-1. Plans and Programs of State and Regional Agencies and Modal Providers). 
Information regarding nationwide, statewide, and regional bicycle or multi-use trails may be found in state or regional plans. The Adventure Cycling Association is working to establish the United States Bicycle Route System (ITR 2-8. Identification of Existing Bicycle and Pedestrian Conditions). Their website contains a map illustrating a National Corridor Plan as well as state-by-state implementation progress. Note that FDOT has adopted a policy "to establish components of the United States Bicycle Route (US BR) system in Florida" (Policy Topic No.: 000-525-060-a) (40).

Practice Notes: The League of American Bicyclists Bicycle Friendly America (BFA) program is a resource tool for private and public entities to use for integrating bicycle needs into the transportation infrastructure. The BFA provides a list of five basic elements of essential bicycle planning: engineering, education, encouragement, enforcement, and evaluation and planning. More information can be found at the BFA website - www. bikeleague.org/bfa.

\section{Ports, Aviation, Rail, and I ntermodal Facilities}

Transportation elements for small communities and rural areas are required to identify airports and ports and access to them (e.g., intermodal connections). In addition, they must address projected airport and aviation development, as well as, land use compatibility around airports.

Practice Notes: Chapter 163, Part II, F.S., requires local governments to address ports, aviation, and related facilities as follows:

- Identify aviation and seaport facilities and access to those facilities. Identify all airports, projected airport and aviation development, and land use compatibility around airports.

- Include applicable airport master plan (optional).

Transportation elements should identify the location and type of intermodal facilities within the jurisdiction, as well as the activities of the center. Details regarding the transportation system that supports freight mobility, including regional goods movement corridors, local truck routes, and hot spots (locations with a high crash rate or difficulty in truck maneuvering) are among the items that could be identified. Below are items to include in the transportation element inventory.

\section{I dentify and map ports, airports, rail, and related facilities, including access}

Each seaport has a master plan that guides its activities and development. Consistency of the transportation element with port and airport plans is the focus of objectives and policies in many transportation elements. According to the Florida Ports Council, fifteen seaports operate in Florida (51). The only major ports outside of urbanized areas are the Port of Port St. Joe and the Port of Key West. Transportation elements should identify ports and port facilities within the jurisdiction, as well as, any ports not in the jurisdiction that may affect the transportation system. Ports should also be noted in a map of transportation facilities or other map. FDOT includes a map of the Florida's Public Airports on its website (Figure 3-4). 
The transportation element should identify the location of each airport and data from the airport master plan pertinent to planning for the surface transportation system.

Railroads have not always been addressed in transportation elements likely because they are privately owned and operated. Yet, rail plays an important role in goods movement and an increasing role in the movement of people. Some statewide passenger service that serves small communities and rural areas on railroads in Florida is currently provided by Amtrak. Rail lines may provide both passenger and freight rail service to small communities. Access to transportation modes and stations should be identified. Figure 3-5 illustrates Florida's Freight Rail System. Some passenger service on railroads in Florida's rural area is currently provided by Amtrak. BP 3-7 illustrates how rail lines in rural communities could be mapped in the element.

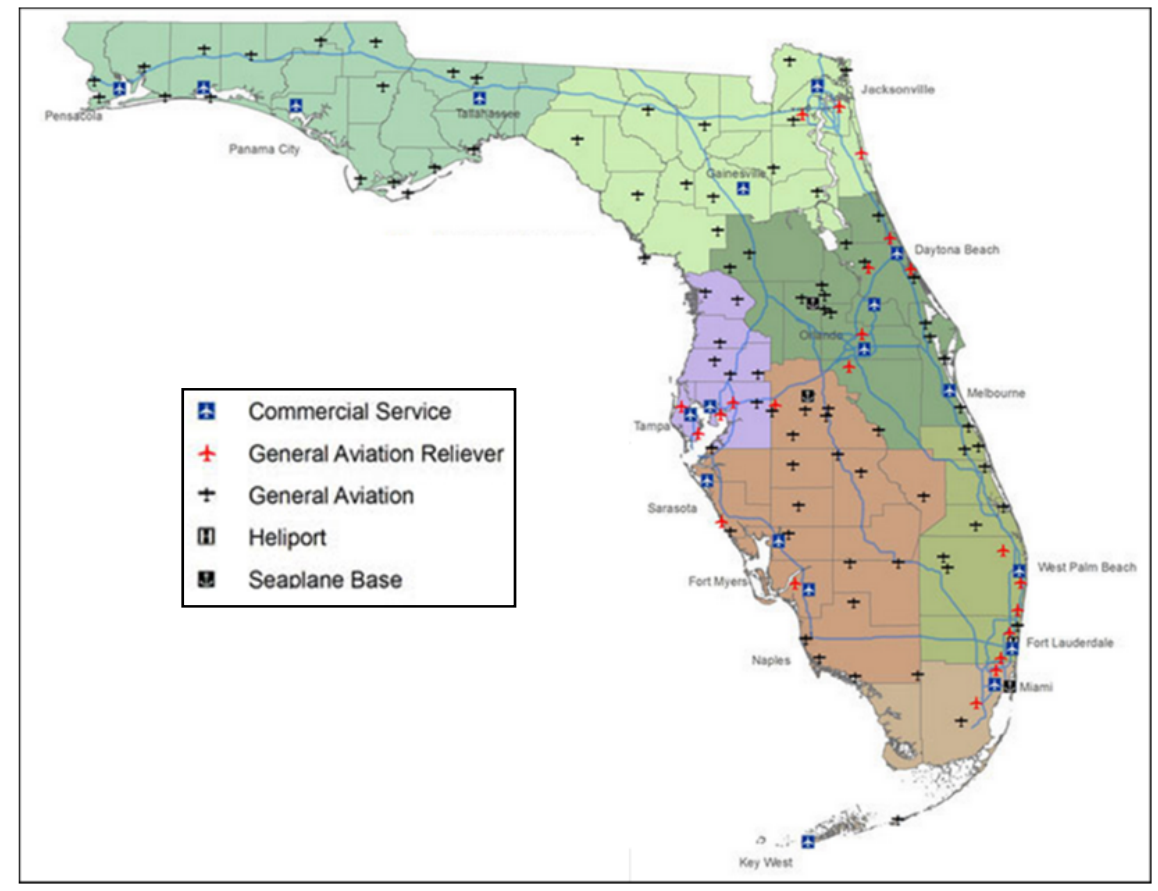

Figure 3-4. Florida's public airports

Source: Florida Department of Transportation - www.dot.state.fl.us/aviation/facilitymap.shtm 


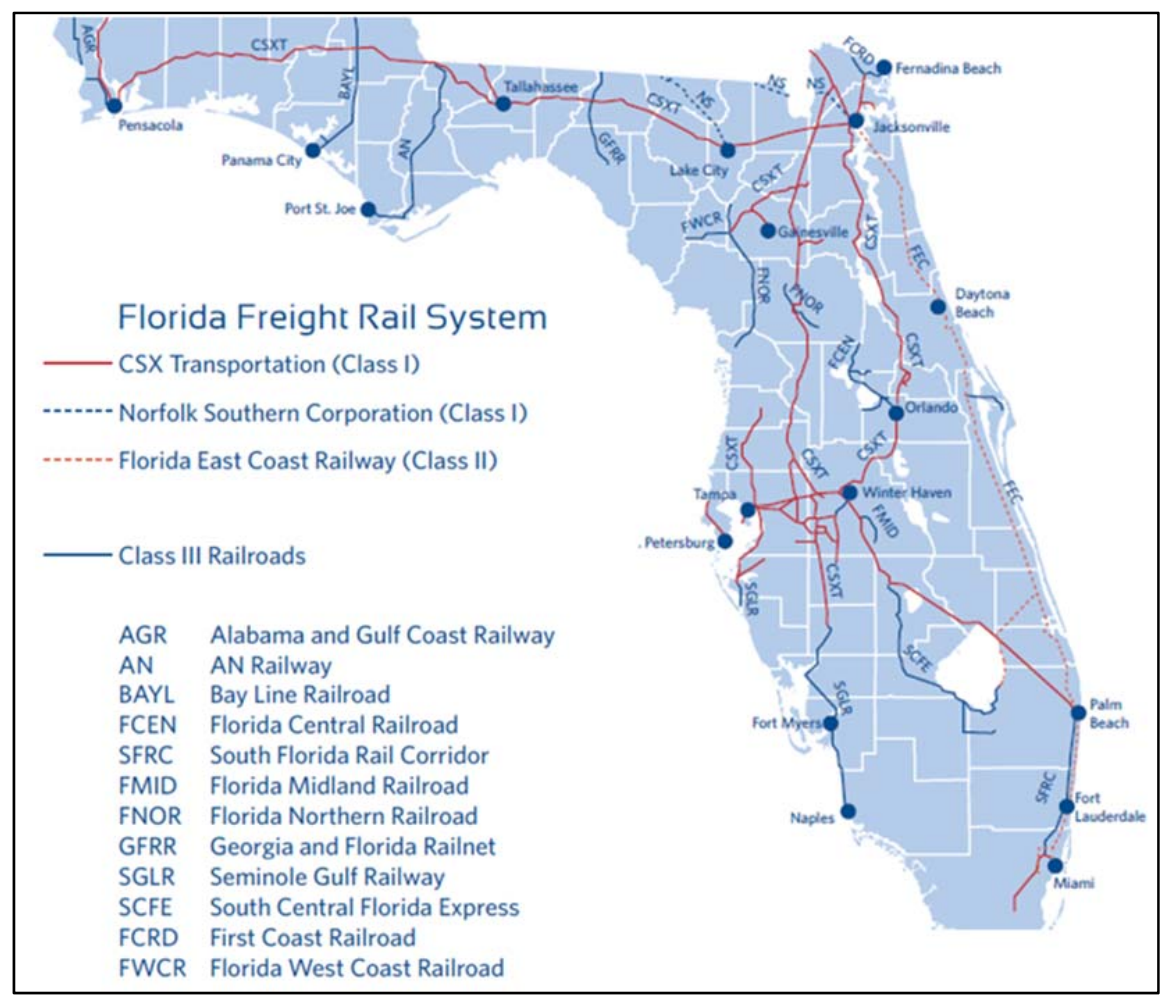

Figure 3-5. Florida's freight rail system

Source: www.freightmovesflorida.com

Access to airports, rail and trucking facilities, and coastal amenities such as boat ramps should be included. Such information is primarily obtained through local knowledge, special studies, or plans (e.g., the SIS Plan) related to these facilities as noted in ITR 2-9 (Ports, Airports, and Freight Planning Information Sources). BP 3-11 provides an example of how access to a port may be described. The Taylor County Coastal Resources Map (BP 3-12) illustrates roads and public boat ramps that provide access to the coast. Access to airports may be mapped as illustrated in BP 3-13.

\section{BP 3-11. Access to Ports}

The Hillsborough County Comprehensive Plan Transportation Element (HCTE) (non-adopted portion) includes information and future trends obtained from existing master seaport plans or Port Authority staff. An inventory and analysis of the seaport facilities located in the County along with a general description of each facility, the number of jobs, the amount of cargo, surrounding land use, heavy truck and rail trips, and the primary corridors used to access the facility. The Transportation Element also discusses inland intermodal facilities. (10 p. 57).

Key Roadway Corridors Serving the Port of Tampa

\begin{tabular}{|l|l|}
\hline North/ South Corridors & East/ West Corridors \\
\hline I-75 & I-4 \\
\hline I-275 & SR 60 (Adamo Drive) \\
\hline US 41 and US 301 & Lee Roy Selmon \\
\hline 21st and 22nd Streets North & Causeway Boulevard \\
\hline
\end{tabular}

Source: Hillsborough County Comprehensive Plan Transportation Element (10) 

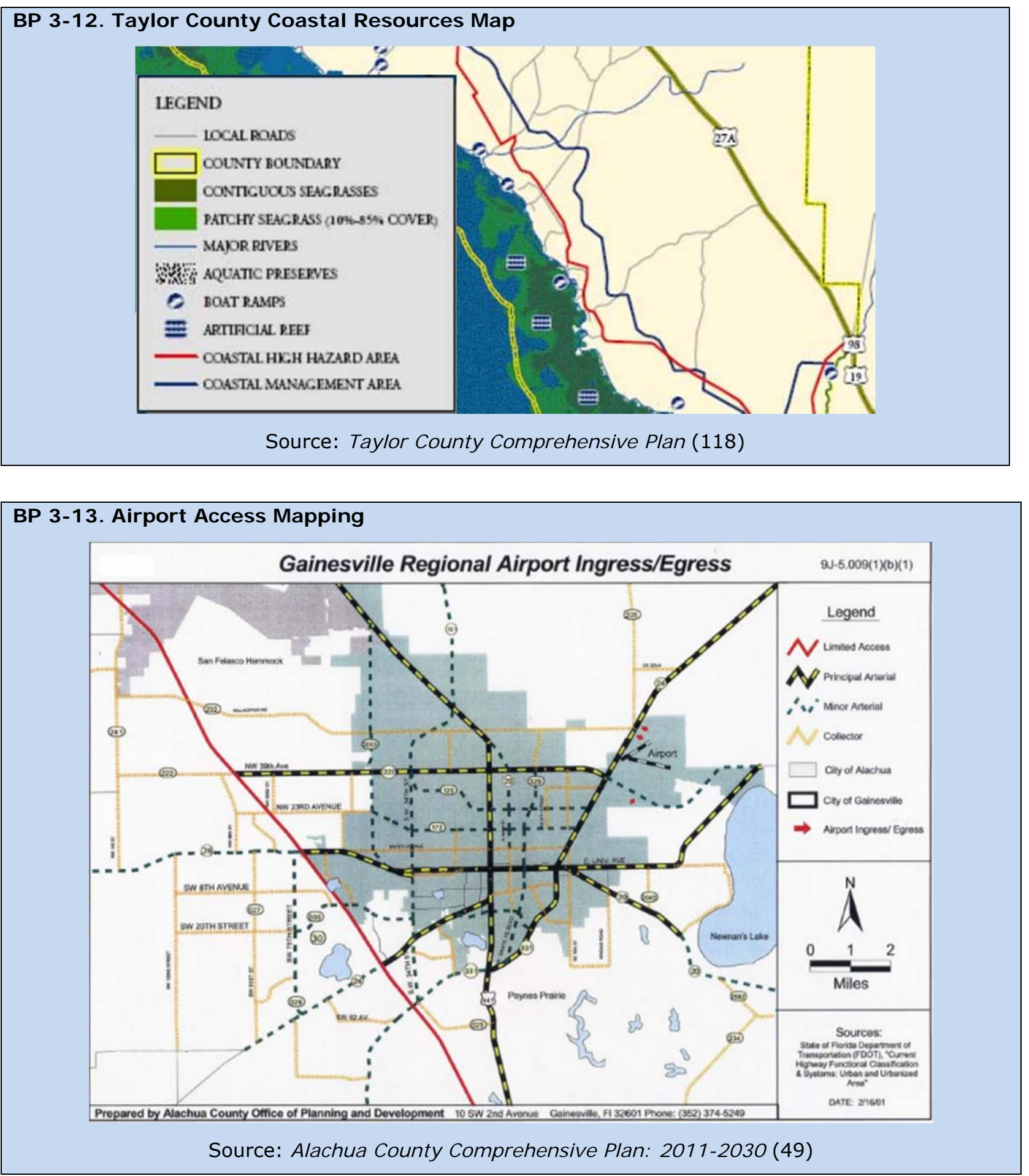

\section{Identify and map intermodal facilities}

Intermodal transportation facilities provide a connection between modes. FDOT is working to develop criteria for the designation of intermodal logistics centers (ILCs), a SIS facility 
created to aid in the shipment of goods through a seaport (94). ILCs are defined as a "facility or group of facilities serving as a point of intermodal transfer of freight in a specific area physically separated from a seaport where activities relating to transport, logistics, goods distribution, consolidation, or value-added activities are carried out and whose activities and services are designed to support or be supported by conveyance or shipping through one or more SIS seaports" (119). (§311.101(2) F.S) They include but are not limited to inland ports. Section 311.101 F.S also establishes the Intermodal Logistics Center Infrastructure Support Program "to provide funds for roads, rail facilities, or other means for the conveyance or shipment of goods through a seaport..." The following ILCs received grant funding from the State in 2013:

- Port of Panama City Intermodal Distribution Center

- Keystone ILC (Jacksonville)

- South Florida Logistics Center (Miami)

- Port Manatee Commerce Center (Palmetto)

3. Describe future need for ports, airports, rail, intermodal facilities, related facilities, and access identified in any master plans or other analysis

An important aspect of planning for ports and airports is the accessibility of these facilities through the surface transportation system.

\section{OPTI ONAL - I ncorporate airport master plan.}

a. I dentify the regional transportation system serving the airport

b. Consistency with the transportation element

c. I dentify interlocal agreements pertaining to the provision of public facilities and services to maintain adopted LOS standards if subject to concurrency

Inclusion of any applicable airport master plan within the comprehensive plan is optional. Figure 3-6 illustrates the Port Planning Area in Port St. Joe. 


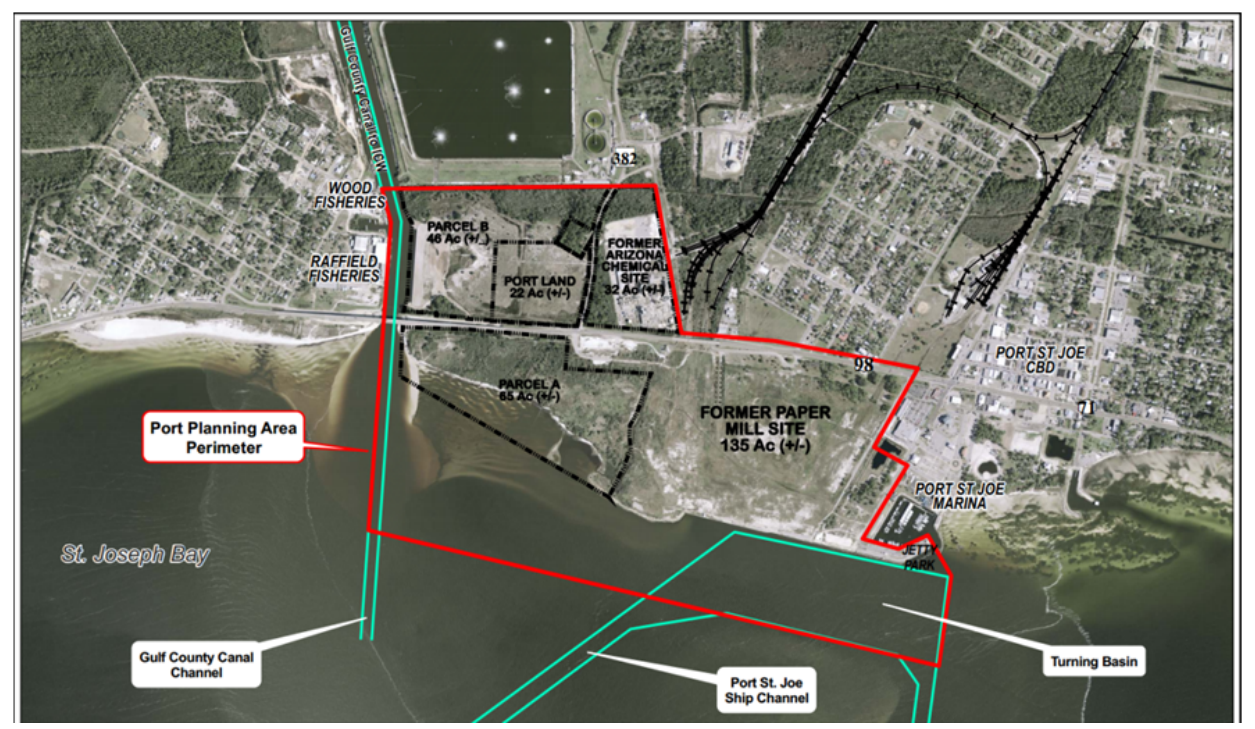

Figure 3-6. Port St. J oe port planning area

Source: Port St J oe Master Plan (120)

If an airport master plan is incorporated into the comprehensive plan, land use compatibility around airports must be addressed consistent with Chapter 333, F.S., Guidance is available on this topic as detailed below; however, the Federal Aviation Administration issued expanded guidance on land uses within the airport runway protection zones (RPZ) in September of 2012 (Appendix E). FAA guidance clarifies that transportation facilities such as rail facilities, public roads/highways, and vehicular parking facilities are among land uses considered not compatible with RPZs. Planning staff should be aware that additional coordination steps are required when building new or expanding existing facilities of this type within the vicinity of the airport.

ACRP Report 27: Enhancing Airport Land Use Compatibility - Volume 1: Land Use Fundamentals and Implementation Resources includes some basic guidance regarding planning techniques appropriate for inclusion in local government comprehensive plans as illustrated in Table 2-4 (Addressing Airports in the Comprehensive Plan) (58 p. 1.149).

FDOT's Airport Compatible Land Use Guidebook provides detailed guidance for the consideration of "land development in the vicinity of public use airports and military airfields" in light of "federal, state, local government laws, statutes, rules, and regulations" (57 p. v.). The Guidebook includes (57 p. ii.):

- Principles underlying land use compatibility requirements;

- Statutes, regulations, and processes governing land use compatibility;

- Process for reviewing development applications; and

- Strategies to prevent or correct lands use incompatibilities.

The City of Gainesville Future Land Use Element Supplemental Data and Analysis points to airport hazard zoning regulations in the Land Development Code to "control development standards for land uses" and "building/structure height standards located within the Airport Zones of Influence and other zones" (121 p. 11). 


\subsection{System Analysis and Future Needs}

Transportation system needs include improvements consistent with other plans, to accommodate new growth, increase safety, and/or increase connectivity and mobility. Determining transportation system needs and appropriate multimodal strategies and capital improvement projects is an iterative process. Information and findings obtained in the inventory of modal and agency plans/visions and existing transportation and land use conditions provides a starting point to analyze the transportation system. The analysis must consider the system's relationship to land use, existing and future system performance, and system needs.

The analysis of existing conditions for all modes will reveal opportunities to improve upon the system in light of the local vision and multimodal objectives. Future transportation system demand must also be analyzed in light of anticipated future growth and land use, as identified in the Future Land Use Element. This information will help identify whether demand for transportation system may exceed supply and where capacity improvements, modal options, and programmatic strategies could be applied to manage that demand and improve mobility. ITR 2-10 (System Analysis Tools and Resources) identifies tools and information sources for this effort. A broad range of actions should be considered in addressing future demand such as policies, institutional and operational strategies, pricing, infrastructure projects, special studies, regulations, education and awareness, financing strategies, and a host of collaborative undertakings.

Practice Notes: Chapter 163, Part II, F.S., requires local governments to:

1) Identify projected transportation system levels of service and system needs based upon the future land use map.

2) Identify how the local government will correct existing facility deficiencies and meet the identified needs of the projected transportation system.

\section{Quality/Level of Service Analysis for all Modes}

Quality/level of service (LOS) analysis is used in planning to determine available capacity based on existing and anticipated travel demand. Florida legislation no longer mandates transportation concurrency or establishes minimum level of service standards for roadways. The local government comprehensive plan capital improvement element must include roadway level of service standards for capacity planning and prioritizing purposes based on professionally accepted methodologies.

In addition, although no longer required to adopt FDOT established level of service standards for the state highway system, local governments should continue to coordinate with FDOT on level of service for state maintained roadways. In April of 2012, FDOT adopted the following policy regarding LOS standards for the State Highway System (62):

"It is the Department's intent to plan, design and operate the State Highway System at an acceptable level of service for the traveling public. The automobile level of service standards for the State Highway System during peak travel hours are " $D$ " in urbanized areas and " $C$ " outside urbanized areas. See Procedure No. 525-000-00, Level of Service Standards and Highway Capacity analysis for the State Highway 
System for more information. No specific level of service standards are established for other highway modes (e.g., bus, pedestrian, bicycle). Quality/level of service for these modes is determined on a case by case basis."

FDOT's 2013 Quality/Level of Service Handbook (see ITR 2-10. System Analysis Tools and Resources) and the accompanying software include techniques from the 2010 Highway Capacity Manual and is designed specifically to provide "a foundation for high quality, consistent capacity and LOS analyses and review in the State of Florida" (65). The 2010 Highway Capacity Manual (66) integrates level of service analysis for four modes (bicycle, pedestrian, transit, automobile), enabling analysis across the modes and allowing adjustments based on policy objectives. Procedures for analysis of intersections, midblock pedestrian crossing, shared-use trails and rural highways are also included. The analysis culminates in four LOS grades (one per mode).

Transit quality/level of service may sometimes be found in the applicable TDP or TDSP as noted in ITR 2-3 (Transit System Information Found in the TDP), or by using LOS analysis resources noted in ITR 2-10 (System Analysis Tools and Resources). FDOT's 2013 Quality/Level of Service Handbook contains a LOS threshold table aimed at urban scheduled transit service (Table 3-1). The table contains Florida-specific adjusted service frequency numbers and is based on a table found in the Transit Capacity and Quality of Service Manual (TCQSM), the nation's leading document for transit/quality of service analysis.

Table 3-1. Service Frequency LOS Thresholds

\begin{tabular}{|c|c|c|c|}
\hline $\begin{array}{c}\text { Level of } \\
\text { Service }\end{array}$ & $\begin{array}{c}\text { Adjusted } \\
\text { Service } \\
\text { Frequency } \\
\text { (Vehicles/hour) }\end{array}$ & $\begin{array}{c}\text { Headway } \\
\text { (minutes) }\end{array}$ & Comments \\
\hline A & $>6$ & $<10$ & $\begin{array}{l}\text { Passengers don't } \\
\text { need schedules }\end{array}$ \\
\hline B & $>4$ & $<15$ & $\begin{array}{l}\text { Frequent service, } \\
\text { passengers } \\
\text { consult schedules } \\
\text { Maximum } \\
\text { desirable time } \\
\text { to wait if transit } \\
\text { vehicle missed }\end{array}$ \\
\hline C & $\geq 3$ & $\leq 20$ & $\begin{array}{l}\text { Service } \\
\text { unattractive to } \\
\text { choice riders }\end{array}$ \\
\hline E & $\geq 2$ & $\leq 30$ & $\begin{array}{l}\text { Service available } \\
\text { during hour }\end{array}$ \\
\hline F & $<1$ & $>60$ & $\begin{array}{l}\text { Service } \\
\text { unattractive to all } \\
\text { riders }\end{array}$ \\
\hline
\end{tabular}

Source: FDOT 2013 Quality/LOS Handbook (122) 
The multimodal transportation element should:

\section{I dentify and describe future needs on major roadways as detailed in the Florida SIS Plan.}

\section{Forecast future travel demand on local thoroughfares. Determine existing and future transportation system performance (e.g. Q/ LOS, bottlenecks) for the identified thoroughfares and transportation routes.}

System needs are forecasted using available modeling tools that incorporate future land use as designated in the future land use element. FDOT forecasts future travel demand for the State Highway System (SHS) and other major thoroughfares using the Florida Standard Urban Transportation Model Structure (FSUTMS) noted in ITR 2-10 (System Analysis Tools and Resources). This modeling as well as existing and future level of service data for the SHS is available to local governments outside of MPO planning areas.

Small communities and rural areas can determine roadway level of service roadways using FDOT's 2013/ Quality/Level of Service Handbook which contains detailed guidance. Roadway service volumes are established according to area type (urban, transitioning, or rural), facility types (freeways, highway, and arterials), number of lanes, and geometric characteristics. Service volumes are shown in generalized service volume tables for transitioning areas and rural areas (see ITR 3-2 and ITR 3-3).

Traffic count data (see ITR 2-4. Roadway Data Sources) may be obtained from the FDOT Statistics Office, the applicable FDOT District office, the County, or municipal government. Existing traffic volumes are compared with the average annual daily traffic service volumes in the applicable generalized service volume table to determine the existing roadway level of service. The roadway level of service can then be compared with LOS standards in the currently adopted comprehensive plan in table format within the comprehensive plan. BP 314 provides an example of level of service reporting within a transportation element.

Anticipated future traffic volumes can be compared to service volumes shown in generalized service volume tables to determine if future traffic volumes will exceed service capacity. This comparison may be illustrated as shown in BP 3-15. Small local governments often forecast traffic volumes using historic growth rates. This method may be appropriate if population growth rates are anticipated to remain at historic growth levels. BP 3-16 illustrates future volume to capacity ratios on major thoroughfares. The Handbook recommends using the generalized planning level of analysis when making future longrange estimates.

Local governments may choose to engage in additional evaluation of quality of service across the various transportation modes to further identify system needs. Table 2-5 (Statistically Significant LOS Criteria for Non-Automotive Modes in HCM 2010) indicates criteria found to be statistically significant by mode in relation to LOS that may be used in the analysis. An understanding of these criteria is also useful in establishing simpler analysis methods, as well as in setting performance measures for the future system. 
BP 3-14. Existing (2010) Operating LOS - State Roads

\begin{tabular}{|c|c|c|c|c|c|c|c|c|c|}
\hline Roadway & From & To & $\begin{array}{l}\text { Los } \\
\text { Std }\end{array}$ & $\begin{array}{l}\text { Daily } \\
\text { Service } \\
\text { Volume }\end{array}$ & $\begin{array}{c}2010 \\
\text { Daily } \\
\text { Traffic } \\
\text { Volume }\end{array}$ & LOS & $\begin{array}{l}\text { PHPD } \\
\text { Service } \\
\text { Volume }\end{array}$ & $\begin{array}{c}2010 \\
\text { PHPD } \\
\text { Traffic } \\
\text { Volume }\end{array}$ & LOS \\
\hline $\begin{array}{l}\text { US } 19 / 27 \\
\text { SR } 20\end{array}$ & Madison Co. & CR 361 & B & 28,600 & 5,800 & A & 1,540 & 313 & A \\
\hline $\begin{array}{l}\text { US } 19 / 27 \\
\text { SR } 20\end{array}$ & CR 361 & $\begin{array}{l}\text { Perry } \\
\text { NE City Limits }\end{array}$ & B & 28,600 & 9,400 & A & 1,540 & 508 & A \\
\hline $\begin{array}{l}\text { US19/98/27A } \\
\text { SR 30/55 }\end{array}$ & $\begin{array}{l}\text { Perry } \\
\text { SE City Limits }\end{array}$ & $\begin{array}{l}\text { Perry } \\
\text { SE Urban Limits }\end{array}$ & C & 32,800 & 10,100 & B & 1,730 & 546 & B \\
\hline $\begin{array}{l}\text { US 19/98/27A } \\
\text { SR 30/55 }\end{array}$ & $\begin{array}{l}\text { Perry } \\
\text { SE Urban Limits }\end{array}$ & CR 361 & B & 28,900 & 9,000 & A & 1,540 & 488 & A \\
\hline $\begin{array}{l}\text { US 19/98/27A } \\
\text { SR 30/55 }\end{array}$ & CR 361 & Dixie Co & B & 28,600 & 5,700 & A & 1,540 & 308 & A \\
\hline
\end{tabular}

Source: Taylor County Comprehensive Plan (118)

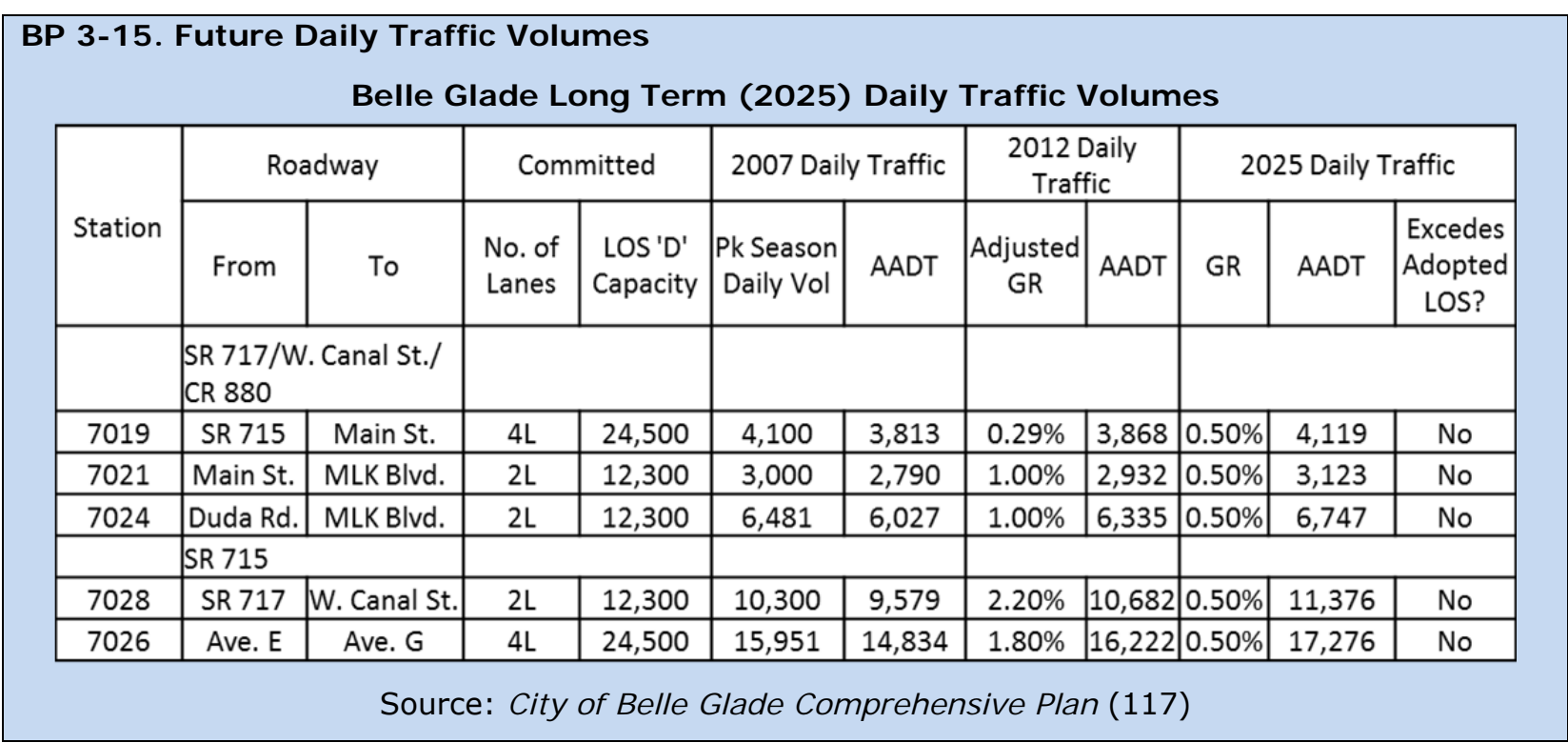


ITR 3-2. Generalized Annual Average Daily Volumes in Florida's Transitioning Areas and Areas over 5,000 Not in Urbanized Areas

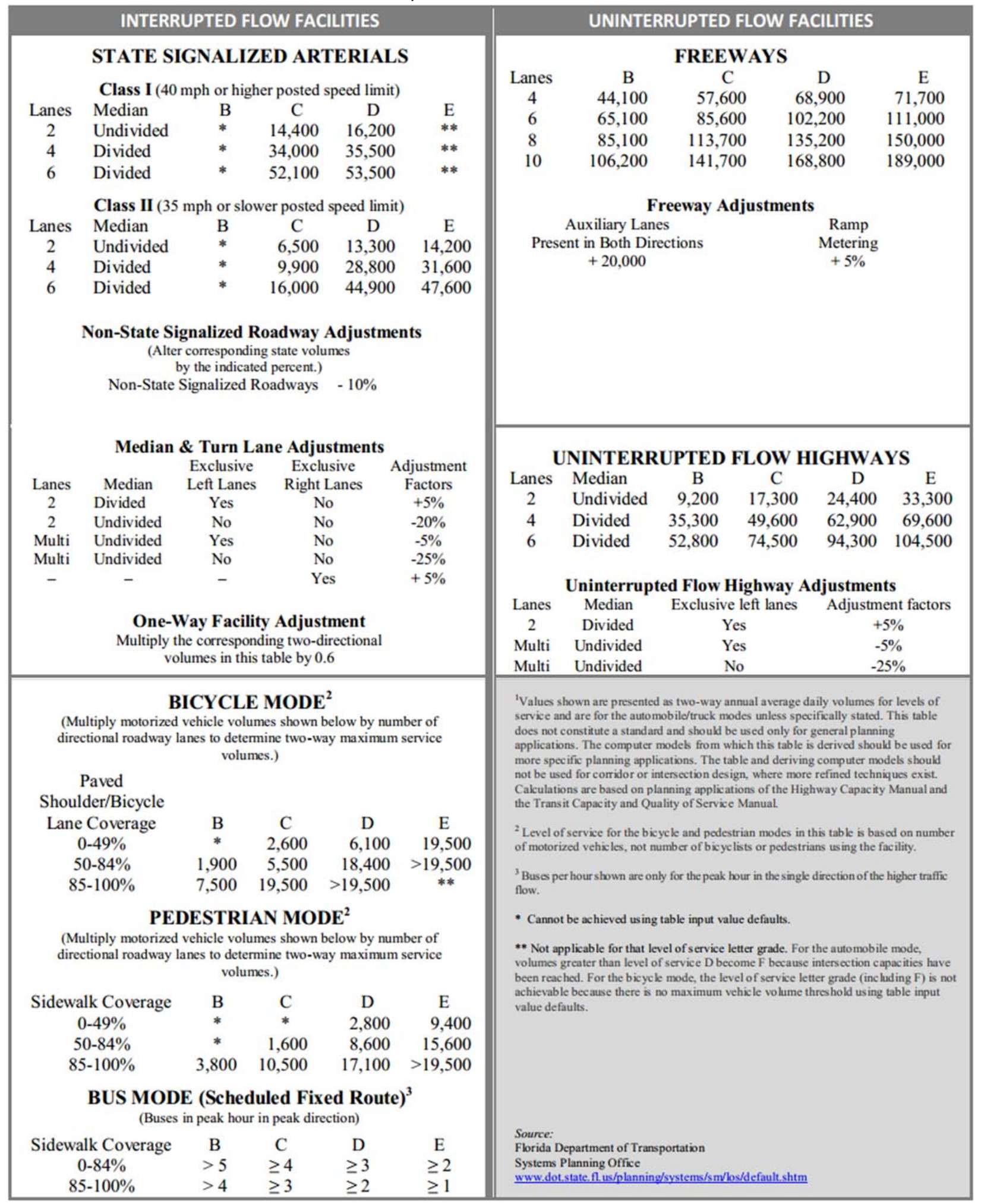


ITR 3-3. Generalized Annual Average Daily Volumes in Rural Undeveloped Areas and Developed Areas Less Than 5,000 Population

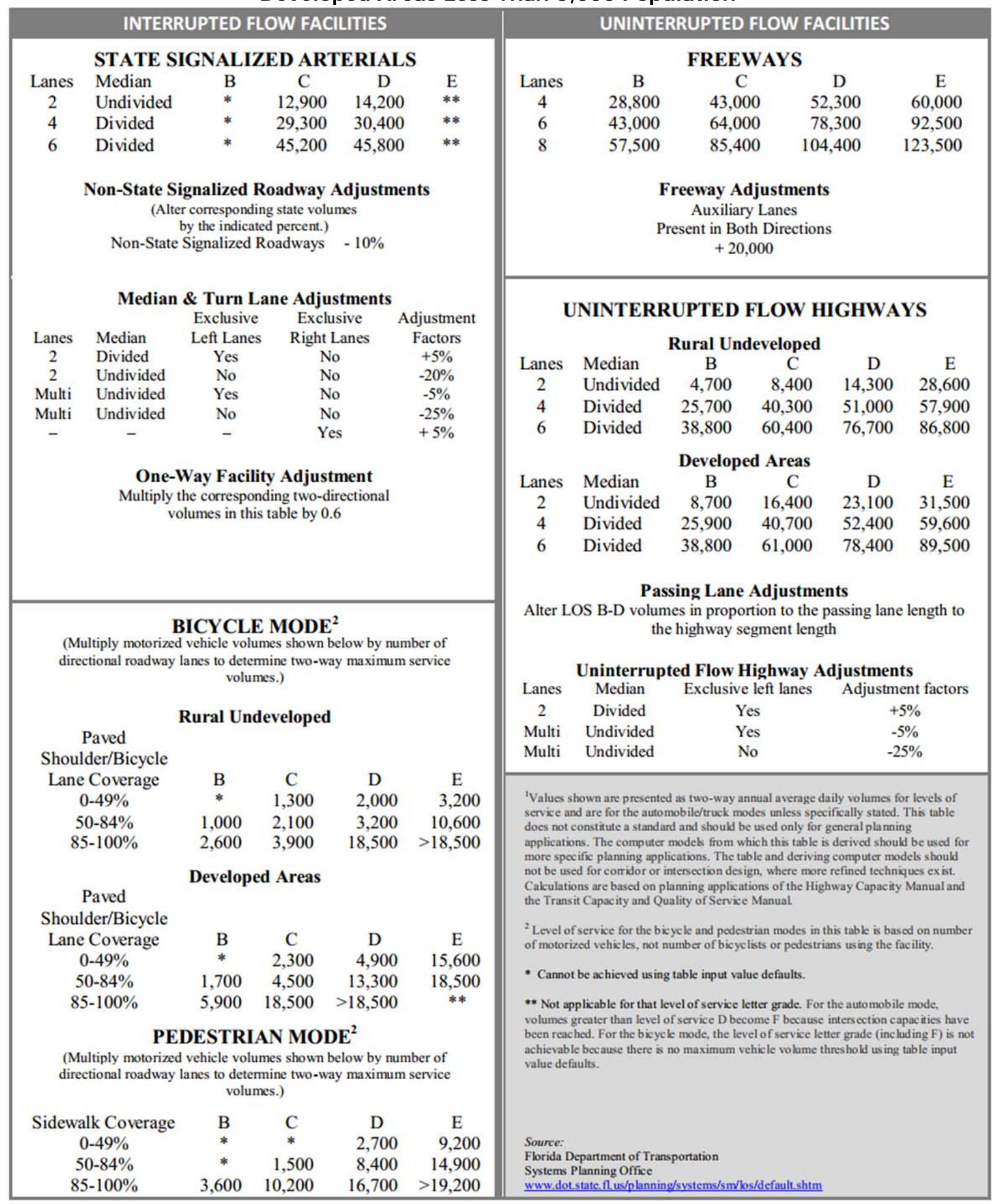


BP 3-16. Future Roadway Volume to Capacity (V/ C) Ratio

Glades County YR 2020 Roadway Volume to Capacity Ratio (V/ C)

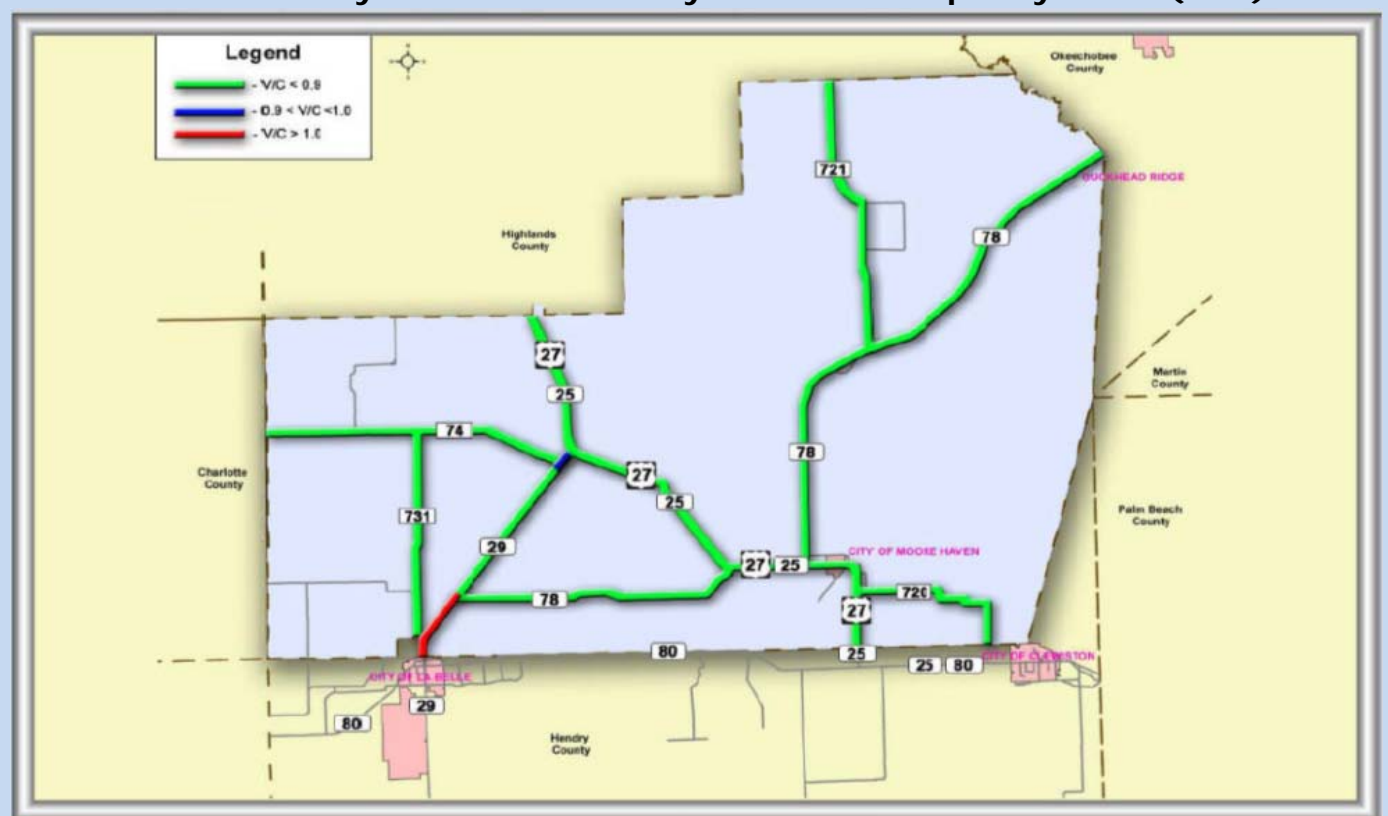

Source: Glades County Comprehensive Plan Transportation Element (115)

\section{Identify needs for other locally identified thoroughfares and transportation routes, including connectivity, continuity, spacing, capacity, and safety needs.}

In addition to future travel demand analysis, results of modeling, sketch planning techniques, and the community vision can provide additional insight into whether additional transportation routes may be needed to support the future land use and multimodal transportation plan. These will primarily include routes that generally function as arterials or collectors. It is also important to consider local networks, including local streets and bicycle and pedestrian routes and crossings for a clear picture of the overall circulation network. BP 2-31 (Apply Spacing and Connectivity Guidelines to the Transportation Network) includes guidelines for determining whether additional arterials, collectors and local streets should be provided to accommodate future land use and modal plans. See Section 2.3 for further information on sketch planning a street network.

Local street network density and connectivity is a primary determinant of the quality of the multimodal environment. People can walk and bike more easily where streets provide relatively short blocks and multiple connections to shops or services from the surrounding residential areas.

Practice Notes: Local governments should identify locations lacking sufficient roadways that function primarily as collector streets and consider providing for additional collector routes in these areas. In the absence of adequate and connected supporting networks, the capacity from adding new lanes to major 
roadways may be counteracted by excessively long signal cycles and delay at major intersections. In addition, residents are forced to use the major highway for local trips. Long signal cycles at intersections indicate a need for other corrective actions such as rerouting left turns or improving the density and connectivity of the secondary street system to reduce arterial left-turn volumes.

\section{Describe future transit demand, need, and performance of public transportation, such as quality of service and operating characteristics, as detailed in TDSPs, TDPs, and regional plans.}

Future local public transportation system needs may include expanded paratransit service and/or increased coordination. Also consider new types of service (e.g., circulators. Transit service and infrastructure should be aligned with community needs, such as access to employment. An example of a needs assessment from a TDSP is contained in BP 3-17. Where there is a perceived need for more transit services, local governments should coordinate with the appropriate transit agency. Small municipalities should work with the system that is provided to their community - likely the local planning agency that prepares the TDSP. For public transportation planning, TCRP Report 161 Methods for Forecasting Travel Demand and Quantifying Need for Rural Passenger Final Workbook is designed to help planners answer questions about the magnitude of the need for public transit services within a geographic area, as well as the annual ridership (i.e. demand) www.trb.org/Main/Blurbs/168758.aspx.

Small communities, and rural areas have transportation challenges that differ from those in urban areas and thus will require different approaches to addressing public transportation. Small community transit investments include creating and improving bus circulator routes, creating transit and intermodal hubs, linking transportation improvements to local destinations and surrounding area transit centers, and the use of creative and diverse funding sources (123 pp. 9-10). The addition of transit systems in smaller communities encourages downtown revitalization, promotes the development of new business, and increases employment opportunities available to the local population.

Incremental and small-scale transportation service projects can be beneficial in small communities without adversely affecting the small town and rural character (123 p. 11). Although a portion of funding for small town transportation projects comes from the federal government, this funding is rarely enough to create a well-functioning transportation system and local governments need to build effective partnerships to support the new transportation systems. The local and regional bus network is generally the foundation for a small community's, or rural area's transit system and requires careful and focused improvements. Case examples include "connecting workers to jobs" in Addison County, Vermont, "increasing mobility by coordinating transportation services" in Allendale County, South Carolina, and providing ADA-accessible vehicles in Choctaw Nation, in rural Oklahoma (123 pp. 15-21).

Circulator systems, routes that operate in a closed loop, are useful in small communities, and rural areas "where there are concentrated trip generators located just a few miles apart" (123 p. 21). Case examples include implementation of four branded circulator routes in Bozeman, Montana; trolleys targeting tourists, workers, and local residents with children 
and connecting them with inland and coastal communities in York County, Maine; and serving tourists while maintaining historic character in Monterey, California (123 pp. 22-26).

The incorporation of intermodal transit centers and transit hubs can promote regionalization, revitalize downtowns, and inspire the provision of needed amenities. Intercity transit via bus or rail benefits both small towns and major urban areas by providing access to jobs, goods, and services, as well as access to a more affordable housing and a more rural lifestyle. 


\section{BP 3-17. TDSP Needs Assessment}

Holmes-Washington TDSP Needs Assessment

Needs Assessment

In assessing the transportation (service and capital purchase) needs and demands for individuals with disabilities, elderly, low income, and high risk and at-risk children, the following projects with estimated costs and funding sources have been identified and are summarized in Table 5 below.

\begin{tabular}{|c|c|c|c|}
\hline Project & County & $\begin{array}{c}\text { Estimated } \\
\text { Cost }\end{array}$ & $\begin{array}{c}\text { Funding } \\
\text { Source }\end{array}$ \\
\hline $\begin{array}{l}\text { Formula (competitive) grant to enhance mobility for } \\
\text { seniors and persons with disabilities by providing } \\
\text { funds for programs to serve the special needs of } \\
\text { transit-dependent populations beyond traditional } \\
\text { public transportation services. }\end{array}$ & $\begin{array}{l}\text { Holmes \& } \\
\text { Washington }\end{array}$ & $\$ 113,000(\mathrm{R})$ & $\begin{array}{l}\text { Enhanced Mobility of } \\
\text { Seniors and Individuals } \\
\text { with Disabilities - } 5310\end{array}$ \\
\hline $\begin{array}{l}\text { Capital and/or operating assistance to provide rural } \\
\text { transportation service in Holmes \& Washington } \\
\text { Counties. }\end{array}$ & $\begin{array}{l}\text { Holmes \& } \\
\text { Washington }\end{array}$ & $\$ 169,000$ & $\begin{array}{l}\text { Non-Urbanized } \\
\text { Area - } 5311\end{array}$ \\
\hline $\begin{array}{l}\text { Capital funding to replace, rehabilitate, and purchase } \\
\text { buses, vans, and related equipment, and to construct } \\
\text { bus-related facilities. Funds are eligible to be } \\
\text { transferred by the state to supplement urban and } \\
\text { rural formula grant programs (e.g., } 5307 \text { and 5311). }\end{array}$ & $\begin{array}{l}\text { Holmes \& } \\
\text { Washington }\end{array}$ & TBD & $\begin{array}{l}\text { Bus \& Bus Facilities } \\
\qquad(5339)\end{array}$ \\
\hline $\begin{array}{l}\text { Provide transportation services for other human } \\
\text { services organizations through the transportation } \\
\text { services coordinated by the Community } \\
\text { Transportation Coordinator (CTC). }\end{array}$ & $\begin{array}{l}\text { Holmes \& } \\
\text { Washington }\end{array}$ & $\begin{array}{r}\$ 328,000 \\
\$ 459,803 \\
\$ 12,000 \\
\$ 0 \\
\$ 2,000 \\
\$ 114,000 \\
\$ 2,800 \\
\$ 2,500 \\
\$ 45,000 \\
\end{array}$ & $\begin{array}{l}\text { CTD-TD } \\
\text { Medicaid } \\
\text { Head Start } \\
\text { Workforce } \\
\text { Older Americans } \\
\text { APD } \\
\text { Eounty } \\
\text { United Way } \\
\text { Farebox } \\
\end{array}$ \\
\hline
\end{tabular}

\section{Barriers to Coordination}

The following are continued barriers to adequate coordination:

- Large County TD population spread throughout the county creating longer trips.

- Lack of specialty doctors in county creates need for long distance out-of-county trips to other medical specialists.

- Lack of cooperation from medical specialists in scheduling medical appointments on designated transportation days provided for out-of-county trips.

- Lack of commitment with scarce tax dollars.

- Perception that coordinated transportation is for the poor.

- Not enough funding to cover demand.

- Lack of medical providers and failure of their willingness to cooperate with transportation coordinator.

- Specific issues related to funding sources.

Source: http://wfrpc.org/dtran/holwas/Holmes-

Washington\%20County\%20TDSP\%20Major\%20Update\%202013.pdf

\section{Describe needs and safety issues for multi-use trails, bicycle, pedestrian and other facilities as detailed in facility-specific master plans or other analysis}


Many tools are available to help local governments evaluate the quality of the bicycle and pedestrian system and identify needs and possible improvement strategies. ITR 2-11 (Bicycle and Pedestrian Planning Analysis Tools and Resources) provides an overview of some of the tools and techniques used for this analysis. Some of the more useful tools for small communities and rural areas are discussed in this section. FDOT's 2013 Quality/Level of Service Handbook generalized service volume tables contain level of service for bicycle and pedestrian modes on major thoroughfares including the SHS. The LOS is based on motorized vehicle volume and the amount of paved shoulder/bicycle lane or sidewalk coverage.

Needs may be gaps in existing networks or where bicycle, pedestrian, or similar travel (e.g. horses, golf carts) travel is most likely, such as:

- arterial or collector streets;

- areas of relatively high residential density or commercial intensity;

- areas with a compact, mixed land use pattern (residential and non-residential within a 1 mile biking distance);

- proximity to transit routes/stops/stations, public schools, public parks; and

- major demand generators.

Creating bicycle and pedestrian-friendly environments is key to encouraging choice of these modes over the automobile, particularly for short-distance trips. Those not using motor vehicles should be able to circulate throughout the community and access land uses. Ample bicycle and pedestrian connections within and between residential areas and supporting community facilities and services, such as shopping areas, employment centers, transit stops, neighborhood parks, and schools provide for this circulation. Such connections may be sidewalks, bicycle facilities, and/or shared use paths provided throughout the community creating tangible non-automobile mode choices. Alachua County discusses promoting network connectivity to create a safer bicycle and pedestrian environment (BP 3-19).

For the pedestrian, sidewalks are essential to pedestrian travel within small communities particularly along major thoroughfares. Bicyclists are capable of traveling greater distances and sharing the road on lower speed roads; however, a bicycle lane is key to safety on higher-speed collectors and arterials. In small communities and rural areas where the main street may be a state highway, consideration should be given to providing pedestrian and bicycle ways on or near the highway to enable residents to access facilities and services. For example, Wilkeson, Washington developed a rural town center corridor plan aimed at providing bicycle and pedestrian facilities along SR 165 through town (BP 3-18).

The inventory of bicycle and pedestrian conditions will help to identify needs such as gaps in the existing networks, facility needs in bike- or pedestrian-focused areas, or other needs based on the community's vision. When the gaps have been identified, they can be mapped and prioritized for future modification. BP 2-20 (Identify Pedestrian Facility Deficiencies) illustrates how gaps in a sidewalk network may be mapped. 


\section{BP 3-18. Non-motorized Rural Town Center Corridor Plan}

The plan states that "the Wilkeson Rural Town Center Corridor Plan is broken into six elements to facilitate project funding and construction. These elements may be constructed in any order; when construction is completed, they will work together to create a comprehensive non-motorized network all along SR 165 through town" (124).

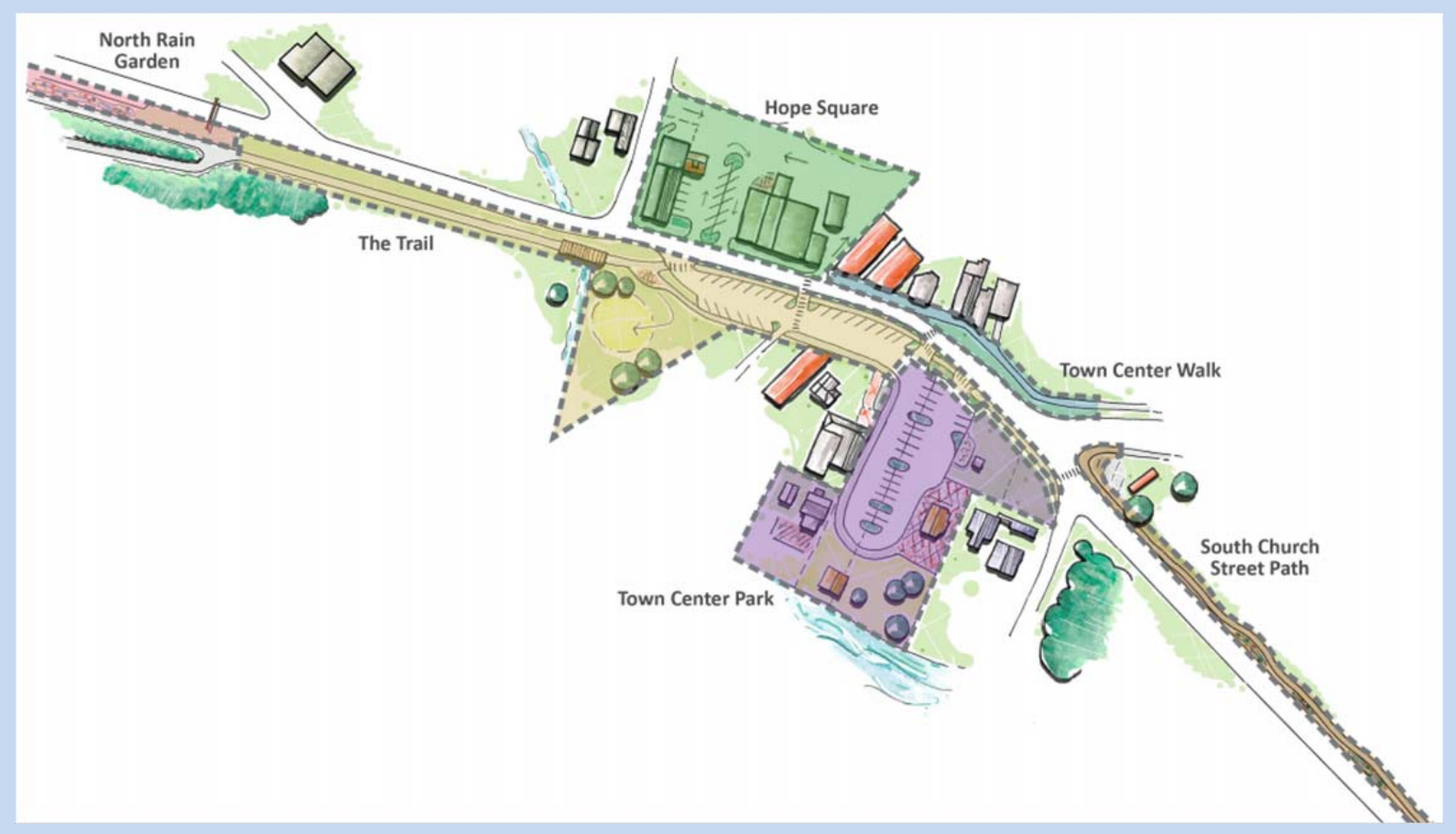

Source: Town of Wilkeson Rural Corridor Plan Award Nomination (124)

\section{BP 3-19. Network Connectivity}

The Alachua County Comprehensive Plan states in Policy 1.6.7 that the transportation network shall be "designed as a continuous interconnected network" (49 p. 22). This interconnected network should be designed to calm traffic speeds and encourage walking and biking while providing connectivity and functionality to the system (49 p. 22). Alachua County has decided to use smaller block lengths to promote greater network connectivity in designated areas. Policy 1.6.7.2 states that "perimeter block lengths shall not exceed 1,300 linear feet within the village center, 1,600 linear feet within the transit supportive area outside of the village center, and 2,000 linear feet outside the transit supportive area" (49 p. 22). Policies 1.6.7.6 and 1.6.7.7 further require that "the street network includes a bicycle and pedestrian circulation system that interconnects all uses, including parks, plazas, squares, and open spaces" (49 p. 23).

Gaps in a sidewalk or bicycle network may be determined by a variety of methods including:

- Bikeway/sidewalk gap analysis - involves mapping gaps to highlight opportunities to improve the connectivity of bicycle and pedestrian networks.

- Equity gap analysis - assesses geographic equity of bicycle or pedestrian facilities with respect to disadvantaged populations. Using GIS, overlays show gaps in the network (pedestrian, bicycle, transit) with spatial data on income, race, and age. 
- Neighborhood access mapping - evaluates access to services such as grocery stores, neighborhood retail, schools, and transit stops within a short walk or bicycle ride. It may be based on a network distance/travel time analysis or a simple concentration of services. Walkscore.com provides one way to conduct this analysis (74)

Upon detailing needs, the community should prioritize bicycle/pedestrian projects. Systematic methods include identifying locations with the greatest potential for bicycle/pedestrian use or integrating bicycle/pedestrian facilities into existing projects, such as including bicycling lanes into a road resurfacing road project. Small communities and rural areas may choose to focus on safety-related projects including those providing safe routes to schools. The transportation element should include policies for establishing design standards for the bicycle and pedestrian modes. Resources containing information on typical design standards are available in ITR 2-11 (Bicycle and Pedestrian Planning Analysis Tools and Resources). 


\subsection{Future Multimodal Transportation Network}

This section of the model element suggests components as well as issues to consider when defining a plan for the future transportation system. The future plan will convey the results of the community vision and priorities, the analysis of transportation and land use conditions, and the identification of system needs and deficiencies into a plan. Estimates of future travel demand in relation to planned future land use will inform the planning effort, as will estimates of potential future changes in travel behavior based on land use and the availability of additional transportation modes. Local vision statements and supporting goals and objectives can provide a framework for evaluating alternatives and selecting appropriate projects and strategies for the community, as discussed in BP 2-32 (Evaluating Plan Alternatives) and BP 2-47 (Prioritize Multimodal Projects and Strategies). ITR 3-4 identifies some example maps to consider when conveying future plans.

\section{ITR 3-4. Small Communities and Rural Future Transportation System Maps}

- Future Land Use and Transportation Concepts

- Roadways by Number of Lanes, Functional Classification, and Jurisdiction

- Roadway Level of Service

- Priority Routes and Facilities by Mode (transit, truck, bicycle, pedestrian and related facilities, such as parking/park-and-ride)

- Thoroughfare Right of Way Needs Identification Map

- Existing and Planned Bicycle and Pedestrian Routes and Facilities (including multiuse trails and facilities)

- Port, Airport and Intermodal Facilities (and relationship to activity centers, key connectors)

- Priority Multimodal Transportation Projects

\section{Address Regional Coordination and Consistency}

\section{Elaborate on the extent to which the comprehensive plan integrates transportation needs and priorities identified in plans of other transportation agencies and local governments.}

The transportation element should identify local planning efforts that advance broader regional mobility objectives. Incompatibilities of other agency and modal plans with the vision and priorities of the local government should also be identified and addressed. Methods to address any incompatibilities, such as pursuit of a joint regional planning study or intergovernmental agreements, could be noted in the goals, objectives, and policies of the transportation and/or intergovernmental coordination element.

Practice Notes: Effective multimodal transportation planning involves a shift in focus from moving cars to moving people and goods. Investing in both motorized and non-motorized vehicle infrastructure is essential. The point is not to choose one over the other, but to distinguish the appropriate location and contexts for each, thereby enabling travel options.

For the state highway system and major arterials, place lower priority on preventing future congestion through widening and fringe highways (that induce exurban growth) and higher priority on managing the existing system (e.g., access management and intelligent transportation systems). For town centers or supporting activity centers, place lower emphasis on relieving congestion (a sign of 
vitality) and greater emphasis on expanding and reinforcing mode choice, improving walkability, and promoting a diverse and compatible mix of land uses.

\section{Integrate Future Land Use and Transportation}

Chapter 163, Part II, F.S., requires local governments to coordinate the proposed transportation map or map series with the future land use map or map series. This can be achieved by preparing an integrated transportation and land use vision or concept plan that is illustrated in a map or maps. When developing this map series, local governments may consider the Rural-Urban Transect and the characteristics of each Transect Zone as they relate to the community. The Rural-Urban Transect is illustrated in Figure 2-8 (Rural-urban transect). BP 3-1 provides an example of a conceptual map that relates the future land use plan to the transportation system by identifying the villages, settlements, employment centers, and other place types in relation to key transportation facilities (see also BP 2-33. Designate Areas Intended for Compact Development and BP 2-34. Include a Map Series Relating to the Transportation and Land Use Elements).

Future land use concepts should identify areas where specific activities are expected to occur such as freight activity versus retail and services. This guides future street design and the application of context sensitive solutions on major corridors, as well as planning and investment decisions relative to goods movement, public transportation, and pedestrian/bicycle services and facilities. Local network density and connectivity is a primary determinant of the quality of the multimodal environment.

Practice Notes: In the absence of coordinated land use and transportation planning, conflicts typically emerge between transportation and development objectives. Development may occur in right-of-way needed for new transportation facilities. Property owners may subdivide arterial frontage into small or narrow lots to maximize the number of lots with direct arterial access. Strip development occurs as local governments rezone highway and interchange area properties for commercial use and extend utilities along the highway. Without adequate supporting street networks, more local trips are made on the arterial. In the absence of effective access management, driveways increase, causing more traffic conflicts, crashes and congestion.

Over time, small communities often end up with strip development along their major thoroughfares. One alternative is to adopt a policy of focusing development into activity centers. Activity centers are dense clusters of trip attractors like retail shops, office space, restaurants, or cultural venues. Some activity centers are very large (such as a central business district), while others can be a collection of neighborhood retail shops. Higher density housing is located in activity centers and the surrounding area contains progressively lower-density residential units, along with green space. Activity center strategies are commonly applied in corridor management plans as a method of reducing strip development and providing walkable centers.

Local governments should consider the location of major activity centers, such as the town center or employment centers, in relation to major thoroughfares with the primary function of serving long distance, high speed travel (see Figure 2-9. Locating activity centers along 
major arterial corridors). If not properly located, centers can result in hazardous conflicts between local circulation and through traffic movement. In addition, major roadways can have a barrier effect on pedestrian activity. The multimodal transportation element should provide supporting networks for activity centers to maximize internal circulation, support transit service, and minimize traffic conflicts on thoroughfares. Generally, a minimum of two safe pedestrian crossings per mile is recommended.

People can walk and bike more easily where streets provide relatively short blocks and multiple connections to shops and services from the surrounding residential areas or one parking location. Enhancing street network connectivity can be applied as a technique to provide local residents alternatives to major roadways, particularly for short trips (Figure 37). Local and collector street networks are often underdeveloped, causing major highways to be used as the only means of access to and from corridor land uses. Fragmented local street systems increase the number and length of automobile trips and also impede emergency access.

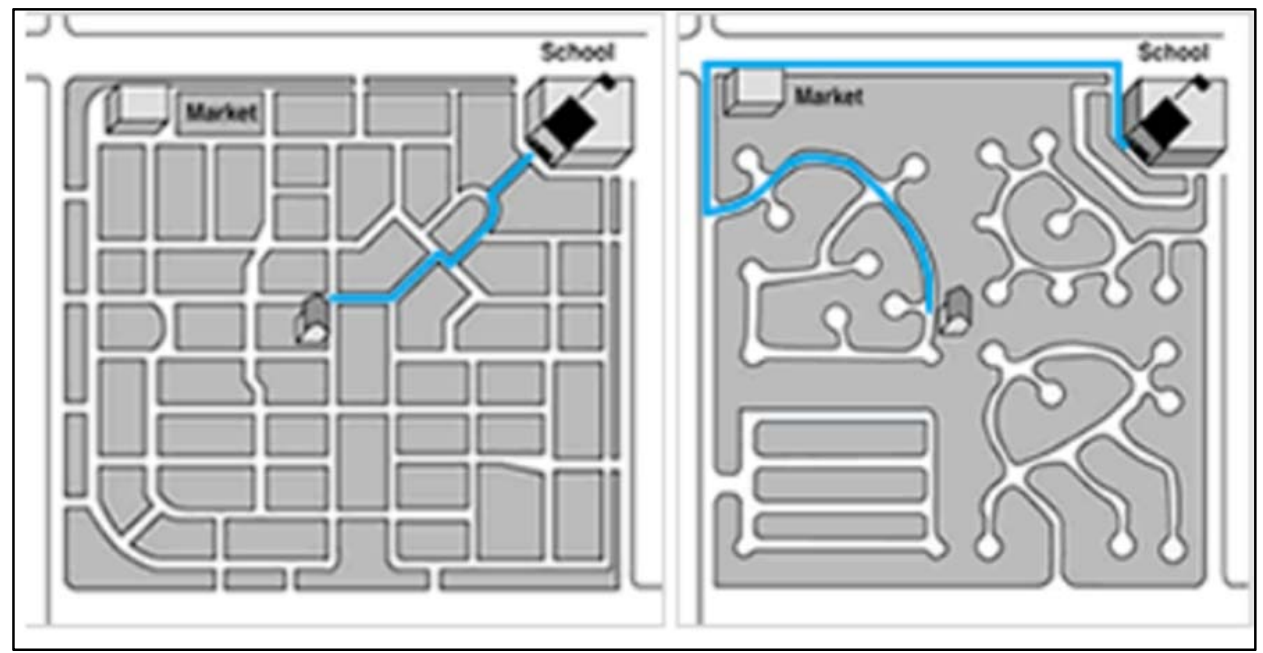

Figure 3-7. Street connectivity

Source: Transportation Mobility Strategy for the City of Olympia (125 p. 3.11)

Interchange land use plans may be developed to guide land use around interchanges and protect the capacity of arterials, collectors, and limited access facilities. A notable Florida example of interchange land use plan policy was developed as part of the Wekiva Coordinating Committee Final Report, March 16, 2004. The Report recommended that where interchanges are proposed (with the exception of at I-4) local governments adopt interchange land use into their long-range transportation plans.

Roadways that are part of Florida's Strategic Intermodal System (SIS) are intended to support economic activity in the state through the efficient movement of goods and services. SIS criteria address community livability and discourage freight movement through residential and commercial areas with high levels of pedestrian activity. When the roadway is a main street, freight and other fast-moving through traffic comes into conflict with slow-moving local traffic, bicycles, and pedestrians. A highway bypass may be appropriate where there is a high percentage of through trips and the bypass would provide significant relief from traffic congestion. It may also be appropriate where there are adverse effects due to heavy truck traffic including noise, fumes, and vibration. 
Development and implementation of a connected roadway network in coordination with future land use can enhance the benefits of a new bypass, as well as minimize or mitigate potentially negative impacts. Similarly, strategies can help to mitigate potential impacts to the existing roadway of the selected alternative - even if a bypass alternative is not chosen. The comprehensive plan should address:

- land use between the community and the bypass and at least one mile beyond the bypass

- both land use and access around interchanges taking care to avoid driveway access near interchange ramps

- both land use and access where the bypass meets the existing roadway

- corridor access management along roadways between the community and the bypass

- land use and corridor management along the bypassed roadway

- multimodal network improvements to connect outlying transportation facilities in an effort to minimize the use of the bypass for local traffic

- multimodal network improvements to enhance local mobility, community character, and livability on the bypassed corridor

After bypass construction, the bypassed roadway is likely to have excess vehicular capacity and a wide crossway unfriendly to pedestrians and bicyclists - but with much less vehicular traffic. The community should consider possible projects that discourage its use for highspeed, high-volume traffic movement and increase focus on local mobility and community character. Projects may include a road diet and the addition of pedestrian, bicycle, and transit facilities and amenities.

\section{Categorize and Manage Future Corridors}

In considering future roadway system needs, small communities may consider a variety of planning tools and strategies to implement the community vision and ensure efficient system operation. Such tools and strategies include access management, rightsizing, context sensitive solutions, and complete streets (see ITR 2-13. Traffic Circulation (Thoroughfare) Planning).

\section{Define the functional categories or typologies to be used and prepare purpose and function statements describing each category, including modal priorities and access versus through movement characteristics. I dentify desired alternative cross-section types for each roadway category.}

Functional classification is a process for categorizing roadways according to their planned function. Commonly used categories are principal and major arterial (including freeways, expressways and other major arterial roadways), minor arterial, major collector, minor collector, local streets, and alleys. The number, details, and character of roadway categories will depend upon the population size, planning objectives, and complexity of the local planning area. Some areas prepare separate thoroughfare plans that are adopted by reference into the comprehensive plan. A suggested approach is to integrate thoroughfare plans directly into the multimodal transportation element. ITR 2-13 (Traffic Circulation (Thoroughfare) Planning) includes resources to consult in this effort. 
A trend in contemporary thoroughfare planning practice is to define street functions and roles in more detail. The context sensitive solutions (CSS) approach has given rise to a number of new functional "typologies" in recent years (see BP 2-38. Functional Typologies for Context Sensitive and Complete Streets and BP 2-39. Functional Classification and Complete Streets Typologies). These typologies build upon the rationale of functional classification, while more explicitly considering the pedestrian and providing additional guidance to street design and modal emphasis in varying land use contexts. Best practice is to include purpose and function statements and example cross-sections or design types for each roadway classification.

Network planning can be accomplished through thoroughfare planning or corridor access management plans. The existing local street network provides an initial framework. Where local streets are not adequate to provide land use access or circulation throughout the community off of the major thoroughfare, the plan can identify preferred future locations. New streets are most effective when the general grid pattern is followed, however, they may need to conform to accommodate the natural terrain or other constraints. BP 3-20 illustrates generalized network concepts including spacing between roadway types. Note the service road concept parallel to the major arterial to provide access to land uses thereby reducing driveway access and allowing through movement on the arterial.

\section{BP 3-20. Generalized Network Concepts for Corridor Management}

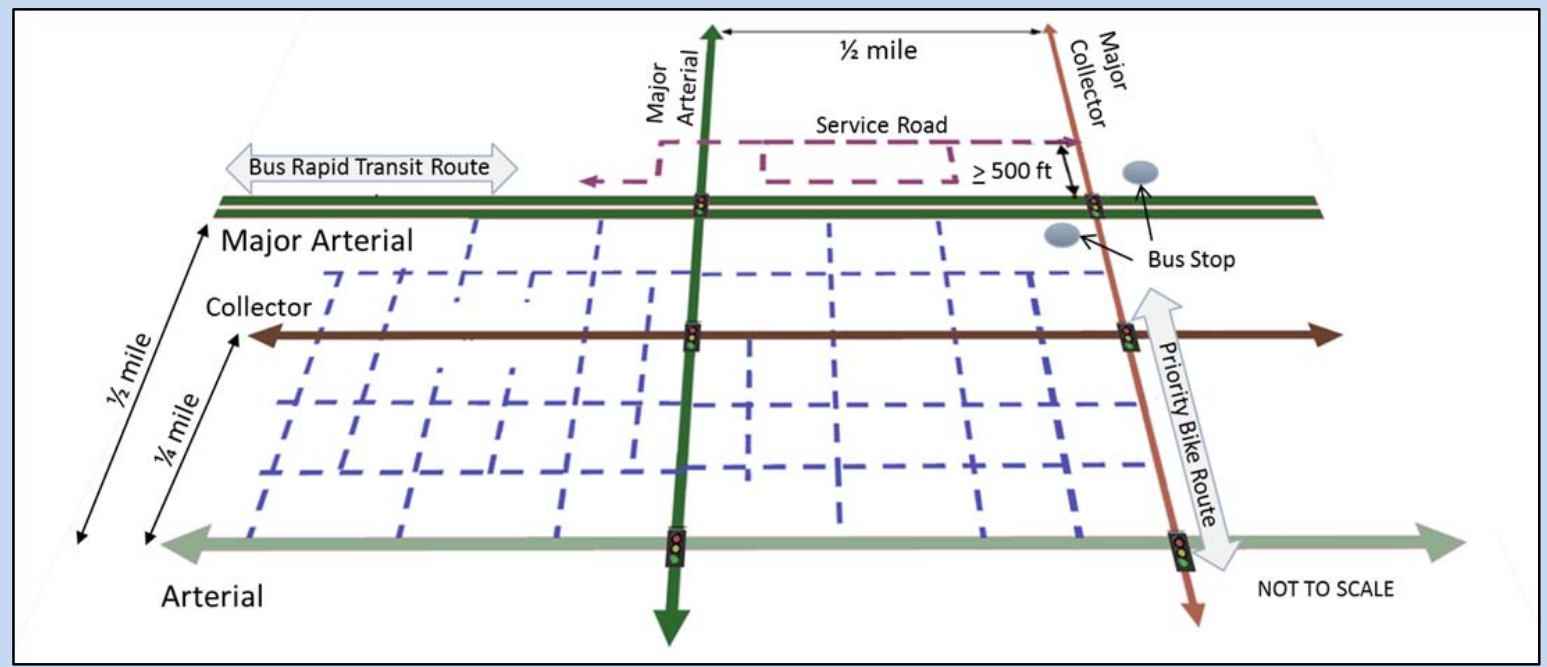

Source: Second Edition of the TRB Access Management Manual (17)

Tools for managing corridors include access management, rightsizing, context sensitive solutions, and complete streets. Access management involves the coordinated planning, regulation, and design of access between roadways and land development. Limiting access along major roadway corridors reduces traffic conflicts and flow interruptions, while improving safety for drivers, pedestrians, and bicyclists. Access levels may be identified using functional classification or via a separate access classification system. The latter approach enables a community to assign different access management standards to roadways of the same functional class, but having different design characteristics and functional needs. These details may be reflected in the transportation element, a separate thoroughfare plan that is adopted by reference into the transportation element, or through policies in the transportation element that are carried out in the land development code. 
Chapter 14-97.003, F.S., Access Control Classification System and Access Management Standards applies to SHS and can serve as a framework for local plans.

Rightsizing techniques are applied to update streets to more appropriately fit their context. As the needs of a community evolve over time, the streets should also change to best serve those needs. Rightsizing may involve a complete redesign of a street to include new infrastructure or could be as simple as restriping the road to change parking (98). A road diet is a type of rightsizing treatment performed that reduces the number of automobile traffic lanes by replacing the existing lanes with any combination of landscaping treatments, wider sidewalks, bicycle lanes, etc.

Context sensitive solutions (CSS) have given rise to a number of new street typologies in recent years. These typologies build upon the rationale of functional classification, while explicitly considering street design and modal emphasis in varying contexts. They aim to provide mobility for all modes of transportation with a greater focus on the pedestrian. CSS can address major thoroughfares as they pass through walkable areas such as a town center or activity center. The CSS process engages stakeholders to plan and design transportation facilities that meet specific principles (for details, see ITE Recommended Practice Designing Walkable Urban Thoroughfares: A Context Sensitive Approach (68)).

Complete streets is oriented toward reducing the dominance of automobiles in street planning and design by ensuring consideration of all users. The National Complete Streets Coalition of Smart Growth America defines complete streets as follows (88): "Complete Streets are streets for everyone. They are designed and operated to enable safe access for all users, including pedestrians, bicyclists, motorists and transit riders of all ages and abilities. Complete Streets make it easy to cross the street, walk to shops, and bicycle to work. They allow buses to run on time and make it safe for people to walk to and from train stations."

Many communities are adopting or seeking to adopt complete streets policies and guidelines in an effort to achieve changes in local and regional practice. A key benefit of a complete streets policy to local government multimodal transportation planning is that it is a relatively simple, yet effective method of achieving greater attention to the full range of modes in street network planning and design. ITR 2-17 (Elements of an Ideal Complete Streets Policy) provides an example of an ideal complete streets policy. A list of complete streets policies in Florida and nationally may be found at the following link: www.smartgrowthamerica.org/documents/cs/policy/cs-chart-allpolicies.pdf.

Small communities and rural areas may choose to target major thoroughfares for improvements rather than the entire network. BP 3-21 contains an example of how the Polk Transportation Planning Organization (TPO) envisioned a complete street for a rural area. A specific resource for rural areas is Complete Streets - a guide for Vermont communities healthvermont.gov/family/fit/documents/Complete streets guide for VT communities.pdf 


\section{BP 3-21. Complete Streets Strategies on Rural Roadways}

\section{COMPLETING RIFLE RANGE ROAD (CR 655)}

\section{EXISTING CONDITIONS SUMMARY \\ - Sidewalk on west side, no sidewalk on east side \\ - No bike lanes; however, significant bike traffic \\ - Bus stops, including a few shelters \\ - Wide driveways and several areas with broken sidewalks}
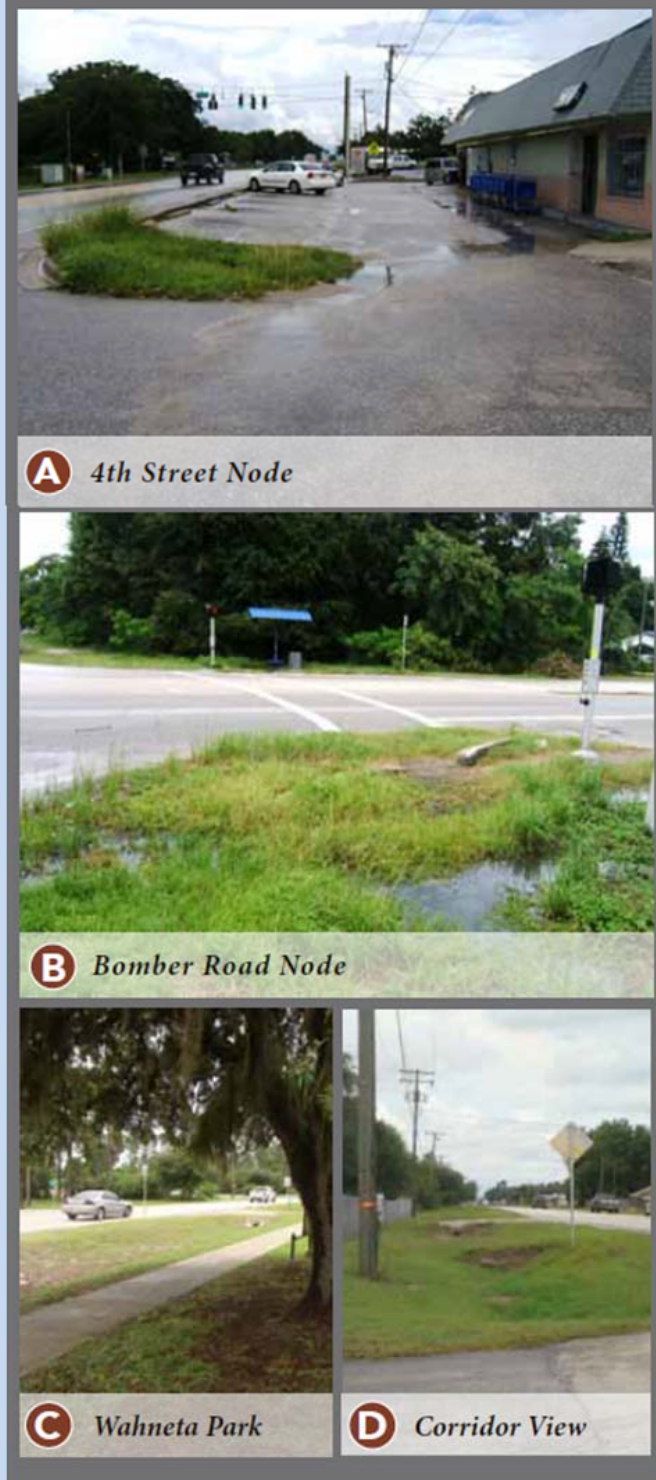

PROPOSED OPTIONS

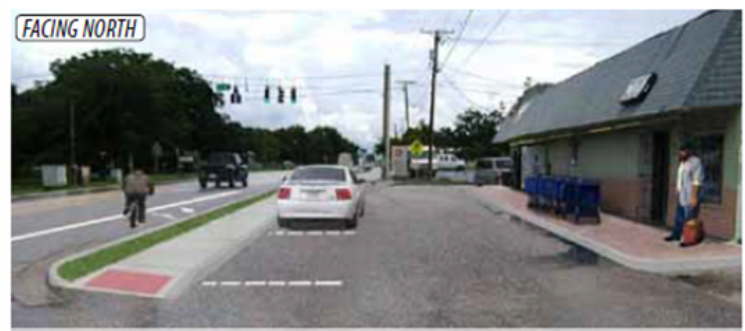

A Create walkable/bikeable node at 4 th Street that connects to Wahneta Elementary
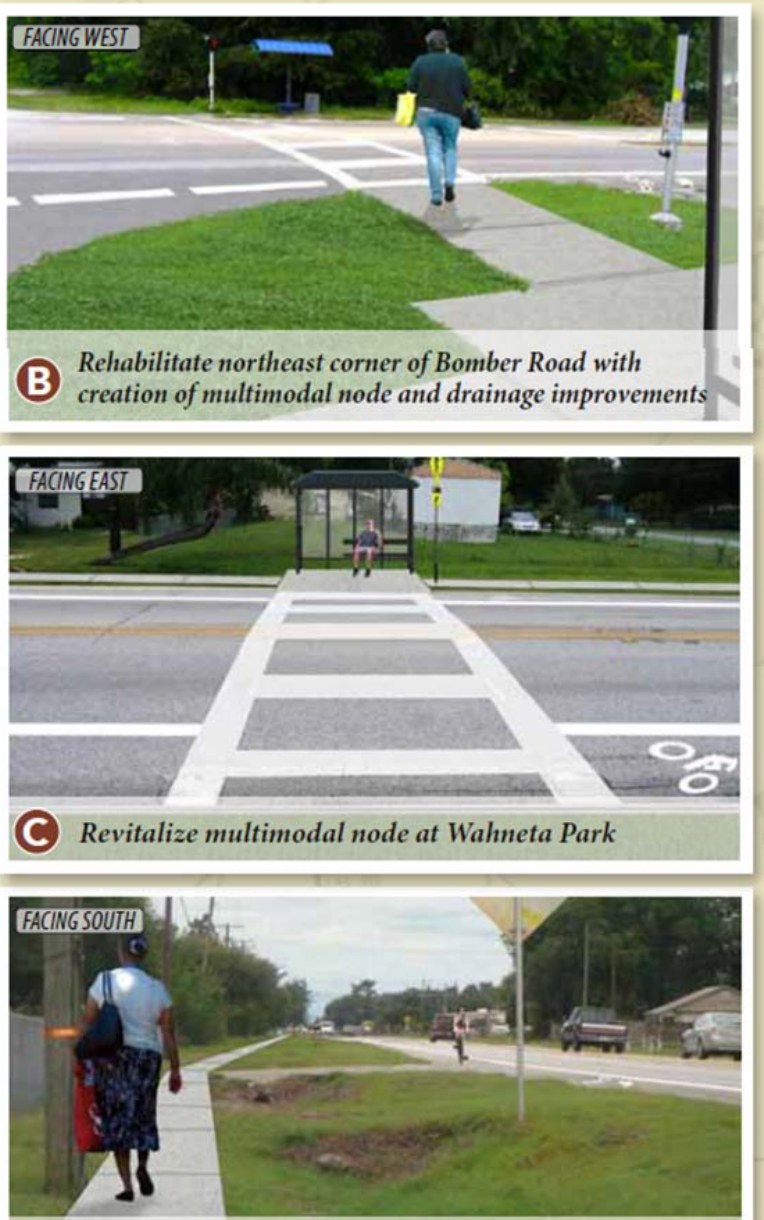

Install continuous sidewalk on east side of corridor along with bike lanes throughout corridor

Source: Polk County Complete Streets Corridor Studies polktpo.com/downloads/1386-Complete-Streets-Polk-County-Corridor-Studies 


\section{Assign roadway categories to each segment of the existing and planned network, through maps and/ or lists. I dentify any special corridor designations.}

The transportation element should include maps and/or lists indicating the classification assigned to roadways in the transportation element (see BP 2-39. Functional Classification and Complete Streets Typologies). Various typical roadway designs can be applied to each of these categories to address local needs and preferences. Designs can include median width and design, number of travel lanes, sidewalk location and width, and utility placement. Some transportation corridors will be planned for special treatment as they relate to local and regional multimodal plans and design standards. Examples may include: SIS roadways, roadways with adopted access management plans, and freight routes. Identifying these corridors in the transportation element helps to ensure appropriate coordination of planning and implementation actions with the objectives of these designations.

3. List, describe, and map planned roadway projects (state, county, and local), including number of lanes, functional classification, and level of service.

The plan should identify transportation projects expected to be completed in the planning horizon, particularly those projects that are part of the State Transportation Improvement Program, the FDOT Five-Year Work Program, and the local capital improvement program. Resources for this effort are noted in ITR 2-1 (Plans and Programs of State and Regional Agencies and Modal Providers). Local governments are encouraged to take a longer-term approach and also designate future transportation corridors that are not "financially constrained," including collector or arterial roadways deemed locally important to the efficiency of the transportation network based upon the analysis of spacing, continuity, and connectivity needs. Projects to fulfill local roadway needs are determined through the system analysis and may include paving existing, unpaved roads and/or construction of additional lanes or new connections between existing roads. BP 3-22 illustrates a future map showing number of lanes and jurisdiction. BP 3-23 and 3-24 are examples of how future functional classification and a hurricane evacuation network might be illustrated. BP 3-25 is an example of mapping future roadway level service.

\section{If applicable, identify and map future public transportation by type and define service area characteristics.}

5. I dentify and map future bus and rail stops, station areas, transfer locations, and system connections.

Transit service and infrastructure should be aligned with future land use plans including areas designated activity centers and/or major traffic generators. Small communities and rural areas should include future transit plans from modal providers. BP 3-26 illustrates how future transit systems routes and centers could be mapped. 
BP 3-22. Future Number of Lanes Map

City of Wauchula 2030 Future Number of Lanes Map

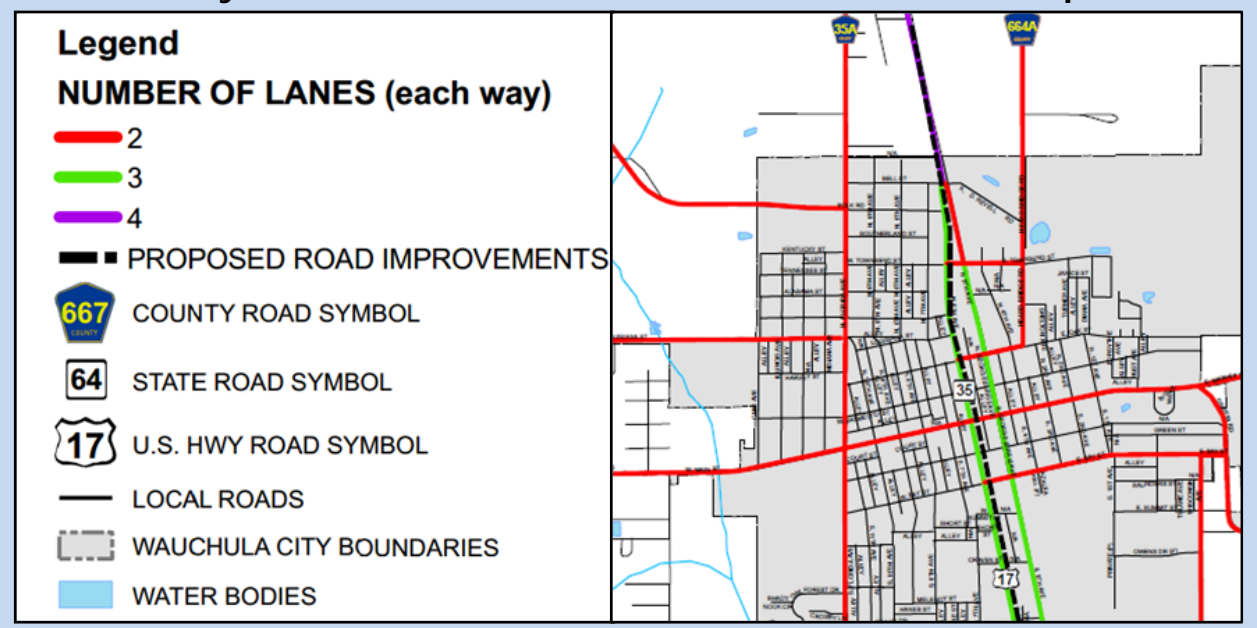

Source: City of Wauchula 2030 Comprehensive Plan (126)

BP 3-23. Future Functional Classification Map

City of Avon Park 2030 Functional Classification

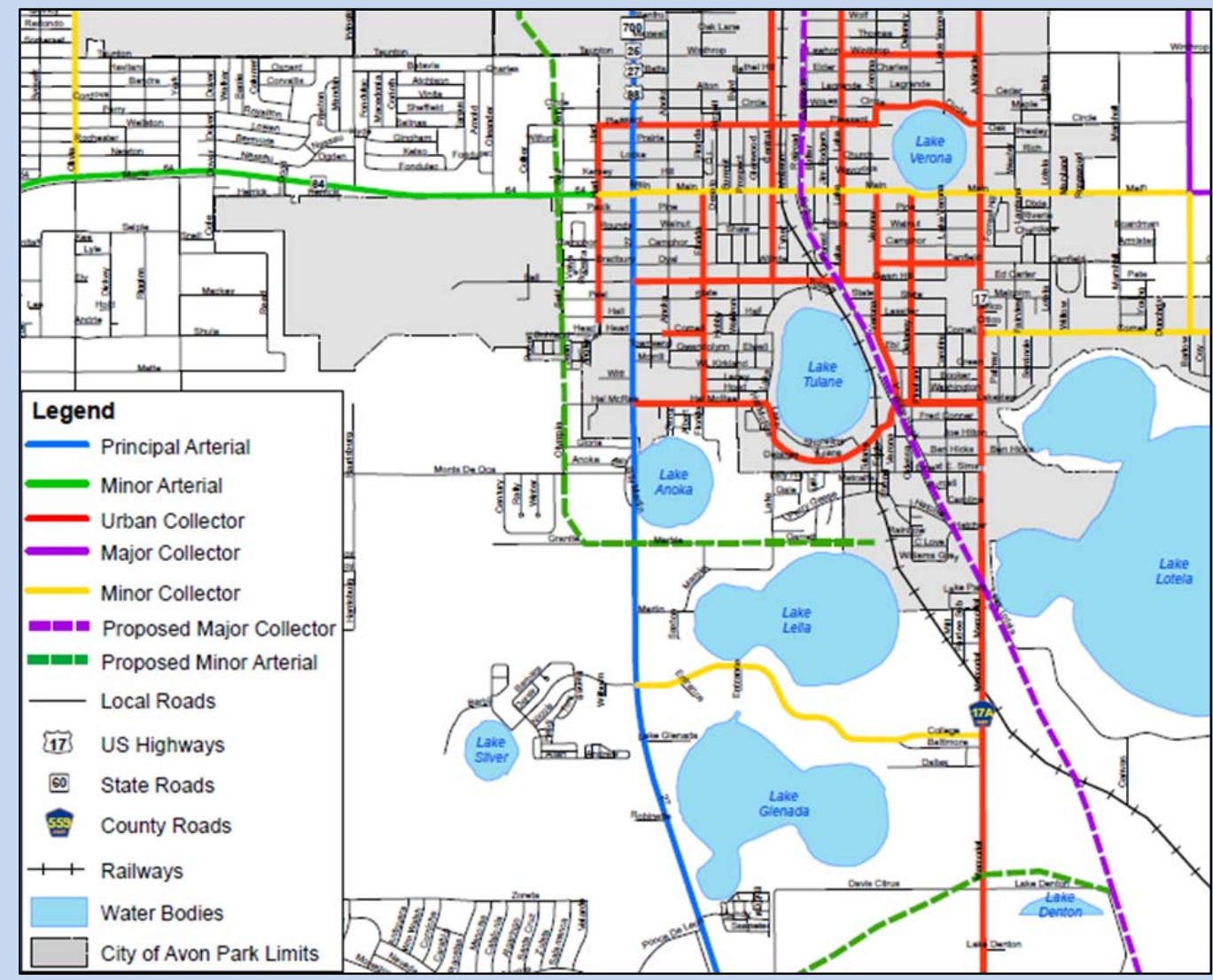

Source: avonpark.cc/planning zoning.php 
BP 3-24. Evacuation Route Map

Gulf County Evacuation Roadway Network

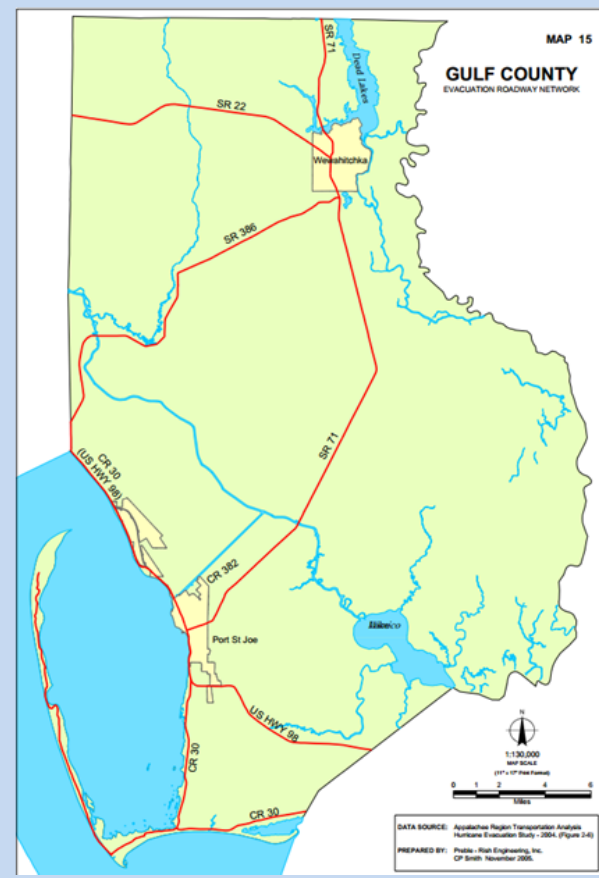

Source: City of Port St. Joe (www.cityofportstjoe.com/)

\section{BP 3-25. Future Roadway Level of Service}

City of Port St. J oe 2020 Level of Service

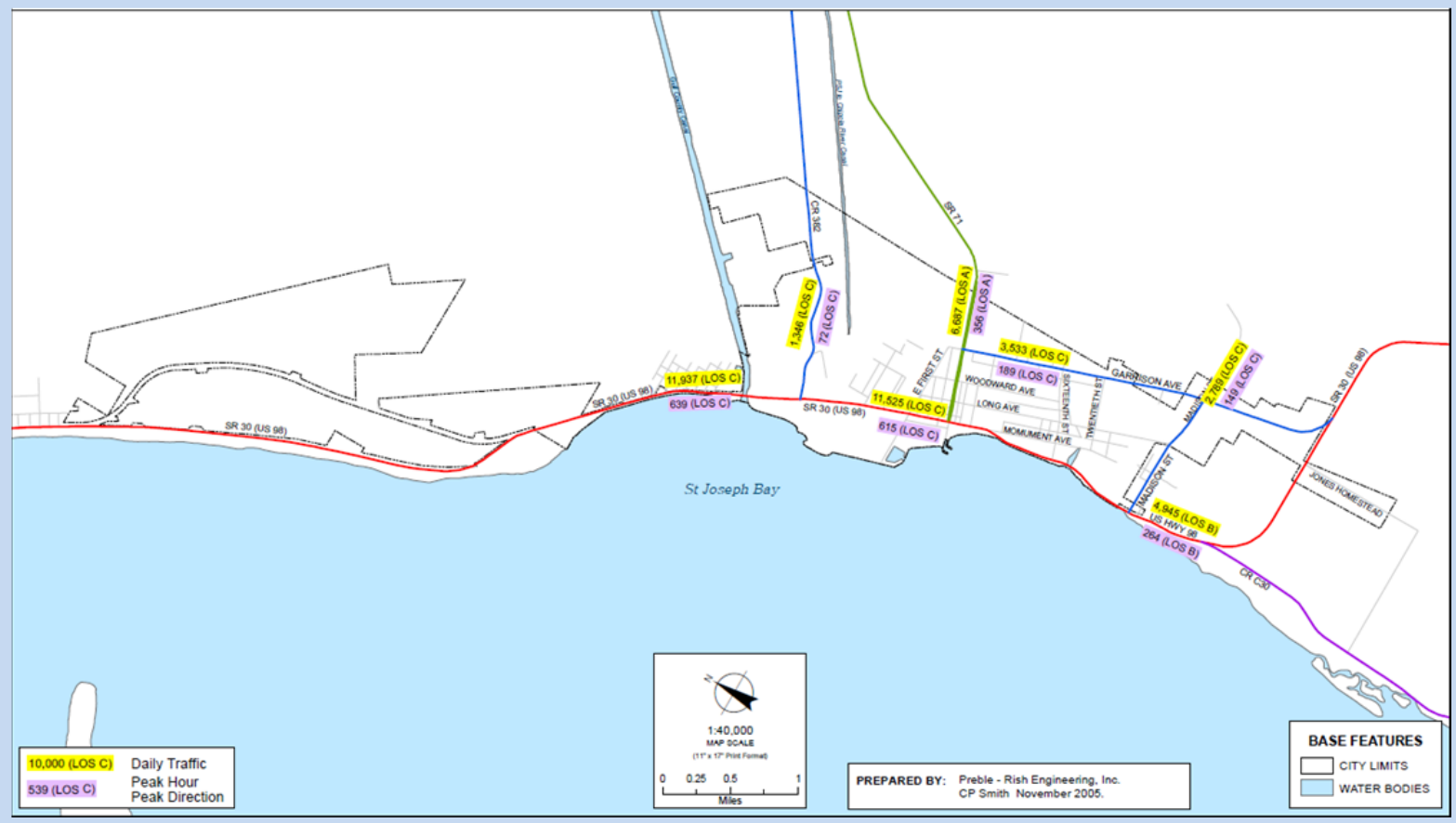

Source: www.cityofportstjoe.com/GISmaps.cfm 
BP 3-26. Mapping Future Transit System and Future Transit Centers

Polk County Comprehensive Plan Future Public Transit System Map

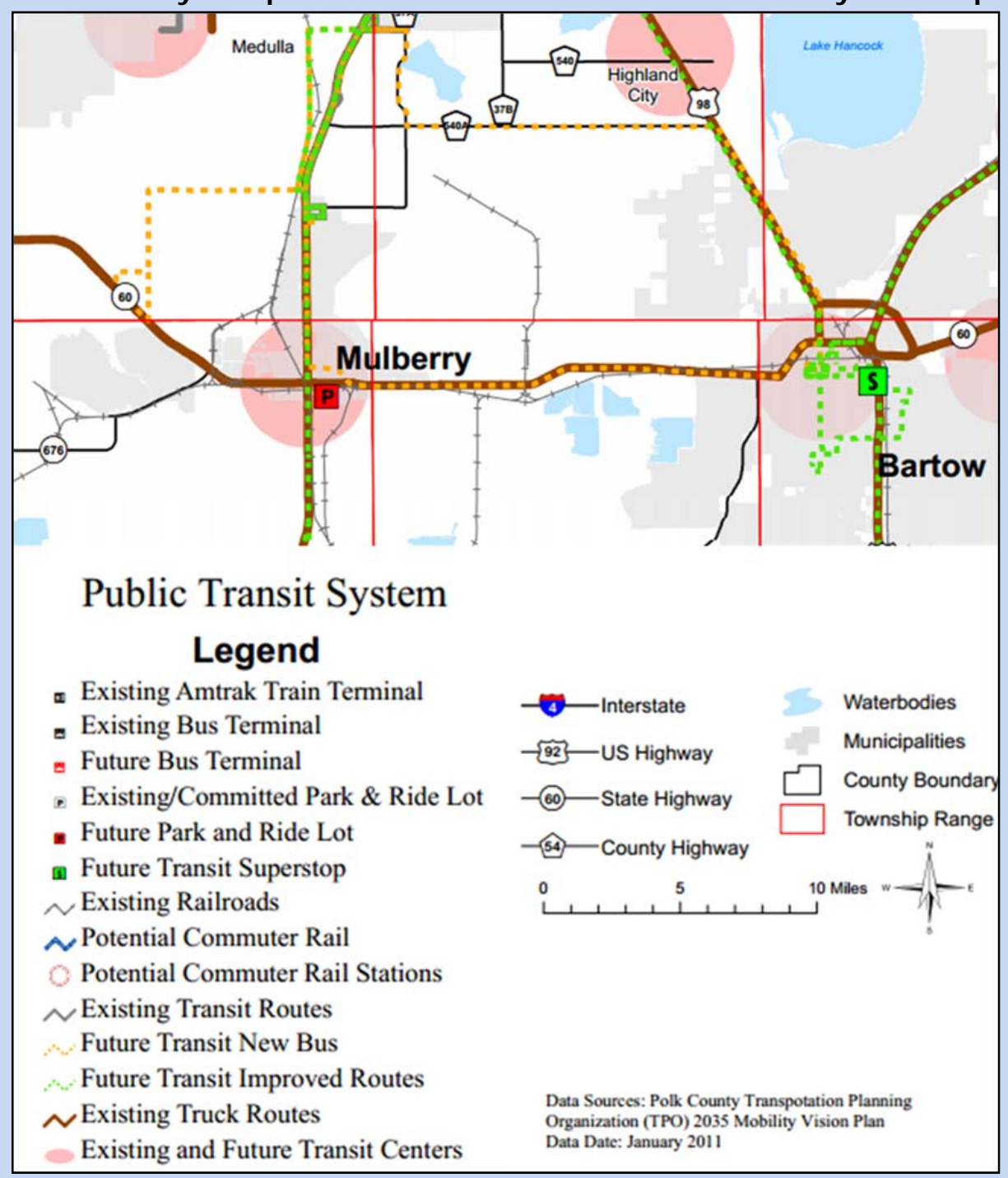

Source: Polk Comprehensive Plan -

www.polk-county.net/subpage.aspx?menu_id=226\&id=478\#Volume_2_Maps

\section{I dentify generalized right-of-way needs for future thoroughfares and collector roadways, and assign through maps, policies, and/ or lists (e.g. right-of-way needs identification map)}

Right-of-way costs often represent the single largest expenditure for a transportation project. Therefore, it is essential to carefully consider the right-of-way needed for each planned roadway. Preserving an adequate amount of right-of-way will be one determinant of the ability to cost-effectively accommodate modal alternatives, utility needs, and design amenities.

Section 337.273(1)(d), F.S., establishes authority for local governments to designate corridors for right-of-way preservation and management. Regarding the process of 
designating transportation corridors, §337.273(6), F.S., states: "A local government may designate a transportation corridor by including the corridor in the entity's comprehensive plan traffic circulation or transportation element...." Thereafter, a transportation management ordinance may be adopted for designated transportation corridors, pursuant to the criteria contained in statute.

Right-of-way needs for each planned roadway can be determined based upon typical or corridor-specific cross-sections and design objectives for that category of roadway. Common practice is to use generalized widths and refine them as more detailed engineering studies are completed. The right of way needs are then mapped, along with the functional classification or typology of the roadway corridor. Finally, goals, objectives, and policies for corridor preservation and management are included in the transportation element (BP 2-41. Thoroughfare Right-of-Way Needs Identification Maps and GOP 2-6. Tallahassee-Leon County Corridor Preservation Policies). Preservation of future transportation right-of-way is accomplished through a variety of strategies, such as on-site density transfers, clustering options, overlay requirements, and impact fee credits. Appendix F provides corridor management policies and objectives from the Tallahassee-Leon County Comprehensive Plan that reflect contemporary best practices. A detailed review of corridor preservation options and legal considerations in Florida is available in the report Corridor Preservation Best Practices available at www.cutr.usf.edu/wpcontent/uploads/2012/07/BestPracticesReport.pdf.

\section{I ntegrate Connections to Ports, Aviation, Rail, and I ntermodal Facilities} An important aspect of local government planning for ports and airports is ensuring the accessibility of these facilities through the surface transportation system for the efficient movement of people and freight. Access to major airports and ports is generally via the SIS, SIS connectors, or other regional roadways.

FDOT has committed to become more multimodal and intermodal by providing more choices for moving freight and people with seamless transfers across mode choices through the SIS (93 p. 2). Intermodal connectors - highways, rail lines, and waterways connecting hubs to corridors - are a core element of the statewide transportation system and are eligible for funding (93 p. 6). Intermodal logistics centers (ILCS), a SIS facility created to aid in the shipment of goods through a seaport, are an important connection (94).

The transportation element should identify all rail and roadway corridors used to access a port or airport facility. Corridor management plans or strategies should be applied to these facilities where necessary to improve truck operations or throughput.

\section{Describe and map planned changes in port, aviation, and rail facilities.}

\section{List and map planned intermodal facilities}

a. future connections to ports, airports, rail, and trucking (e.g. roads, public boat ramps, etc.)

b. future intermodal logistics centers, future connections between automobile, transit, bicycle, and pedestrian modes

The future planning effort should address any intermodal needs identified through the system analysis and review of agency modal plans, such as inadequate existing or future 
capacity of roadways providing access to airports, ports, rail stations, trucking centers, or intermodal logistics centers.

\section{I ntegrate Bicycle and Networks}

Bicycle and pedestrian networks and enhancements should be carefully integrated into the overall transportation plans (see BP 2-43. Identify Alternative Strategies for Improving Bicycle and Pedestrian Ways). Local governments should consider safety and connectivity needs between activity centers and surrounding residential areas, as well as with public transportation.

1. I dentify planned bicycle and pedestrian ways and related facilities in modal plans.

\section{Establish prioritized list of proposed local projects.}

\section{I dentify Desired Safety and Operational Projects}

The system analysis will identify a number of potential adjustments to the existing transportation system for inclusion in the transportation element. These may include safety and operational/capacity projects, programs, and services across the various transportation modes. The element should identify and strategically prioritize and phase projects for inclusion in the capital improvements element. Examples may include medians, intersection redesign, mid-block crossings, and so on. A point system is an effective project prioritization mechanism that is tied to the community vision, priorities, and planning goals and objectives, as discussed in BP 2-47 (Prioritize Multimodal Projects and Strategies). Some strategies may require partnerships with other agencies, creating an opportunity to link the transportation and intergovernmental coordination elements.

\section{Set Future Q/ LOS Standards, Performance Measures, and Benchmarks}

Chapter 163, Part II, F.S., requires local governments to determine projected system level of service. To accomplish this, level of service standards/performance measures should be established, to the extent applicable, as described below:

- roadway level of service (LOS)

- public transportation quality of service standards

- bicycle and pedestrian quality of service or performance standards, targets, or benchmarks

ITR 2-14 (Establishing Level of Service Standards and/or Performance Measures) notes various resources to consult in this effort. ITR 2-15. Selected Performance Review Measures Fixed Route Transit Services) provides a variety of sample measures that could be considered in relation to specific multimodal strategies.

Although LOS is defined in $§ 163.3164$, F.S., in terms of capacity, both quantity and quality of service are considered appropriate measures of service for non-automobile modes of transportation, such as transit, bicycle, and pedestrian modes. A variety of performance standards, targets, or benchmarks may be considered for modes other than the automobile. Such standards could be developed or adopted by reference from the plans of other modal providers within the community. Specific Q/LOS targets could be set for each mode and facility, based on their long term objectives, roadway function and so on. Future 
quality/level of service standards or performance measures should be set for the following based on the community vision:

- major roadway network

- transit system

- bicycle network

- pedestrian network

- special treatment areas (i.e. transportation concurrency exception areas, area-wide transportation concurrency, multimodal transportation districts).

Table 2-5 (Statistically Significant LOS Criteria for Non-Automotive Modes in HCM 2010) indicates criteria found to be statistically significant by mode in relation to LOS that are used in the analysis. An understanding of these criteria is also useful in establishing simpler methods and measures. Figure 3-8 is an example of quality/level of service criteria applied across the various modes.
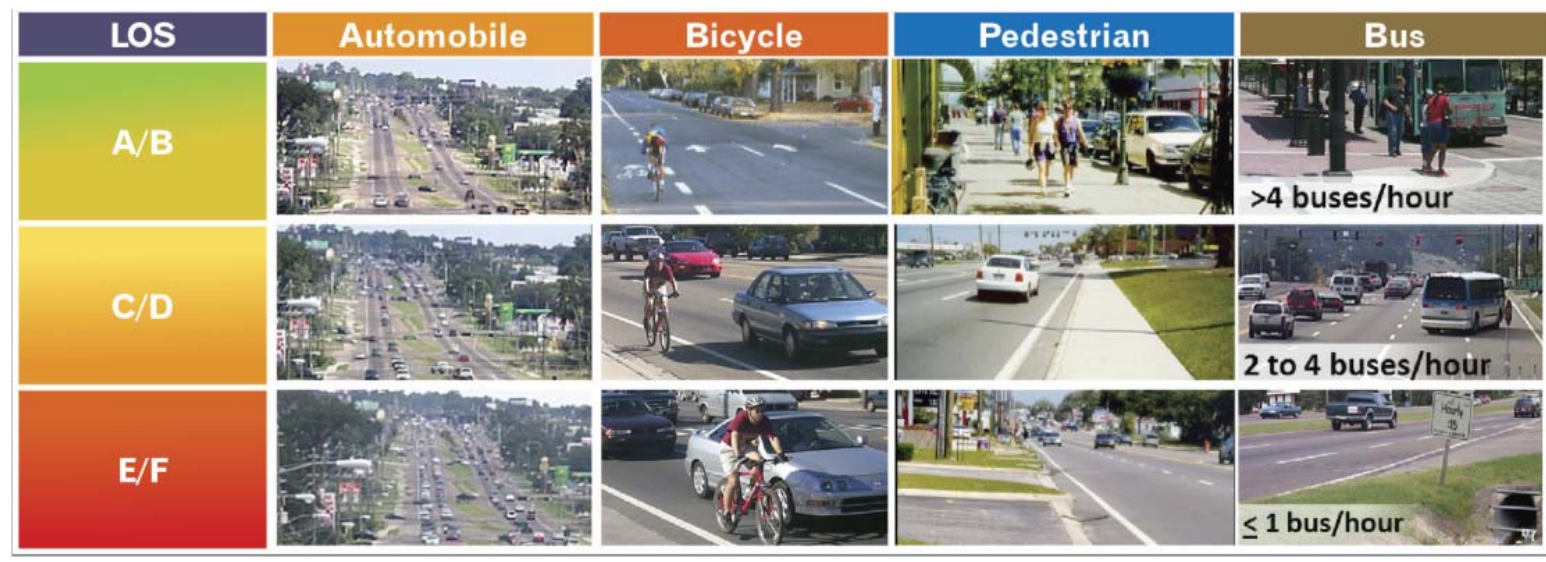

buses/hour

Figure 3-8. Multimodal quality of service illustration

Source: Multimodal Q/LOS Webinar (64)

Practice Notes: Level of service standards technically must appear in the capital improvements element. Including them in the transportation element is an opportunity to establish consistency between the elements.

\section{Establish Desired Multimodal Strategies and Services}

The local government should select desired multimodal strategies and services from the possible alternatives developed in response to transportation system needs. Often, facility needs are greater than available funding highlighting the importance of establishing a methodology for prioritizing needs. Alternatives and solutions depend upon the cost, impact, and feasibility to implement. Although there are a variety of methods available to rank projects, small communities may choose to focus on safety-related projects.

The plan should incorporate a variety of multimodal strategies and policies. Section 3.5 identifies a broad range of strategies that may be considered by topic. Example goals, objectives, and/or policies relative to the various strategies are also provided. 


\subsection{Goals, Objectives, and Policies}

Chapter 163.3177(1), F.S., requires principles and strategies, commonly listed as goals, objectives, and policies, to reflect "community commitments to implement the plan..." In addition, reflection of the community vision and priorities in goals, objectives, and policies ensure that they are addressed through the comprehensive planning process. Chapter 163, Part II, F.S., defines these terms as follows:

- Goal means the long-term end toward which programs or activities are ultimately directed;

- Objective means a specific, measurable, intermediate end that is achievable and makes progress toward a goal; and

- Policy means the way in which programs and activities are conducted to achieve an identified goal.

The community's future vision and priorities will typically require revisions and additions to existing goals, objectives, and policies. For example, if the community desires improved walkability, the plan goals and objectives should address the sidewalk network. ITR 2-16 (Planning Process from Citizen Input through Performance Measurement) illustrates the process of turning citizen input into GOPs and performance measures.

As defined in Florida statutes, objectives should be measurable. Establishing measures of effectiveness and a means of measurement along with each objective will ensure that this requirement is met. GOP 2-15 (Port, Airport, Rail, and Intermodal Integration) is an example from the Pasco County MPO Long Range Transportation Plan that illustrates the application of measures to specific objectives.

The following are planning best practices and strategies for consideration in the development of effective multimodal transportation goals, objectives and policies.

\section{Regional and I nternal Consistency}

Goals, objectives, and policies should also be consistent to the extent feasible with applicable transportation-related plans and programs such as regional transportation plans, transportation agency plans (including FDOT), and neighboring local government comprehensive plans. The transportation element should discuss how the element is consistent with other plans. Because of the complex nature of the comprehensive plan, some goals, objectives, and policies may be contradictory. Additional policies may be necessary "to establish how best to resolve those conflicts" (100 p. 98).

Plan consistency is essential when addressing regional transportation facilities to ensure appropriate timing and coordination of facility modifications. The Port St. Joe goal, objective, and policies provide an example of coordinated transportation planning through interjurisdictional agreements (GOP 3-1). Strategies include:

1. Support the Florida Transportation Plan, the Strategic Intermodal System Plan, and other applicable state plans and guidelines.

2. Be consistent with adopted regional mobility plan or regional vision plan, such as that established through a regional collaborative, including the transportation 
disadvantaged service plan, transit development plan, and strategic regional policy plan (GOP 3-1).

3. Coordinate with land use, transportation, corridor management, mobility plans, and programs of adjacent local governments.

4. Strive for internal consistency of local comprehensive plan objectives and policies, as well as with those of specialized plans.

\section{GOP 3-1. Coordination of Transportation Planning}

The traffic circulation element of the Port St. Joe, Florida Comprehensive Plan promotes coordinated transportation planning in the following goals, objectives, and policies:

Goal 2: Increase interjurisdictional agreements to coordinate transportation planning and programs, to ensure continuing cooperative and comprehensive transportation planning throughout the local area.

Objective 2.1: Establish an annual review and discussion with the State and County Highway Departments to determine the impact of proposed improvements on the roadways in and around Port St. Joe.

Policy 2.1.1: Appoint a committee to meet with the State Department of Transportation (FDOT) to review the impact of the Five-Year Adopted Work Program established by FDOT on an annual basis.

Policy 2.1.2: Meet with the County Highway Department on an annual basis to discuss maintenance responsibilities, repaving programs, and other traffic-related topics as may affect traffic circulation.

Source: City of Port St. Joe Traffic Circulation Element (127)

\section{Land Use/ Multimodal Environment}

Land use organization, location, mix, and density/intensity paired with multimodal policy contribute to a multimodal environment. For example, the organization of land uses into a town center and supporting activity centers of varying sizes having higher densities and a mix of uses create destinations where people can interact among land uses in the community without using the automobile or with lower VMT. Such centers may be served by transit, if available, or may be served by future transit. The following strategies will help to create a multimodal environment.

1. Designate and reinforce a strong town center and supporting activity centers as appropriate.

2. Establish appropriate densities and intensities within designated town centers, activity centers, and public transportation station areas.

3. Provide for a complementary and integrated mix of retail, services, residential, institutional, cultural, recreational, and employment opportunities within the town center and supporting activity centers.

4. Provide for accessible food, health, education, retail and service uses on a neighborhood level within or in close proximity to residential areas.

5. Establish design criteria for the town center, supporting activity centers, and applicable transit station areas to preserve or improve livability. 
6. Establish priority on enhancing bicycle and pedestrian mobility within the town center, supporting activity centers, and major thoroughfares.

7. Provide for, and require new development to contribute to, bicycle and pedestrian-friendly facilities on the public streetscape.

8. Call for transportation impact assessment procedures that address development impacts on all modes of transportation and minimize vehicular, transit, bicycle, and pedestrian conflicts.

Local governments may choose to establish an objective of developing a detailed mobility strategy as illustrated in BP 3-27. BP 2-52 (Measure the Success of a Complete Streets Policy) provides an example of how the success of a complete streets policy could be measured.

\section{BP 3-27. Recommendation for Key Policy Themes}

The Transportation Mobility Strategy for Olympia (Washington) summarized key recommendations for key policy themes described below:

- Community Transit Network (CTN). While the City does not operate the transit system in Olympia, it can expand its role in supporting transit by adopting a Community Transit Network (CTN). The CTN will enhance opportunities for transit by targeting transportation improvements along corridors that are designated for the most intensive transit use and ensuring that transit investment is coordinated with land use policy.

- Complete Streets. The City has many policies in place that adhere to Complete Street principles (streets that are designed and operated to enable safe access for all users). The strategy proposes developing and adopting a formalized, comprehensive "complete streets" policy and tracking land use policy regulations/incentives that align with complete streets principles.

- Connectivity. Similar to complete streets, the City has policies in place that encourage a wellconnected street network for motorized and non-motorized modes of transportation, but no formal policy framework or methods for tracking progress. The strategy recommends enhancing connectivity for all modes of transportation by 1) creating new connections as development occurs, 2) improving street and pathway connections within the existing transportation network, and 3 ) establishing a connectivity index to help target investment and track progress.

- Transportation Demand Management. The City currently supports a variety of strategies aimed at reducing demand for drive-alone trips. The TMS recommends that the City build from prior success (such as the "Walk and Roll" school program) and focus on parking policy, existing and new school programs, telework, and community-based marketing for commute-trip reduction and transit use.

- Funding. The TMS recommends that the City develop a clear description of current and potential funding so that allocation of spending can be tracked by mode and expenditure type over time. The TMS also recommends that the City consider opportunities to leverage funds raised by community and neighborhood organizations.

- Concurrency, Transportation I mpact Fees (TIF), and State Environmental Policy Act (SEPA). Concurrency is a state requirement that local governments make sure public infrastructure is provided at the same time as development. The TMS report recommends that the City consider refining its concurrency program to focus on measuring person trips instead of vehicle trips.

Source: Transportation Mobility Strategy for the City of Olympia (125 p. ES.3) 


\section{Multimodal Quality/ Level of Service}

Level of service (LOS) is a planning tool used to determine available capacity based on existing and anticipated travel demand. Although Florida legislation no longer mandates transportation concurrency or minimum level of service standards for roadways, roadway level of service standards should be retained for capacity planning purposes based on professionally accepted methodologies. Communities may choose to establish multimodal level of service standards in the transportation element consistent with standards in the capital improvements element. Examples are illustrated in GOP 2-4 (Multimodal Level of Service Standards) and GOP 2-5 (Multimodal Performance Targets).

\section{Major Roadway Network}

Major roadways serve mobility at a regional and local level. They include roadways functionally classified as arterials, as well as major collectors. The regional roadway system in rural areas is typically planned by the FDOT in coordination with local governments. Some major roadways deemed locally important may also be planned, funded, and maintained by local governments. In coordinating with other agencies or planning additional local roadways, keep in mind the following strategies.

1. Adopt a complete streets policy and guidelines to guide the functional classification of roadways and their design (ITR 2-13. Traffic Circulation (Thoroughfare) Planning, ITR 2-17. Elements of an ideal Complete Streets Policy, and BP 2-52. Measure the Success of a Complete Streets Policy).

2. Designate transportation corridors requiring additional right of way and/or corridor management for preservation and management and include transportation corridor management policies to preserve right-of-way needed for all transportation modes and provide for dedication of land or conveyance of easements to local governments for planned transportation projects as provided in §337.273(6), F.S., (Appendix F, and BP 3-20).

3. Provide for construction of parallel relievers or service roads along major highway corridors or within interstate interchange quadrants (BP 3-20).

4. Provide for construction of additional travel lanes and/or turn lanes to address existing or anticipated motor vehicle traffic volume where appropriate.

5. Establish priority for critical projects related to hurricane evacuation (GOP 3-2).

6. Include new arterial or major collector roadways to relieve motor vehicle traffic congestion and increase network connectivity.

7. Include design elements and projects to increase bicycle and pedestrian safety and mobility (ITR 2-11. Bicycle and Pedestrian Planning Analysis Tools and Resources).

8. Include network enhancements and design elements in support of modal priorities (e.g. truck routes, express bus routes, complete streets).

9. Provide park-and-ride facilities that accommodate carpooling and/or regional transit service. 


\section{GOP 3-2. Evacuation Routes and Maximum Evacuation Clearance}

To meet the goal of providing for hurricane evacuation, Monroe County adopted objectives and policies in the Conservation and Coastal Management Element (2010) specifically related to evacuation clearance times. Policies addressed:

- establishment of a permit allocation system in coordination with municipalities to maintain consistency between new residential permits and the Future Land Use Element,

- establishment of staffing and equipment needs,

- update of transportation modeling of hurricane evacuation,

- development of a draft and implementation of a program for resident and visitor hurricane awareness,

- establishment of staged/phased evacuation procedures,

- prioritization of elevation of the 18 mile stretch of US 1 northbound from Key Largo,

- establishment of required hurricane contingency plans for marinas,

- development of a plan to set aside funds for future technological advances, and

- development of a complete a post-disaster recovery plan.

The following are policies from the 2014 Comprehensive Plan Draft Update specifically in relation to the transportation system:

Objective 2156.1 - Monroe County shall maintain a maximum hurricane evacuation clearance time of 24 hours.

Policy 2156.1.116 - Monroe County shall coordinate with the Florida Department of Transportation (FDOT) to ensure that US 1 roadway capacity improvements necessary to maintain hurricane evacuation clearance time at 24 hours are completed.

Policy 2156.1.127 - By January 4, 1998, Monroe County shall continue to evaluate programs to reduce the number of evacuating vehicles including, but not limited to programs to encourage ride-sharing and transit usage and, consistent with applicable law, evacuating vehicle registration requirements.

Policy 2156.1.138 - Reduced evacuation clearance times which may result from adjustments to evacuation model variables, programs to reduce the number of evacuating vehicles or increased roadway facility capacity, shall not be used to increase development expectations beyond the growth allocations provided herein, except to the extent that a hurricane evacuation clearance time of 24 hours can be maintained. Any necessary reduction in hurricane clearance times shall be accomplished by a plan amendment within 180 days of the re-assessment.

Policy 2156.1.32 - During a hurricane evacuation, Monroe County shall designate US 1 and Card Sound Road as evacuation routes as directed by the Department of Emergency Management. [\$163.3178(2)(d), F.S.]

Source: Monroe County Comprehensive Plan Update Website - Conservation and Coastal Management Element (2014): keyscompplan.com/

\section{Access Management}

Access management preserves the safe and efficient movement of people and goods by reducing conflicts on the roadway system. Keep in mind the following policies and strategies to advance access management objectives for major roadways and around freeway interchanges. 
1. Include policies and strategies to provide alternative access to development on arterial roadways, such as parallel relievers, service roads, parking lot cross access, and requirements for unified on-site circulation.

2. Include policies and strategies to close excessive or unsafe driveway connections or to redesign overly-wide or poorly designed connections.

3. Include policies and strategies to replace continuous two-way left turn lanes with medians on multi-lane arterials.

4. Require conformance of new signals with signal coordination plans and FDOT signal spacing standards for the state highway system.

5. Restrict access in the functional area of highway interchanges BP 3-28.

6. Control access in the functional area of roadway intersections.

7. Require adequate, uninterrupted throat length for driveways and frontage roads that connect to arterial roadways.

8. Include measures to close or redesign inadequately designed median openings.

\section{BP 3-28. I nterchange Land Use Plan Policy}

A notable Florida example of interchange land use plan policy was developed as part of the Wekiva Coordinating Committee Final Report, March 16, 2004. The Report recommended that where interchanges are proposed (with the exception of at I-4) local governments adopt interchange land use into their long-range transportation plans. The Orange County Comprehensive Plan 2010-2030, Destination 2030 Goal, Objectives, and Policies amended November 13, 2012, contains the following objective and supporting policies regarding interchange land use within a 1-mile radius of each interchange along the Wekiva Parkway:

- Objective FLU6.7 Wekiva Interchange Land Use Plan Overlay designation. Orange County establishes the Wekiva Interchange Land Use Plan Overlay (WILUPO), which is intended to be a tool for compatible and consistent future development, transition of densities and preservation of environmentally sensitive areas within the Overlay and the Wekiva Study Area. Creation of this Overlay does not create development entitlements on any parcel of land or amend any previously-approved entitlements.

\section{Minor Street Network}

The minor street network serves to provide connectivity from land uses to the major roadway network. It includes roadways functionally classified as minor collectors and local streets or alleys. The following strategies are aimed at improving the connectivity and availability of local and collector street networks and promoting increased connection of activity centers to surrounding neighborhoods to enhance local mobility and reduce local trips on major roadways.

1. Include network-enhancing local and minor collector street projects (BP 3-20).

2. Promote direct connections between activity centers and surrounding residential areas.

3. Include policies and strategies to increase street network connectivity (GOP 2-8. Street Network Connectivity). 
4. Include measures to increase pedestrian safety at intersections, mid-block crossings, and along roadways.

5. Include measures to increase bicycle safety.

6. Include measures to provide safe routes to schools. Coordinate with school board and local law enforcement regarding Safe Routes to Schools within a 2-mile walking distances from schools. Effort should focus on physical improvements as well as educational and enforcement activities.

A Connectivity Index is a network measure used to quantify how well a street network connects destinations (87 p. 14). To measure a connectivity index, the number of street segments, intersections, and cul-de-sacs are counted within the study area. Street segments are considered links and intersections or cul-de-sacs are considered nodes. The connectivity index is calculated by dividing the number of links by the number of nodes. Areas with a score of 1.4 or higher are considered walkable (87 p. 14). In rural areas, bicycle and pedestrian connections can also be provided independent of the street network using strategies such as connecting dead end streets and cul-de-sacs with shared pathways.

A maximum block length requirement ranging from 245-660 feet could be established in code, depending upon the access management needs of the affected primary or secondary roadway. Maximum block perimeter standards (e.g. 1320 feet) may be preferred as these can provide more flexibility to accommodate variations in terrain and existing buildings or barriers. For block lengths in excess of 660 feet, a 20-foot wide bicycle/pedestrian easement may be necessary to maintain adequate continuity of the bike/ped system. GOP 2-8 (Street Network Connectivity) is an example of a goal, objectives, and policies for street network and connectivity that supports walking, bicycling, and transit use. As new development occurs, it is important to ensure that multimodal infrastructure is included to support the multimodal environment. GOP 2-3 (Developer Contributions to the Multimodal Environment) is an example of an objective to address new development contributions to the multimodal environment.

\section{Public Transportation}

Public transportation in rural areas may consist of intercity bus and paratransit services. Goals, objectives, and policies may focus on coordination with agencies that provide these services. In addition, incremental, small-scale services such as local circulators may be beneficial to small communities and thus a focus for future planning efforts. Strategies may include.

1. Address statewide/regional long-distance bus service traveling through or with endpoints within plan boundaries.

2. Address express transit service to/from urban areas.

3. Address paratransit service within plan boundaries.

4. Improve the quality of service for public transportation, considering the potential for enhanced route and destination connectivity via locally provided transit circulators that connect to a regional public transportation system.

GOP 3-3 provides an example of an objective and policy for transit. 


\section{GOP 3-3. Transit Corridor Objective (Taylor County)}

Objective II .11: Transit Corridors - As the Vision 2060 Plan is implemented over time, the opportunity to provide transit services and corridors within and between development areas shall be considered.

Policy II.11: Prior to development under the optional Vision 2060 Plan, in conjunction with approval of a DRI development order, the applicant may consider transit as a mitigation strategy; the required traffic analysis will address the demand for and financial feasibility of providing transit services.

\section{Bicycle and Pedestrian Network and Safety}

A bicycle and pedestrian network comprised of a system of interconnected and direct routes is an important part of a multimodal transportation system.

1. Require a bicycle/pedestrian safety audit.

2. Identify the corridors that have the most severe injury bicycle and/or pedestrian crashes and fatalities and recommend projects for improved safety.

3. Identify opportunities to implement bicycle lanes and ADA accessible sidewalks of appropriate width on or near all collector and arterial routes where appropriate.

4. Include planned projects to address bicycle and pedestrian network connectivity.

5. Adopt bicycle and pedestrian quality of service standards and/or performance measures.

6. Address the continuation of, or establish new, shared use paths.

7. Require new development to maintain continuous pedestrian networks, including connections to transit stops, adjacent lots, and between building entrances and the internal and external sidewalk network.

8. Require new development to maintain continuous bicycle networks, including connections to transit stops and adjacent properties, and to provide bicycle parking at all non-residential uses, multi-family uses and other key destinations.

GOP 2-13 (Bicycle/Pedestrian Network Connectivity) provides example objectives of bicycle and pedestrian network connectivity that supports walking, bicycling, and transit use.

\section{Ports, Aviation, Rail, and I ntermodal Facilities}

A freight system based on rail, ports, aviation and the intermodal connections between each of these modes is crucial to an effective multimodal transportation system.

1. Align planning for ports, aviation, rail, and intermodal connections with the future land use element.

2. Coordinate with applicable plans (airport master plan, port master plan, etc.).

3. Address existing SIS facilities, necessary improvements to those facilities, and the interconnections between modes on the SIS network.

4. Designate local routes intended for freight movement by large trucks and establish appropriate roadway design and operational measures for their efficiency. 
GOP 3-4 provides two example policies from the City of Port St. Joe that relate to SIS. An example goal and objectives are provided in GOP 2-15 (Port, Airport, Rail, and Intermodal Integration) that address the integration of ports, aviation, rail, and related intermodal facilities into Pasco County's transportation system.

\section{GOP 3-4. Access to Ports and Airports}

The City of Port St. Joe, a small community, includes the following policies supporting access to the port and the port designation as a Planned Emerging Strategic Intermodal System (SIS) facility in its Traffic Circulation Element:

Policy 1.5.6: The City shall collaborate with the Port St. Joe Port Authority, county, state, and federal agencies and with private entities responsible for water, highway, and rail connectivity to ensure that the intermodal transportation infrastructure and connectivity essential to Port operations are in place.

Policy 1.6.3: The City supports the Port of Port St Joe designation as a Planned Emerging Strategic Intermodal System (SIS) facility and will support redevelopment efforts in the Port Planning Area to promote local and regional economic development in the area consistent with the Port Master Plan included in the Coastal Management Element.

Source: City of Port St. Joe Traffic Circulation Element (127) 


\section{Chapter 4. Conclusions and Next Steps}

This report is intended for use by local government planners and consultants in preparing the transportation element of the local government comprehensive plan. Florida Department of Transportation (FDOT) District staff will also find it useful in their review of local government comprehensive plans and plan amendments in relation to the state transportation system. The model elements set forth best practices that relate to Florida's multimodal transportation planning requirements.

Training, as well as pilot applications of the model elements and best practices, are suggested as appropriate next steps. Pilot applications would produce additional example applications and clarify any need for further refinements or additions to the model element contents or best practices. In addition, training would provide another venue for identifying communities with an interest in applying the planning concepts in collaboration with FDOT.

Benefits to communities engaging in pilot applications of the models include additional technical assistance in the multimodal transportation planning process and improved coordination opportunities with FDOT and other transportation agencies. Toward this end, this section includes: (a) example community selection criteria for pilot applications, (b) identification of potential pilot community candidates using the criteria, and (c) initial recommendations for working with pilot communities, including training and outreach to implement the findings of the research.

\section{Pilot Community Selection Criteria}

A variety of criteria are identified below for consideration by the Florida Department of Transportation in the screening of potential candidates for pilot application of the model multimodal transportation element and best practices. The purpose of the screening criteria is to identify a cross-section of communities with interest in updating their multimodal transportation plan. Suggested screening criteria include the following:

1. Applicable Category of Planning Requirements: What planning requirements in Appendix A apply to the candidate community?

o One community in Category A, C and D (Category B being less pertinent in light of its limited application)

2. Governance Structures and Relationships: For example, is the transit agency a part of the local government or separate? Is the MPO an independent agency or housed within the local government? Is the community a newly formed MPO? Ideally, candidates would represent a cross-section of the following structures:

o Local Government - Transit Agency (independent or within local agency)

o Local Government - MPO (independent or within local agency)

3. Type of Transit Service Planned or Provided and Size of Service Area: Identify a cross-section of communities with different sizes of transit service areas and that have or plan to include transit service for one or more of the following:

o Rail: commuter rail, light rail, streetcar

o Bus Rapid Transit

o Local bus transit and circulators 
4. Community Location: Identify communities from different areas of the state and in different FDOT Districts and/or Regional Planning Councils.

o FDOT District in which the community is located

o RPC in which the community is located

5. Local Government Demographics: Identify communities of different sizes, socioeconomic levels, population characteristics, and density/intensity of development.

o Total Population

o Percentage of low income, minority and elderly residents

o Median income

o Density/persons per square mile

6. Presence of an airport, seaport, or intermodal facility: At least one pilot community contains one or more of the following:

o a seaport

o an international airport

o an intermodal facility

7. Evidence of past coordination with other transportation plans and programs:

o Previous agreements or requests for assistance in addressing other agency plans or programs, such as,

- MPO

- Transportation Authority

- Florida Transportation Plan

- FDOT

8. Evidence of past or current desire to coordinate land use and transportation elements. For example, the following strategies are to be applied (to be determined during selection process):

o Transit oriented development or traditional neighborhood development

o Mixed use activity centers

o Multimodal transportation districts

Along with the aforementioned criteria, the timing of pilot applications should coincide with a local government's timeline for updating the transportation element of its comprehensive plan. Local governments have flexibility in determining when and whether to update their comprehensive plan. At a minimum, the Florida Department of Economic Opportunity (DEO) requires all local governments to review their comprehensive plan at least every seven years to determine whether the need exists to amend the plan to reflect changes in state requirements since the last plan update (Rule Chapter 73C-49, FAC).

These Evaluation and Appraisal Report (EAR) requirements call for local governments to notify DEO of their determination. Local governments that determine they must update their plan are to complete the amendments within a year of notifying DEO of this decision, although some flexibility is generally provided to communities in completing the update. The current evaluation and appraisal notification schedule, which includes 2012 to 2018, was 
evaluated by the research team for insight as to which communities may be updating their plan in the near future (e.g., 2014/2015 timeframe).

In addition, communities sometimes choose to coordinate their comprehensive plan update with their respective MPO's long-range transportation plan (LRTP) update. Florida MPOs are presently in the process of updating their LRTPs through the year 2040. The plans are being adopted on different schedules with about one-third (nine plans) to be adopted in 2014, half (thirteen plans) in 2015 and the remainder in 2016 (four plans) or 2017 (one plan). Appendix $\mathrm{H}$ includes the current schedule of MPO long-range transportation plan (LRTP) updates. Finally, for assistance in identifying possible candidates, a questionnaire was sent to FDOT District Growth Management Coordinators for their suggestions.

\section{Potential Pilot Community Candidates}

Based on the above selection criteria, as well as suggestions from FDOT District Growth Management Coordinators, a short list of suggested candidates for consideration in the pilot application process was prepared by the project team. These communities were examined using a more detailed spreadsheet matrix that included each of the following criteria:

- Place Name

- County

- Category/Type

- $\quad$ EAR Deadline

- $\quad$ LRTP Adoption Schedule

- Population (2010)

- \% Minority

- \% Elderly

- Median Household Income

- \% Below Poverty Level

- Density (per Sq. Mi.)

- Within MPO (Y/N)

- Name of MPO
- Independent MPO $(\mathrm{Y} / \mathrm{N})$

- $\mathrm{MPO}$ Bike/Ped Plan (Y/N)

- Bike/Ped Plan Title

- Airport/Port/Intermodal Facility

- Transit Agency

- Type of Transit

- FDOT District

- RPC

- DEO District/Region

- FDOT GM Coordinator Comments

Upon review of the matrix, 13 jurisdictions stood out as potential pilot communities for further consideration (see Table 4-1). The 13 potential pilot communities represent a sample of jurisdictions varying in size, population density, available transit services, and presence of ports and airports.

Although the number of potential candidates and desired approach for pilot applications has yet to be determined by the Department through its scoping process, initial conversations indicate that approximately three pilot applications may be considered. It is suggested that these candidates reflect a representative cross-section of the communities identified in Table 4-1, recognizing that additional candidates not suggested during this current project period may emerge through future outreach.

It is suggested that additional weight be given to those communities in the list that express a clear desire to participate in the pilot applications. This willingness could be expressed in any form acceptable to the Department. A suggested approach prior to actual commencement of the application is in the form of a letter of agreement specifying terms and conditions of participation in the pilot, as prepared and signed by the appropriate local 
government officials and the appropriate representatives of the Florida Department of Transportation. These conditions could be drafted to reflect the recommendations for working with pilot communities identified below, and other appropriate considerations identified by the Department and local governments involved in the pilot applications.

\begin{tabular}{|c|c|c|c|c|c|c|c|}
\hline Place Name & $\begin{array}{c}\text { Category } \\
\text { / Type }\end{array}$ & $\begin{array}{l}\text { EAR } \\
\text { Deadline }\end{array}$ & $\begin{array}{l}\text { LRTP } \\
\text { Adoption } \\
\text { Schedule }\end{array}$ & $\begin{array}{l}\text { Transit } \\
\text { Agency }\end{array}$ & $\begin{array}{l}\text { Type(s) of } \\
\text { Transit }\end{array}$ & $\begin{array}{l}\text { Airport/ } \\
\text { Port }\end{array}$ & $\begin{array}{c}\text { FDOT } \\
\text { District }\end{array}$ \\
\hline Aventura & C & $1 / 1 / 2014$ & $10 / 29 / 2014$ & $\begin{array}{l}\text { Miami-Dade } \\
\text { Transit }\end{array}$ & Bus & $\mathrm{N} / \mathrm{A}$ & 6 \\
\hline Avon Park & $A$ & $3 / 1 / 2015$ & $\mathrm{~N} / \mathrm{A}$ & Veolia & Paratransit & 1 Airport & 1 \\
\hline Chiefland & A & $5 / 1 / 2017$ & $\mathrm{~N} / \mathrm{A}$ & $\begin{array}{l}\text { Levy County } \\
\text { Transit }\end{array}$ & $\mathrm{N} / \mathrm{A}$ & $\mathrm{N} / \mathrm{A}$ & 2 \\
\hline Clearwater* & D & $12 / 1 / 2015$ & $12 / 9 / 2014$ & PSTA & $\begin{array}{l}\text { Bus/Trolley, } \\
\text { Light Rail } \\
\text { (planned) }\end{array}$ & $\mathrm{N} / \mathrm{A}$ & 7 \\
\hline $\begin{array}{l}\text { Daytona } \\
\text { Beach* }\end{array}$ & $\mathrm{D}$ & $10 / 1 / 2016$ & $11 / 2 / 2015$ & VOTRAN & $\begin{array}{l}\text { Bus/Trolley, } \\
\text { Rail } \\
\text { (Amtrak) }\end{array}$ & $\mathrm{N} / \mathrm{A}$ & 1 \\
\hline $\begin{array}{l}\text { Deerfield } \\
\text { Beach* }\end{array}$ & $\mathrm{D}$ & $5 / 1 / 2014$ & $12 / 13 / 2014$ & BCT \& SFRTA & Bus, Rail & 2 Airports & 4 \\
\hline Dunedin* & $\mathrm{C}$ & $12 / 1 / 2015$ & $12 / 9 / 2014$ & PSTA & Bus/Trolley & $\mathrm{N} / \mathrm{A}$ & 7 \\
\hline $\begin{array}{l}\text { Manatee } \\
\text { County* }\end{array}$ & $\mathrm{D}$ & $12 / 1 / 2013$ & $12 / 13 / 2015$ & MCAT & Bus, Trolley & $\begin{array}{l}3 \text { Airports, } \\
1 \text { Port }\end{array}$ & 5 \\
\hline $\begin{array}{l}\text { North } \\
\text { Miami* }\end{array}$ & $\mathrm{D}$ & $12 / 1 / 2014$ & $10 / 29 / 2014$ & $\begin{array}{l}\text { Miami-Dade } \\
\text { Transit }\end{array}$ & Bus, Rail & N/A & 6 \\
\hline $\begin{array}{l}\text { Port St. } \\
\text { Lucie* }\end{array}$ & D & $9 / 1 / 2012$ & $2 / 2 / 2016$ & $\begin{array}{l}\text { Treasure } \\
\text { Coast } \\
\text { Connector }\end{array}$ & Bus, Trolley & N/A & 4 \\
\hline Quincy & C & $1 / 1 / 2015$ & $12 / 15 / 2015$ & $\begin{array}{l}\text { Big Bend } \\
\text { Transit }\end{array}$ & Paratransit & N/A & 3 \\
\hline $\begin{array}{l}\text { St. } \\
\text { Augustine* }\end{array}$ & C & $12 / 1 / 2018$ & $11 / 12 / 2014$ & $\begin{array}{l}\text { Sunshine Bus } \\
\text { Company }\end{array}$ & Bus & 1 Airport & 2 \\
\hline $\begin{array}{l}\text { St. Johns } \\
\text { County* }\end{array}$ & $\mathrm{D}$ & $8 / 1 / 2017$ & $11 / 12 / 2014$ & $\begin{array}{l}\text { Sunshine Bus } \\
\text { Company }\end{array}$ & Bus & N/A & 2 \\
\hline
\end{tabular}

*Denotes Required Coastal Management Element

\section{Suggested Pilot Application Process}

The purpose of the pilot applications is twofold:

1. To provide guidance to local governments wishing to strengthen their multimodal transportation element through application of multimodal best practices and models, and

2. To provide insight into potential refinements of the model multimodal transportation element(s), including additional examples of applications in different planning contexts.

The following procedures are suggested for working with each local government on the pilot applications.

Step 1. Task Team: Establish a pilot application task team with representatives from the local government planning department (land use, transportation), FDOT District, Regional Planning Council, and other applicable transportation 
agencies (e.g., area transit provider, MPO, transportation authority, port, airport).

a. Strive to include similar agency representatives for communities within the same District, RPC, DEO Region, etc.

Step 2. Kick off Meeting: Kick off meetings with each task team to clarify pilot project objectives and local government multimodal transportation planning objectives and establish a quarterly meeting schedule.

a. Convey responsibilities of the task team in assisting the local government in locating available data it may need to proceed with the update, offering suggestions relative to applying the contents of the model element in relation to the pilot application, and identifying potential additions or refinements to the model element.

Step 3. Training: On-site (and/or internet) training workshops with local government staff on contents of the model element and their application to the local government plan update.

a. Task team members would be invited and asked to participate in providing guidance to the local agency on application of the model element from their perspective.

Step 4. Technical Support and Outreach: Ongoing monitoring and individualized technical support on contents of the model element would be provided by the project team during pilot application, including regular conference calls to assess the status of the pilot application and address issues of concern. Targeted outreach sessions for elected officials and key stakeholder groups could be considered at key points of this process. It is anticipated that this process will last for approximately nine (9) months.

a. Issues that require additional technical guidance in the model element will be identified and documented throughout this process.

Step 5. Feedback: Local government and task team report to the project team and FDOT Project Manager on areas benefitting from additional guidance and/or topics that should be included in the model element that are not presently addressed.

a. At the conclusion of the pilot application, the project team would collect the draft local government multimodal elements and debrief pilot application participants. In-person interviews would be held with pilot participants to understand their experience working with the model element and supporting guidance documents.

b. Simultaneous to the pilot application testing, the model elements and supporting guidance would be evaluated by the task team members. At the conclusion of the pilot application, the project team would debrief the task team and obtain further recommendations on enhancements to the model. 
Step 6. Document Findings and Recommendations: Findings from the participant and task team debriefings should be documented in a technical memorandum. Model element additions and refinements would be proposed based on the pilot application evaluation and could be executed as part of the pilot projects or in a subsequent work order. 


\section{References}

1. Florida Department of Transportation: District 5. State Road 50 Multi-Modal Corridor Study: Executive Summary. Prepared by Kittelson and Associates, Inc., December 2011.

2. Meyer, Michael D. Chapter 1: Introduction to Transportation Planning. ITE Transportation Planning Handbook 3rd Edition. Washington D.C: Institute of Transportation Engineers, 2009, pp. 1-9.

3. Wright, Michael J. "Memo: City Transportation Language Policy." Palm Beach, Florida: November 14, 1996.

4. Renaissance Planning Group. 2011 Mobility Plan: Linking Land Use and Transportation. [Online] 2011. [Accessed: July 23, 2013.] www.cityoffortpierce.com/pdf/StLucieMobilityPlan_03082012.pdf.

5. City of Tampa. Comprehensive Plan: Mobility Element. undated, circa 2008.

6. City of El Paso, Texas. Plan El Paso: Transportation Element. March 6, 2012.

7. Florida Department of Transportation. "Transportation and Land Use," Trends and Conditions Report - 2009: Impact of Transportation. [Online] 2009. [Accessed: February 25, 2014.] www.dot.state.fl.us/planning/trends/tc-report/landuse090409.pdf.

8. North Florida TPO. Envision 2035 Long Range Transportation Plan. [Online] 2010. [Accessed: March 3, 2014.] www.firstcoastmpo.com/images/uploads/general/Summary_Report_revised_0921111.pdf.

9. City of Fort Lauderdale. Transportation Element. City of Fort Lauderdale Comprehensive Plan. [Online] 2008. [Accessed: July 8, 2013.]

10. Hillsborough County. Transportation Element. Comprehensive Plan for Unincorporated Hillsborough County Florida. [Online] 2008. [Accessed: March 14, 2013.] www.planhillsborough.org/wp-content/uploads/2012/10/Transportation-Element-08-08-08NON-ADOPTED-PORTION.pdf.

11. Pasco County. "Chapter 7: Transportation Element - Technical Support Data." 2025 Pasco County Comprehensive Plan. 2006.

12. Renaissance Planning Group. A Framework for Transit Oriented Development in Florida. Prepared for the Florida Department of Transportation, 2011.

13. Williams, Kristine and Seggerman, Karen. Model Regulations and Plan Amendments for Multimodal Transportation Districts. National Center for Transit Research, 2004.

14. Committee for the Study on the Relationships Among Development Patterns, Vehicle Miles Traveled, and Energy Consumption. "Driving and the Built Environment: The Effects of Compact Development on Motorized Travel, Energy Use, and CO2 Emissions." Special Report 298. Transportation Research Board of the National Academies. Washington, D.C.: 2009.

15. Ewing, Reid, Pendall, Rolf and Chen, Don. Measuring Sprawl and its Impact. Prepared for Smart Growth America, 2010.

16. Ewing, Reid and Cervero, Robert. "Travel and the Built Environment: A Meta Analysis." Journal of the American Planning Association. 2010, Vol. 76, 3, pp. 265-294. 
17. Williams, Kristine, Stover, Vergil, Dixon, Karen, et al. NCHRP 15-43: Second Edition of the TRB Access Management Manual. Washington, D.C.: Transportation Research Board of the National Academies, publication pending.

18. Adirondack/Glen Falls Transportation Council. Access Management Guide. Adirondack , New York, 2007.

19. Williams, Kristine and Levinson, Herbert. "Access Management Past, Present, and Future." Proceedings of the 2008 Access Management Conference. Baltimore, Md. 2008.

20. Treasure Coast Regional Planning Council. Florida TOD Guidebook. 2012.

21. Litman, Todd. "Parking Management: Strategies, Evaluation, and Planning." [Online] 2013. [Accessed: February 27, 2014.] www.vtpi.org/park_man.pdf.

22. City of Delray Beach. Parking Management Plan. [Online] 2010. [Accessed: February 25, 2014.]

mydelraybeach.com/sites/default/files/assets/departments/planning\%20and\%20zoning/Par king-Mgmt-Plan-REVISED-061810.pdf.

23. Institute of Transportation Engineers. Smart Growth Transportation Guidelines: An ITE Recommended Practice. Washington, D.C., 2010.

24. MetroPlan Orlando. "Technical Report 6: Freight Urban Village Land Use Plan and Strategies." 2030 Long Range Transportation Plan, 2010.

25. Florida Department of Transportation. "Transit Oriented Development Workshop Sketchbook." [Online] 2011. [Accessed: July 16, 2013.]

business.sunrail.com/uploads/assets/tod/TOD\%20Sketchbook\%202011\%20Update\%20Sect ion\%202.pdf.

26. Federal Transit Administration. Characteristics of Bus Rapid Transit for Decision-Making. [Online] 2009. [Accessed: July 16, 2013.]

www.nbrti.org/docs/pdf/High\%20Res\%20CBRT\%202009\%20Update.pdf.

27. Levinson, H., et al. TCRP Report 90 Bus Rapid Transit Volume 2: Implementation Guidelines. Transportation Research Board, 2003. Washington, D.C.

28. PB Americas, Inc. LYMMO Expansion Alternatives Analysis: East/West LYMMO Corridor AA Report. Orlando: 2011.

29. City of Orlando. Transportation Element: Goals, Objectives, and Policies. [Online] December 5, 2011. [Accessed: September 3, 2013.] www.cityoforlando.net/planning/cityplanning/PDFs/GMP/2012/jan/04_Transportation_GOPs _Supp_5.pdf.

30. MetroPlan Orlando. SunRail: Understanding Central Florida's Commuter Rail Project. 2011.

31. Florida Department of Transportation. Florida Intercity Passenger Rail "Vision Plan". [Online] 2006. [Accessed: July 16, 2013.]

www.dot.state.fl.us/rail/Publications/Plans/06VisionPlan/ExecReportFinal.pdf.

32. American Public Transportation Association. Transit Ridership Report: First Quarter 2013. [Online] 2013. [Accessed: August 28, 2013.] www.apta.com/resources/statistics/Documents/Ridership/2013-q1-ridership-APTA.pdf. 
33. South Florida Regional Transportation Authority. South Florida Transit Resource Guide. [Online] September 2008. [Accessed: September 04, 2013.] www.sfrta.fl.gov/docs/planning/Existing\%20System/TransitResourceGuide.pdf.

34. City of Lakeland Community Development Department. Lakeland 2010-2020 Comprehensive Plan. [Online] 2010. [Accessed: January 8, 2014.] www.lakelandgov.net/Portals/CommDev/CompPlan/03\%20TR\%20Mass\%20Transit\%20T12-003.pdf.

35. Broward Metropolitan Planning Organization. 2035 Broward Transformation Long Range Transportation Plan. February 14, 2013.

36. City of Gainesville. City of Gainesville Regional Transit System (RTS) Transit Development Plan. [Online] 2009. [Accessed: May 27, 2013.] gorts.com/files/August2009TDP.pdf.

37. City of Altamonte Springs. "Multi-Modal Transportation Element: Data, Inventory, and Analysis." City Plan 2030. [Online] 2010. [Accessed: April 12, 2013.] www.altamonte.org/department/growth/Pdf/DIA/MultiModal\%20Transportation\%20Element\%20DIA.pdf.

38. Polzin, Steven and Chu, Xuehao. Florida Department of Transportation Long Range VMT Forecasts: Methodologies and Sample Scenarios. Tampa, FL : Center for Urban Transportation Research, 2009.

39. MetroPlan Orlando. "2030 Long Range Transportation Plan: Overview." [Online] 2009. [Accessed: May 3, 2013.] www.metroplanorlando.com/files/view/2030-long-rangetransportation-plan-overview.pdf.

40. Florida Department of Transportation. Forms and Procedures: Procedure Documents Listed by Title. [Online] [Accessed: September 30, 2013.]

www2.dot.state.fl.us/proceduraldocuments/procedures/proceduresbytitle.asp?index=a\&type = policy \%20statement\&rCount=all.

41. Seggerman, Karen and Hendricks, Sara. "Incorporating TDM into the Land Development Process." National Center for Transit Research. [Online] August 2005. www.nctr.usf.edu/pdf/576-11.pdf.

42. Hendricks, Sara. "Land Developer Participation in Providing for Bus Transit Facilities/Operations." National Center for Transportation Research at CUTR/USF. [Online] 2002. www.nctr.usf.edu/pdf/Land\%20Developer.pdf.

43. Gayah, Vikash V. "Two-Way Street Networks: More Efficient than Previously Thought?" Access. Fall 2012, 41.

44. MetroPlan Orlando. Pedestrian Safety Action Plan. [Online] 2012. [Accessed: March 12, 2014.] www.metroplanorlando.com/files/view/pedestrian-safety-action-plan-july-2012.pdf.

45. University of Florida. "Signal Four Analytics." [Online] 2013. [Accessed: February 25, 2014.] s4.geoplan.ufl.edu/.

46. Cambridge Systematics. Hillsborough County Transportation Vulnerability Assessment and Adaptation Pilot Project. [Online] 2014. [Accessed: April 9, 2014.] www.planhillsborough.org/wp-content/uploads/2013/10/Phase-1-Technical-Memo-Draft-34-14.pdf. 
47. Pedestrian and Bicycle Information Center. [Online] undated. [Accessed: June 11, 2013.] www.bicyclinginfo.org/develop/activities.cfm.

48. Broward County. Broward County Comprehensive Plan: Transportation Element. [Online] 2011. [Accessed: June 24, 2013.] www.broward.org/PlanningAndRedevelopment/ComprehensivePlanning/Documents/TransG OPS2011.pdf.

49. Alachua County Growth Management Department. Alachua County Comprehensive Plan 2011-2030. [Online] 2011. [Accessed: June 14, 2013.] growthmanagement.alachuacounty.us/comprehensive_planning/documents/2011_2030_Comprehe nsive_Plan.pdf.

50. City of Largo. City of Largo Comprehensive Plan: A Blueprint for the Community. City of Largo. [Online] 2009. [Accessed: July 1, 2013.] www.largo.com/egov/documents/242031300386268.pdf.

51. Florida Department of Economic Opportunity. Sector Planning Program. [Online] [Accessed: April 23, 2013.] www.floridajobs.org/community-planning-anddevelopment/programs/technical-assistance/planning-initiatives/rural-planning/sectorplanning-program.

52. Polk TPO. Polk 2035 Mobility Vision Plan. 2010.

53. City of Jacksonville. 2030 Comprehensive Plan: Transportation Element. [Online] 2013. [Accessed: June 26, 2013.] cityclts.coj.net/docs/20110241\%5CExhibits/Revised\%20Exhibit\%201.pdf.

54. All Aboard Florida. "Welcome to All Aboard Florida." [Online] [Accessed: October 7, 2013.] www.allaboardflorida.com.

55. City of Miami. "Transportation Element: Data Inventory and Analysis." Miami Comprehensive Neighborhood Master Plan, [Online] November 2004. [Accessed: August 21, 2013.] www.miamigov.com/Planning/pages/community_planning/MCNP_Appendix_TR1(08-08).pdf.

56. City of Gainesville. Transportation Mobility Element. [Online] 2001. [Accessed: May 23, 2013.] www.cityofgainesville.org/portals/0/plan/docs/transmobility02.pdf.

57. Florida Department of Transportation. Airport Compatible Land Use Guidebook. 2012.

58. Ward, Stephanie A.D., et al. ACRP Report 27: Enhancing Airport Land Use Compatibility - Volume 1: Land Use Fundamentals and Implementation Resources. Washington, D.C.: Transportation Research Board, 2010.

59. Jones, Brad W., Cassady, C. Richard and Bowden Jr., Royce O. Developing a Standard Definition of Intermodal Transportation. National Center for Intermodal Transportation (NCIT). [Online] 2003. [Accessed: April 22, 2013.]

60. Florida Department of Transportation. Tiger Discretionary Grants: Miami Intermodal Center. [Online] [Accessed: July 9, 2013.] www.dot.state.fl.us/planning/economicstimulus/MIC/MIC-Application.pdf.

61. Florida Department of Transportation. TBEST: Transportation Boardings Estimation and Simulation Tool Version 4.1. [Online] 2013. tbest.org/about-2/. 
62. Florida Department of Transportation. Policy Statements. [Online] April 18, 2012.

[Accessed: September 30, 2013.]

(www2.dot.state.fl.us/proceduraldocuments/procedures/proceduresbytitle.asp?index=a\&typ $\mathrm{e}=$ policy $\% 20$ statement\&rCount=all)

63. Hillsborough County. Comprehensive Plan for Unincorporated Hillsborough County Florida: Nonadopted Portion. Livable Communities Element. [Online] 2008. [Accessed: June 17, 2013.] www.planhillsborough.org/wp-content/uploads/2012/10/LIVABLECOMMUNITIES_11_2012.pdf.

64. Strader, Brad. Webinar: Multimodal Quality Level of Service. Institute of Transportation Engineers, 2010.

65. Elefteriadou, Lily, et al. Expanded Transportation Performance Measures to Supplement Level of Service (LOS) for Growth Management and Transportation Impact Analysis. Gainesville: The University of Florida, 2012.

66. Guttenplan, M. and Reynolds, S. "Measuring Multimodal Mobility with the Highway Capacity Manual 2010 and Other New Analysis Tools." TR News, No. 280. Transportation Research Board of the National Academies, Washington, D.C. May-June 2012.

67. Institute of Transportation Engineers. Planning Urban Arterial and Freeway Systems: A Proposed Revised Recommended Practice. Washington, D.C: ITE, 1997.

68. Institute of Transportation Engineers. Designing Walkable Urban Thoroughfares: A Context Sensitive Approach. [Online] 2010. www.ite.org/css/RP-036A-E.pdf.

69. Florida Department of Transportation. Florida Pedestrian Planning and Design Handbook. [Online] 1999.

safety.fhwa.dot.gov/intersection/resources/fhwasa09027/resources/Florida\%20Pedestrian\% 20Facilities\%20Planning\%20and\%20Design\%20Handbook.pdf.

70. Florida Department of Transportation. Florida Bicycle Facilities Planning and Design Handbook. [Online] 1999.

safety.fhwa.dot.gov/intersection/resources/fhwasa09027/resources/Florida\%20Bicycle\%20F acilities\%20Planning\%20and\%20Design\%20Handbook.pdf.

71. Shepard, Gloria M., et al. "Memorandum: Bicycle and Pedestrian Facility Design Flexibility." Federal Highway Administration (FHWA). [Online] August 20, 2013. [Accessed: October 1, 2013.]

www.fhwa.dot.gov/environment/bicycle_pedestrian/guidance/design_guidance/design_flexi bility.cfm.

72. Walk Friendly Communities. "Community Assessment Tool." [Online] November 1 , 2011. [Accessed: June 18, 2013.] www.walkfriendly.org/WFCAssessmentTool_Nov2011.pdf.

73. National Bicycle Documentation and Pedestrian Documentation Project. [Online] undated. [Accessed: June 24, 2013.] bikepeddocumentation.org/.

74. Ryan, Sherry and Lindsey, Greg. "Counting Bicyclists and Pedestrians to Inform Transportation Planning," Research Brief, Robert Woods Johnson Foundation, February 2013. 
75. Sprinkle Consulting. "Methods for Assessing Bicycle Trip Activity." [Online] n.d. [Accessed: April 22, 2013.]

www.sprinkleconsulting.com/Images/UserSubmitted/Latent\%20Demand.pdf.

76. Steuteville, Robert and Phillip Langdon. New Urbanism Best Practices Guide, $4^{\text {th }}$ Ed. New Urbanism News Publications, 2009.

77. Spikowski, Bill. "Form Based Codes Session." Annual Florida APA Conference, Orlando, Florida, 2013.

78. Florida Department of Transportation. I-95 Corridor Mobility Plan. [Online] [Accessed: October 2, 2013.] myplanspace.com/i95/index.cfm.

79. Florida Department of Transportation, Florida Multimodal Transportation Districts and Multimodal Areawide Quality of Service Handbook. 2003 [out of print].

80. Center for Urban Transportation Research. Broward County Transit Development Plan 2009-2018. [Online] 2008. [Accessed: May 26, 2013.]

www.broward.org/BCT/Documents/TDP2009.pdf.

81. City of Jacksonville Planning and Development Department. 2030 Mobility Plan. [Online] May 2011. [Accessed: May 20, 2013.]

82. Institute of Transportation Engineers. Designing Urban Thoroughfares for Walkable Communities. Washington, D.C.: ITE, 2010.

83. Institute of Transportation Engineers. Planning Roadway Systems: An ITE Recommended Practice. Washington, D.C., 2011.

84. Florida Department of Transportation, Transportation Statistics Office. FHWA Urban Boundary and Federal Functional Classification Handbook. Tallahassee. 2003.

85. American Association of State Highway and Transportation Officials. A Policy on Geometric Design of Highways and Streets. Washington, D.C., 2011.

86. Florida Department of Transportation. Manual of Uniform Minimum Standards for Design, Construction, and Maintenance for Streets and Highways. [Online] 2011. www.dot.state.fl.us/rddesign/FloridaGreenbook/FloridaGreenbook.pdf.

87. Florida Department of Transportation Office of Roadway Design. Traditional Neighborhood Development Handbook. [Online] 2011. [Accessed: April 30, 2013.] www.dot.state.fl.us/rddesign/FloridaGreenbook/TND-Handbook.pdf.

88. National Complete Streets Coalition of Smart Growth America. [Online] [Accessed: 5 3, 2013.] www.smartgrowthamerica.org/complete-streets/complete-streetsfundamentals/complete-streets-faq) .

89. Kimley Horn and Associates, Inc. Broward County Complete Streets Guidelines:

Providing Guidance for Developing Safer and Healthier Streets Accommodating All Users. [Online] 2013. [Accessed: September 4, 2013.]

dl.dropboxusercontent.com/u/29194392/Broward\%20Complete\%20Streets\%20Guidelines\% 20-\%20Complete.pdf.

90. Federal Highway Administration. Managed Lanes Primer. Washington, D.C., August 2008. FHWA-HOP-05-031. 
91. Florida Department of Transportation. UPA/CRD Annual Report: Miami, FL I-95 Express Lanes. [Online] 2011. [Accessed: July 15, 2013.]

www.upa.dot.gov/docs/fhwajpo11044/armiami1.pdf.

92. Palm Beach County. Comprehensive Plan Transportation Element. [Online] April 25, 2013. [Accessed: September 18, 2013.] www.co.palm-

beach.fl.us/pzb/planning/comprehensiveplan/tableofcontent.htm. 2013-12, 13.

93. Florida Department of Transportation. Florida's Strategic Intermodal System Strategic Plan. 2010.

94. Florida Department of Transportation. "Intermodal Logistics Centers Primer: Boosting Florida's Economy through Freight Logistics." [Online] 2013. [Accessed: May 22, 2013.] freightmovesflorida.com/docs/default-source/ilcdocs/ilc-primer---final-2013-02-28.pdf.

95. Polk County. Polk County Comprehensive Plan. [Online] 2010 [Accessed: April 30, 2014.] www.polk-county.net/subpage.aspx?menu_id=226\&id =478

96. Fischer, Edward L., et al. Pedestrian and Bicycle Safety and Mobility in Europe. [Online] February 2010. [Accessed: June 18, 2013.]

www.international.fhwa.dot.gov/pubs/pl10010/pl10010.pdf.

97. City of Largo. "Section 6 - Proposed Projects, Prioritization, and Phasing," City of Largo Multimodal Plan. [Online] 2012. www.largo.com/egov/documents/1370870716_79088.pdf.

98. Ullman, Seth. Rightsizing Streets Guide. [Online] 2013. [Accessed: April 15, 2014.] www.pps.org/reference/rightsizing/.

99. Broward County. Code of Ordinances: Chapter 5, Article IX. Building Regulations and Land Use. 2005.

100. Washington Department of Commerce. Your Community's Transportation System: A Guide to Reviewing, Updating, and Implementing Your Transportation Element. [Online] 2012. [Accessed: October 2, 2013.] www.commerce.wa.gov/Documents/GMSTransportation-2012.pdf.

101. City of Boca Raton. "Transportation Element." City of Boca Raton Comprehensive Plan, [Online] 2012. [Accessed: July 12, 2013.] www.ci.boca-

raton.fl.us/dev/2010EAR_draft.shtm.

102. City of Boca Raton. "Future Land Use Element." City of Boca Raton Comprehensive Plan, [Online] 2012. [Accessed: July 12, 2013.] www.ci.bocaraton.fl.us/dev/pdf/2010EAR_TransDCA_NEW/ComprPlanEleMapSeries/FLUEGOPadoption\%2010-26-10-final.pdf.

103. City of Temple Terrace. Mobility Element 2025: Comprehensive Plan for the City of Temple Terrace, Florida. [Online] 2009. www.planhillsborough.org/wpcontent/uploads/2012/08/Temple-Terrace-Comprehensive-Plan-Introduction.pdf.

104. Southern California Association of Governments. 2008 Regional Transportation Plan: Making the Connections. [Online] 2008.

www.scag.ca.gov/rtp2008/pdfs/finalrtp/f2008RTP_Complete.pdf.

105. Smart Growth America. National Complete Streets Coalition - Policy Elements. Smart Growth America. [Online] 2010. [Accessed: February 24, 2014.]

www.smartgrowthamerica.org/complete-streets/changing-policy/policy-elements. 
106. National Complete Streets Coalition of Smart Growth America. "The Best Complete Streets Policies of 2012." [Online] April 2013. www.smartgrowthamerica.org/documents/cs2012-policy-analysis.pdf.

107. Tallahassee-Leon County Planning Department. Mobility Element. Tallahassee-Leon County Comprehensive Plan, Tallahassee, Florida: 1990, as amended.

108. The City of Boca Raton. "Capital Improvements Element." City of Boca Raton Comprehensive Plan. [Online] 2010. [Accessed: October 1, 2013.] www.ci.bocaraton.fl.us/dev/pdf/2010EAR_TransDCA/Complan_Elements_And_Map_Series/CIEGOPTrans mittal.pdf.

109. Manatee County. The Manatee County Comprehensive Plan Page Replacement Package: Supplement \#16. [Online] 2010. [Accessed: September 10, 2013.]

110. Pasco County MPO. 2035 Long Range Transportation Plan: Final Report. 2009.

111. City of Winter Haven. Winter Haven 2025 Comprehensive Plan: Transportation Element. [Online] 2011 [Accessed: April 30, 2014.] www.egovlink.com/public_documents300/winterhaven/published_documents/Winter\%20Ha ven/Planning/Planning\%20Documents\%20and\%20Downloads/Comprehensive\%20Plan/Tran sportation\%20Element.pdf

112. Florida Department of Transportation. Rural Economic Development Initiative (REDI). Rural Coordination and Support. [Online] 2014. [Accessed: February 25, 2014.] www.dot.state.fl.us/planning/policy/ruralsupport/.

113. Federal Highway Administration. Study of Adequacy of Commercial Truck Parking Facilities - Technical Report. [Online] 2002. [Accessed: February 27, 2014.] www.fhwa.dot.gov/publications/research/safety/01158/01158.pdf.

114. City of Palatka. City of Palatka Comprehensive Plan: Traffic Circulation Element. [Online] 2008. [Accessed: September 2, 2013.] palatkafl.gov/Documents/Comp_Plan/adopted\%202020\%20Traffic\%20Element.pdf.

115. Glades County. Glades County Comprehensive Plan Transportation Element. [Online] 2010. [Accessed: May 7, 2014.] http://www.myglades.com/resources.php.

116. City of Mukilteo. City of Mukilteo Comprehensive Plan. [Online] 2012. [Accessed: April 16, 2014.] www.ci.mukilteo.wa.us/files/cp-CompPlan(final).pdf.

117. Kimley-Horn and Associates, Inc. City of Belle Glade Comprehensive Plan: Data, Inventory, and Analysis. [Online] 2008. [Accessed: January 13, 2014.]

118. Taylor County. Taylor County Comprehensive Plan. [Online] 2010. www.taylorcountygov.com/gm/ComprehensivePlan.htm.

119. Florida Department of Transportation. Intermodal System Handbook. [Online] 2012. [Accessed: April 24, 2013.]

www.dot.state.fl.us/planning/systems/mspi/pdf/SIS\%20Handbook\%20\%20Final\%20Clean\%20Copy.pdf.

120. Port St. Joe Port Authority. Port St. J oe Master Plan 2013. [Online] 2013. [Accessed: February 26, 2014.] www.portofportstjoe.com/Draft\%20Port\%20Master\%20Plan $\% 202013 . \% 20$ May\%2023.\%20 2013.pdf. 
121. City of Gainesville. "Exhibit A-2: Future Land Use Element Supplemental Data and Analysis for the 2013-2023." [Online] April 2, 2013.

gainesville. legistar.com/LegislationDetail.aspx?ID=1237203\&GUID=923AB415-0CD5-4841B198-F6B467B6B3D1\&Options=\&Search.

122. Florida Department of Transportation. 2013 Quality Level of Service Handbook. [Online] 2013. [Accessed: April 1, 2013.]

www.dot.state.fl.us/planning/systems/programs/sm/los/pdfs/2013\%20QLOS\%20Handbook. pdf.

123. Forbes, Sasha, et al., Putting Transit to Work in Main Street America: How Smaller Cities and Urban Places are Using Transit and Mobility Investments to Strengthen their Economies and Communities, Reconnecting America and Community Transportation Association. 2012.

124. SCJ Alliance. Town of Wilkeson Rural Town Center Corridor Plan: PAW Awards Nomination. [Online] 2013. [Accessed: April 15, 2014.] washingtonapa.org/documents/Wilkeson_Rural_Town_Center_Corridor_Plan_APAPAW_Award_Nomin.pdf.

125. ECONorthwest. Transportation Mobility Strategy for the City of Olympia. [Online] 2009. [Accessed: April 15, 2014.]

126. City of Wauchula. 2030 Comprehensive Plan. [Online] 2011. [Accessed: February 25, 2014.]

www.cityofwauchula.com/Pages/WauchulaFL_CommunityDevelopment/ComprehensivePlan. pdf.

127. City of Port St. Joe. "Traffic Circulation Element." City of Port St. J oe Comprehensive Plan, [Online] 2007. [Accessed: December 17, 2013.]

www.cityofportstjoe.com/pdf/comp/TRANSPORTATION\%20ELEMENT\%20adopted\%20revisio ns\%20093009\%20clean\%20version.pdf.

128. American Public Transportation Association. "Fact Book Glossary." APTA Resource Library. [Online] 2013. [Accessed: August 29, 2013.] www.apta.com/resources/statistics/Pages/glossary.aspx.

129. Committee on Access Management. Access Management Manual. Washington, D.C.: Transportation Research Board of National Academies, 2003. 


\section{Appendix A - Florida Statutory Requirements for Transportation Elements}

$\S 163.3177($ b) F.S. A transportation element addressing mobility issues in relationship to the size and character of the local government. The purpose of the transportation element shall be to plan for a multimodal transportation system that places emphasis on public transportation systems, where feasible. The element shall provide for a safe, convenient multimodal transportation system, coordinated with the future land use map or map series and designed to support all elements of the comprehensive plan. A local government that has all or part of its jurisdiction included within the metropolitan planning area of a metropolitan planning organization (M.P.O.) pursuant to s. 339.175 shall prepare and adopt a transportation element consistent with this subsection. Local governments that are not located within the metropolitan planning area of an M.P.O. shall address traffic circulation, mass transit, and ports, and aviation and related facilities consistent with this subsection, except that local governments with a population of 50,000 or less shall only be required to address transportation circulation. The element shall be coordinated with the plans and programs of any applicable metropolitan planning organization, transportation authority, Florida Transportation Plan, and Department of Transportation adopted work program.

1. Each local government's transportation element shall address traffic circulation, including the types, locations, and extent of existing and proposed major thoroughfares and transportation routes, including bicycle and pedestrian ways. Transportation corridors, as defined in s. 334.03, may be designated in the transportation element pursuant to s. 337.273. If the transportation corridors are designated, the local government may adopt a transportation corridor management ordinance. The element shall include a map or map series showing the general location of the existing and proposed transportation system features and shall be coordinated with the future land use map or map series. The element shall reflect the data, analysis, and associated principles and strategies relating to:

a. The existing transportation system levels of service and system needs and the availability of transportation facilities and services.

b. The growth trends and travel patterns and interactions between land use and transportation.

c. Existing and projected intermodal deficiencies and needs.

d. The projected transportation system levels of service and system needs based upon the future land use map and the projected integrated transportation system.

e. How the local government will correct existing facility deficiencies, meet the identified needs of the projected transportation system, and advance the purpose of this paragraph and the other elements of the comprehensive plan.

2. Local governments within a metropolitan planning area designated as an M.P.O. pursuant to s.339.175 shall also address:

a. All alternative modes of travel, such as public transportation, pedestrian, and bicycle travel.

b. Aviation, rail, seaport facilities, access to those facilities, and intermodal terminals.

c. The capability to evacuate the coastal population before an impending natural disaster.

d. Airports, projected airport and aviation development, and land use compatibility around airports, which includes areas defined in ss. 333.01 and 333.02.

e. An identification of land use densities, building intensities, and transportation management programs to promote public transportation systems in designated public 
transportation corridors so as to encourage population densities sufficient to support such systems.

3. Municipalities having populations greater than 50,000 , and counties having populations greater than 75,000, shall include mass-transit provisions showing proposed methods for the moving of people, rights-of-way, terminals, and related facilities and shall address:

a. The provision of efficient public transit services based upon existing and proposed major trip generators and attractors, safe and convenient public transit terminals, land uses, and accommodation of the special needs of the transportation disadvantaged.

b. Plans for port, aviation, and related facilities coordinated with the general circulation and transportation element.

c. Plans for the circulation of recreational traffic, including bicycle facilities, exercise trails, riding facilities, and such other matters as may be related to the improvement and safety of movement of all types of recreational traffic.

4. At the option of a local government, an airport master plan, and any subsequent amendments to the airport master plan, prepared by a licensed publicly owned and operated airport under s.333.06 may be incorporated into the local government comprehensive plan by the local government having jurisdiction under this act for the area in which the airport or projected airport development is located by the adoption of a comprehensive plan amendment.

In the amendment to the local comprehensive plan that integrates the airport master plan, the comprehensive plan amendment shall address land use compatibility consistent with chapter 333 regarding airport zoning; the provision of regional transportation facilities for the efficient use and operation of the transportation system and airport; consistency with the local government transportation circulation element and applicable M.P.O. long-range transportation plans; the execution of any necessary interlocal agreements for the purposes of the provision of public facilities and services to maintain the adopted level-of-service standards for facilities subject to concurrency; and may address airport-related or aviationrelated development. Development or expansion of an airport consistent with the adopted airport master plan that has been incorporated into the local comprehensive plan in compliance with this part, and airport-related or aviation-related development that has been addressed in the comprehensive plan amendment that incorporates the airport master plan, do not constitute a development of regional impact. Notwithstanding any other general law, an airport that has received a development-of-regional-impact development order pursuant to s. 380.06, but which is no longer required to undergo development-of-regional-impact review pursuant to this subsection, may rescind its development-of-regional-impact order upon written notification to the applicable local government. Upon receipt by the local government, the development-of-regional-impact development order shall be deemed rescinded. 
Table A-1. Required and Optional Components of Transportation Elements

\begin{tabular}{|c|c|c|c|}
\hline \multirow{2}{*}{ Category } & \multicolumn{2}{|r|}{ Required } & \multirow{2}{*}{ Optional } \\
\hline & Core Contents & Related Details & \\
\hline $\begin{array}{l}\text { (A) All Local } \\
\text { Governments } \\
\text { (including those } \\
<50,000 \\
\text { population } \\
\text { outside of MPOs) }\end{array}$ & $\begin{array}{l}\text { Traffic circulation plan, } \\
\text { including: } \\
\text { Major thoroughfares and } \\
\text { transportation routes } \\
\text { Identification of } \\
\text { bicycle/pedestrian ways }\end{array}$ & $\begin{array}{l}\text {-Coordinate with plans and programs of any } \\
\text { applicable MPO, transportation authority, FTP, and } \\
\text { DOT adopted work program. } \\
\text {-Map or map series that shows existing and } \\
\text { proposed system } \\
\text {-Coordinate transportation map(s) with future land } \\
\text { use map(s)* } \\
\text {-Goals, objectives, policies and strategies** } \\
\text {-Existing major thoroughfare and transportation } \\
\text { route LOS, LOS standards and system needs and } \\
\text { availability of transportation facilities and services } \\
\text {-Growth trends, travel patterns and } \\
\text { LU/transportation interactions } \\
\text {-Projected LOS based on FLUM and projected } \\
\text { system } \\
\text {-Existing and projected intermodal } \\
\text { deficiencies/needs } \\
\text {-Methods to correct identified deficiencies, meet } \\
\text { identified needs, and advance other plan elements } \\
\text { Reflect supporting data and analysis*** }\end{array}$ & $\begin{array}{l}\text { Corridor } \\
\text { designation and } \\
\text { management, per } \\
\text { s. } 337.273 \text {, F.S. }\end{array}$ \\
\hline $\begin{array}{l}\text { (B) Jurisdiction }> \\
50,000 \\
\text { population } \\
\text { Outside of MPO } \\
\text { Planning Area }\end{array}$ & $\begin{array}{l}\text { (A) above, plus: } \\
\text { Mass transit, ports and } \\
\text { aviation and related } \\
\text { facilities "consistent with } \\
\text { this subsection" }\end{array}$ & $\begin{array}{l}\text {-Existing and projected quality of service (QOS) } \\
\text { for mass transit (public transportation), QOS } \\
\text { standards, and system needs and availability of } \\
\text { mass transit facilities and services }\end{array}$ & \multirow{2}{*}{$\begin{array}{l}\text { Airport Master } \\
\text { Plan: } \\
\text { LU compatibility } \\
\text { (s.333.003(2) and } \\
\text { (3), F.S.) } \\
\text { Provision of } \\
\text { regional facilities } \\
\text { related to the } \\
\text { airport } \\
\text { Consistency with } \\
\text { transportation } \\
\text { circulation } \\
\text { element and MPO } \\
\text { LRTP if applicable } \\
\text { Interlocal } \\
\text { agreements to } \\
\text { provide public } \\
\text { facilities and } \\
\text { services needed } \\
\text { to maintain LOS } \\
\text { for concurrency }\end{array}$} \\
\hline $\begin{array}{l}\text { (C) All or Portion } \\
\text { of Jurisdiction } \\
\text { Within MPO } \\
\text { Planning Area }\end{array}$ & $\begin{array}{l}\text { (A) above, plus: } \\
\text { Plans for all alternative } \\
\text { modes of travel (e.g., } \\
\text { public transportation, } \\
\text { pedestrian and bicycle } \\
\text { travel) } \\
\text { Address aviation, rail and } \\
\text { seaport facilities, access } \\
\text { to those facilities, and } \\
\text { intermodal terminals. }\end{array}$ & $\begin{array}{l}\text {-Capability to evacuate coastal populations } \\
\text {-Existing and projected quality of service for public } \\
\text { transportation, QOS standards, and system needs } \\
\text { and availability of mass transit facilities and } \\
\text { services } \\
\text {-Public transportation: land use densities, building } \\
\text { intensities, and transportation management } \\
\text { programs sufficient to promote public } \\
\text { transportation systems in designated public } \\
\text { transportation corridors. } \\
\text {-Quality of service (QOS) or performance } \\
\text { standards, targets, or benchmarks for bicycle and } \\
\text { pedestrian facilities, system needs and availability } \\
\text { of bicycle and pedestrian facilities and services. } \\
\text {-Airports: also address projected airport and } \\
\text { aviation development, and land use compatibility } \\
\text { around airports }\end{array}$ & \\
\hline $\begin{array}{l}\text { (D) Municipality } \\
\text { population }> \\
50,000 \text { OR } \\
\text { County } \\
\text { population }> \\
75,000 \\
\text { (regardless of } \\
\text { MPO planning } \\
\text { areas) }\end{array}$ & $\begin{array}{l}\text { (A) above, plus: } \\
\text { Mass-transit provisions } \\
\text { Plans for port, aviation, } \\
\text { and related facilities } \\
\text { coordinated with the } \\
\text { general circulation and } \\
\text { transportation element. } \\
\text { Plans for all types of } \\
\text { recreational traffic, } \\
\text { including bicycle facilities, } \\
\text { exercise trails, riding } \\
\text { facilities. }\end{array}$ & $\begin{array}{l}\text {-Existing and projected quality of service for public } \\
\text { transportation, QOS standards, and system needs } \\
\text { and availability of mass transit facilities and } \\
\text { services } \\
\text { Transit provisions include: } \\
\text {-proposed methods for moving people, } \\
\text {-rights-of-way, } \\
\text {-existing and proposed major trip generators } \\
\text { and attractors, } \\
\text {-safe and convenient public transit terminals, } \\
\text {-land uses, and } \\
\text {-accommodation of the special needs of the } \\
\text { transportation disadvantaged. } \\
\text { Recreational traffic facilities: the circulation, } \\
\text { improvement, and safety of movement. }\end{array}$ & \\
\hline
\end{tabular}




\section{TABLE A-1 NOTES:}

The table and notes below are provided as a quick reference of multimodal transportation element statutory requirements and other requirements pertinent to transportation planning. Please refer to Chapter 163.3177 F.S. for additional details.

*"Each map depicting future conditions must reflect the principles, guidelines and standards within all elements..."

** Optional format for addressing the required principles and guidelines for plan implementation (i.e., programs, activities, and meaningful and predictable standards for the use and development of land/meaningful guidelines for the content of more detailed land development and use regulations.) A separate section indicates the comprehensive plan must contain "guidelines or policies for implementation..." ( $\$ 163.3177(5)(b)$, F.S.) Another section refers to the need for the transportation element to reflect associated principles and strategies. $(\S 163.3177(6)(a)$, F.S. $)$

*** Data and analysis: The comprehensive plan must be based on appropriate data. "To be based on data means to react to it in an appropriate way and to the extent necessary indicated by the data available on that particular subject at the time of adoption of the plan or plan amendment at issue." Data and analysis may include, but is not limited to: surveys, studies, community goals and vision, and other available date. (§163.3177(1)(f), F.S.)

Copies of key studies and data used in preparing the plan should be included in the plan or they "may not be deemed a part of the comprehensive plan." ( $\$ 163.3177(1)(f) 1, F . S$.$) Other supporting studies, data or supporting$ documents may still be used in determining compliance and "must be made available to the public."

Data must be taken from professionally accepted sources. The methodology used in data collection or whether a particular methodology is professionally accepted may be evaluated. However, the evaluation may not include whether one accepted methodology is better than another. ( $\$ 163.3177(1)(f) 2, F . S$.$) Original data collection by$ local governments is not required. However, local governments may use original data so long as methodologies are professionally accepted. Where data is relevant to several elements consistent data shall be used, including population estimates and projections (unless alternative data can be justified through new supporting data and analysis). (§163.3177(2), F.S.)

Each local comprehensive plan must include two planning periods - a 5 year period following adoption and a 10 year period. Additional periods are permitted.

Coordination of the several elements of the local comprehensive plan shall be a major objective of the planning process. The elements must be consistent. Each map depicting future conditions must reflect the principles, guidelines, and standards within all elements and must be contained within the comprehensive plan.

$(\S 163.3177(2)$, F.S. $)$

Related Requirements of the Future Land Use Element:

- $\quad$ Promote the efficient and cost-effective provision or extension of public infrastructure and services.

- $\quad$ Promote walkable and connected communities and provide for compact development and a mix of uses at densities and intensities that support a range of housing choices and a multimodal transportation system, including pedestrian, bicycle, and transit if available.

- $\quad$ FLUM - must show MMTD, TCMA and/or TCEA boundaries where applicable.

Related Requirements of the Capital Improvements Element:

- Must cover at least a 5-year period and must be reviewed annually (may be modified as needed by ordinance; no CPA required)

- Must include standards to ensure the availability of public facilities and adequacy of those facilities to meet established acceptable levels of service.

- $\quad$ Projects needed to achieve and maintain LOS for the 5-year period must be identified as either funded or unfunded and given a level of priority for funding.

- The schedule must include transportation improvements in the applicable MPO's transportation improvement program (TIP) "to the extent that such improvements are relied upon to ensure concurrency and financial feasibility." The schedule must be coordinated with the applicable MPO's long-range transportation plan.

Related Requirements of the Intergovernmental Coordination Element:

- Interlocal agreements within 1 year of adoption that ensures coordination in establishing LOS standards for public facilities maintained by another entity.

Related Requirements of the Coastal Management Element:

- $\quad$ Limit public expenditures that subsidize development in high-hazard coastal areas. 


\section{Appendix B - Florida Bicycle and Pedestrian Plans}

The Florida bicycle and pedestrian plans noted below represent those identified through a search of the internet as of February 2014. Local governments are encouraged to check with their MPO, FDOT District Bicycle and Pedestrian Coordinator, and/or County, in the case of municipalities, for the latest information on bicycle and pedestrian planning and safety action planning activities pertinent to their jurisdiction.

Table B-1. Florida Bicycle and Pedestrian Plans

\begin{tabular}{|c|c|c|}
\hline Plan Name & Lead Agency & Date Adopted \\
\hline Alachua Countywide Bicycle Master Plan & Alachua County MTPO & June 2001 \\
\hline $\begin{array}{l}\text { Bay County Bicycle Pedestrian Master } \\
\text { Plan }\end{array}$ & Bay County TPO & September 2013 \\
\hline $\begin{array}{l}\text { Charlotte Harbor Heritage Trails Master } \\
\text { Plan }\end{array}$ & $\begin{array}{l}\text { Charlotte County-Punta } \\
\text { Gorda MPO }\end{array}$ & August 2002 \\
\hline $\begin{array}{l}\text { Collier County Comprehensive Pathways } \\
\text { Plan }\end{array}$ & Collier MPO & December 2012 \\
\hline $\begin{array}{l}\text { Florida-Alabama Bicycle Pedestrian } \\
\text { Master Plan }\end{array}$ & Florida-Alabama TPO & December 2010 \\
\hline $\begin{array}{l}\text { Gadsden County Bicycle and Pedestrian } \\
\text { Facilities Master Plan }\end{array}$ & Gadsden County & July 2012 \\
\hline $\begin{array}{l}\text { City of Gainesville Bicycle Pedestrian } \\
\text { Action Plan }\end{array}$ & City of Gainesville & In Progress \\
\hline $\begin{array}{l}\text { Hillsborough Countywide Bicycle Safety } \\
\text { Action Plan }\end{array}$ & Hillsborough County MPO & April 2011 \\
\hline $\begin{array}{l}\text { Hillsborough countywide Pedestrian } \\
\text { Safety Action Plan }\end{array}$ & FDOT & February 2010 \\
\hline $\begin{array}{l}\text { Indian River County MPO Bicycle and } \\
\text { Pedestrian Plan Update }\end{array}$ & Indian River MPO & July 2004 \\
\hline $\begin{array}{l}\text { Lee Countywide Bicycle and Pedestrian } \\
\text { Action Plan }\end{array}$ & Lee County MPO & September 2013 \\
\hline $\begin{array}{l}\text { Martin County Bicycle and Pedestrian } \\
\text { Five-Year Action Plan }\end{array}$ & Martin County MPO & February 2012 \\
\hline City of Miami Bicycle Action Plan & City of Miami & October 2008 \\
\hline Miami Bicycle Master Plan & City of Miami & October 2010 \\
\hline $\begin{array}{l}\text { North Florida Regional Bicycle and } \\
\text { Pedestrian Master Plan }\end{array}$ & North Florida TPO & In Progress \\
\hline
\end{tabular}


Ocala/Marion County 2015 Bicycle

Pedestrian Master Plan Update

Okaloosa-Walton Bicycle Pedestrian

Master Plan Addendum

Orlando Pedestrian Safety Action Plan

Palm Beach County Master

Comprehensive Bicycle Transportation

Plan

Pasco Countywide Pedestrian Safety

Action Plan

Pinellas Countywide Pedestrian and

Bicycle Master Plan

Pinellas County Pedestrian Safety Action

Plan

Sarasota County Trails Master Plan

Sarasota-Manatee MPO Bicycle, Pedestrian and Trails Master Plan

Shifting Gears Bicycle and Pedestrian Master Plan

St. Augustine Bicycle Master Plan

St. Lucie County Greenways and Trails Plan

City of St. Petersburg CityTrails Bicycle Pedestrian Master Plan

Wakulla County Bicycle, Pedestrian, and Blueways Master Plan
Ocala/Marion TPO June 2004

Okaloosa-Walton TPO March 2012

MetroPlan Orlando MPO July 2012

Palm Beach County MPO March 2011

Pasco County MPO January 2012

Pinellas County MPO May 2006

FDOT $\quad$ August 2009

Sarasota County $\quad$ Fall 2006

Sarasota-Manatee MPO November 2013

City of Clearwater 2006

North Florida TPO December 2011

St. Lucie County May 2008

City of St. Petersburg 2009

Wakulla County

June 2012 


\title{
Appendix C - Funding Options for Transit Systems
}

\author{
Prepared by: Brian Waterman, Transit Planning Manager, StarMetro, Tallahassee, Florida
}

\section{Option \# 1: Revise the Concurrency Management System to include Transit Incentives}

Comprehensive plans in the State of Florida are required to establish levels of service (LOS) standards for the major infrastructure in their community. The standards are usually regulated through the Concurrency Management System whereas a new development's (residential, commercial, industrial, etc.) impacts to the infrastructure, such as road capacity. If capacity is not available, the developer is required to provide sufficient compensation to add the necessary capacity based on level of impact. Originally, the concurrency management system was required under Florida Statutes; however, recent legislation has repealed most of the provisions and gives greater flexibility to local governments on maintenance of their infrastructure.

It is this greater flexibility in maintaining local infrastructure that lends itself to the inclusion of transit incentives in the concurrency management process. While this option is not a major revenue generator itself, it would help create a more transit friendly environment which in turn leads to higher ridership, more farebox revenue, more federal/state funds, and other funding opportunities. The transit incentives, if employed by the developer, could lower their concurrency payment to the affected municipality. Incentives could include constructing and maintaining stop amenities, decoupling parking from residential rents, implementing travel demand management strategies, or entering service agreements with the transit system for improved transit service or discounted bus passes.

The issue with this option along with option 4 below is the tying of transit funding to development activity. When the economy is booming and construction is up, options such as this provide ample funding to expand or improve transit service within the community. As development activity wanes and comes to a standstill, many of the transit projects created through the additional concurrency funding are no longer supported through fees and must either be discontinued or supported by the local general fund. Broward County, FL, for example, implemented a Transit Concurrency Management System and used funds from new development to support improvements to the system. As the economy slowed, the expense of maintaining the enhanced system was passed on to the local government which had to make difficult funding decisions on whether to keep enhanced service going.

Similarly, concurrency funding locally is used in cities and counties as a funding source to improve road capacity in the community. Lowering the amount of currency funding available through incentives could affect the ability to construct or improve roads. Implementation of this system would require interdepartmental and inter-jurisdictional cooperation to ensure sufficient funds are still made available to make road improvements associated with community growth.

A carefully constructed transit incentive program for the concurrency management system is an effective way to get transit infrastructure built and to foster greater support for the transit system. This option in the long run would increase transit ridership, increase the transit mode share, increase mixed-use development, and increase funding opportunities for the system. 


\section{Option \#2: Special Assessment Districts}

Florida Statutes also authorizes municipalities to establish special assessment districts to support public transportation (Section 170.01 FS). The special assessment must be approved by a majority of the affected property owners. The funds raised by the special assessment could be used to operate and improve the transit experience (higher frequency, stop upgrades, etc.) within the affected districts. Since the money would be used to operate transit service within a designated district, the existing funds dedicated to the affected route(s) would be reallocated to operate and/or improve routes outside of the assessment district

\section{Option \# 3: Creating a Parking Management District}

A Parking Management District (PMD) is an area defined by ordinance, vote of affected property owners, or other legislative mechanisms which uses the funds collected from paid parking spaces to fund improvements to support other modes of transportation within the district. A sample ordinance from Austin, TX is found in Attachment C-1.

Below is a synopsis of two cities that have created PMDs. Tables 1, 2, and 3 provide the performance measures for the two cities.

Ann Arbor, MI

- A leading example of how parking revenue can be used to: expand commuter options; reduce supply expansions; and achieve mode shift goals. Providing financial support to bring commuter bus service to downtown is an example of all three. By providing the kind of transit service parking customers said they would try, the Downtown Development Authority and the local transit authority were able to launch a successful new service that provides affordable downtown access, reduces pressure on the parking inventory, and expands the modal options of downtown workers - all of which help local businesses attract and retain employees.

- Ann Arbor presents a model in which parking income essentially pays for the cost of providing and maintaining public, shared parking facilities.

- Supporting economic development and vitality is the primary mission of the authority tasked with parking management.

- Directly ties alternative transportation investments to the economics of parking, using alternative transportation investments such as bike parking and sidewalk improvements to reduce the need to expand supplies.

- Recent changes in revenue-sharing agreements highlight the need to protect parking revenues from disappearing into general municipal funds.

Boulder, CO

- An example of the power of employee transit benefits on both opening up customer parking opportunities and shifting commute mode splits away from driving.

- Provides unlimited transit passes to most downtown employees at a fraction of the cost of providing them with parking. A leading example of both the demandmanagement potential of PMDs and the role of a demand-management in economic development.

- Parking largely pays for itself. 
- Spends significant program revenues on local, program-directed investments critical for maintaining public awareness of the program's role in district revitalization and ongoing improvements.

Table C-1. I nventory and Utilization

\begin{tabular}{|l|r|r|}
\hline \multicolumn{1}{|c|}{ Measure } & Ann Arbor & \multicolumn{1}{c|}{ Boulder } \\
\hline Inventory - On-Street & 1,063 & 810 \\
\hline Inventory - Surface & 898 & 263 \\
\hline Inventory - Structured & 3,749 & 2,209 \\
\hline Inventory - All & 5,710 & 3,282 \\
\hline On-Street/ Off-Street Ratio & & 0.33 \\
\hline Weekly Peak Utilization & $81 \%$ & NO DATA \\
\hline
\end{tabular}

Table C-2. Financial Performance

\begin{tabular}{|l|r|r|}
\hline \multicolumn{1}{|c|}{ Measure } & \multicolumn{1}{c|}{ Ann Arbor } & \multicolumn{1}{c|}{ Boulder } \\
\hline Direct Parking Income (Fees, Fines, Etc.) & $\$ 18,254,775$ & $\$ 5,797,553$ \\
\hline Other Parking-Related Revenue & $\$ 68,027$ & $\$ 2,471,976$ \\
\hline Direct Income per Space & $\$ 3,196.98$ & $\$ 1,766.47$ \\
\hline Parking-Related Costs & $\$ 18,131,945$ & $\$ 6,818,875$ \\
\hline Parking Costs per Space & $\$ 3,175.47$ & $\$ 2,077.66$ \\
\hline$\%$ of Parking Costs Covered by Parking Income & $101 \%$ & $85 \%$ \\
\hline
\end{tabular}

Table C-3. Alternative Modes and Other Benefit

\begin{tabular}{|l|r|r|}
\hline \multicolumn{1}{|c|}{ Measure } & Ann Arbor & \multicolumn{1}{c|}{ Boulder } \\
\hline Alternative Transportation Investments & $\$ 600,000$ & $\$ 722,173$ \\
\hline Local Improvement Investments & $\$-$ & $\$ 505,000$ \\
\hline Total Inter-Fund Transfers & $\$ 2,000,000$ & $\$-$ \\
\hline Alternative Transport Investments / Space & $\$ 105$ & $\$ 220$ \\
\hline
\end{tabular}

Source: Montgomery County (MD) Parking Policy Study, Spring 2011

Attachment C-2 provides another example of how to fund transportation infrastructure through parking fees.

\section{Option \#4: I mplement a Mobility Fee}

Florida law allows communities to adopt a Mobility Fee as an alternative to the concurrency management system. The transportation mitigation allowed under a mobility fee is different from traditional impact fees as the mobility fee payment includes both the cost of the capital infrastructure and the cost of operating the transit system. A portion of the multi-modal mobility fee is collected for transit operations and could be utilized to pursue additional funding opportunities (such as Federal and State grants) to increase frequency and hours of service.

An example of a mobility fee program in Florida is found in Alachua County. Alachua County adopted in April 2011 a mobility fee for developments within identified Transportation 
Districts within Alachua County. The mobility fee is used in lieu of concurrency calculations within these districts and factor in both transit capital and transit operations. Based on Alachua County's analysis, mobility fee is lower than a roadway only based concurrency fee. In Alachua County, $77 \%$ of the funds go toward road and dedicated transit lane construction, $10 \%$ to transit operations, $9 \%$ to transit capital, and $4 \%$ to bicycle and pedestrian capital. Pasco County adopted a similar program in 2011. Nassau County is currently evaluating a mobility fee to replace concurrency.

As with option 3, a drawback of this option is tying transit funding to development activity. This make the revenue stream unpredictable since it is contingent on local economy and development activity. A mobility fee in partnership with transit incentives (Option 3), however, encourages transit supportive developments that could lead to additional ridership, more farebox revenue, and additional federal and state funding.

\section{Option \# 5: Create a Transportation I mprovement District}

A transportation deficiency fund is a method of financing transportation (or redevelopment projects) by earmarking future tax monies by declaring a transportation deficiency area. A Transportation Deficiency Area is a geographic region with inadequate transportation facilities. Once a deficient area has been identified, a county or municipality may create a transportation development authority to manage transportation improvements. The authority will adopt a transportation sufficiency plan as part of the local government comprehensive plan. A local trust fund (called a Transportation Deficiency Fund) is financed through a property tax increment. The revenue raised may be used for capital or transit operating expenses.

Property values will likely rise as improvements are made to transportation infrastructure and system. Tax increment financing (TIF) allows transportation improvements to be funded by capturing a portion of the increased property tax revenues that may result if the redevelopment stimulates private investment. Bonds are issued to cover up-front costs, and later repaid from a portion of revenues generated by property tax increases.

For example, Alachua County, FL developed a method to fund transportation improvements and promote TOD's within the Southwest Transportation Improvement District. The original plan was to freeze property values when the district was established, and set a percentage of property tax revenues generated by increases in property values. This additional revenue would remain inside the boundaries of the district, to fund transportation projects and transit operations. The county commission however referred to Florida State law that declared that the county could not make a pledge to use future property tax or ad valorem revenues to pay off the debt on transportation projects. The commissioners pledged to use non-ad valorem tax revenues that was equal to what would have been pledged through property tax revenues. From 2012 to 2025, that amount of funding would be equal to 30 percent of the property tax revenues generated by increases in values. From 2026 to 2035, it is 25 percent. Of the tax money in the district, 70 percent would go toward construction of infrastructure such as roads, bicycle and pedestrian paths and transit lanes. The other 30 percent would go toward transit operations.

There are two significant issues with this option. The first is dedication of additional property tax funds for a specific project. Similar to a Community Redevelopment Agency, future property tax revenue is dedicated to transportation improvements within the boundaries of the district. This could affect the budgeting of future revenue and expenses for 
municipalities. Extensive negotiations would be needed to divide up the future revenue among the involved parties. Second, it requires the creation of an approval board comprised of elected and/or appointed officials to oversee and authorize the expenditure of funds on the transportation projects. This option, however, is a good transitional step to fund transit improvements while other proposals, such as the Regional Transit Authority, are explored.

\section{Option \#6: Create a Regional Transit Authority}

There are three ways to become a regional transit authority.

- Legislatively Created - Under Chapter 343, F.S., or Chapter 349, F.S, a regional transit authority is created through an act of the Florida Legislature. The size, board makeup, powers, and duties are defined in the enabling legislation. Legislatively created regional authorities do not have dedicated funding sources. Charter counties within a legislatively created regional transportation authority, however, are allowed to levy surtax of up to $1 \%$ by a majority vote of the electorate [Section $212.055(1)$ F.S.]. Funding levels by the participating jurisdictions, however, are specified in the enabling legislation for the South Florida Regional Transportation Authority. In addition, any changes to the size, board, powers, etc. must be approved by the Legislature. All regional authorities are authorized to levy revenue bonds for the purchase of infrastructure. Five regional authorities (Central Florida, Jacksonville, Northwest Florida, South Florida, and Tampa Bay) were created with this method.

- Locally Created under Section 163.56, F.S. - Any two or more contiguous jurisdictions through the charter process may join to form a regional transit authority. Under this process, the involved jurisdictions convene a charter committee to specify the rights, powers, and duties of the regional agency. Once the charter is filed with the Department of State, the Governor appoints two members to serve on the charter board. The jurisdictions involved automatically become a special tax district with the authority to levy up to 3 mills ad valorem tax by referendum. If specified in the charter agreement, the authority is also allowed to issue bonds to fund infrastructure projects. There are no regional transportation authorities in Florida created with this method.

- Memorandums of Understanding or Interlocal Agreements - Through an interlocal agreement or a memorandum of understanding, the surrounding jurisdiction(s) could contract with the transit provider to provide transit service to their community. The powers, duties, costs, and responsibilities of the service would be defined in the agreement with the funding of the service the sole responsibility of the interested jurisdiction(s). Polk County formed a regional agency with this method in 2007.

There are benefits and drawbacks to the three methods mentioned above. In addition, the use of interlocal agreements could be an interim step to becoming a locally or legislatively created authority. 
ORDINANCE NO. 20111006-053

\section{AN ORDINANCE AMENDING TITLE 12 OF THE CITY CODE TO ADD CHAPTER 12-6 ESTABLISHING A PARKING BENEFIT DISTRICT PROGRAM.}

\section{BE IT ORDAINED BY THE CITY COUNCIL OF THE CITY OF AUSTIN:}

PART 1. Title 12 of the City Code is amended to add a new Chapter 12-6 to read as follows:

\section{CHAPTER 12-6. PARKING BENEFIT DISTRICTS.}

\section{§ 12-6-1 DEFINITIONS.}

In this chapter:

(1) DIRECTOR means the director of the Austin Department of Transportation or the director's designee.

(2) DISTRICT means a parking benefit district.

(3) NEIGHBORHOOD ORGANIZATION means an organization that is registered as a neighborhood organization with the City.

(4) NOTICE OWNER means the owner of real property as shown on the records of the tax appraisal district in the county in which the property is located.

\section{§ 12-6-2 PARKING BENEFIT DISTRICT.}

A parking benefit district is an area defined by separate ordinance in which a percentage of the funds collected from a paid parking space within district is used to fund improvements that promote walking, cycling, and public transit use within the district.

\section{§ 12-6-3 PARKING BENFIT DISTRICT REQUIREMENTS.}

(A) A district must include at least 96 paid parking spaces, the minimum number of spaces required to pay for the expenses of maintaining and operating parking pay stations and meters in the district.

(B) At the time that a district is created, the required paid parking spaces may include both existing and new spaces.

(C) Fifty-one percent of the funds from the paid parking spaces within the district that is in excess of the cost of maintaining and operating parking pay stations and meters shall be set aside to pay for improvements within the district. 
(D) Funds from the paid parking spaces may be used in conjunction with other city funds available for neighborhood improvements within the district.

(E) The director shall determine the timing and order in which the improvements identified in the ordinance creating the district will be initiated.

(F) Unless terminated earlier by Council, a district shall remain in existence until each improvement identified in the ordinance creating the district is complete.

(G) The City may terminate a district if paid parking spaces do not generate more than the amount needed to pay all annual expenses.

\section{§ 12-6-4 APPLICATION TO CREATE A DISTRICT.}

A representative of a neighborhood organization whose boundaries are completely or partially located within the proposed district may file an application for a district with the director.

\section{§ 12-6-5 PRE-APPLICATION REQUIREMENTS.}

(A) A pre-application meeting with the director's staff is required. Lete

(B) A pre-application community meeting is required. dste

(1) The applicant shall convene a community meeting at least 2 weeks - before an application for the creation of a district is submitted to the director.

(2) Not later than two weeks before the community meeting, the applicant shall:

(a) coordinate with staff to send notification of the meeting by electronic mail to all registered neighborhood organizations whose boundaries are located:

(i) completely or partially within the proposed district; and

(ii) within 1500 feet of the proposed district;

(b) place at least two signs providing notification of the meeting on each block face within the proposed district; and

(c) distribute flyers in the proposed district. we cuell to

(3) A notice provided under Subsection (B)(2) shall include the time, date, location, subject matter, and applicant contact information. 


\section{§ 12-6-6 APPLICATION REQUIREMENTS.}

(A) The director shall establish submittal requirements for an application for the creation of a district and for the modification of an existing district. At a minimum, an application shall include:

(1) the boundaries of the proposed district identified by streets and static land features;

(2) a justification for the proposed district;

(3) a visual representation of the proposed block faces that have paid parking spaces or that are proposed to have paid parking spaces; waf

(4) identification of other parking management tools that have been requested;

(5) proposed improvement projects, in priority order, to be funded by parking pay station and meter revenue, including an estimated timeline for project completion and expected sustainability of the project;

(6) a copy of the sign-in sheets from the community meeting; and

(7) if a vote on the application occurred at the community meeting, the results of the vote.

(B) The $\cdot$ director may not accept an application unless the application is complete.

\section{§ 12-6-7 APPLICATION REVIEW.}

(A) The director shall review each application for the creation of a district or the modification of an existing district submitted under Section 12-6-6 (Application Requirements). The director shall set the application for a public hearing and shall provide the Urban Transportation Commission with:

(1) a recommendation on the application; and

(2) if a vote on the application occurred at the community meeting, the results of the vote.

(B) The Urban Transportation Commission shall hold a public hearing on the application not later than the $60^{\text {th }}$ day after the application is filed and shall submit a recommendation on the application to the council.

(C) The council shall consider an ordinance for the creation of a proposed district or the modification of an existing district not later than the $60^{\text {th }}$ day 
after the date of the Urban Transportation Commission action on the application.

(D) An ordinance adopted by the city council under this section shall include a list of improvements to be funded by revenue from the paid parking spaces.

\section{§ 12-6-8 NOTICE OF PUBLIC HEARING.}

(A) The director shall give notice of a public hearing before the Urban Transportation Commission by mailing notice not later than the 11th day before the date of the hearing to the:

(1) applicant;

(2) notice owner of real property located:

(a) within the proposed district; and

(b) within 500 feet of the proposed district;

(3) a registered neighborhood organization whose declared boundaries are within 1500 feet of the proposed district; and

(4) utility account addresses as shown in the City utility records on the date of the filing of the application that are located:

(a) within the proposed district; and

(b) within 500 feet the proposed district.

(B) The director shall give notice of a public hearing before the council by mailing notice not later than the 16 th day before the date of the hearing to the:

(1) applicant;

(2) notice owner of real property located:

(a) within the proposed district; and

(b) within 500 feet of the proposed district;

(3) a registered neighborhood organization whose declared boundaries are within 1500 feet of the proposed district; and

(4) utility account addresses located as shown in the City utility records on the date of the filing of the application that are located:
(a) within the proposed district; and
(b) within 500 feet of the proposed district.

Page 4 of 6 
(C) Notice provided under this section must:

(1) generally describe the subject matter of the public hearing;

(2) identify the applicant and the boundaries of the proposed district;

(3) identify the body holding the public hearing and the date, time, and place of the public hearing; and

(4) include the address and telephone number of the city office from which additional information may be obtained.

\section{§ 12-6-9 PROCEDURES AND REQUIREMENTS FOR NOTICE.}

(A) Mailed notice is effective on the date a letter is deposited in a depository of the U.S. Post Office, first class, postage paid, and addressed:

(1) to an applicant, by mailing notice to the address shown on the application or on a written change of address form filed with the responsible director;

(2) to a notice owner of real property, by mailing notice to the owner shown on the records of the county tax appraisal district;

(3) to a neighborhood organization, by mailing notice to the agent or officer of the organization at the mailing address specified in the City registration information.

(B) Notice by hand delivery may be substituted for notice by mail if the addressee provides a receipt of delivery.

(C) When mailed notice to a notice owner is required, the director shall prepare the list of notice owners.

(D) When possible, the director shall send the notice for public hearings before the Urban Transportation Commission and the City Council in one notice. 


\section{GOVERNING}

Should Parking Lots Be Taxed to Fund Bike Paths?

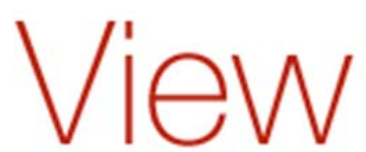

SUBSCRIBE

NEWSLETTERS

ADVERTISE

POSTED BY RYAN HOLEYWELL | JANUARY 8, 2013

Massachusetts Gov. Deval Patrick is expected to introduce in the coming days his plan for shoring up transit and road funding in the Commonwealth. His former transportation director has been offering some ideas too.

James Aloisi, who served as Massachusetts Transportation Secretary in 2009 for less than a year, recently wrote a three-part-series outlining his thoughts on how the state can help fund transportation projects, and in particular, end the massive shortfalls facing the Massachusetts Bay Transportation Authority.

Among his proposals: taxing parking lots and garages through a system he calls "carbon impact parking assessment." Here's how it would work.

Aloisi envisions the tax being levied on nonresidential parking lots and garages of more than 20 spaces within the MBTA district. The tax could be part of a new system of Transit Improvement Districts -- targeted areas within a community that depend on public transportation for success.

Revenue from the parking tax would provide a steady stream of funding that could then be invested in the public transportation system as well as bicycle and pedestrian pathway improvements.

Aloisi says he isn't aware of any jurisdiction that uses such a system, but it's similar to the idea of tax incremental financing, in which increased property tax revenue that results from development in a given area are then re-invested in the same place.

Aloisi says the plan would mitigate the environmental impact of automobiles while providing funding for other modes of transportation and ensuring that funding remains locally controlled.

Such a plan would almost certainly face political obstacles and fuel the ongoing debate between drivers and transit advocates. "I don't think it's about a war on cars," Aloisi says. "Maybe we should have a war on fossil fuels."

"It's really (about) the impact of fossil fuels on the environment, on our energy security, and on our ability not to innovate that I think is at the core of the issue."

Parking taxes are not unusual in major cities, but at times, they have been politically unpopular. Last year the University of Scranton sued the city of a new tax on parking 
garages and lots. Chicago Mayor Rahm Emanuel has enacted a \$2-per-day "congestion fee," met with many grumbles, on downtown parking to help fund investments in transit and bike lanes.

Aloisi says the fee could be enticing to private-sector financiers, as a steady revenue stream is the type of thing that can help facilitate public-private partnerships.

Transportation funding is poised to be one of the key topics addressed by the state legislature in Massachusetts this year. The state's primary source of transportation funding, a 19-cent gas tax, has been unchanged since 1993 .

Patrick has kept the details of his soon-to-be-released plan close to his chest, but it will seek to close funding gaps for the transit system in the Boston area. The governor's attempt at increasing the state gas tax in 2009 wasn't successful, and the legislature instead opted to dedicate an increase in sales tax revenue to transit and roads. That funding has been insufficient to address the state's transportation needs. 


\section{Appendix D - Types of Public Transportation}

The term public transportation encompasses various modes of service including automated guideway, bus, cable car, commuter rail, ferry boat, heavy rail, light rail, monorail, paratransit, trolleybus, and vanpool defined according to the American Public Transportation Association (APTA) below (128):

Mode is a system for carrying transit passengers described by specific right-of-way, technology, and operational features.

Automated Guideway Transit (also called personal rapid transit, group rapid transit, or people mover) is an electric railway (single or multi-car trains) of guided transit vehicles operating without an onboard crew. Service may be on a fixed schedule or in response to a passenger activated call button.

Bus is a mode of transit service (also called motor bus) characterized by roadway vehicles powered by diesel, gasoline, battery, or alternative fuel engines contained within the vehicle. Vehicles operate on streets and roadways in fixed route or other regular service. Types of bus service include local service, where vehicles may stop every block or two along a route several miles long. When limited to a small geographic area or to short-distance trips, local service is often called circulator, feeder, neighborhood, trolley, or shuttle service. Other types of bus service are express service, limited-stop service, and bus rapid transit (BRT).

Cable Car is a railway with individually controlled transit vehicles attached while moving to a moving cable located below the street surface and powered by engines or motors at a central location not on board the vehicle.

Commuter Rail is a mode of transit service (also called metropolitan rail, regional rail, or suburban rail) characterized by an electric or diesel propelled railway for urban passenger train service consisting of local short distance travel operating between a central city and adjacent suburbs. Service must be operated on a regular basis by or under contract with a transit operator for the purpose of transporting passengers within urbanized areas, or between urbanized areas and outlying areas.

Such rail service, using either locomotive hauled or self-propelled railroad passenger cars, is generally characterized by multi-trip tickets, specific station to station fares, railroad employment practices and usually only one or two stations in the central business district. Intercity rail service is excluded, except for that portion of such service that is operated by or under contract with a public transit agency for predominantly commuter services. Most service is provided on routes of current or former freight railroads.

Ferry Boat is a transit mode comprising vessels carrying passengers and in some cases vehicles over a body of water, and that are generally steam or diesel-powered. When at least one terminal is within an urbanized area, it is urban ferryboat service. Such service excludes international, rural, rural interstate, island, and urban park ferries.

Heavy Rail is a mode of transit service (also called metro, subway, rapid transit, or rapid rail) operating on an electric railway with the capacity for a heavy volume of traffic. It is characterized by high speed and rapid acceleration passenger rail cars operating singly or in multi-car trains on fixed rails; separate rights-of-way from 
which all other vehicular and foot traffic are excluded; sophisticated signaling, and high platform loading.

Light Rail is a mode of transit service (also called streetcar, tramway, or trolley) operating passenger rail cars singly (or in short, usually two-car or three-car, trains) on fixed rails in right-of-way that is often separated from other traffic for part or much of the way. Light rail vehicles are typically driven electrically with power being drawn from an overhead electric line via a trolley or a pantograph; driven by an operator on board the vehicle; and may have either high platform loading or low level boarding using steps.

Monorail is an electric railway of guided transit vehicles operating singly or in multicar trains. The vehicles are suspended from or straddle a guideway formed by a single beam, rail, or tube.

Paratransit is a mode of transit service (also called demand response or dial-a-ride) characterized by the use of passenger automobiles, vans or small buses operating in response to calls from passengers or their agents to the transit operator, who then dispatches a vehicle to pick up the passengers and transport them to their destinations. The vehicles do not operate over a fixed route or on a fixed schedule. The vehicle may be dispatched to pick up several passengers at different pick-up points before taking them to their respective destinations and may even be interrupted en route to these destinations to pick up other passengers.

Trolleybus is a mode of transit service (also called trolley coach) using vehicles propelled by a motor drawing current from overhead wires via connecting poles called a trolley poles from a central power source not on board the vehicle.

Vanpool is ridesharing by prearrangement using vans or small buses providing round trip transportation between the participant's prearranged boarding points and a common and regular destination. Data included in this report are the sum of vanpool data reported in the National Transit Database (NTD) and do not include any data for vanpools not listed in the National Transit Database. Vanpool service reported in the NTD must be operated by a public entity, or a public entity must own, purchase, or lease the vehicle(s). Vanpool included in the NTD must also be in compliance with mass transit rules including Americans with Disabilities Act (ADA) provisions, be open to the public and that availability must be made known, and use vehicles with a minimum capacity of 7 persons. 


\section{Appendix E - FAA Memorandum \\ Federal Aviation Administration}

\section{Memorandum}

Date:

SEP 272012

To:

Regional Airports Division Managers

610 Branch Managers

620 Branch Managers

ADO Managers

From:

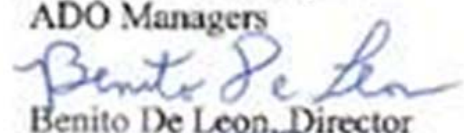

Ofjeg of Airportelanning and Programming (APP-1)

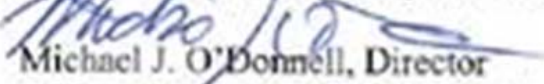

Office of-Airport Safety and Standards (AAS-1)

Subject: Interim Guidance on Land Uses Within a Runway Protection Zone

Background

The FAA Office of Airports (ARP) has identified the need to clarify our policy on land uses within the Runway Protection Zone (RPZ). This memorandum presents interim policy guidance on compatible land uses within Runway Protection Zones (RPZ) to address recurrent questions about what constitutes a compatible land use and how to evaluate proposed land uses that would reside in an RPZ. While Advisory Circular 150/5300-Change 17(Airport Design) notes that "it is desirable to clear all objects from the RPZ," it also acknowledges that "some uses are permitted" with conditions and other "land uses are prohibited."

RPZ land use compatibility also is often complicated by ownership considerations. Airport owner control over the RPZ land is emphasized to achieve the desired protection of people and property on the ground. Although the FAA recognizes that in certain situations the airport sponsor may not fully control land within the RPZ, the FAA expects airport sponsors to take all possible measures to protect against and remove or mitigate incompatible land uses.

ARP is developing a new guidance document for the Regional Office (RO) and Airport District Office (ADO) staff that clarifies our policy regarding land uses in the RPZ. This new guidance document will outline a comprehensive review process for existing and proposed land uses within an RPZ and is slated for publication in 2013. We also intend to incorporate RPZ land use considerations into the ongoing update to the Land Use Compatibility Advisory Circular (AC) which is slated for publication in 2014.

This memorandum outlines interim guidance for ARP RO and ADO staff to follow until the comprebensive RPZ land use guidance is published. 
Interim Guidance

\section{New or Modified Land Uses in the RPZ}

Regional and ADO staff must consult with the National Airport Planning and Environmental Division, APP-400 (who will coordinate with the Airport Engincering Division, AAS-100), when any of the land uses described in Table 1 would enter the limits of the RPZ as the result of:

1. An airfield project (e.g, runway extension, runway shift)

2. A change in the critical design aircraft that increases the RPZ dimensions

3. A new or revised instrument approach procedure that inereases the RPZ dimensions

4. A local development proposal in the RPZ (either new or reconfigured)

\section{Table I: Land Uses Requiring Coordination with APP-400}

-Buildings and structures (Examples include, but are not limited to: residences, schools, churches, hospitals or other medical care facilities, commercial/industrial buildings. etc.)

- Recreational land use (Examples include, but are not limited to: golf courses, sports fields, amusement parks, other places of public assembly, etc.)

- Transportation facilities. Examples include, but are not limited to:

- Rail facilities - light or heavy, passenger or freight

- Public roads/highways

- Vehicular parking facilities

- Fuel storage facilities (above and below ground)

- Hazardous material storage (above and below ground)

- Wastewater treatment facilities

- Above-ground utility infrastructure (i.e. electrical substations), including any type of solar panel installations.

Land uses that may create a safety hazard to air transportation resulting from wildlife hazard attractants such as retention ponds or municipal landfills are not subject to RPZ standards since these types of land uses do not create a hazand to people and property on the ground. Rather, these land uses are controlled by other FAA policies and standards. In aceordance with the relevant Advisory Circulars, the Region/ADO must coordinate land use proposals that create wildlife hazards with AAS-300, regardless of whether the proposed land use occurs within the limits of an RPZ.

\section{Alternatives Analysis}

Prior to contacting APP. 400 , the RO and ADO staff must work with the airport sponsor to identify and document the full range of alternatives that could:

1. Avoid introducing the land use issue within the RPZ

2. Minimize the impact of the land use in the RPZ (i.e., routing a new roadway through the controlled activity area, move farther away from the runway end, etc.) 
3. Mitigate risk to people and property on the ground (i.e., tunneling, depressing and/or protecting a roadway through the RPZ, implement operational measures to mitigate any risks, etc.)

Documentation of the alternatives should include:

- A description of each alternative including a narrative discussion and exhibits or figures depicting the alternative

- Full cost estimates associated with each alternative regardless of potential funding sources.

- A practicability assessment based on the feasibility of the alternative in terms of cost, constructability and other factors.

- Identification of the preferred alternative that would meet the project purpose and need while minimizing risk associated with the location within the RPZ.

- Identification of all Federal, State and local transportation agencies involved or interested in the issue.

- Analysis of the specific portion(s) and percentages of the RPZ affected, drawing a clear distinction between the Central Portion of the RPZ versus the Controlled Activity Area, and clearly delineating the distance from the runway end and runway landing threshold.

- Analysis of (and issues affecting) sponsor control of the land within the RPZ.

- Any other relevant factors for HQ consideration.

APP- 400 will consult with AAS- 100 when reviewing the project documents provided by the RO/ADO. APP-400 and AAS- 100 will work with the Region/ADO to make a joint determination regarding Airport Layout Plan (ALP) approval after considering the proposed land use, location within the RPZ and documentation of the alternatives analysis.

In addition, APP- 400 and AAS-100 will work with the Region/ADO to craft language for inclusion in the airspace determination letter regarding any violations to ensure that all stakeholders (including tenants, operators, and insurers) are fully apprised of the issues and potential risks and liabilities associated with permitting such facilities within the RPZ.

\section{Existing Land Uses in the RPZ}

This interim policy only addresses the introduction of new or modified land uses to an RPZ and proposed changes to the RPZ size or location. Therefore, at this time, the RO and ADO staff shall continue to work with sponsors to remove or mitigate the risk of any existing incompatible land uses in the RPZ as practical.

For additional information or questions regarding this interim guidance, please contact either Ralph Thompson, APP-400, at ralph.thompson@faa.gov or (202) 267-8772 or Danielle Rinsler, APP-401, at danielle.rinsler a fan.gov or (202) 267-8784. 


\title{
Appendix F - Tallahassee-Leon County Corridor Preservation Policies
}

\author{
OBJECTIVE 1.6: [M] (Effective 12/15/11)
}

CORRIDOR PRESERVATION

Identify right-of-way needed for planned future transportation improvements and protect it from building encroachment as development occurs to preserve the corridor for transportation use, to maintain transportation level of service for concurrency, to improve coordination between land use and transportation, and to minimize the adverse social, economic, and environmental impacts of transportation facilities on the community.

Policy 1.6.1: [M] (Effective 12/15/11)

The City and County shall adopt and maintain corridor management ordinances, in accordance with subsection 337.273(6), F.S., which are designed to protect future transportation corridors designated in the Tallahassee-Leon County Comprehensive Plan from development encroachment, to provide for right-of-way acquisition, and to mitigate potential adverse impacts on affected property owners.

Policy 1.6.1(a): [M] (Effective 12/15/11)

Development orders may require conveyance of transportation rights-of-way consistent with a Future ROW Needs Map and Future Right-of-Way Needs and Access Classifications Table, as a condition of plat or development approval, provided that any required dedication shall not exceed the amount of land that is roughly proportionate to the impacts of the development on the transportation network.

Policy 1.6.2: [M] (Effective 12/15/11)

Acquire and maintain sufficient right-of-way when building new roads or widening old facilities in order to protect waterbodies, wetlands, and flood plains. Plan corridor alignments to avoid environmentally sensitive areas and where this is not possible, acquire wide roadside buffers and prohibit driveways by purchase of access rights, as necessary, to prevent development from occurring within the environmentally sensitive area, as a result of the roadway availability.

Policy 1.6.3: [M] (Effective 12/15/11)

Future right-of-way needs for selected transportation corridors designated for improvement in the Tallahassee-Leon County Comprehensive Plan are generally depicted in the table below and in the Future Right-of-Way Needs Map and the Long Range Transportation Plan. 


\begin{tabular}{|l|c|}
\hline \multicolumn{2}{|c|}{$\begin{array}{c}\text { Future Right-of-Way Needs } \\
\text { WITHOUT an Existing Corridor } \\
\text { Alignment }\end{array}$} \\
\hline Functional Classification & $\begin{array}{l}\text { ROW } \\
\text { (ft. }^{1-3}\end{array}$ \\
\hline Blueprint Principal $_{\text {Arterial }^{4}}$ & 230 \\
Principal Arterial $^{\text {Minor Arterial }}$ & 200 \\
Major Collector & 176 \\
Minor Collector & 146 \\
\hline
\end{tabular}

Figure F-1. Future Right-of Way Needs Without an Existing Corridor Alignment

1) Widths represent maximum anticipated ROW needs for generalized corridors; not precise alignments. Where a specific alignment is established through alignment studies, engineering studies or design, such alignment shall apply for the purpose of development review. Actual road location and design will be determined by specific corridor and design studies.

2) Alternative widths may be established by the local government, in consultation with other affected agencies, pursuant to an adopted Critical Area Plan or based upon an analysis of existing constraints, community planning objectives, and other considerations unique to the roadway or surrounding land development.

3) In addition to the number of travel lanes, the following are important considerations in the determination of right-of-way needs for future corridors:

a. Space for sidewalks to provide safe and convenient movement of pedestrians. b. The provision of bike lanes or separate bike paths.

c. Space for current or future location of utilities so that, when necessary, they can be safely maintained without undue interference with traffic. The utility strip needs to be of sufficient width to allow placement of a water main so that in the case of rupture, neither the roadway pavement nor adjacent property will be damaged.

d. Accommodation of stormwater at the surface or in storm drains.

e. Accommodation of auxiliary lanes at intersections.

f. Placement of trees to improve the aesthetic qualities of the roadway, to shade pedestrians, and improve community appearance. The space needs to be adequate to accommodate tree growth without damaging sidewalks, abutting development, or curb and gutter.

g. Allowing for changes in the paved section, utilities, or other modifications, that may be necessary in order to meet unseen changes in vehicular, pedestrian, bicycle, or other transportation needs as a result of changes in land use and activity patterns.

4) Planned ROW needs for Capital Circle from Centerview to W. Tennessee, as accepted by the Blueprint Intergovernmental Agency on November 19, 2001. 
Policy 1.6.4: [M] (Effective 12/15/11)

All proposed development plans on designated future transportation corridors shall be reviewed or consistency with the Future Right-of-Way Needs Map, the Long Range Transportation Plan, and any specific alignment or engineering studies and shall be consistent with identified right-of- way needs for designated future transportation corridors as a condition of development approval.

Policy 1.6.5: [M] (Effective 12/15/11)

The Future Right-of-Way Needs Map shall be reviewed, and updated if necessary, every five years concurrent with the Long Range Transportation Plan update, or more frequently as necessary to address the growth and mobility needs of the local government.

Policy 1.6.6: [M] (Effective 12/15/11)

City and County Staff shall consult with the Florida Department of Transportation in determining conceptual alignments, acquiring future right-of-way, and reviewing proposed development that substantially impacts state highways designated for improvement in the Tallahassee-Leon County Comprehensive Plan to ensure that local decisions are consistent with state and federal policy, and to ensure that development activity does not substantially impair the viability of the future state transportation corridor.

Policy 1.6.7: [M] (Effective 12/15/11)

Explore land banking policies, procedures and funding options to facilitate early acquisition of right-of-way for designated future transportation corridors.

Policy 1.6.8: [M] (Effective 12/15/11)

Right-of-way acquisition shall be facilitated by the establishment of a program to identify, prioritize, and acquire needed right-of-way consistent with the Right-of-Way Needs Map and Capital Improvements Element.

Policy 1.6.9: [M] (Effective 12/15/11)

Where needed right-of-way is identified in the energy efficiency district connectivity plans, such projects shall also be included on the Right-of-Way Needs Map and/or in the Long Range Transportation Plan. 


\section{Appendix G - Fort Lauderdale Complete Streets Policy}

The City of Fort Lauderdale intends to create a mobility system for its neighbors that will realize long-term cost savings in terms of improved public health, reduced fuel consumption, reduced demand for single occupancy motor vehicles, and increased public safety through the implementation of this Complete Streets Policy. Complete Streets contribute to walkable, livable neighborhoods which can build community and create a sense of community pride and improved quality of life.

The City will plan for, design, construct, operate and maintain appropriate facilities for pedestrians, bicyclists, motor vehicles, transit vehicles and transit riders, freight carriers, emergency responders, and adjacent land users. All users will experience a safe, functional, and visually appealing environment while traveling safely and conveniently on and across all surface roadways in Fort Lauderdale. This policy will apply to all development and redevelopment in the public domain.

\section{CONNECTI VITY}

(A) The City of Fort Lauderdale will ensure the transportation network in the city is designed, operated and maintained to provide a connected network of facilities and services accommodating all modes of travel and all users.

(B) The City will actively look for opportunities to repurpose rights-of-way to enhance connectivity for pedestrians, bicyclists, and transit riders.

(C) The City will focus non-motorized connectivity improvements on access to transit, services, schools, parks, civic uses, regional connections and commercial uses.

(D) The City will require new developments and redevelopment projects to provide interconnected internal street and path networks with small blocks, as appropriate.

(E) The City will review existing regulations which may impact the successful implementation of Complete Streets and propose necessary revisions to promote multimodal-oriented development.

\section{J URI SDI CTI ON}

(A) This Complete Streets Design Manual is intended to cover all development and redevelopment in the public domain and all street improvements within Fort Lauderdale, and will also focus on regional connectivity.

(B) Every street within the City of Fort Lauderdale, regardless of the jurisdictional ownership or agency responsible for its maintenance and operation, shall be subject to the Design Manual.

(C) Every City Department including Transportation \& Mobility, Public Works, Parks \& Recreation, and Sustainable Development will follow the Design Manual.

(D) The City requires all developers and builders to obtain and comply with the Design Manual. 
(E) The City requires those agencies that it has permitting authority over, including, but not limited to, utilities and service contractors to comply with the Complete Streets Manual.

(F) The City will leverage the resources of other agencies, including, but not limited to, Federal agencies, Broward County Government, Broward County Transit (BCT), Florida Department of Transportation (FDOT), Broward Public School District, Florida Department of Health in Broward County, South Florida Regional Transportation Authority (SFRTA), and the Broward Metropolitan Planning Organization (Broward MPO) to achieve Complete Streets.

\section{APPROACH}

The City of Fort Lauderdale will apply this policy to all roadway projects. This includes projects involving new construction, reconstruction, retrofits, repaving, rehabilitation, or changes in the allocation of pavement space on an existing roadway, as well as those that involve new privately built roads and easements intended for public use. Complete Streets elements may be achieved through single projects or incrementally through a series of smaller improvements or maintenance and operation activities over time.

(A) The City will complete the Multimodal Transportation Plan to illustrate the needed transportation improvements in accordance with the Complete Streets Policy.

(B) The City will review and modify the Transportation Element of its Comprehensive Plan and its Unified Land Development Regulations (ULDR) to ensure consistency with the Policy and Manual.

(C) The City shall coordinate its infrastructure investments with the Broward MPO Transportation Improvement Program (TIP) and the Long-range Transportation Plan (LRTP), agency work programs, the BCT Transit Development Plan (TDP), SFRTA TDP, and adjacent municipalities to increase the coordination of Complete Streets implementation.

\section{EXCEPTIONS}

The City of Fort Lauderdale will pursue Complete Streets elements in all corridors. Complete Streets principles and practices will be included in street construction, reconstruction, repaving, and rehabilitation projects, as well as other plans and manuals, except under one or more of the following conditions:

(A) A project that involves only ordinary or emergency maintenance activities designed to keep assets in serviceable condition such as mowing, cleaning, sweeping, spot repair, concrete joint repair, or pothole filling, or when interim measures are implemented on temporary detour routes.

(B) A project that is deemed excessive and to have a disproportionate cost according to Federal Highway Administration regulations.

(C) Unless otherwise determined by the City Commission, the Transportation \& Mobility Department will determine if certain Complete Streets projects/features are not feasible or cost effective to implement. 


\section{DESI GN}

The City will use the Complete Streets Design Manual to guide the design of new and modified streets in Fort Lauderdale while ensuring a context sensitive approach to unique circumstances of different streets and communities. All relevant City plans, manuals, rules, regulations and programs will incorporate Complete Streets Design Principles.

The City will also:

(A) Provide well-designed pedestrian accommodations on all streets and crossings. Pedestrian accommodations can take numerous forms, including, but not limited to, traffic signals, access management, lighting, enhanced crosswalks, roundabouts, bulb-outs, curb extensions, sidewalks, buffer zones, shared-use pathways, and perpendicular curb ramps, among others.

(B) Provide well-designed bicycle accommodations along all streets. Bicycle accommodations can take numerous forms, including, but not limited to, the use of bicycle lanes, sharrows, shared use paths, slow speeds, education, enforcement, bicycle storage, traffic calming, signs, and pavement markings, among others.

(C) Where physical conditions warrant, landscaping shall be planted or other shading devices installed whenever a street is improved (such as the addition of medians or wider sidewalks), newly constructed, reconstructed, or relocated. An emphasis shall be placed on the addition of native trees that provide shade for pedestrians.

(D) Provide transit amenities when transit services are provided on the corridor including shelters, bus bulb-outs, safe pedestrian and bike access, benches, and bike racks, etc. An emphasis shall be placed on provided connectivity between transit stops and destinations.

\section{CONTEXT SENSITI VITY}

In accordance with Smart Growth Principles, the City of Fort Lauderdale will plan its streets in harmony with adjacent land uses and neighborhoods and promote walkable, livable communities through the design of a strong street network.

The City will solicit input from local stakeholders during the planning process and will design streets with a strong sense of place that will integrate natural features, such as beaches and waterways, into design of streets and use architecture, landscaping, street furniture, public art, signage, etc. to reflect the community and neighborhood. In and along retail and commercial corridors, the City will coordinate street improvements with merchants to develop vibrant and livable districts.

\section{PERFORMANCE MEASURES}

The City will evaluate policy implementation using the following performance measures:

1. Total miles of on-street bikeways defined by streets with clearly marked or signed bicycle accommodation.

2. Total miles of streets with pedestrian accommodation.

3. Number of missing or non-compliant curb ramps along City streets. 
4. Percentage of new street projects that are multi-modal.

5. Traffic counts for major streets.

6. Transit trips on services provided in the City.

7. Multi-modal Level of Service improvements.

8. Number and severity of pedestrian-vehicle and bicycle-vehicle crashes.

\section{MPLEMENTATI ON}

(A) Lead Department: The Transportation \& Mobility Department shall lead the implementation of this policy and coordinate with other impacted departments to ensure a comprehensive adoption of the Design Guidelines.

(B) Inventory. The City will maintain a comprehensive inventory of the pedestrian and bicycling facility infrastructure integrated with the City's database and will prioritize projects through the Multimodal Transportation Plan to eliminate gaps in the sidewalk and bikeways networks.

(C) Capital Improvement Project Prioritization. The City will reevaluate Capital Improvement Project prioritization to encourage implementation of bicycle, pedestrian, and transit improvements.

(D) Revisions to Existing Plans and Policies. The City will reference and modify the Transportation Element of its Comprehensive Plan and any other existing plans related to the design of the public right of way to ensure consistency with the Design Manual.

(E) Public Official and Staff Training. The City will train (through online tools such as webinars and brief videos) pertinent leaders and staff on the content of the Complete Streets principles and best practices for implementing the policy.

(F) Coordination. The City will utilize inter-departmental project coordination to promote the most responsible and efficient use of fiscal resources for activities within the public right of way.

(G) Funding. The City will actively seek sources for public and private funding to implement Complete Streets. Furthermore, the City shall attempt to coordinate its infrastructure investments and Complete Streets implementation with the Broward MPO Transportation Improvement Program (TIP) and Long-range Transportation Plan (LRTP), Florida Department of Transportation (FDOT) work programs, and the Broward County and SFRTA Transit Development Plans. 


\section{Appendix H - MPO Long-Range Transportation Plan Adoption Schedule}

Table H-1. Florida MPO LRTP Adoption Schedule

\begin{tabular}{lcc}
\hline MPO & LRTP Adoption Date & Next Adoption Date \\
\hline Miami-Dade Urbanized Area MPO & & \\
& $10 / 29 / 2009$ & $10 / 29 / 2014$ \\
Hillsborough County MPO & $12 / 9 / 2009$ & $12 / 9 / 2014$ \\
Pinellas County MPO & $12 / 9 / 2009$ & $12 / 9 / 2014$ \\
Pasco County MPO & $12 / 10 / 2019$ & $12 / 10 / 2014$ \\
Hernando County MPO & $12 / 15 / 2009$ & $12 / 15 / 2014$ \\
Palm Beach MPO & $12 / 17 / 2009$ & $12 / 17 / 2014$ \\
Broward MPO & $12 / 10 / 2009$ & $12 / 10 / 2014$ \\
Gainesville MTPO & $11 / 2 / 2010$ & $11 / 3 / 2015$ \\
Space Coast TPO & $11 / 10 / 2010$ & $11 / 10 / 2015$ \\
Volusia TPO & $11 / 22 / 2010$ & $11 / 2 / 2015$ \\
Ocala-Marion County TPO & $11 / 29 / 2010$ & $11 / 29 / 2015$ \\
Polk TPO & $12 / 7 / 2010$ & $12 / 7 / 2015$ \\
Lee MPO & $12 / 8 / 2010$ & $12 / 8 / 2015$ \\
Lake Sumter MPO & $12 / 8 / 2010$ & $12 / 8 / 2015$ \\
Collier MPO & $12 / 10 / 2010$ & $12 / 10 / 2015$ \\
Sarasota-Manatee MPO & $12 / 13 / 2010$ & $12 / 13 / 2015$ \\
Charlotte-Punta Gorda MPO & $12 / 14 / 2010$ & $12 / 14 / 2015$ \\
Indian River County MPO & $12 / 14 / 2010$ & $12 / 14 / 2015$ \\
Florida Alabama TPO & $12 / 14 / 2010$ & $12 / 14 / 2015$ \\
Capital Region TPA & $12 / 15 / 2010$ & $12 / 15 / 2015$ \\
St. Lucie TPO & $2 / 2 / 2011$ & $2 / 2 / 2016$ \\
Martin MPO & $2 / 2 / 2011$ & $2 / 2 / 2016$ \\
Bay County TPO & $7 / 27 / 2011$ & $7 / 27 / 2016$ \\
Okaloosa Walton TPO & $3 / 15 / 2012$ & $3 / 15 / 2017$ \\
\hline
\end{tabular}

